\title{
Phosphoinositides, aging and Alzheimer's disease
}

Citation for published version (APA):

Bothmer, J. (1992). Phosphoinositides, aging and Alzheimer's disease. [Doctoral Thesis, Maastricht University]. Datawyse / Universitaire Pers Maastricht. https://doi.org/10.26481/dis.19921126jb

Document status and date:

Published: 01/01/1992

DOI:

10.26481/dis.19921126jb

Document Version:

Publisher's PDF, also known as Version of record

\section{Please check the document version of this publication:}

- A submitted manuscript is the version of the article upon submission and before peer-review. There can be important differences between the submitted version and the official published version of record.

People interested in the research are advised to contact the author for the final version of the publication, or visit the DOI to the publisher's website.

- The final author version and the galley proof are versions of the publication after peer review.

- The final published version features the final layout of the paper including the volume, issue and page numbers.

Link to publication

\footnotetext{
General rights rights.

- You may freely distribute the URL identifying the publication in the public portal. please follow below link for the End User Agreement:

www.umlib.nl/taverne-license

Take down policy

If you believe that this document breaches copyright please contact us at:

repository@maastrichtuniversity.nl

providing details and we will investigate your claim.
}

Copyright and moral rights for the publications made accessible in the public portal are retained by the authors and/or other copyright owners and it is a condition of accessing publications that users recognise and abide by the legal requirements associated with these

- Users may download and print one copy of any publication from the public portal for the purpose of private study or research.

- You may not further distribute the material or use it for any profit-making activity or commercial gain

If the publication is distributed under the terms of Article $25 \mathrm{fa}$ of the Dutch Copyright Act, indicated by the "Taverne" license above, 
PHOSPHOINOSITIDES, AGING AND ALZHEIMER'S DISEASE 
CIP=DATA KONINKLLIKE BIBLIOTHEEK, DEN HAAG

Bothmer, John

Phosphoinositides, aging and Alzheimer's disease / John Bothmer. - Maastricht : Universitaire Pers Maastricht. III.

Thesis Maastricht. - With ref.

ISBN 90-5278-046-3

NUGI 743

Subject headings: phosphoinositides / aging / Alzheimer's disease.

Druk: Datawyse Maastricht / Krips Repro Meppel 


\title{
PHOSPHOINOSITIDES, AGING AND ALZHEIMER'S DISEASE
}

\author{
PROEFSCHRIFT
}

\author{
ter verkrijging van de graad van doctor \\ aan de Rijksuniversiteit Limburg te Maastricht, \\ op gezag van de Rector Magnificus, Prof. Mr. M.J. Cohen, \\ volgens het besluit van het College van Dekanen, \\ in het openbaar te verdedigen \\ op donderdag, 26 november 1992 om 14.00 uur
}

door

JOHN BOTHMER

geboren op 26 augustus 1964 te Geleen

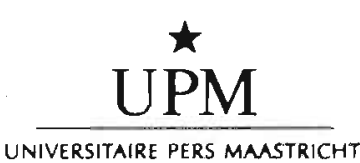




\section{PROMOTOR:}

Prof. Dr. J. Jolles

\section{BEOORDELINGSCOMMISSIE:}

Prof. Dr. R.F.A. Zwaal (voorzitter)

Dr. G. Hornstra

Prof. Dr. D.L. Knook (Rijksuniversiteit van Leiden)

Prof. Dr. V.M. Wiegant (Landbouw Universiteit van Wageningen)

Prof. Dr. K.W.A. Wirtz (Rijksuniversiteit van Utrecht)

The studies described in this thesis were carried out at the department of NeuroPsychology \& Psychobiology within the research programme 'Aging of Brain and Behavior' of the University of Limburg, Maastricht, The Netherlands. 
Aan

mijn vader

Voor

mijn moeder Francine 


\section{CONTENTS}

Chapter 1: Phosphoinositides, aging and Alzheimer's disease: As survey ..

Chapter 2: Phosphatidic acid and polyphosphoinositide formation in rat brain in vitro: Effects of post-mortem delay and procedural manipulations

Chapter 3: Phosphatidic acid and polyphosphoinositide formation in a broken cell preparation from rat brain: Effects of different incubation conditions

Chapter 4: Evidence for a new inositol phospholipid in rat brain mitochondria .

Chapter 5: Brain phosphatidic acid and polyphosphoinositide formation in a broken cell preparation: Regional distribution and the effect of age .

Chapter 6: The effect of age on phosphoinositide kinase, phosphoinositide phosphate kinase and diacylglycerol kinase in rat brain cortex .

Chapter 7: Phosphatidylinositol kinase is reduced in Alzheimer's disease.

Chapter 8: Reduced PI kinase activity in Alzheimer's disease: Effects of age and onset.

Chapter 9: Evidence for a selective decrease in type 1 phosphatidylinositol kinase activity in brains of patients with Alzheimer's disease. .

Chapter 10: Platelet phosphoinositide kinase activity is not altered in Alzheimer's disease.

Chapter 11: Summary and concluding remarks

Samenvatting en conclusies

List of publications 155

Curriculum vitae 157

Dankwoord. 


\section{CHAPTER 1}

\section{PHOSPHOINOSITIDES, ALZHEIMER'S DISEASE : A SURVEY. \\ AND}

J. Bothmer 


\section{CONTENT}

1. Introduction.

2. Phosphoinositide metabolism.

2.1. Introduction.

2.2. Receptor-stimulated hydrolysis of polyphosphoinositides.

2.3. Arachidonic acid

2.4. D-3 phosphorylated inositol phospholipids

2.5. Glycosylated inositol phospholipids.

2.6. Kinases in inositol phospholipid metabolism.

3. Neurochemical aspects of aging.

3.1. Theories of aging.

3.2. Phosphoinositide metabolism and aging.

3.2.1. Phospholipids and aging.

3.2.2. Receptor-mediated phosphoinositide hydrolysis and aging.

3.2.3. The cytoskeleton and aging.

3.2.4. Inositolphosphate action and aging.

3.2.5. Protein kinases and aging.

4. Neurochemical aspects of Alzheimer's disease.

4.1. Introduction.

4.2. Neuritic plaques and the role of beta-amyloid in Alzheimer's disease.

4.3. Neurofibrillary tangles.

4.4. Theories of Alzheimer's disease.

4.5. Phosphoinositide metabolism and Alzheimer's disease.

4.5.1. Phospholipids and Alzheimer's disease.

4.5.2. Receptor-mediated phosphoinositide hydrolysis and Alzheimer's disease.

4.5.3. Calcium release, protein phosphorylation and Alzheimer's disease.

4.5.4. Aluminum and Alzheimer's disease.

5. Outline of this thesis.

6. References. 


\section{INTRODUCTION}

In the twentieth century, the aging of the population is becoming an increasing problem in economically developed western countries as a result of an increased longevity and a relatively low birth rate. Aging is a problem because it is associated with decreased functioning. The most obvious changes with age in humans are grey hair, wrinkled skin, replacement of muscles by fat, but also a decline in the ability to see, hear and taste. Furthermore, decreased motor function, sleep, behaviour and cognitive functions, which probably all result from age-related deficiencies in the brain, are also observed. The effort and the expense of caring for disabled eldery people are enormous and still growing. More important, however, is the loss of the quality of life caused by age-related deficits in the last decades of life. Aging research should therefore focus on factors that influence succesful aging, which seems to be more important than trying to prolong the maximal life-span of humans, by searching for the causative factor of aging. According to Knook (1982), biochemical research on cellular aging could lead to a better insight into the disturbed physiological functions associated with aging and probably to the prevention of many serious age-related diseases, such as different types of cancer, osteoporosis, atherosclerosis and age-related brain diseases, such as dementing conditions and especially Alzheimer's disease.

A decline in the performance of some brain functions is an important factor in the loss of the quality of life in eldery people. In the study of brain functions in relation to aging, much effort has been put into histological research, in the counting of cells and synapses, and in the detection of molecules with antibodies etc. Pharmacological research has a strong tradition in studies with receptor blockers, receptor agonists, ion-channel blockers and agonists etc. Electrophysiological research aims at detecting electrical signal transduction in various regions of the heterogenous brain as a function of age. The present thesis aims at presenting more information on the neurochemical basis of brain aging and Alzheimer's disease. Three enzyme activities, important for the functioning of phosphoinositide metabolism, are studied.

The good functioning of the brain is based on the communication between neurons, which are the main building blocks of the brain. These neurons are well equipped with different means to communicate not only with neighbouring cells but also with more distant cells. These means include signal-sending as well as, signal-processing systems. One of these signal-processing systems is the receptor* mediated phosphoinositide metabolism system which is essential for the activation of some cell functions. This system will be described in section 2 . The most common theories of aging are described in section 3 of this chapter, followed by the more specific age-related changes directly related to phosphoinositide metabolism and its functions. Dementing diseases and especially Alzheimer's disease decreases the quality of life severely. In section 4, cellular changes occurring in Alzheimer's disease, which is the most frequently occurring type of dementia, are discussed in relation to the phosphoinositide metabolism and its functions. Section 5 describes the outline of this thesis. 


\section{PHOSI'HOINOSITIDE METABOLISM}

\subsection{Introduction}

The main characteristic of the brain is that its constituent cells communicate with each other and with the other parts of the body. Much of this communication is achieved by chemical signals, such as neurotransmitters, neuropeptides and hormones, which are released by one cell and create a reaction in an other cell. However, most chemical signals do not enter the target cells, so this extracellular signal has to be transformed into an intracellular signal. Phosphoinositides, a class of phospholipids which are relatively enriched in brain tissue (Hawthorne and Kai, 1970), play an important role in one of the pathways of signal transformation through the plasma membrane. Phosphoinositides are phospholipids with the C6-sugar inositol as polar head group and, predominantly, 1-stearoyl, 2-arachidonoyl as fatty acid tails attached to the glycerol backbone (Hawthorne, 1982). Phosphatidylinositol, the most abundant phosphoinositide, can be phosphorylated by addition of one or more phosphates to the inositol ring with ATP as phosphate donor, resulting in the formation of polyphosphoinositides.

The observation of Hokin and Hokin (1953) that acetylcholine increased the incorporation of labelled phosphate into phosphatidate and phosphatidylinositol of brain slices was the first report of a connection between signal transduction and the metabolism of these acidic phospholipids. Since then, many investigators have studied the metabolism of phosphoinositides in relation to receptor mediated signal transduction. Other (possible) functions of phosphoinositides have also received attention, such as regulation of growth, cytoskeletal rearrangements, and protein anchoring to the membrane. Many articles and reviews have been published on these topics. Phosphatidylinositol appears to have a rich diversity of forms and functions within cells, as do the enzymes associated with its metabolism. This part of the introduction, however, does not give a historical survey (as in Hokin, 1985) or a complete review of the whole field, but just a "state of the art" of the topics which are essential to this thesis.

\subsection{Receptor-stimulated hydrolysis of polyphosphoinositides}

An extracellular signal, such as a neurotransmitter, initiates signal transduction through the membrane by binding to a specific receptor on the cell surface. This receptor is coupled to a "second messenger-producing system" at the cytosolic site of the membrane, or to an ion channel. Receptors coupled to the phosphoinositide signal transduction mechanism are coupled to phospholipase C (PLC), a phosphoinositide-specific hydrolase, via an intermediate G-protein (Litosch, 1987; Strnad et al., 1986), in analogy to the adenylate cyclase messenger system. PLC activities have been purified from a wide variety of sources (Rhee et al., 1989; Baldassare et al., 1989). The G-protein requires GTP to be active in the stimulation of second messenger generation (Litosch, 1987). Besides stimulation 
of phosphoinositide hydrolysis by agonist-receptor interactions " inhibition of hydrolysis has also been observed after agonist-receptor interactions (Linden and Delahunty, 1989). In analogy to the adenylate cyclase messenger system, Linden and Delahunty (1989) hypothesized a distinct G-protein for the inhibition of phosphoinositide hydrolysis. However, up to now there is no evidence to support this notion.

Because $I(1,4,5) P_{3}$ is the first inositol metabolite which accumulates after receptor activation (Burgess et al., 1985; Irvine et al., 1985), the main candidate for receptor-stimulated hydrolysis is the twice phosphorylated phosphatidylinositol 4,5-bisphosphate $\left(\mathrm{PIP}_{2}\right)$ (Berridge et al,, 1983), formed by the consecutive phosphorylation of phosphatidylinositol (PI) to phosphatidylinositol 4-phosphate (PIP) by PI 4-kinase and of $\mathrm{PI}(4) \mathrm{P}$ to $\mathrm{PI}(4,5) \mathrm{P}_{2}$ by $\mathrm{PI}(4) \mathrm{P} 5$-kinase (reviewed by Carpenter and Cantley, 1990; Downes and MacPhee, 1990). However, the receptorstimulated hydrolysis of PI and PIP has also been suggested (Berridge, 1987; Wilson et al., 1985). Only a small portion of the inositol lipid pool is involved in signalling (Billah and Lapetina, 1982; Fain and Berridge, 1979b; Monaco and Woods, 1983) and appears to be confined to the plasma membrane (Rana et al., 1986). Remarkably, the phosphoinositides seem to be located predominantly in the cytoplasmic leaflet of the plasma membrane (Berridge, 1984; Hokin, 1985). Even PI(4,5) $\mathrm{P}_{2}$ may not be distributed homogenously in the plasma membrane (Koreh and Monaco, 1986; Muller et al., 1986). The hydrolysis of $\mathrm{PI}(4,5) \mathrm{P}_{2}$ results in the release of the second messengers inositol-1,4,5-trisphosphate $\left(I(1,4,5) P_{3}\right)$ and diacylglycerol (DAG) (Berridge, 1984).

Water-soluble $\mathrm{I}(1,4,5) \mathrm{P}_{3}$ enters the cytosolic compartment and either binds to an $\mathrm{I}(1,4,5) \mathrm{P}_{3}$ receptor or is metabolized (reviewed by Catt et al., 1991). Binding to the $\mathrm{I}(1,4,5) \mathrm{P}_{3}$ receptor results in the release of $\mathrm{Ca}^{2+}$ from intracellular stores (Streb et al., 1983), probably the endoplasmic reticulum (Streb et al., 1984), via the opening of a Ca2+ channel (Smith et al., 1985). This Ca2+ release from intracellular stores is followed by the entrance of extracellular calcium (Berridge, 1987). Increased $\mathrm{Ca} 2+$ levels result in the activation of $\mathrm{Ca}^{2+} /$ calmodulin-dependent protein kinase (Berridge, 1984). It has been suggested that the entry of extracellular calcium is initiated by inositol tetrakisphosphate $\left(\mathrm{I}(1,3,4,5) \mathrm{P}_{4}\right)$ (Irvine and Moor, 1986; Morris et al., 1987). However, both $\mathrm{IP}_{3}$ and $\mathrm{IP}_{4}$ are required for a full response (Morris et al., 1987; Berridge and Irvine, 1989), in which $I(1,4,5) P_{3}$ causes a transient rise in $\mathrm{Ca}^{2+}$ and the presence of $\mathrm{I}(1,3,4,5) \mathrm{P}_{4}$ leads to a sustained $\mathrm{Ca}^{2+}$ level, probably by replenishing the $\mathrm{I}(1,4,5) \mathrm{P}_{3}$ sensitive $\mathrm{Ca}^{2+}$ pool (Irvine et al., 1988).

$\mathrm{IP}_{4}$ is the phosphorylation product of $\mathrm{I}(1,4,5) \mathrm{P}_{3}$ in rat brain cytosol (Irvine et al., 1986) and other tissues (Berridge, 1987), and is present in the cytosol together with $\mathrm{IP}_{3}$ after receptor stimulation (Batty et al., 1985). $\mathrm{I}(1,3,4,5) \mathrm{P}_{4}$ is dephosphorylated to $\mathrm{I}(1,3,4) \mathrm{P}_{3}$, which has no Ca2+-mobilizing activity (Batty et al., 1985; Irvine et al., 1986). $I(1,3,4) P_{3}$ can be hydrolysed back to inositol by other routes (Berridge and Irvine, 1989). $\mathrm{I}(1,4,5) \mathrm{P}_{3}$ is rapidly dephosphorylated to $\mathrm{I}(1,4) \mathrm{P}_{2}$ by an enzyme similar, if not identical, to the enzyme which dephosphorylates $\mathrm{IP}_{4}$ (Batty et al., 1985). $\mathrm{I}(1,4) \mathrm{P}_{2}$ is also inactive in releasing Ca2+ (Berridge and Irvine, 1984). $\mathrm{I}(1,4) \mathrm{P}_{2}$ 
extracellular signal

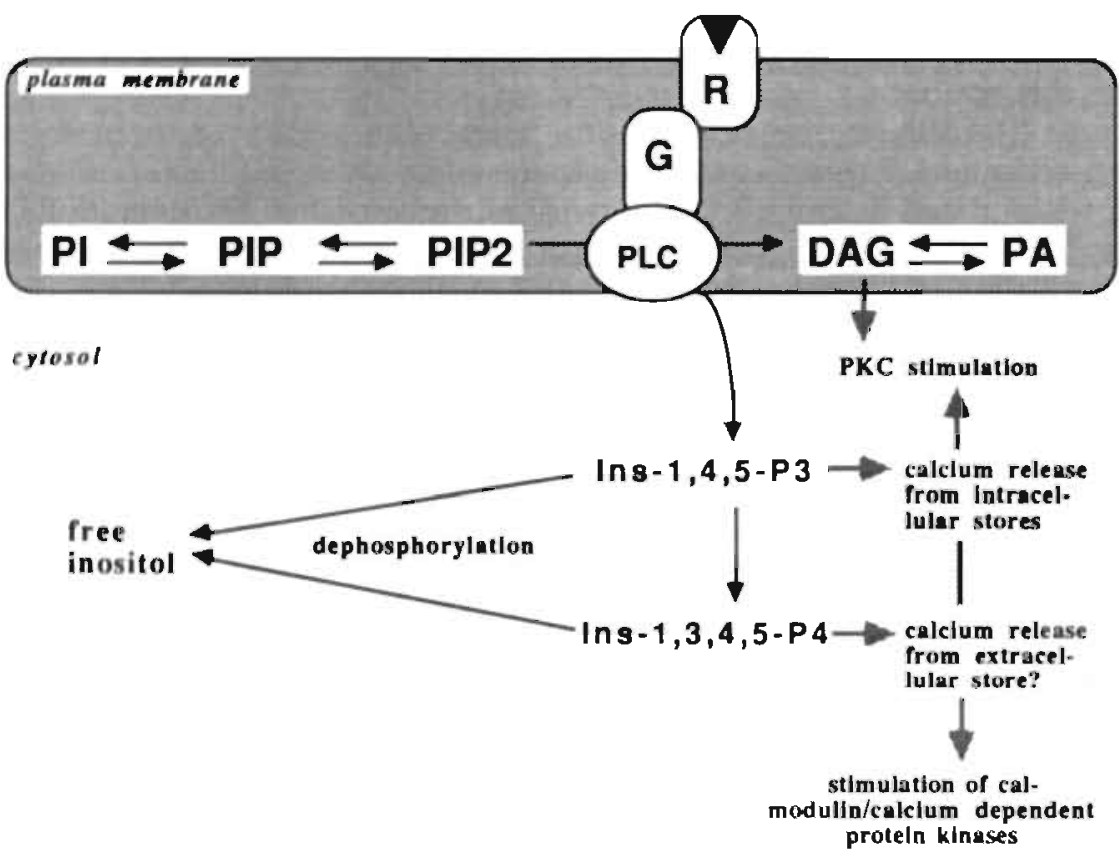

Fig. 1 : Receptor-mediated phosphoinositide metabolism. PI: phosphatidylinositol, PIP: phosphatidylinositol phosphate, $\mathrm{PIP}_{2}$ : phosphatidylinositol bisphosphate, PLC: phospholipase C, G: G-protein, R: receptor, DAG: diacylglycerol, PA: phosphatidic acid, Ins-

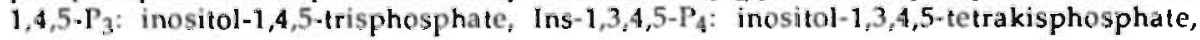
PKC: protein kinase $\mathrm{C}$.

is further dephosphorylated to myo-inositol (Storey et al., 1984), a reaction which can be inhibited by $\mathrm{Li}^{+}$ions (Berridge et al., 1982; Sherman et al., 1981), resulting in a reduction in the supply of inositol. Because the inhibition by $\mathrm{Li}^{+}$of signal transduction is non-competitive, $\mathrm{Li}^{+}$ions are selectively active towards overactive receptors. This is the putative basis of the action of $\mathrm{Li}+$ ions in manic depression, in contrast to the minimal effect of $\mathrm{Li}+$ in subjects not suffering from manic depression (Berridge and Irvine, 1989). The significance of the complexity of inositol phosphate metabolism is unknown, although Berridge and Irvine (1989) hypothesized that this is simply an inevitable result of the 3 phosphorylation of $\mathrm{I}(1,4,5) \mathrm{P}_{3}$ to $\mathrm{I}(1,3,4,5) \mathrm{P}_{4}$, so more enzymes will be required to catabolize these and a complex pattern of intermediates cannot be avoided. In addition, higher phosphorylated derivatives, such as $\mathrm{IP}_{5}$ and $\mathrm{IP}_{6}$, have been 
identified in various tissues including brain (Tilly et al., 1987) and possibly act as extracellular messengers (Vallejo et al., 1987). However, most of the inositol metabolites that accumulate in the cytosol of stimulated cells seem to be products of the metabolism of a single compound, $\mathrm{I}(1,4,5) \mathrm{P}_{3}$ (Downes, 1986).

Besides this $\mathrm{Ca}^{2+-m o b i l i z i n g ~ s e c o n d ~ m e s s e n g e r, ~ D A G ~ i s ~ a l s o ~ r e l e a s e d ~ b y ~ t h e ~}$ receptor-stimulated hydrolysis of $\mathrm{PIP}_{2}$ (Berridge, 1984). DAG, composed of two fatty acid tails attached to a glycerol backbone, remains in the plasma membrane and activates protein kinase C (PKC), although phosphatidylserine and calcium are also required for PKC activation (Nishizuka, 1984). DAG increases the affinity of PKC for $\mathrm{Ca}^{2+}$, so that maximal PKC activity is possible at basal cytosolic $\mathrm{Ca}^{2+}$ concentrations (Nishizuka, 1988). When PKC is fully activated it is tightly associated with the plasma membrane (Kaczmarek, 1987). This physical translocation of PKC from the cytosol into the membrane might be mediated by $\mathrm{Ca}^{2+}$ (May et al., 1985). Phospholipid-, calcium- and DAG-dependent PKC regulates many key processes in growth and development (Nishizuka, 1989), but also ion channels and neurotransmitter release (Kaczmarek, 1987). Remarkably, PKC appears to be a target for phorbol esters, as these tumour-promoting agents activate this enzyme directly both in vitro and in vivo, and there is an approximate correlation between the ability of individual phorbol esters to promote tumours and to activate the enzyme (Castagna et al., 1982; Yamanishi et al., 1983). Thus, PKC seems to be a receptor for tumour promotors, and possibly some, if not all, of the pleiotropic actions of tumour-promoting phorbol esters may be mediated through the action of PKC (Nishizuka, 1984). The level of DAG required for activation of PKC is a function of its production from phosphoinositides and its phosphorylation to PA or its degradation to its building blocks (Hokin, 1985).

Upon cell stimulation, DAG is rapidly converted by diacylglycerol kinase to phosphatidic acid (PA) (Kanoh et al., 1990), which could have two functions: first, to initiate the resynthesis of the phosphoinositides, and second, to control the concentration of the second messenger DAG, thus acting as a regulator of PKC (Nishizuka, 1986). Thus PA formed after DAG phosphorylation could be "just" an intermediate in the resynthesis of phosphoinositides as described above, but there are also indications that PA may directly mediate the inward movement of $\mathrm{Ca}^{2+}$ after activation of membrane receptors (Putney et al., 1980), or may mimic the action of growth factors by stimulating the hydrolysis of $\mathrm{PI}(4,5) \mathrm{P}_{2}$ (Moolenaar et al., 1986). DAG breakdown is catalysed by DAG lipase resulting in the liberation of arachidonic acid (AA). The DAG phosphorylation product PA can be broken down to release AA by the activation of specific phospholipase $A_{2}$ (Billah et al., 1981; Lapetina and Billah, 1981). AA and its metabolites are discussed in section 2.3.

The $\mathrm{IP}_{3}$ branch and the DAG branch of the phosphoinositide signal cascade appear to act synergistically to phosphorylate proteins, the former by elevating $\mathrm{Ca}^{2+}$ concentrations to activate calmodulin-dependent protein phosphorylation, and the latter to activate PKC, which needs $\mathrm{Ca}^{2}+$ for its activity (Berridge, 1987; Hokin, 1985). These protein kinases regulate many other enzymes, ion-channels 
etc. by phosphorylation, ultimately resulting in a biological response (Magnoni et al., 1991).

Different sources of inositol can be used for the resynthesis of phosphatidylinositol: Inositol can be formed de novo, by dephosphorylation of inositol phosphates, or by import from the extracellular fluid (Downes and MacPhee, 1990). Inositol is formed de novo by a myo-inositol-1-phosphate synthase, which forms $\mathrm{IP}_{1}$ out of glucose 6-phosphate (Eisenberg, 1967), followed by dephosphorylation (Sherman et al., 1981). Phosphatidylinositol is also formed from myo-inositol and CDP-DAG (product of CTP and PA) by the action of PI synthase or CDP-DAG:myo-inositol 3-phosphatidyl transferase (Downes and MacPhee, 1990).

Receptor-stimulated inositol phospholipid hydrolysis or the so-called "PI effect" is found in various tissues of several species (listed in Abdel-Latif, 1986; Berridge, 1984; Hokin, 1985) including, of course, the central nervous system (CNS). Fisher et al. (1992) listed in their extensive review the receptors present on neurons and/or glia known to be linked to phosphoinositide turnover. They distinguish two groups of receptors: Categrory 1 receptors, which elicit a robust increase in inositol phospholipid turnover in tissue preparations of both the CNS and neurotumour cells, including muscarinic cholinergic, adrenergic, histaminergic, serotonergic, glutamatergic, and endothelin receptors; and Category 2 receptors, which elicit only a small increase in inositol phospholipid turnover in CNS-derived preparations, as evidenced by the use of neurotumour cells or other neural-related tissues, including purinergic, nerve growth factor, prostaglandin, bradykinin, vasopressin, oxytocin, thyrotropin-releasing hormone, and other receptors (Fisher et al., 1992).

\subsection{Arachidonic acid}

Receptor stimulation, which results in the release of the second messengers $\mathrm{IP}_{3}$ and DAG, also appears to stimulate a lipase acting preferentially on species of DAG and PA which carry arachidonic acid on the 2-position (Berridge, 1984). Arachidonic acid (AA) is released from phosphoinositides and PA by different phospholipase $\mathrm{A}_{2}$ (PLA $)$ enzymes leading to the accumulation of lysophospholipids (Billah et al., 1981; Flower and Blackwell, 1976; Lapetina and Billah, 1981). The release of AA from phosphoinositides, however, requires much higher levels of $\mathrm{Ca}^{2+}$ and may only occur at supramaximal stimulation (Billah et al., 1980). AA can also be released from the second messenger DAG by a DAG lipase (Bell et al., 1979). AA is metabolized in the brain via three pathways (Piomelli and Greengard, 1990), namely the cyclooxygenase pathway, leading to the formation of prostaglandins, prostacyclins and thromboxane $A_{2}$, the lipoxygenase pathway, leading to the formation of leukotrienes, and the cytochrome $P 450$ pathway, leading to the formation of an array of epoxyeicosatrienoic acids. AA appears to be involved in the induction of longterm potentiation, the modulation of signal transduction, the regulation of enzyme activities, and in intracellular $\mathrm{Ca}^{2+}$ homeostasis (see Strosznajder and 
Samochocki, 1991, and ref.). Free AA and its metabolites raise the cytosolic Ca2+ level independently of $\mathrm{IP}_{3}$ (Halushka and Burch, 1984; Wolf et al., 1986). Sekar and Hokin (1986) suggest in their review that the action of free arachidonate must be interpreted in the light of the detergent actions of this fatty acid.

\subsection{D-3 phosphorylated inositol phospholipids}

The metabolism of inositolphospholipids has recently become more complex with the discovery of D-3 phosphorylated inositol phospholipids. Whitman et al. (1987) divided the PI kinases into two different types. Type 1 PI kinase appears to be a PI 3-kinase (Whitman ef al. 1988). The D-3 phosphorylation of the novel inositol phospholipid (PI(3)P) was also shown by Stephens et al. (1989). The characteristics of the different PI kinases are discussed in section 2.6. Besides $\mathrm{PI}(3) \mathrm{P}, \mathrm{PI}(3,4) \mathrm{P}_{2}$ (with $\mathrm{PI}(4) \mathrm{P}$ as substrate) and $\mathrm{PI}(3,4,5) \mathrm{P}_{3}$ (with $\mathrm{PI}(4,5) \mathrm{P}_{2}$ as substrate) were also detected (Auger et al 1989). An inositol tetrakisphosphate containing inositol phospholipid was also found by Traynor-Kaplan et al. (1988) and Vadnal and Parthasarathy (1989), who suggested that PIP $_{3}$ could be the parent

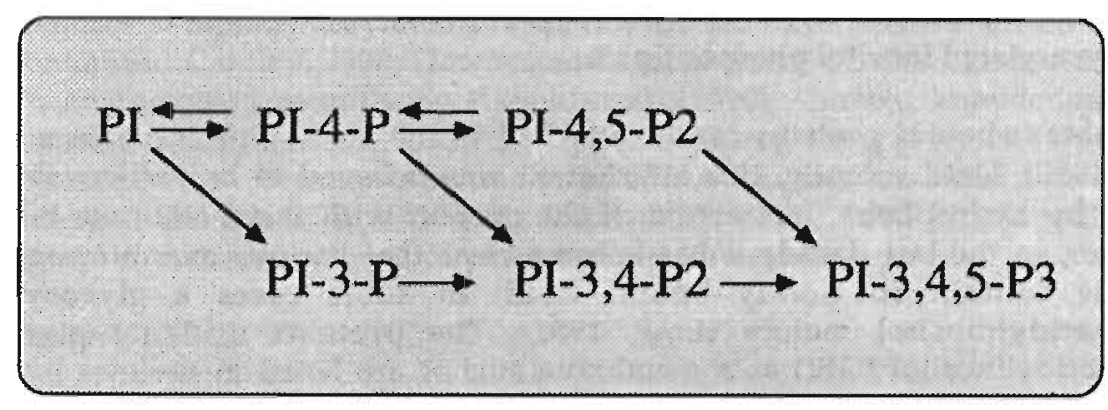

Fig. 2 : A schematic diagram of the known phosphoinositide phosphorylation routes. The upper pathway is the "conventional" polyphosphoinositide pathway, and the lower pathways are the D-3 phosphorylation pathways.

compound for $\mathrm{IP}_{4}$. However, polyphosphoinositides phosphorylated in the D-3 position are poor substrates for phospholipase $C$ from rat liver and bovine brain (Serunian et al., 1989). Probably, just one enzyme is responsible for the production of these D-3 phosphorylated compounds, as purified type 1 PI 3-kinase can use $\mathrm{PI}, \mathrm{PI}(4) \mathrm{P}$ and $\mathrm{PI}(4,5) \mathrm{P}_{2}$ as substrate with almost equal kinetic 
characteristics (Carpenter et al., 1990). However, Cunningham et al. (1990) reports the phosphorylation of $\mathrm{PI}(3) \mathrm{P}$ to $\mathrm{PI}(3,4) \mathrm{P}_{2}$ and $\mathrm{PI}(3,4) \mathrm{P}_{2}$ to $\mathrm{PI}(3,4,5) \mathrm{P}_{3}$. The main feature of this enzyme activity or these enzyme activities is its (their) association with activated protein tyrosine kinases of growth factor receptors and oncogene products. These protein tyrosine kinases include pp $60 \mathrm{v}$-src, the polyoma middle $T$ antigen / Pp60c-src complex, the PDGF receptor, the CSF-1 receptor, the insulin receptor, and p68v-ros, the transforming protein of the avian sarcoma virus UR2, as listed by Cantley et al. (1991). Therefore, PI 3-kinase seems to be involved in cell transformation and cell divison. This notion is strengthened by the results of mutation studies in which a loss of PI 3-kinase association coincides with a loss of the potency to transform cells (Chan et al., 1990; Courtneidge and Heber, 1987; Fukui and Hanafusa, 1989; Kaplan et al., 1986; Kaplan et al., 1987; Varticovski et al., 1991; Whitman et al., 1985). However, cells in a terminally differentiated form, such as neutrophils and platelets, also produce D-3 phosphorylated phosphoinositides as a result of cell activation by agonists (listed in Auger and Cantley, 1991). Auger and Cantley (1991) suggest that the novel polyphosphoinositides are involved in cytoskeletal reorganization because the effects found in neutrophils and platelets, as mentioned above, coincide with cytoskeletal changes, and a lack of association of PI 3-kinase appears to correlate with the lack of actin reorganization and mitogenic signals.

\subsection{Glycosylated inositol phospholipids}

Membrane-bound proteins can be attached to the membrane in various ways (Low, 1987). Until recently, this attachment was believed to be non-covalent in nature, by hydrophobic interaction of the protein with the membrane bilayer. However, in the last decade it has become clear that various membrane-bound proteins contain covalently bound lipid, in some cases a glycosylated phosphatidylinositol moiety (Low, 1987). The proteins utilizing glycosylphosphatidylinositol (GPI) as a membrane anchor are listed in reviews by Low (1989) and Lisanti et al. (1990). The structure of the glycan protein consists of ethanolaminephosphate, three mannose residues, and glucosamine linked to PI. The PI used for protein anchoring has a fatty acid composition rich in myristic acid, whereas the fatty acids attached to $\mathrm{PI}(4,5) \mathrm{P}_{2}$ are predominantly stearoylarachidonyl in composition (Berridge and Irvine, 1989). Lisanti et al. (1990) discuss the possible functions of this strange and complicated way of membrane attachment, and suggest functions in the cellular distribution of proteins, lateral mobility of proteins, the exclusion of the anchored proteins from clathrin-coated pits, and/or, the regulation of the release of proteins (Berridge and Irvine, 1989; Lisanti et al., 1990).

In several cell types, a GPI has been described which shares the core structure of PI-glucosamine and contains additional monosacharides, but which lacks ethanolamine and is not attached to protein (Saltiel and Cuatrecasas, 1988). These non-protein-bound GPIs located on the cytoplasmic aspect of the plasma membrane can be hydrolysed by an insulin-stimulated and phospholipase- 
mediated mechanism, resulting in the release of a novel second messenger, the inositol-glycan, and DAG (Saltiel and Cuatrecasas, 1986; Saltiel et al., 1986). This novel second messenger affects particular enzymes in vitro, but its mechanism of action is not known, although it has marked effects on protein phosphatase and could have a direct regulatory mechanism of action (Saltiel, 1991). With respect to the many insulin-mediated effects, insulin can regulate both the phosphorylation of particular proteins by PKC (activated by DAG release), and the dephosphorylation of other proteins by protein phosphatases factivated by inositol-glycan). Besides insulin, insulin-like growth factors and a limited number of other peptides, for example NGF, also share this signal transduction mechanism. These agonists also share insulin-like biological activities such as the promotion of neurite outgrowth, enchancement of survival of certain neurons etc. (Saltiel, 1991).

\subsection{Kinases in inositol phospholipid metabolism}

For the generation of the second messengers $\mathrm{IP}_{3}$ and $\mathrm{DAG}, \mathrm{PI}(4,5) \mathrm{P}_{2}$ has to be formed out of PI by sequential phosphorylation via $\mathrm{PI}(4) \mathrm{P}$ to $\mathrm{PI}(4,5) \mathrm{P}_{2}$. The DAG formed after $\mathrm{PIP}_{2}$ hydrolysis is rapidly phosphorylated resulting in the formation of PA. The kinases involved in the formation of $\mathrm{PIP}_{2}$ out of $\mathrm{PI}$ and in the formation of D-3-phosphorylated phosphoinositides have been reviewed recently (Carpenter and Cantley, 1990; Downes and Macphee, 1990). DAG kinase activities have been reviewed recently by Kanoh et al. (1990). Current knowledge of the characteristics of kinases and the (possible) regulatory mechanisms are summarized below. Because only one form of DAG kinase has been purified and characterized (Kanoh et al., 1990), the information about DAG kinase will not be as lengthy as that for the inositol phospholipid kinases.

\section{- PI kinase}

There are three types of PI kinase (Carpenter and Cantley, 1990). These types differ in the position at which they phosphorylate the inositol ring, in some kinetic properties and in molecular mass. Whitman et al. (1987) identified two types of PI kinases in fibroblasts which differed in their sensitivity to adenosine and non-ionic detergents (Triton $X-100$ ).

Type 1, which appears to phosphorylate the D-3 position of the inositol ring (Whitman et al. 1988), is inhibited by detergent and is almost unaffected by adenosine (Whitman et al., 1987). This PI 3-kinase was originally described as a PI kinase that co-purified with pp60v-src, polyoma middle $\mathrm{T}$ antigen/pp60v-src complex and the PDGF receptor, which are all protein tyrosine kinases (Kaplan et al., 1987; Sugimoto et al., 1984; Whitman et al., 1985). PI 3-kinase is present in all eukaryotic organisms examined to date, but has not been found in bacteria (Carpenter and Cantley, 1990). This enzyme phosphorylates phosphatidylinositol, but also phosphatidylinositol-4-phosphate and phosphatidylinositol 4,5bisphosphate at the D-3 position, with apparent $\mathrm{Km}$ values for ATP of $30-60 \mu \mathrm{M}$ 
(Carpenter et al., 1990). The molecular mass of the native heterodimer enzyme appeared to be $190 \mathrm{kDa}$ and is composed of a $85 \mathrm{kDa}$ unit, which is the same protein shown to associate with polyoma virus middle $\mathrm{T}$ antigen and the PDGF receptor (Kaplan et al., 1987) and a $110 \mathrm{kDa}$ unit (Carpenter et al., 1990). Both, the $110 \mathrm{kDa}$ unit and the native $190 \mathrm{kDa}$ protein have been purified from bovine thymus cytosol as active PI 3-kinases (Shibasaki et al., 1991), although Morgan et al. (1990) purified an active PI 3-kinase from bovine brain with a molecular mass of $85 \mathrm{kDa}$. However, further research revealed that the $85 \mathrm{kDa}$ unit is a receptor tyrosine kinase substrate (Hayashi et al., 1991). Tyrosine phosphorylation of the 85 $\mathrm{kDa}$ subunit associated with PI 3-kinase activity results in trafficking or recruitment from the cytosol to the membrane (Cohen et al., 1990). Thus, an interaction between an agonist and a receptor which contains intrinsic tyrosine kinase activity (such as the insulin receptor) reveals an active tyrosine kinase which phosphorylates the $85 \mathrm{kDa}$ subunit, resulting in the association of the PI 3kinase with the receptor (Otsu et al., 1991). The activation of PI 3-kinase by the stimulation of receptors which contain intrinsic tyrosine kinase activity has been shown for PDGF (Auger et al., 1989), EGF (Pignatoro and Ascoli, 1990), IL-2 (Merida et al., 1991; Remillard et al., 1991), CSF-1 (Varticovski et al., 1989), insulin (Hayashi et al., 1991; Rudermann et al., 1990), and IGF-1 (Kapeller et al., 1990). However, whether the tyrosine phosphorylation of the $85 \mathrm{kDa}$ unit also causes the activation of PI 3-kinase in addition to its translocation is unknown (Carpenter and Cantley, 1990). It has been suggested that a G-protein could be involved in the activation of PI 3-kinase (Traynor-Kaplan et al., 1988). The human gene encoding for PI 3-kinase associated p85 is located at chromosome region 5q12-13 (Cannizzaro et al., 1991). The $85 \mathrm{kDa}$ subunit has been cloned (Escobedo et al., 1991; Skolnik et al., 1991) and appears to contain SH2 domains homologous to domains found in other receptor-associated enzymes (Escobedo et al., 1991). These domains provide a binding site for sequences that contain phosphotyrosine (Mayer and Hanafusa, 1990). It is anticipated that the $110 \mathrm{kDa}$ unit, which is the PI 3-kinase itself (Shibasaki et al., 1991), will be cloned in the near future.

Type 2. PI kinase appears to phosphorylate the D-4 position of the inositol ring (Whitman et al, 1988), is activated by non-ionic detergents, and is inhibited by adenosine. However, Endemann et al. (1987) reported the existence of two PI 4kinases in bovine brain, which differed clearly in molecular mass. The most extensively studied enzyme, the type 2 enzyme with a molecular mass of $55 \mathrm{kDa}$, appears to be an integral membrane protein as it requires detergent for its extraction from the membrane and is not present in large amounts in the soluble fraction of homogenized cells (Carpenter and Cantley, 1990; Downes and MacPhee, 1990). The type 2 PI kinase has been found in bovine brain (Endemann et al., 1991; Jenkins et al., 1991; Wetzker et al., 1991), sheep brain (Scholz et al., 1991), porcine liver microsomes (Hou et al., 1988), bovine uterus (Porter et al., 1988), and A431 cells (Walker et al., 1988). Type 2 PI kinase has a Km value for ATP of 20-60 $\mu \mathrm{M}$ and $\mathrm{a} \mathrm{Ki}$ for adenosine of $10-70 \mu \mathrm{M}$.

The type 3 PI 4-kinase is also membrane bound (Endemann et al., 1987), 
although a type 3 PI 4-kinase seems to be present in the soluble fraction of the human placenta (Downes and MacPhee,1990). Type 3 PI 4-kinase has a high Km for ATP, is relatively resistant to adenosine inhibition and has an apparent molecular mass of 200 kDa (Carpenter and Cantley, 1990; Downes and MacPhee, 1990). However, the properties of the type-3-like PI kinases are not completely consistent (Li et al., 1989; Yamakawa and Takenawa, 1988) with the properties of the type 3 PI kinase reported by Endemann et al. (1987). The classification of PI kinases presented by Carpenter and Cantley (1990) is not complete, as other PI 4kinases have been purified with properties other than those of the type 2 and type 3 PI kinases (Belunis et al., 1988; Kanoh et al., 1990; Saltiel et al., 1987).

Membrane-associated PI 4-kinase activity is located predominantly in lowdensity membranes possibly involved in membrane trafficking, and in the plasma membrane (Carpenter and Cantley, 1990; Lundberg and Jergil, 1988). Because PI is synthesized in the endoplasmic reticulum, this PI could be phosphorylated on its way to the plasma membrane. However, erythrocytes do not have intracellular membranes, yet contain a rather active PI 4-kinase (Downes and MacPhee, 1990). Careful analysis of type 2 versus type 3 PI 4-kinase activities in subcellular fractions has not been done (Carpenter and Cantley, 1990). The regulation of PI 4-kinase activity is poorly understood for several reasons listed by Carpenter and Cantley (1990). However, some possible mechanisms for the regulation of PI 4-kinase activity include activation by EGF (in A431 cells; Walker and Pike, 1987), activation by phorbol esters (Halenda and Feinstein, 1984; Taylor et al., 1984), activation by an elevation of cAMP (Kato et al., 1989) and activation by polyamines (Schuber, 1989).

\section{- PIP kinase}

$\mathrm{PI}(4) \mathrm{P}$ 5-kinase catalyses the ultimate step in the production of the IP ${ }_{3}$ and DAG precursor $\mathrm{PI}(4,5) \mathrm{P}_{2}$. PI(4)P 5-kinase is found in both soluble and membrane-bound forms (Carpenter and Cantley, 1990; Downes and MacPhee, 1990). The membranebound form is not as tightly bound to the membrane as PI 4-kinase is, as it can be solubilized by high salt concentrations in the absence of detergent (Ling et al., 1989; Moritz et al., 1990). Ling et al. (1989) have been the only group to demonstrate the phosphorylation of the 5-position of the inositol ring. PIP kinase has been purified from human red blood cells (Bazenet et al., 1990; Ling et al., 1989), human platelets (Suzuki et al., 1991), bovine brain (Moritz et al., 1990) and rat brain (Cochet and Chambaz, 1986; Van Dongen et al., 1984). The PI(4)P 5kinase of human red blood cells has been studied in detail. Bazenet et al. (1990) found two distinct PI(4)P 5-kinases, a membrane-bound type 1, which has a more ubiquitous distribution and is responsible for most $\mathrm{PI}(4,5) \mathrm{P}_{2}$ synthesis, and a membrane-bound and cytosolic type 2, which is abundant only in cells of bone marrow origin and is identical to the enzyme purified by Ling et al. (1989). The latter type 2 PI(4)P 5-kinase has an apparent molecular mass of $53 \mathrm{kDa}$ by SDSPAGE (Bazenet et al., 1990; Ling et al., 1989) whereas the composition of the type 1 enzyme is still uncertain. The two forms of human platelet membrane PI(4)P 5- 
kinase have molecular weights of 51 and $47 \mathrm{kDa}$, respectivily (Suzuki et al., 1991). The PI(4)P 5-kinase of rat brain cytosol (Cochet and Chambaz, 1986) has a molecular mass of $45 \mathrm{kDa}$, whereas the membrane-bound PI(4)P 5-kinase of bovine brain has a molecular mass of $110 \mathrm{kDa}$ by SDS-PAGE (Moritz et al., 1990).

PI(4)P 5-kinase could be regulated by product feedback inhibition (Van Rooijen et al., 1985), via the loss of $\mathrm{PI}(4,5) \mathrm{P}_{2}$, as a number of investigators have reported a stimulation of $\mathrm{PIP}_{2}$ formation during/after receptor stimulation (Renard et al., 1987; Taylor et al., 1984). However, this is unlikely to be the only form of regulation (Imai et al., 1986). Jolles et al. (1980) reported an inverse relationship between $\mathrm{B}-50$ phosphorylation by $\mathrm{PKC}$ and $\mathrm{PIP}_{2}$ formation, which suggests that PKC could inhibit PIP kinase activity via the phosphorylation of a brain-specific protein (B-50). However, more recent data suggest that PKC is involved in the stimulation of PIP kinase, as phorbol esters increase PIP formation in intact cells (Chaffoy de Courcelles et al., 1985; Halenda and Feinstein, 1984; Taylor et al., 1984). Other possible regulators of PI(4)P 5-kinase activity could be the previously mentioned elevation of c-AMP (Kato et al., 1989) or polyamines (Schuber, 1989), which might be the physiological regulators of $\mathrm{PI}(4,5) \mathrm{P}_{2}$ formation (Downes and MacPhee, 1990).

\section{- DAG kinase}

DAG kinase phosphorylates the second messenger DAG, resulting in the formation of phosphatidic acid (PA). DAG kinase is predominantly present in the cytosol, although DAG kinase activity has also been demonstrated in membrane fractions (Kanoh and Akesson, 1978; Kanoh et al., 1983; Stubbs et al., 1988). A 80 kDa DAG kinase has been purified from pig brain and thymus (Kanoh et al., 1983; Sakane et al., 1989). The antibody raised against this enzyme precipitated only part of the enzyme activity from the brain cytosol and failed to react with DAG kinase from pig liver cytosol, suggesting the presence of DAG kinase iso-enzymes (Kanoh et al., 1990). A heat stable $150 \mathrm{kDa}$ DAG kinase purified from pig thymus showed no contamination with the $80 \mathrm{kDa}$ enzyme (Sakane et al., 1989; Yamada and Kanoh, 1988). Human platelets appear to contain three DAG kinase isoenzymes, which differ in molecular weight and sensitivity to deoxycholate, phosphatidylserine, and the DAG kinase inhibitor R59022 (Yada et al., 1990).

Very little is known about the mechanisms regulating DAG kinase. DAG kinase activity seems to be regulated by substrate (DAG) availability, as PA is directly formed after receptor-mediated hydrolysis of $\mathrm{PI}(4,5) \mathrm{P}_{2}$ (Agranoff et al., 1983; Litosch et al., 1983). Because of the important regulatory functions of DAG and AA, which are derived from both DAG and PA, DAG kinase seems to be a modulator of signal transduction (Kanoh et al., 1990). DAG kinase is thought to be activated by its translocation from the cytosol to the membrane as observed in several cell types including rat brain (Besterman et al., 1986; Kanoh et al., 1990). One possibility for the initiation of such a translocation is phosphorylation of DAG kinase, which has been shown in vitro to occur with purified DAG kinase and PKC from pig thymus cytosol (Kanoh et al., 1989). In addition, Jeng et al. 
(1988) found an endogenous, water-soluble, macromolecular inhibitor of DAG kinase activity in rat brain homogenate, and this compound is suggested to be a possible physiological regulator.

\section{NEUROCHEMICAL ASPECTS OF AGING}

\subsection{Theories of aging}

All living things change with age. The numerous biogerontological theories which describe the possible universal cause for age-related changes have one common feature: there are both supporting and contradictory arguments for each theory. According to Hayflick (1985), one reason why so many biogerontological theories exist is that the manifestations of biological changes over time affect virtually all components of living systems, from the molecular level up to that of the whole organism. Most of these theories are aspect theories, which arise from transforming the observation of one narrow aspect of the numerous age changes into a generalized theory of universal applicability. Examples of such aspect theories are the organ theories of the immune system and of the brain/neuroendocrine system (Meites et al., 1987; Meites, 1988). The general concept of the immune system theory is that the immune system deteriorates with age and that this deterioration causes a decline in functionality with age in the whole organism. The brain/endocrine system theory has the same basic concept. However, many organisms that do age lack an immune system or brain/endocrine system. Furthermore, these systems are regulated by other factors such as hormones (reviewed by Everitt and Meites, 1989) and the genome which makes it more plausible that changes in these regulatory mechanisms cause the changes in the organ systems mentioned. Meites et al. (1987), however, argue that aging in more complex animals probably involves the critical cells of the homeostatic and integrative systems of the body. The current cellular and molecular theories of aging cannot be applied to the age-related changes in the neuroendocrine system according to Meites et al. (1987). More specific than the endocrine system theory is the cholinergic hypothesis of gerialric dysfunction (reviewed by Bartus et al., 1982). They describe biochemical, electrophysiological and pharmacological evidence supporting a role for cholinergic dysfunction in age-related memory disturbances.

There are other aspect theories that could be generalized to all cells, such as the free radical theory, the cross-linkage theory, the waste-product accumulation theory and the genome-based theories (reviewed by Hayflick, 1985). The basic concept of the free radical theory is that free radicals, formed during the reduction of $\mathrm{O}_{2}$ to water in mammals, oxidize intracellular structures, resulting in cell damage and ultimately in loss of function (Harman, 1981). Lipofuscin, the so called age-pigment, which accumulates in non-dividing cells, is one of the products of free radical oxidation of polyunsaturated fatty acids. This makes the theory of waste-product accumulation, with lipofuscin as the predominant waste 
product, just a sub-theory of the free radical theory of aging. There is no evidence that lipofuscin actually damages cells by impeding their function (Hayflick, 1985), which makes the waste-product accumulation theory unlikely to be a general and universal aging theory. Harman (1981) stated that all cells are susceptible to damage by free radicals. In vitro, this damage can be prevented by the addition of antioxidants. In vivo, feeding antioxidants to laboratory animals increases life expectation. Harman (1981) suggested that the aging process may be simply the sum of the deleterious free radical reactions that occur in cells and tissues. However, the role of the "fundamental cause of age" of the free radical theory is doubtful as it only affects life expectation and not life span. Antioxidants may, for example, simply inhibit or delay the expression of some diseases just as vaccines and antibiotics, which also increase life expectation but which are not involved with aging (Hayflick, 1985).

The free radical theory is, according to Bjorksten (1974), simply a special case of the more general cross-linkage theory because free radicals are effective crosslinkers. The basic concept of this cross-linkage theory is that with age molecular changes occur in substances within the extracellular compartment and intracellularly localized information-containing molecules such as DNA and RNA (Bjorksten, 1974), resulting in covalent or hydrogen bounds between macromolecules. These linkages cause DNA damage, mutation or cell death, impedance of intracellular transport, decreased solubility, elasticity and permeability, and decreased extracellular transport impairing the flow of nutrients and waste products. An increase in cross-linking in collagen, other proteins and DNA with time has been demonstrated (Bjorksten, 1974). However, this potentially universal theory cannot account for the great differences in the life-span of animals. It is not realistic, for example, that mice have a 30 times faster cross-linkage than man to account for their shorter life-span (Hayflick, 1985).

The genome-based theories can be subdivided into the somatic mutation theory, the error theory, and the programme theory. The central concept of the somatic mutation theory, which has much in common with the error theory, consists of the accumulation of a sufficient level of mutations in somatic cells with age, which will produce the physiological decrements characteristic of aging. However, experiments testing this theory revealed no supporting evidence as irradiated animals did not show accelerated age-changes and life-span was unaffected (Curtis and Miller, 1971). In contrast, there is evidence that DNA sequence variations accumulate during aging (reviewed by Vijg, 1990b). Furthermore, Vijg discussed the possible role of somatic mutations in aging. These mutations would most likely occur through a disturbance in the subtly balanced gene regulatory network present in each differentiated cell of a higher eukaryote.

The central concept of the programme theory is that a purposeful sequence of events written into the genome leads to age changes, in a similar way as instructions in the genetic message lead to the orderly expression of developmental sequences (Hayflick and Moorhead, 1961). Sacher (1982) believes 
aging to be errors in logic. Aging is, in his view, a programme of life phases with a functional role for senescence and/or death in a specific temporal relationship with other life processes. The best evidence in support of this theory is the fundamental fact that aging occurs naturally in intact animals (Hayflick, 1985), which makes it also a potentially universal theory. A variation on this theory is a theory of Medawar (1952), who postulated the presence of deleferious genes which pile up as a result of a selection process in the post-reproductive period, when their expression would do less harm to the species. Williams (1957) postulated, as a variation on the theory of Medawar (1952), pleiotropic genes with both favourable and, in the post-reproductive phase, unfavourable or deleterious actions. These molecular-based theories are, supplemented with new data, discussed by Vijg (1990a). Vijg emphasizes the existence of a balance between favourable and unfavourable genes, in which the favourable genes code for enzymes that defend the organism against damage for example, superoxide dismutase.

Two other theories are discussed by Swaab (1991). He promotes an aging theory for neurons called "use it or lose it" in contrast to the "wear and tear" theory. The "wear and tear" theory is a theory in which, for example, the free radical theory and the cross-linkage theory are represented. According to this theory, increased activity causes an increased formation of reactive metabolites, resulting in increased damage in the cells used. This theory does not apply to the central nervous system, according to Swaab (1991): "Activation of nerve cells within the physiological range seem to lead to maintenance of neurons during aging and in Alzheimer's disease, possibly by preferentially stimulating the action of protective mechanisms such as DNA repair". This "use it or lose it" principle might explain why certain neurons degenerate in aging and Alzheimer's disease (Swaab, 1991). Greenamyre (1991) suggests that rather than "use it or lose it", it may be a case of "use it and lose it", because glutamate, for example, normally acts as a neurotransmitter, although under energy-deficient periods glutamate is excitotoxic. The "use it or lose it" theory of Swaab is supported by the review of Raff (1992) on social controls on cell survival and cell death. Programmed death seems to occur by default unless suppressed by signals from other cells. This programmed death of cells would also be an argument supporting the programme theory of aging.

Besides the theories listed above, there is in addition the so-called membrane theory of aging. The main tenet of this theory is that the membrane shows an ageassociated increase in microviscosity which correlates with the increase in the cholesterol/phospholipid ratio with age. The condition of the membrane is essential for communication, import of nutrients and export of waste-products because proteins performing these functions are embedded in this membrane, and the cytoskeleton is attached to it. A less fluid membrane could result in a decline in cell function (Naeim and Walford, 1985).

However, according to Knook (1982) the process of aging is so complex that it is doubtful that one theory could explain all aspects of aging. I will therefore, not focus on one particular theory, but on those aspects of aging that are directly 
related to phosphoinositide metabolism as described before.

\subsection{Phosphoinositide metabolism and aging}

Phosphoinositide metabolism has many different aspects that are important for the functioning of cells, as we have seen in part 2. According to Magnoni et al. (1991), there is considerable evidence,that the aging process affects this signalling cascade at different levels, from receptor availability to stimulation of second and third (protein phosphorylation) messengers. An overview of current knowledge of these different levels of the inositide signalling cascade in relation to aging is given below.

\subsubsection{Phospholipids and aging}

Phosphoinositides are normal components of the plasma membrane, mentioned earlier. The most remarkable change in the plasma membrane with age is the increase in the cholesterol/phospholipid ratio (Calderini et al., 1983; ref. in Naeim and Walford, 1985). This increase in cholesterol/phospholipid ratio appears to correlate with the microviscosity of the membranes involved (Rivnay et al., 1978, 1979), which means that membrane fluidity decreases with age. A diet low in calories and high in fibre appears to reduce the increase in cholesterol/phospholipid ratio or even restore it to the ratio of young animals in aged rat brains (Tacconi et al., 1991). The effects of changes in membrane fluidity on integral membrane proteins are discussed later. Other age-associated changes in plasma membrane components include an increased turnover of phospholipids in rat brain (Pettegrew et al., 1990), an increased methylation of phosphatidylethanolamine by phospholipid methyltransferase I whereas phospholipid methyl transferase II is unaffected in rat brain (Crews et al., 1981), a decreased phosphatidylethanolamine and phosphatidylcholine synthesis, which seems to involve mostly neuronal rather than glial cells (Gaiti et al., 1982), a rapid loss of membrane lipids after 90 years of age in humans (Svennerholm et al., 1991) and last, but potentially the most important for this thesis, a decrease in lipid-myo-inositol concentrations in human anterior temporal cortex (Brodman area 38) (Stokes et al., 1983). Biochemical changes in the membranes of cytoplasmic organelles of aging cells are mostly similar to those occurring in the plasma membrane (Naeim and Walford, 1985). In mitochondrial membranes of aged animals, however, lipid peroxidation is increased (Hegner, 1980). Lipofuscins, or age pigments, that are precipitated in lysosomes, are derived from the peroxidation of subcellular membranes containing polyunsaturated lipids (Naeim and Walford, 1985 and ref. therein).

\subsubsection{Receptor-mediated phosphoinositide hydrolysis and aging}

Receptor-mediated phosphoinositide hydrolysis is one of the signal transformation systems by which a cell transforms an extracellular signal into an 
intracellular response via the release of intracellular messengers. A disruption of the phosphoinositide second messenger systems with age, could be related to the impairment of neurological responsiveness and behavioural deficits observed with aging (Li et al., 1991). Recently, the carbachol stimulated release of inositol phosphates in hippocampal slices was found to increase with age (Tandon et al., 1991). Similar findings were done with cerebral cortex slices (Mundy et al., 1991; Nalepa et al., 1989), and noradrenaline-stimulated release of inositol phosphates, also in cerebral cortical slices (Nalepa et al., 1989). These effects occur in the absence of a change in the number of binding sites (Mundy et al., 1991; Tandon et al., 1991). However, other investigators have reported no change in receptormediated inositol phosphate release (muscarinic receptor, Surichamorn et al., 1989). A decrease in inositol phosphate release was even reported after stimulation of cortical alpha-1-adrenergic receptors, (Burnett et al., 1990), cortical muscarinic receptors (Pietrzak et al., 1990) and striatal muscarinic receptors (Mundy et al., 1991).

Age-related changes in receptor-stimulated inositol phosphate release may be dependent upon the receptor-effector coupling or a change in the stoichiometry of the receptor-G-protein-phospholipase C interaction (Pietrzak et al., 1990). This latter idea is supported by the finding that in cultured rat heart myocytes the inhibition of c-AMP accumulation through Gi-proteins is lost with age (MosconaAmir et al., 1989) and that the decrease in adenylate cyclase activity in the submandibular salivary glands of aged rats seems partly due to changes in the availability of G-proteins (Ahmad et al., 1990). An age-related uncoupling of the receptor-G-protein-phospholipase $C$ interaction could be caused by age-related changes in membrane properties, such as membrane fluidity, as described before (Calderini et al.,1983; Heron et al., 1980). Uncoupling of the "muscarinic receptor/c-AMP inhibition" interaction in aged rat heart myocytes in culture is restored by phosphatidylcholine-liposome treatment (Moscona-Amir et al., 1989). Membrane viscosity also appears to correlate with alpha-1-adrenergic signal transduction in the cerebral cortex of aged rats (Miyamoto et al., 1990) and, in addition, chronic treatment with phosphatidylserine restores muscarinic cholinergic receptor deficits in the brains of aged mice (Gelbmann and Muller, 1991). The effect of membrane fluidity on the "receptor-G-protein-second messenger production" interaction is accompanied by an effect of membrane fluidity on receptor binding with age (Heron et al.,1980; Hershkowitz et al., 1982); however, receptor binding as a function of age is not discussed here.

\subsubsection{The cytoskeleton and aging}

The cytoskeleton plays an important role in receptor-mediated phosphoinositide metabolism by keeping the receptors, G-proteins and enzymes involved together, as receptors are directly linked to the cytoskeleton (Naeim and Walford, 1985), as are inositol phospholipid kinases, diacylglycerol kinase and phospholipase C (Grondin et al., 1991; Payastre et al., 1991). Furthermore, D-3 phosphorylated inositol phospholipids seem to be involved in cytoskeleton turnover processes 
(part 2).

In aging, there is a disequilibrium between polymer and monomer forms of tubulin and a disorganization of the cytoskeleton (Naeim and Walford, 1985). The microtubule-associated proteins MAP1 and MAP2, which contribute significantly to the polymerization of brain tubulin, are degraded to a greater extent in aged rat brain because of an increased proteolytic activity of cathepsin D (Matus and Green, 1987). The age-related changes in the cytoskeleton are probably partially due to age-related changes in $\mathrm{Ca}^{2+}$ homeostasis, as calcium/calmodulindependent kinase II is an important regulator of the neuronal cytoskeleton (Harris and Delorenzo, 1987).

\subsubsection{Inositol phosphate action and aging}

Age-related changes in the level of inositol phosphates released after receptor stimulation have been described. Inositol trisphosphate releases calcium from intracellular stores, and cytosolic free calcium is an important second messenger controlling many aspects of neuronal function and excitability. However, the cytosolic calcium concentration has to be normalized by calcium extrusion at the plasrna membrane ( $\mathrm{Na} / \mathrm{Ca}$ exchanger, and $\mathrm{Ca} 2+$-ATPase) and calcium sequestration in intracellular organelles (mitochondria and endoplasmic reticulum). Calcium homeostasis and its changes with age are reviewed by Gibson and Peterson (1987). The action of inositol polyphosphates in releasing $\mathrm{Ca}^{2+}$ from intracellular stores is suggested to be affected by the aging process (Barritt, 1987). The density of inositol trisphosphate receptors is decreased in the cerebellum, but not in the cerebral cortex of old rats (Li et al., 1991). Furthermore, the amount of calcium released from microsomes by inositol trisphosphate decreases with age in rat brain (Burnett et al., 1990) and parotid cells (Ishikawa et al., 1988), and resting levels of cytosolic free calcium are decreased in fibroblasts from aged humans (Peterson et al., 1986).

\subsubsection{Protein kinases and aging}

Two protein kinases are activated as a result of receptor stimulated phosphoinositide hydrolysis. First, calcium/calmodulin-dependent protein kinase is activated by the elevated cytosolic calcium concentrations caused by the action of inositol trisphosphate. Second, protein kinase $C$ is activated by calcium and diacy!glycerol, the second messenger which is released simultaneously with inositol trisphosphate. PKC has been reported to be modified during aging in various cerebral areas, as a result of either enzyme activity or substrate availability (Magnoni et al., 1991). How aging affects the activity of calcium/calmodulin-dependent protein kinase needs to be explored.

In Sprague-Dawley rats, phorbol ester binding and PKC activity are reduced in the cortex, enhanced in the hippocampus and unmodified in the ceretellum (Battaini et al., 1990a). At the level of the hypothalamus, PKC activity appears to decrease with age (Battaini et al., 1990b) in contrast to pituitary PKC, which shows 
an age-related up-regulation (Battaini et al., 1990b). Fisher 344 rats also show an age-related reduction in PK.C activity in the cortex, but no changes in the hippocampus and the cerebellum (Friedmann and Wang, 1989). The age-related impairment in PKC activity in rat brain cortex may affect transmitter release, because antibodies against the PKC substrate B-50 inhibit noradrenaline release, and, furthermore, B-50 phosphorylation is promoted by depolarization (Dekker et al., 1989). In addition, the stimulatory action of activated PKC on serotonin release in the cortex of adult rats is changed to an inhibition with age (Friedmann and Wang, 1989). The age-related modifications of the PKC pathway in different cerebral areas and rat strains are reviewed by Magnoni et al. (1991). Hershkowitz et al. (1982) have shown that a decrease in lipid fluidity, which occurs with age, results in a modulation of protein phosphorylation in synaptic membranes.

\section{NEUROCHEMICAL ASPECTS OF ALZHEIMER'S DISEASE}

\subsection{Introduction}

Aging as defined in part 1 also includes age-associated disorders such as dementia. About $55-75 \%$ of the cases of senile dementia are of the Alzheimer type. Alzheimer's disease (AD) generally occurs at ages greater than 65 years, but in a small number of cases it strikes people in their forties and fifties (Iqbal, 1991). The diagnosis of AD is very difficult especially in the early stages of AD because the symptoms overlap with those seen in normal aging (Jolles and Hijman, 1983). There is no certain means of diagnosis other than brain biopsy (Tanzi et al., 1991). AD is characterized clinically by a progressive deterioration in memory, personality and intellect (Advokat and Pellegrin, 1992). In addition to the clinical syndrome, $\mathrm{AD}$ is characterized histochemically by the occurrence of neuritic plaques and neurofibrillary tangles. These protein deposits in the brain were first described by Alois Alzheimer in 1907 (Selkoe, 1991). According to Selkoe (1991), the difference between normal brain aging and $A D$ is quantitative rather than qualitative, because normal non-demented subjects also develop at least a few senile plaques and neurofibrillary tangles, particularly in the hippocampus and other brain regions important for memory. Tangles appear with age in the olfactory nucleus, the parahippocampal gyrus and the hippocampus, but are rare in the neurocortex except in demented persons. Conversely, plaques may develop first in the neocortex, which implies that tangles and plaques first develop in different parts of the brain. (Price et al., 1991). The neurochemical composition and probable development of the neuritic plaques and neurofibrillary tangles are outlined in the following sections.

\subsection{Neuritic plaques and the role of beta-amyloid in Alzheimer's disease.}

Plaques consist of a central core of amyloid fibrils surrounded by dystrophic neurites together with reactive microglia and astrocytes. (Hardy and Allsop, 1991). 
With increasing severity of dementia, these mature plaques are formed out of diffuse plaques which do not have a central core and are already present in very mildly demented people. (Price et al., 1991). Down's syndrome, which shows remarkable similarities to $\mathrm{AD}$, especially in the occurrence of plaques, also shows a maturation of diffuse plaques in early-stage patients to mature plaques in latestage patients (Mann and Esiri, 1988).

Masters et al. (1985) isolated and sequenced the B-amyloid (B/A4) polypeptide from the core of these plaques. $\mathrm{B} / \mathrm{A} 4$, which is the major component of plaque cores, appears to be the same protein as the meningo-vascular $B$ protein isolated by Glenner and Wong (1984). The sequence of B/A4 is encoded by a host gene for a much longer protein, which has been termed the amyloid precursor protein (APP) (Tanzi et al., 1989). APP has been highly conserved through evolution and is expressed in a variety of tissues (Holtzman and Mobley, 1991). APP spans the membrane once and has a large extracellular amino-terminal domain with a short carboxy-terminal cytoplasmatic tail (Tanzi et al., 1989). The B/A4 sequence in APP begins close to the membrane on the extracellular side and ends part-way through the putative transmembrane region (Hardy and Allsop. 1991). Under normal conditions, the extracellular part can be released by enzyme action in the B/A4 region (Esch et al., 1990; Sisodia et al., 1990), resulting in the release of a solublle APP. A protease activity associated with acethylcholinesterase releases soluble APP from the membrane-bound form of APP (Small et al., 1992). In addition, Small et al. (1992) suggest that as acethylcholinesterase is decreased in $\mathrm{AD}$, the association with this protease might explain why APP is processed abnormally in $\mathrm{AD}$. In $\mathrm{AD}$ the $\mathrm{B} / \mathrm{A} 4$ sequence is released intact, which means that there has to be an extracellular cleavage site and another site in the transmembrane region of APP. How an enzyme gains access to that transmembrane region is still unsolved.

The physiological role of a soluble, normally processed APP is not clear. Two of the three most abundant isoforms of APP (see Hardy and Allsop, 1991) contain an internal Kunitz-type protease inhibitor insert (Kitaguchi et al., 1988), suggesting that APP may act as protease inhibitor in the brain and elsewhere (Holtzman and Mobley, 1991). Holtzman and Mobley (1991) also presented results suggesting a role for APP in the modulation of cell growth and adhesion.

Several investigators hypothesize the release of $B / A 4$ to be the primary cause of $\mathrm{AD}$, and think that all other aspects of $\mathrm{AD}$ (some of them are discussed later) are secondary events. The fact that a mutation of the APP gene, as in familial $\mathrm{AD}$, can give rise to all of the neuropathological hallmarks of $\mathrm{AD}$ without there being any other defect strongly suggests that amyloid mismetabolism and deposition is the seminal event in the pathogenesis of all cases of AD (Selkoe, 1991: Hardy and Allsop, 1991). This is called "the biochemical amyloid cascade theory" (Hardy, 1992). The molecular genetics of familial AD and the regulation and genetic control of brain amyloid (reviewed by Tanzi et al. (1991) and Gajdusek et al. (1991), respectively) will not be dealt with in this survey. In addition to this biochemical amyloid cascade theory, Hardy (1992) presented an "anatomical cascade hypothesis" for AD in which beta-amyloid is initially 
deposited in the limbic areas for unknown reasons; this stimulates a stress response in the surrounding neurophil, which leads to up-regulation of A.PP and other proteins and, after APP is axonally transported (Koo et al., 1990), to increased deposition of B/A4. The reasons behind B/A4 deposition must include an altered APP' metabolism, which possibly results from trisomy 21 (Down's syndrome), APP gene mutation (familial AD), other unknown mutations and/or environmental factors such as brain damage (Hardy and Allsop, 1991). Consistent with this hypothesis is that the promotor of the gene encoding APP contains both heat-shock and interleukin-responsive elements (Hardy, 1992), and that APP expression is up-regulated by heat shock in lymphocytes (Abe et al., 1991a) and by ischaemia in the brain (Abe et al., 1991b). This up-regulation of APP expression, which already occurs in an early stage of brain damage (Kawarabayashi et al., 1991), would give the enzymes which release the intact B/A4 the opportunity to act in addition to the enzymes which release the soluble APP, as hypothesized by Selkoe (1991). In vitro, B/A4 stimulates glial cells to produce growth factors which accumulate in senile plaques in $A D$, suggesting that in this way cascades may arise that contribute to the process of plaque development (Araujo and Cotman, 1992). Furthermore, APP is deposited in rat hippocampus lesioned by ibotenic acid injection (Nakamura et al., 1992), and needle stab injury in rat brain results in the rapid appearance of APP immunoreactivity in damaged axons and reactive glial cells (Otsuka et al., 1991). However, it is doubtful whether neurons react in a stress response against extracellular $B / A 4$ because the $B / A 4$ protein (parts of) has neurotrophic effects (Araki et al., 1991; Whitson et al., 1989; Whitson et al., 1990; Yankner et al., 1990). Furthermore, according to the hypothesis of Hardy and Allsop (1991) neurofibrillary tangles would develop secondary to the deposition of B/A4. However, Price et al. (1991) have shown that the first development of tangles and plaques occurs in different parts of the brain.

\subsection{Neurofibrillary tangles}

Another prominent feature in $\mathrm{AD}$ brains is the abnormal accumulation of markedly insoluble filamentous material within neuronal cell bodies and neurites (Holtzman and Mobley, 1991). These neurofibrillary tangles (NFTs) are found in several neurodegenerative diseases besides AD, such as postencephalitic Parkinson's disease, Guam Parkinsonism dementia complex, dementia pugulistica, and Down's syndrome (Iqbal, 1991). Neurofibrillary tangles are widely distributed in AD brains, especially in the temporal and frontal cortices, hippocampus, some parts of the brain stem and hypothalamus. Microscopically, they appear as bundles of paired helical filaments (PHFs) in which microtubule-associated protein (MAP), called tau, is an important constituent (Grundke-Iqbal et al., 1986; Kosik et al., 1986 ; Wood et al., 1986). Under normal conditions, tau acts as a promoting and stabilizing factor in tubule polymerization (Weingarten et al., 1975). It has been suggested that tau is abnormally phosphorylated in PHFs (Baudier and Cole, 1987; Grundke-Iqbal et al., 1986; Ihara et al., 1986), a notion that is supported by the fact that the monoclonal 
antibody for normal tau recognizes tau in PHFs only after treatment with alkaline phosphatase (Bancher et al., 1989; Lee et al., 1988; Wood et al., 1986). A68 proteins in $\mathrm{AD}$ appears to be composed of several tau isoforms in a phosphorylated state which affects their electrophoretic mobility (Brion et al., 1991). This abnormal phosphorylation of tau has been demonstrated in AD and Down's syndrome (Brion et al., 1991; Hanger et al., 1991). PHF tau appears to contain 12 moles of phosphate per mole of tau, in contrast to normal tau from the brain of $\mathrm{AD}$ and control brain, which contains approximately 3 moles of phosphate per mole of tau (Ksiezak-Reding et al, 1990). Because phosphorylation by cAMP-dependent protein kinase inhibits the degradation of tau by calpain, it is suggested that phosphorylation has a role in regulating the degradation of tau. In addition, abnormal phosphorylation could result in a protease-resistant tau, which may contribute to the formation of paired helical filaments in AD (Literski and Johnson, 1992). Because of the important function of tau in promoting and stabilizing tubule polymerization, a disturbance in the phosphorylation of tau could possibly lead to destabilization of the cytoskeleton and ultimately to degeneration of axons and dendrites, which does occur in AD (Flood et al., 1987). Among other proteins, only ubiquitin has convincingly been shown to be a part of the PHFs (Kosik et al.,1989), although there are indications that tropomyosine, a microfilament protein (Galloway and Perry, 1991), neurofilament proteins (Mulvihill and Perry, 1989) and MAP 2 and 5 (Kosik et al., 1984) are also constituents of PHFs.

\subsection{Theories of Alzheimer's disease}

In analogy to the aging theories, there are several theories as to the possible cause of $\mathrm{AD}$ in addition to the widely supported B/A4 theory of Hardy and colleagues described above. These theories overlap with the aging theories, such as the free radical theory reviewed by Vollicer and Crino (1990), the "use it or lose it" theory postulated by Swaab (1991), the somatic mutation theory (in a somewhat other form proposed by Hardy and Allsop, 1991, and Mullaart et al. 1990 ), and the endocrine system theory. With respect to AD the endocrine system theory is divided into an excitatory amino acid theory (reviewed by Advokat and Pellegrin, 1992) and a cholinergic theory (Bartus et al., 1982). The excitatory amino acid transmitter system may be involved in mechanisms underlying learning and memory under normal conditions. However, overactivity of this system produces excitotoxic damage to neurons. Both a decline in cognitive function and damage to neurons occur in $A D$, which suggests that excitatory amino acids may contribute to the aetiology of AD (Advokat and Pellegrin, 1992). A sub-theory of the excitatory amino acid theory is the hypothesis that a dysfunction of glutamate, the major excitatory neurotransmitter, is involved in the pathophysiology of AD (Maragos et al., 1987). In addition, a cholinergic theory has been formulated for $\mathrm{AD}$ comparible to the cholinergic theory of aging, because 1.) acetylcholine synthesis in AD biopsy samples has been reported to be decreased, 2.) a severe loss of cholinergic neurons in the nucleus basalis of Meynert has been 
reported, 3.) a positive correlation has been shown between the extent of cognitive loss in senile dementia, the decrease in choline acetyltransferase activity, and the incidence of major neurophathological markers (reviewed by Bartus et al., 1982).

Furthermore, the hypothesis that calcium-activated proteases (calpains) are causal agents in brain aging and, in particular, in the gradual development of abnormalities and degeneration (Lynch et al., 1986) also seems applicable as an $\mathrm{AD}$ theory. That is, calpain is involved in the turnover of cytoskeletal and structural elements (Lynch et al., 1986), which are affected in AD. In addition, tau, which is abnormally phophorylated in AD, is degraded by calpain under normal conditions (Literski and Johnson, 1992), and calpain immunoreactivity is localized in senile plaques and in neurons undergoing neurofibrillary degeneration in AD (Iwamoto et al., 1991).

The overlap between aging theories and $\mathrm{AD}$ theories is probablly not accidental because, according to Swaab (1991), present evidence indicates that $A D$ is a precocious accelerated form of aging.

\subsection{Phosphoinositide metabolism and Alzheimer's disease}

As in aging, the different levels of the inositide signalling cascade are or could be involved in AD. Fowler et al. (1990) hypothesized that there is a decline in the functional integrity of receptor-mediated signal transduction mechanisms, such as cAMP release and the inositol phosphate/diacylglycerol release systems, in AD, although most studies of receptor function in $A D$ have considered only the receptor rẹcognition site (reviewed by Morgan et al., 1988). Interestingly, several of the neurotransmitter systems affected in $A D$, such as the cholinergic, serotonergic and noradrenergic systems, are coupled to these effector systems (Fowler et al., 1990). Because AD patients are also subject to aging, age-matched controls and not young controls should be used in studies with AD patients.

\subsubsection{Phospholipids and Alzheimer's disease}

Phospholipids are the main components of the membrane, and the condition of this membrane can influence the proteins attached to it, for instance receptors, G-proteins and enzymes, as mentioned above. 31P NMR studies have demonstrated that there are increased levels of phosphomonoesters, which could be the result of higher PLC activities, early in the course of AD and increased levels of phosphodiesters as the disease progresses (Pettegrew, 1989). The levels of PME are inversely correlated with the number of senile plaques whereas the levels of PDE are positively correlated with the numbers of senile plaques (Pettegrew and Klunk, 1990). These and additional findings resulted in the hypothesis that the earliest molecular/metabolic changes in $A D$ result in elevated levels of PME in the neocortex and allocortex, followed by a cortical and subcortical elevation of PDE later in the course of the disease, which reflects cellular degeneration and death (Pettegrew, 1989 and ref. thercin). 
A physiologically relevant action of L-phosphoserine, one of the phosphomonoesters elevated in $\mathrm{AD}$, has been suggested because whole brain concentrations may reach over $1 \mathrm{mM}$ in $\mathrm{AD}$ and $\mathrm{L}$-phosphoserine has close structural similarities to L-glutamate, suggesting that it could interact with the glutamate receptor (Klunk et al., 1991).

Furthermore, there appears to be an increased degradation of phospholipids in AD brains as phosphatidylcholine and phosphatidylethanolamine levels and the levels of their precursors choline and ethanolamine were decreased in contrast to the levels of their deacylation products, which were increased (Nitsch et al., 1992). These phospholipid abnormalities appear not to be an epiphenomenon of neurodegeneration but may be specific for the pathomechanism of AD (Nitsch et al., 1992). In the anterior temporal cortex of AD brains, PI levels are significantly lower than in the same area of age-matched control brains (Stokes and Hawthorne, 1987). Stokes and Hawthorne (1987) have also reported that PIP and PIP2 levels tend to decrease in AD; however, these data may have been affected by the long and variable post-mortem delay, because polyphosphoinositides are rapidly degraded post-mortem (Dawson and Eichberg, 1965)

The composition of brain membranes is thus altered in $A D$, and this probably results in functionally significant alterations in the biophysical properties of brain cell membranes, as shown by Zubenko (1986).

\subsubsection{Receptor-mediated phosphoinositide hydrolysis and Alzheimer's disease}

As mentioned above, most studies on receptor-mediated functions in AD have considered only the receptor recognition side (Fowler et al., 1990). Receptor binding and receptor number are reviewed by Morgan et al., (1988) and will not be discussed further here. However, the "receptor-G-protein-second messenger producer" coupling in AD brain membranes had not been studied up to two years ago. Stimulated adenylate cyclase activity appears to be reduced in AD brains (Cowburn et al., 1991; Ohm et al., 1991), although in another study stimulated adenylate cyclase activity was unaffected (Bergstrom et al., 1991). In addition, Cowburn et al. (1992) report a widespread impairment of G-protein-stimulated adenylate cyclase activity in AD brains. This impairment occurs in the absence of altered enzyme catalytic activity and is unlikely to be the result of non-diseaserelated factors associated with the nature of the terminal illness of individuals. The coupling of the 5.hydroxytryptamine-1A receptor, which has been reported to be coupled to both adenylate cyclase and phospholipase C, to G-proteins appears to be intact in AD (O'Neill et al., 1991). In addition, the coupling of MImuscarinic receptors, which preferentially activate phospholipase $C$, to Gproteins in $\mathrm{AD}$ is also unaffected (Pearce and Potter, 1991). According to McLaughlin et al. (1991), alterations in the amount of G-protein alpha-subunits are not a feature of $A D$, in contrast to the aberrant accumulation of phospholipase C-delta in AD brains. This accumulation is suggested to be a crucial event that may ultimately contribute to the formation of PHF (Shimohama et al., 1991). Because there is very little tritium labelling of 
polyphosphoinositides following incubation of autopsy samples, receptormediated inositol phospholipid breakdown in post-mortem material is difficult to measure (Fowler et al., 1990). The bradykinin-induced formation of $\mathrm{IP}_{3}$ and $\mathbf{I P}_{2}$ was measured in fibroblasts from AD donors, but did not differ from that of normal aged donors (Huang et al., 1991). The enzyme PLC does not appear to be affected in AD brains (Shimohama et al., 1992), thus a possible change in inositol phosphate release can only be caused at the receptor-G-protein-PLC coupling level, at the level of receptor density, or at the level of $\mathrm{PLP}_{2}$ supply (activity of PI and PIP kinases).

\subsubsection{Calcium release, protein phosphorylation and Alzheimer's disease}

It is not known whether the release of inositol phosphates is altered in AD brain, mainly because of the technical problems mentioned above. However, the number of $\mathrm{IP}_{3}$ binding sites essential for calcium release in the temporal cortex and hippocampus of $\mathrm{AD}$ brain is severely reduced (50-70\% loss) (Young et al., 1988). The same technical problems mentioned above for measurements of inositol phosphate release also exist for measurements of calcium concentrations and fluxes in. AD brains. Cytosolic free calcium and cell spreading of calcium is decreased in fibroblasts from AD donors (Peterson et al., 1986). Furthermore, $\mathrm{Na}+/ \mathrm{Ca}^{2}+$ exchange activity is increased in AD brain tissue, which is interpreted as indicating that neurons surviving in brain regions suffering the greatest degeneration due to $\mathrm{AD}$ have increased $\mathrm{Na}+/ \mathrm{Ca}^{2}+$ exchange activity (Colvin et al., 1991). According to Mattson et al. (1991), a disturbed calcium homeostasis, resulting in higher intracellular calcium concentrations, together with a disturbed inositol phospholipid metabolism, could be involved in neurofibrillary degeneration through the activation of protein kinases, because tau, a microtubule-associated protein, is abnormally phosphorylated in PHFs.

Elevated calcium levels and activation of PKC both induce an increased PHFtau immunoreactivity in neuronal cell cultures and addition of the PKC inhibitor H-7 blocks the increase in immune reactivity (Mattson et al., 1991). Furthermore, PKC is able to phosphorylate tau (Baudier et al., 1987; Hoshi et al., 1987) as well as neurofilament proteins (Georges et al., 1989; Sihag et al., 1988).

Protein phosphorylation and the occurrence of senile plaques also seem to be related. A synthetic peptide corresponding to a region of APP is phosphorylated by $\mathrm{PKC}$, suggesting that APP could be a physiological substrate of PKC (Gandy et al., 1988). Furthermore, PKC immunoreactivity is present in mature plaques (Clark et al., 1991; Masliah et al., 1990), whereas diffuse plaques only show immunoreactivity for the PKC subtype BII. This PKC BII subtype is probably an early biochemical marker of $A D$, because diffuse plaques do not show immunoreactivity for senile plaque markers such as casein kinase II, tau, PHF (Masliah et al., 1991). Interestingly, this BII PKC subtype is strongly associated with the cytoskeleton and is probably responsible for the phosphorylation of the growth-associated GAP43 or B-50 protein (Tanaka et al., 1991). In AD brains, the level of PKC and the in vitro phosphorylation of its $86 \mathrm{kDa}$ substrate are 
decreased, and there is a translocation of PKC activity from the particulate pool to the soluble cytosolic pool (Cole et al., 1988).

A possible function of $P K C$ is the regulation of protein tyrosine phosphorylation (Cochet et. al., 1984; Northwood and Davis, 1989). The protein tyrosine kinase activity in the particulate fraction of A.D frontal cortex appeared to decrease twofold whereas cytosolic protein tyrosine kinase activity was not affected (Shapiro et al.,1991). However, the amount of two (55 and $60 \mathrm{kDa}$ ) phosphotyrosine immunoreactive polypeptides appeared to be increased in AD (Shapiro et al, 1991).

\subsubsection{Aluminum and Alzheimer's disease}

Aluminum has been associated with Alzheimer's disease for the reason that aluminum induces neurofibrillary changes in experimental animals (Terry and Pena, 1965), although these changes do not mimic exactly the NFTs of AD (Krishnan et al., 1987). Orally administered aluminum increases the phosphorylation of rat brain cytoskeletal proteins (Johnson and Jope, 1988), which could be the mechanism underlying the aluminum-induced neurofibrillary changes. As aluminum has a high affinity for phosphate (Martin, 1986), this metal ion is found predominantly in the nuclear compartment of the cell, but even there it has a particular compartmentalization in AD, where it could have an effect on the nuclear structure (Lukiw et al., 1991). Aluminum also appears to impair cholinergic activity in rat brain in vitro (Johnson and Jope, 1986), and in rabbit brain tissue containing "in vivo aluminum-induced" tangles (Yates et al., 1980). Interestingly, a cholinergic deficit is a major characteristic of AD. The high affinity of aluminum for phosphate may also be the reason for the interaction of aluminum ions with polyphosphoinositide metabolism. Free aluminum ions appear to stimulate $\mathrm{PI}$ hydrolysis while inhibiting $\mathrm{PI}(4,5) \mathrm{P}_{2}$ hydrolysis in a concentration-dependent manner (McDonald and Mamrack, 1988). In contrast, aluminum salts activate inositol phospholipid hydrolysis in rat cerebral cortex membranes, probably by activating a regulatory G-protein at a location distinct from the GTP-binding site or by direct stimulation of PLC (Candura et al., 1991).

\section{OUTLINE OF THIS THESIS}

The metabolism of phosphoinositides and its relevance for cell functioning has been outlined in section 2 of this chapter. The membrane-associated processes involved in receptor-stimulated inositol phosphate release, the effectiveness of the inositol phosphate response, the maintenance of calcium homeostasis, and protein kinase activities as a function of age and AD have been studied extensively, as described in sections 3 and 4 of this chapter. However, the production of the inositol trisphosphate precursor, phosphatidylinositol bisphosphate, by phosphatidylinositol (PI) kinase and phosphatidylinositol 
phosphate (PIP) kinase, and the phosphorylation of DAG into phosphatidic acid have not received much attention in aging research and $A D$ research. As far as we know, there are no data on these kinase activities as a function of age and AD, with the exception of a study in rat brain which revealed a decrease in $\mathrm{PIP}_{2}$ formation in synaptic plasma membranes of the hippocampus and whole brain with advancing age (Van Dongen et al., 1983). Changes in the activity of these enzymes could explain changes in the receptor stimulated inositol phosphate response and changes in protein kinase $C$ activity with advancing age and possibly also in AD.

PI, PIP and DAG kinases are, at least partially, membrane bound (Stubbs et al., 1988), and therefore can be influenced by age- and AD-related changes in the physical properties of membranes (Naeim and Walford, 1985), as described in sections 3 and 4 . Furthermore, these kinases could be sensitive to age- and ADrelated changes in the cytoskeletal system, as described in sections 3 and 4 , because PI, PIP and DAG kinase appear to be associated with the cytoskeleton (Grondin et al., 1991; Payrastre et al., 1991).

Interestingly, the function of PI kinase has become more important with the discovery of the D-3 phosphorylated inositides, which are implicated in growth, mitogenic signalling and cytoskeletal turnover processes (Carpenter and Cantley, 1990). Because AD is characterized by cytoskeletal deterioration in the brain, a change in these D-3 phosphorylating inositide kinases could be involved in the development of NFTs in AD brains.

Enzymes or other functional proteins can also lose their functionality by covalent modifications, such as mixed function oxidation, deamidation, ubiquitin conjugation and glycation, as a consequence of aging, but also in $\mathrm{AD}$ (Smith et al., 1991).

As described above, the enzymes PI kinase, PIP kinase and DAG kinase have not been studied as a function of age and AD. In the first part of this thesis we investigated whether PI kinase, PIP kinase and DAG kinase are affected by age in the rat brain. Because of the possible influence of the micro-environment of these kinases on activity, the effect of age was studied in a membrane-cytosol preparation of different rat brain regions (Chapter 5). The relationship between enzyme activity and endogenous substrate availability was measured and not just enzyme activity or phospholipid concentrations. The preparation of this membrane cytosol preparation is described in chapter 2. Chapter 3 describes the effect of changing the conditions of the phosphorylation assay on the different kinase activities. In chapter 4 the subcellular distribution of PI, PIP and DAG kinase activities, measured with endogenous lipids as substrate, is described, together with the detection of a probably new inositol phospholipid species in mitochondria (Chapter 4). In Chapter 6, specific PI, PIP and DAG kinase activities were measured, with exogenous lipids as substrate, as a function of age in rat brain.

The second part of this thesis deals with PI kinase and PIP kinase activities in post-mortem human brain cortex as a function of age and AD. Chapter 7 describes the specific PI and PIP kinase activities (measured with exogenous lipid substrate) 
in cytoplasmic fractions prepared from brains of AD patients and of age-matched controls. In chapter 8 the effect of age on these activities was determined in the control group and the AD group, but also the effect of "age of first symptoms" in the AD group. Chapter 9 describes the search for a specific type of PI kinase activity involved in $A D$, because of recent reports on the different types of PI kinases and their different functions (see chapter 1). Finally, chapter 10 deals with PI and PIP kinase activities in the blood platelets of AD patients and controls because there is growing evidence that $A D$ is a systemic disease and not just a disease of the central nervous system.

\section{REFERENCES}

Abdel-Latif A.A. (1986) Calcium-mobilizing receptors, polyphosphoinositides, and the generation of second messengers. Pharmacol. Rev. 38, 227-272.

Abe K., George-Hyslop P.H.St., Tanzi R.E., and Kogure K. (1991a) Induction of amyloid precursor protein mRNA after heat shọck in cultured human iymphoblastoid cells. Neurosci. Lett. 125, 169171.

Abe K., Tanzi R.E., and Kogure K. (1991b) Selective induction of Kunitz-type protease inhibitor domaincontaining amyloid precursor protein mRNA after persistent focal ischemia in rat cerebral cortex. Neurosci. Lett. 125, 172-174.

Advokat C., and Pellegrin A.I. (1992) Excitatory amino acids and memory: Evidence from research on Alzheimer's disease and behavioral pharmacology. Neurosci. Biobehav. Rev. 16, 13-24.

Agranoff B.W., Murthy P., and Seguin E.B. (1983) Thrombin-induced phosphodiesteratic cleavage of phosphatidylinositol bisphosphate in human platelets. 1. Biol. Chem. 258, 2076-2078.

Ahmad S.N., Alam S.Q., and Alam B.S. (1990) Effect of ageing on adenylate cyclase activity and Gproteins in rat submandibular salivary glands. Archs. Oral Biol. 35, 885i-890.

Araki W., Kitaguchi N., Tokushima Y., Ishii K., Aratake H., Shimohama S., Nakamura S., and Kimura J. (1991) Trophic effect of B-amyloid precursor protein on cerebral cortical neurons in culture. Biochem. Biophys. Res. Comm. 181, 265-271.

Araujo D.M., and Cotman C.W. (1992) B-Amyloid stimulates glial cells in vitro to produce growth factors that accumulate in senile plaques in Alzheimer's disease. Brain Res. 569, 141-145.

Auger K.R., Serunian L.A., Soltoff S.P., Libby P., and Cantley L.C. (1989) PDGF-dependent tyrosine phosphorylation stimulates production of novel polyphosphoinositides in intact cells. Cell 57, $167-$ 175.

Auger K.R., and Cantley L.C. (1991) Novel polyphosphoinositides in cell growth and activation. Cancer Cell. 3, 263-270.

Baldassare J.J., Henderson P.A., and Fisher G.J. (1989) Isolation and characterization of one soluble and two membrane-associated forms of phosphoinositide-specific phospholipase $C$ from human platelets. Biochemistry 28, 6010-6016.

Buncher C., Brunner C., Lassmann H., Budka H., Jellinger K., Wiche G., Seitelberger F., Grundke-Iqbal 1., lq̨bal K., and Wisniewski H.M. (1989) Accumulation of abnormally phosphorylated tau precedes the formation of neurofibrillary tangles in A.lzheimer's disease. Brain Res. 477, 90-99.

Barritl G.J. (1987) Intracellular free calcium and inositol polyphosphate action as potential targets in the ageing process. Neurobiol. Aging 8, 357-359.

Bartus R.T., Dean R.L., Beer B., and Lippa A.S. (1982) The cholinergic hypothesis of geriatric memory dysfunction. Science 217, 408-417.

Battaini F., Del Vesco R., Govoni S., and Trabucchi M. (1990a) Regulation of phorbol ester binding and protein kinase $C$ activity in aged rat brain. Neurobiol. Aging 11, 563-566.

Battaini F., Del Vesco R., Govoni S., Moresco R.M., and Trabucchi M. (1990b) In: Aging brain and dementia: New trends in diagnosis and therapy (Battistin L., and Gerstenbrand F. eds.) pp. 169-187, 
Alan R. Liss, N.Y.

Batty I.R., Nahorski S.R., and Irvine R.F. (1985) Rapid formation of inositol 1,3,4,5tetrakisphosphate following muscarinic receptor stimulation of rat cerebral cortical slices. Biochem. J. 232, 211-215.

Baudier J., and Cole R.D. (1987) Phosphorylation of tau proteins to a state like that in Alzheimer's brain is catalyzed by a calcium/calmodulin-dependent kinase and modulated by phospholipids. I. Biol. Chem. 262, 17577-17583.

Baudier J., Lee S.-H., and Cole R.D. (1987) Separation of the different microtubule-associated tau protein species from bovine brain and their mode II phosphorylation by $\mathrm{Ca}^{2}+/$ phosphoilpiddependent protein kinase C. I. Biol. Chem. 262, 17584-17590.

Bazenet C.E., Ruano A.R., Brockman J.L., and Anderson R.A. (1990) The human erythrocyte contains two forms of phosphatidylinositol 4-phosphate 5-kinase which are differently active toward membranes. J. Biol. Chem. 265, 18012-18022.

Bell R.L., Kennerly D.A., Stanford N., and Majerus P.N. (1979) Diglyceride lipase; a pathway for arachidonate release from human platelets. Proc. Natl. Acad. Sci. USA 76, 3238-3241.

Belunis C.J., Bae-Lee M., Kelley M.J., and Carman G.M. (1988) Purification and characterization of phosphatidylinositol kinase from saccharomyces cerevisiae. I. Biol. Chem. 263, 18897-18903.

Bergstrom L., Garlind A., Nilsson L., Alafuzoff 1., Fowler C.J., Winblad B., and Cowburn R.y. (1991) Regional distribution of somatostatin receptor binding and modulation of adenylyl cyclase activity in Alzheimer's disease brain. I. Neurol. Sci. 105, 225-233.

Berridge M.J., Downes C.P., and Hanley M.R. (1982) Lithium amplifies agonist-dependent phosphatidylinositol responses in brain and salivary glands. Biochem. J. 206, 587-595.

Berridge M.J., Dawson R.M.C., Downes C.P., Heslop J.P., and Irvine R.F. (1983) Changes in the levels of inositol phosphates after agonist dependent hydrolysis of membrane phosphoinositides. Biochen. J. 212, 473-482.

Berridge M.J. (1984) Inositol trisphosphate and diacylglycerol as second messengers. Biochem. I. 220, 345-360.

Berridge M.J., and Irvine R.F. (1984) Inositol trisphosphate, a novel second messenger in cellular signal transduction. Nalure 312, 315-321.

Berridge M.J. (1987) Inositol trisphosphate and diacylglycerol: Two interacting second messengers. Ann. Rev. Biochem. 56, 159-193.

Berridge M.J., and Irvine R.F. (1989) Inositol phosphates and cell signalling. Nature 341, 197-205.

Besterman J.M., Pollienz R.S., Booker E.L., and Cuetrecasas P. (1986) Diacylglycerol-induced translocation of diacylglycerol kinase: Use of affinity-purified enzyme in a reconstitution system. Proc. Nall. Acad. Sci. USA 83, 9378-9382.

Billah M.M., Lapetina E.G., and Cuatrecasas P. (1980) Phospholipase A2 and phospholipase C activities of platelets. J. Biol. Chem. 255, 10227-10231.

Billah M.M., Lapetina E.G., and Cuatrecasas P. (1981) Phospholipase A2 activity specific for phosphatidic acid. J. Biol. Chem. 256, 5399-5403.

Billah M.M., and Lapetina E.G. (1982) Rapid decrease of phosphatidyl 4,5-bisphosphate in trombinstimulated platelets. J. Biol. Chem. 257, 12705-12708.

Bjorksten J. (1974) In: Theoretical aspects of aging (Rockstcin M., ed.) pp 43, N.Y. Academic Press.

Brion J.-P., Hanger D.P., Couck A.-M., and Anderton B.H. (1991) A68 proteins in Alzheimer's disease are composed of several tau isoforms in a phosphorylated state which affects their electrophoretic mobilities. Biochem. J. 279, 831-836.

Burgess G.M., McKinney J.S., Irvine R.F., and Putney J.W. (1985) Inositol 1,4,5-trisphosphate and inositol 1,3,4-trisphosphate formation in Ca2+-mubilizing hormone-activated cells. Biochem. I. 232, 237-243.

Burnett D.M., Bowyer J.F., Masserano J.M. and Zahniser N.R. (1990) Effect of aging on alpha-1 adrenergic stimulation of phosphoinositide hydrolysis in various regions of rat brain. J. Pharmacol. Exp. Ther. 225, 1265-1270.

Calderini G., Bonetti A.C., Battistella A., Crews F.T., and Toffano G. (1983) Biochemical changes of rat brain membranes with aging. Neurochem. Res. 8, 483-492. 
Candura S.M., Castoldi A.F., Manzo L., and Costa L.G. (1991) Interaction of aluminum ions with phosphoinositide metabolism in rat cerebral cortical membranes. Life Sci. 49, 1245-1252.

Cannizzaro L.A., Skolnik E.Y., Margolis B., Corce C.M., Schlesinger 1., and Huebner K. (1991) The human gene encoding phosphatidylinositol 3-kinase associated p85alpha is at chromosome region 5q12-13. Cancer Res. 51, 3818-3820.

Cantley L.C., Auger K.R., Carpenter C., Duckworth B., Graziani A., Kapeller R., and Soltoff S. (1991) Oncogenes and signal transduction. Cell 64, 281-302.

Carpenter C.L., and Cantley L.C. (1990) Phosphoinositide kinases. Biochemistry 29, 11147-11156.

Carpenter C.L., Duckworth B.C., Auger K.R., Cohen B., Schaffhausen B.S., and Cantley L.C. (1990) Purification and characterization of phosphoinositide 3-kinase from rat liver. J. Biol. Chem. 265, 19704-19711.

Castagna M., Takal Y., Kaibuchi K., Sano K., Kikkawa U., and Nishizuka Y. (1982) Direct activation

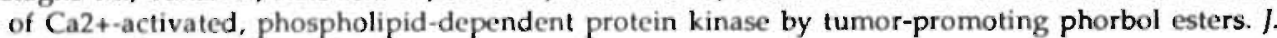
Biol. Chem. 257, 7847- 7851.

Catt K.J., Hunyady L., and Balla T. (1991) Second messengers derived from inositol lipids. /. Bioenerg. Biomembr. 23, 7-27.

Chaííoy de Courcelles D., Roevers P., and Van Belle H. (1985) R59022, a diacylglycerol kinase inhíbitor. I. Biol. Chem. 260, 15762-15770.

Chan T.-O., Tanaka A., Bjorge J.D., and Fujita D.I. (1990) Association of type I phosphatidylinositol kinase activity with mutationally activated forms of human pp60c-src. Mol. Cell. Biol. 10, 32803283.

Clark E.A., Leach K.L., Trojanowski J.Q., and Lee V.M.-Y. (1991) Characterization and differential distribution of the three major protein kinase C isozymes (PKC-alpha. PKC-beta and PKC-gamma) of the central nervous system in normal and Alzheimer's disease brains. Lab. Invest. 64, 35-44.

Cochet C., Gill G.N., Meisenhelder J., Cooper J.A., and Hunter T. (1984) C-kinase phosphorylates the epidermal growth factor receptor and reduces its epidermal growth factor-stimulated tyrosine protein kinase activity. 1. Biol. Chem. 259, 2553-2558.

Cochet C., and Chambaz. E.M. (1986) Catalytic properties of a purificd phosphatidylinositol 4phosphate kinase from rat brain. Biochem. J. 237, 25-31.

Cohen B., Yoakim M., Piwnica-Worms H., Roberts T.M., and Schaffhausen B.S. (1990) Tyrosine phosphorylation is a signal for the trafficking of pp85, an $85-\mathrm{kDa}$ phosphorylated polypeptide associated with phosphatidylinositol kinase activity. Proc. Natl. Acait. Sci. USA 87, 4458-4462.

Cole G., Dobkins K.R., Hansen L.A., Terry R.D., Saitoh T. (1988) Decreased levels of protein kinase C in Alzheimer brain. Brain Res. 452, 165-174.

Colvin R.A., Bennett J.W., Colvin S.L., Allen R.A., Martinez J., and Miner G.D. (1991) Na+/Ca2+ exchange activity is increased in Alzheimer's disease brain tissue. Brain Res. 543, 139-147.

Courtneidge S.A., and Heber A. (1987) An 81 kd protein complexed with middle T antigen and pp60sre: A possible phosphatidylinositol kinase. Cell 50, 1031-1037.

Cowburn R.F., Fowler C.J,, Garlind A., Alafuzoff I., Nilsson L., Winblad B., and Bergstrom L. (1991) Somatostatin receptors and the modulation of adenylyl cyclase activity in Alzheimer's disease. J. Neurol. Neurosurg. Psychiat. 54, 748-749.

Cowburn R.F., O'Neill C., Ravid R., Alafuzoff 1., Winblad B., and Fowler C.J. (1992) Adenylyl cyclase activity in postmortem human brain: Evidence of altered $G$ protein mediation in Alzheimer's disease. I. Neurochem. 58, 1409-1419.

Crews F.T., Calderini G., Battistella A., and Toffano G. (1981) Age dependent changes in the methylation of rat brain phospholipids. Brain Res. 229, 256-259.

Cunningham T.W., Lips D.L., Bansal V.S., Caldwell K.K., Mitchell C.A., and Majerus P.W. (1990) Pathway for the formation of D-3 phosphate containing inositol phospholipids in intact human platelets. I. Biol. Chem. 265, 21676-21683.

Curtis J.H., and Miller K. (1971) Chromosomal aberrations in liver cells of guinea pigs. J. Geront. 26, 292293.

Dawson R.M.C., and Eichberg J. (1965) Diphosphoinositide and triphosphoinositide in animal tissues. Biochem. 1. 96, 634i-643. 
Dekker L.V., De Graan P.N.E., Oestreicher A.B., Versteeg. D.H.G., and Gispen W.H. (1989) Inhibition of noradrenaline release by antibodies to B-50 (GAP-43). Nature 342, 74-76.

Downes C.P. (1986) Inositol phosphates: concond or confusion? TINS 9, 394-396.

Downes C.P., and MacPhee C.H. (1990) myo-Inositol metabolites as cellular signals. Eur. I. Biochem. 193, 1-18.

Eisenberg F.Jr. (1967) D-Myoinositol 1-phosphate as product of cyclization of glucose 6-phosphate and substrate for a specific phosphatase in rat testis. J. Biol. Chem. 242, 1375-1382.

Endemann G., Dunn S.N., and Cantley L.C. (1987) Bovine brain contains two types of phosphatidylinositol kinase. Biochemistry 26, 6845-6852.

Endemann G.C., Graziani A., and Cantley LC. (1991) A monoclonal antibody distinguishes two types of phosphatidylinositol 4-kinase. Biochem. I. 273, 63-66.

Esch F.S., Keim P.S., Beattie E.C.,, Blacher R.W., Culwell A.R., Oltersdorf T., McClure D., and Ward P.J. (1990) Science 248, 1122-1124.

Escobedo J.A., Navankasattusas S., Kavanaugh W.M., Milfay D., Fried V.A., and Williams L.T. (1991) cDNA cloning of a novel $85 \mathrm{kd}$ protein that has $\mathrm{SH} 2$ domains and regulates binding, of PL3-kinase to the PDGF beta-receptor. Cell $65,75-82$.

Everitt A., and Meites J. (1990) Aging and the anti-aging effects of hormones. I. Gerontol. 44, 139-147.

Fain J.N., and Berridge M.J. (1979) Relationship between phosphatidylinositol synthesis and recovery of 5-hydroxytrypamine-responsive Ca2+ flux in blowfly salivary gland. Biochem. I. 180, 655-661.

Fisher S.F., Heacock A.M., and Agranoff B.W. (1992) Inositol lipids and signal transduction in the nervous system: an update. I. Neurochem. 58, 18-38.

Flood D.G., Buell S.J., Horwitz G.J., and Coleman P.D. (1987) Dendritic extent in human dentate gyrus granule cells in normal aging and senile dementia. Brain Res. 402, 205-216.

Flower R.J., and Blackwell G.J. (1976) The importance of phospholipase A2 in prostaglandin biosynthesis. Biochem. Pharmacol. 25, 285-291.

Fowler C.J., O'Neill C., Garlind A., and Cowburn R.F. (1990) Alzheimer's disease: is there a problem beyond recognition? TIPS 11, 183-184.

Friedman E., and Wang H.-Y. (1989) Effect of age on brain cortical protein kinase C and its mediation of 5-hydroxytryptamine release. I. Neurochem. 52, 187-192.

Fukui Y., and Hanafusa H. (1989) Phosphatidylinositol kinase activity associates with viral p60sre protein. Mol. Cell. Biol. 9, 1651-1658.

Gaiti A., Brunetti M., Piccinin G.L.W., Oelk K., and Porcelatti G. (1982) the synthesis in vivo of choline and ethanolamine phosphoglycerides in different brain areas during aging. Lipids 17, 291 296.

Gajdusek D.C., Beyreuther K., Brown P., Cork L.C. Cunningham D.D., et al. (1991) Regulation and genetic control of brain amyloid. Brain Res. Rev. 16, 83-114.

Galloway P., and Perry G. (1991) Tropomyosin distinguishes Lewy bodies of Parkinson disease from other neurofibrillary pathology. Brain Res. 541, 347-349.

Gandy S., Czernik A.J., and Greengard P. (1988) Phosphorylation of Alzheimer disease amyloid precursor peptide by protein kinase $\mathrm{C}$ and $\mathrm{Ca} 2+/ \mathrm{calmodulin-dependent} \mathrm{protein} \mathrm{kinase} \mathrm{II.} \mathrm{Proc.} \mathrm{Natl.}$ Acad. Sci. USA 85, 6218-6221.

Gelbmann C.M., and Muller W.E. (1991) Chronic treatment with phosphatidylserine restores muscarinic cholinergic receptor deficits in the aged mouse brain. Neurobiol. Aging 13, 45-50.

Georges E., Lindenbaum M.H., Sacher M.G., Trifaro J.-M., and Mushynski W.E. (1989) Neurofilament phosphorylation in cultured bovine adrenal chromaffin cells is stimulated by phorbol ester. $I$. Neurochem. 52, 1156-1161.

Gibson G.E.and Peterson C. (1987) Calcium and the aging nervous system. Neurobiol. Aging 8, 329-34.3.

Glenner G.G., and Wong C.W. (1984) Alzheimer's disease: Initial report of the purification and characterization of a novel cerebrovascular amyloid protein. Biochem. Biophys. Res. Comm. 120, 885-890.

Greenamyre J.T. (1991) Neuronal bioenergetic defects, excitotoxicity and Alzheimer's disease: "Use it and lose it". Neurobiol. Aging 12, 334-336.

Grondin P., Plantavid M., Sultan C., Breton M., Mauco G., and Chap H. (1991) Interaction of pp60c-src, 
phospholipase C, inositol-lipid, and diacylglycerol kinases with the cytoskeletons of thrombinstimulated platelets. J. Biol. Chem. 266, 15705-15709.

Grundke-Iq̣ball I., Iq̣bal K., Tung Y.-C., Quinlan M., Wisniewski H.M., and Binder L.I. (1986) Abnormal phosphorylation of the microtubule-associated protein tau in Aizheimer cytoskeletal pathology. Proc. Nall. Acad. Sci. USA 83, 4913-4917.

Halenda S.P., and Feinstein M.B. (1984) Phorbol myristate acetate stimulates formation of phosphatidylinositol 4-phosphate and phosphatidylinositol 4,5-bisphosphate in human platelets. Biochem. Biophys. Res. Comm. 124, 507-513.

Halushka P.V., and Burch R.M. (1984) Prostaglandins and ions, in advances in ion transport regulation. In: Prostaglandins and membrane ion transpor! (Braquet F., Garay R., Frohiich J., and Nicosia S., eds.), pp. 323-326. Ravan Press, N.Y.

Hanger D.P., Brion J.-P., Gallo J.-M., Cairns N.J., Luthert P.J., and Anderton B.H. (1991) Tau in Alzheimer's disease and Down's syndrome is insoluble and abnormally phosphorylated. Biochem. J. 275, 99-104.

Hardy J. (1992) An 'anatomical cascade hypothesis' for Alzheimer's disease. TINS 15, 200-201.

Hardy J., and Allsop D. (1991) Amyloid deposition as the central event in the aetiology of Alzheimer's disease. TIPS 12, 383-388.

Harman D. (1981) The aging process. Proc. Natl. Acad. Sci. USA 78, 7124-7128.

Harris J.K., and DeLorenzo R.J. (1987) Calcium and neuronal cytoskeletal proteins: Alterations with aging. Neurobiol. Aging 8, 359-361.

Hawthorne J.N. (1982) inositol phospholipids. In: New comprehensive biochemistry. Vol.4 Phospholipids (Hawthorne J.N., and Ansell G.B., eds.) pp. 263-278. Eisevier Biomedical Press.

Hawthorne J.N.,and Kai M. (1970) Metabolism of phosphoinositides. In: Handbook of neurochemistry, 'Lajtha A., ed.), pp. 491-508. Plenum Press, N.Y.

Hayashi H., Miyake N., Kanai F., Shibasaki F., Takenawa T., and Ebina Y. (1991) Phosphorylation in vitro of the $85 \mathrm{kDa}$ subunit of phosphatidylinositol 3-kinase and its possible activation by insulin receptor tyrosine kinase. Biochem. J. 280, 769-775.

Hayflick L. (1985) Theories of biological aging. Exp. Gerontol. 20, 145-159.

Hayflick L., and Moorhead P.S. (1961) The serial cultivation of human diploid cell strains. Exp. Cell Res. 25, 585-621.

kegner D. (1980) Age-dependence of molecular and functional changes in biological membrane properties. Mech. Aging Dev. 14, 101-118.

Heron D.S., Shinitzky M., Hershkowitz M., and Samuel D. (1980) Lipid fluidity markedly modulates the binding of serotonin to mouse brain membranes. Proc. Natl. Acad. Sci. USA 77, 7463-7467.

Hershkowiz M., Heron D., Samuel D., and Shinitzky M. (1982) The modulation of protein phosphorylation and receptor binding in synaptic membranes by changes in lipid fluidity: Implications for aging. Progr. Brain. Kes. 56, 419-434.

Hokin L.E. (1985) Receptors and phosphoinositide-generated second messengers. Ann. Rev. Biochem. 54, 205-235.

Hokin M.R., and Hokin L.E. (1953) Enzyme secretion and the incorporation of 32Pi into phospholipids of pancreas slices. I. Biol. Chem. 203, 967-977.

Holtzman D.M., and Mobley W.C. (1991) Molecular studies in Alzheimer's disease. TIBS 16, 140-144.

Hoshi M., Nishida E., Miyata Y., Sakai H., Miyoshi T., Ogawara H., and Akiyama T. (1987) Protein kinase $C$ phosphorylates tau and induces its functional alterations. FEBS Lett. 217, 237-241.

Hou W.-M., Zhang Z.-L., and Tai H.-H. (1988) Purification and characterization of phosphatidylinositol kinase from porcine liver microsomes. Biochim. Biophys. Acta 959, 67-75.

Huang H.-M., Toral-Barza L., Thaler H., Tofel-Grehl B., and Gibson G.E. (1991) Inositol phosphates and intracellular calcium after bradykinin stimulation in fibroblasts from young, normal aged and Alzheimer donors. Neurobiol. Aging 12, 469-473.

Ihara Y., Nukina N., Miura R., and Ogawara M. (1986) Phosphorylated tau protein is integrated into paired helical filaments in Alzheimer's disease. /. Biochem. Tokyo 99, 1807-1810.

Imai A., Rebecchi M.J., and Gershengorn M.E. (1986) Differential regulation by phosphatidylinositol 4,5-bisphosphate of pituitary plasma-membrane and cytosolic phosphoinositide kinases. Biochem. 
I. 240, 341-348.

Ishikawa Y., Gee M.V., Ambudkar I.S., Bodner L., Baum B.J., and Roth G.S. (1988) Age-related impairment in rat parotid cell alpha1-adrenergic action at the level of inositol trisphosphate responsiveness. Biochim. Biophys. Acta 968, 203-210.

Iqbal K. (1991) Prevalence and neurobiology of Alzheimer's disease: some highlights. In: Alzheimer's discase: Basic mechanisms, diagnosis and therapeutic strategies (Igbal K., McLachlan D.R.C., Winblad B., and Wisniewski H.M., eds.) pp. 1-5. J.Wiley \& Sons.

Irvine R.F., Angard E.E., Letcher A.J., and Downes. C.P. (1985) Metabolism of inositol 1,4,5trisphosphate and inositol 1,3,4,-trisphosphate in rat parotid glands. Biochem. I. 229, 505-511.

Irvine R.F., Letcher A.J., Heslop J.P., and Berridge M.J. (1986) The inositol tris/tetrakisphosphate pathway - demonstration of Ins(1,4,5)P3 3-kinase activity in animal tissues. Nature 320, 631-634.

Irvine R.F., and Moor R.M. (1986) Micro-injection of inositol 1,3,4,5-tetrakisphosphate activates sea urchin eggs by a mechanism dependent on external calcium. Biochem. J. 240, 917-920.

Irvine R.F., Moor R.M., Pollock W.K., Smith P.M., and Wreggett K.A. (1988) Philos. Trans. R. Soc. Lond. B. 320, 281-298.

Iwamoto N., Thangnipon W., Crawford C., and Emson P.C. (1991) Localization of calpain immunoreactivity in senile plaques and in neurones undergoing neurofibrillary degeneration in Alzheimer's disease. Brain Res. 561, 177-180.

Jeng I., Klemm N., and Wu C. (1988) An endogenous regulator of diacylglycerol kinase. Biochem. Biophys. Res. Comm. 151, 1088-1092.

Jenkins G.H., Subrahmanyam G., and Anderson R.A. (1991) Purification and reconstilution of phosphatidylinositol 4-kinase from human erythrocytes. Biochim. Biophys. Acfa 1080, 11-18.

Jolles J., Z.wiers H., Van Dongen C.J., Schotman. P., Wirtz K.W.A., and Gispen W.H. (1980) Modulation of brain polyphosphoinositide metabolism by ACTH-sensitive protcin phosphorylation. Nalure 286, 623-625.

Jolles J., and Hijman R. (1983) The neuropsychology of aging and dementia. In: Aging of the brain (Gispen W.H., and Traber J., eds.) pp. 227-250. Elsevier, Amsterdam.

Johnson G.V.W., and Jope R.S. (1986) Aluminum impairs glucose utilization and cholinergic activity in rat brain in vitro. Toxicol. 40, 93-102.

Johnson G.V.W., and Jope R.S. (1988) Phosphorylation of rat brain cytoskelctal proteins is increased after orally administered aluminum. Brain Res. 456, 95-103.

Kaczmarek L.K. (1987) The role of protein kinase $C$ in the regulation of ion channcls and neurotransmitter release. TINS 10, 30-34.

Kanoh H., and Akesson B. (1978) Properties of microsomal and soluble diacylglycerol kinase in rat liver. Eur. I. Biochem. 85, 225-232.

Kanoh H., Kondoh H., and Ono T. (1983) Diacylglycerol kinase from pig brain. 'Purification and phospholipid dependencies'. I. Biol. Chem. 258, 1767-1774.

Kanoh H., Yamada K., Sakane F., and Imaizumi T. (1989) Phosphorylation of diacylglycerol kinase in vitro by protein kinase C. Biochem. J. 258, 455-462.

Kanoh H., Yamada K., and Sakane F. (1990) Diacylglycerol kinase: a key modulator of signal transduction? TIBS 15, 47-50.

Kapeller R., Chen K.S., Yoakim M., Schaffhausen B.S., Backer J., White M.F., Cantley L.C., and Ruderman N.B. (1991) Mutations in the juxtamembrane region of the insulin receptor impair activation of phosphatidylinositol 3-kinase by insulin. Mol. Endocrinol. 5, 769-777.

Kaplan D.R., Whitman M., Schafthausen B., Raptis L., Garcea R.L., Pallas D., Roberts T.M., and Cantley L. (1986) Phosphatidylinositol metabolism and polyoma-mediated transformation. Proc. Natl. Acad. Sci. USA 83, 3624-3628.

Kaplan D.R., Whitman M., Schaffhausen B., Pallas D.C., White M., Cantley L., and Roberts T.M. (1987) Common elements in growth factor stimulation and oncogenic transformation: $85 \mathrm{kd}$ phosphoprotein and phosphatidylinositol kinase activity. Cell 50, 1021-1029.

Kato H., Uno I., Ishikawa T., and Takenawa T. (1989) Activation of phosphatidylinositol kinase and phosphatidylinositol-4-phosphate kinase by C-AMP in saccharomyces cerevisiae. J. Biol. Chem. $264,3116-3121$ 
Kawarabayashi T., Shoij M., Harigaya Y., Yamaguchi H., and Hirai S. (1991) Expression of APP in the early stage of brain damage. Brain Res. 563, 334-338.

Kitaguchi N., Takahashi Y., Tokushima Y., Shiojiri S., and Ito H. (1988) Novel precorsor of Alzheimer's disease amyloid protein shows protease inhibitory activity. Nature 331, 530-532.

Klunk W.E., McClure R.J., and Pettegrew J.W. (1991) L.Phosphoserine, a metabolite elevated in Alzheimer's disease, interacts with specific L-glutamate receptor subtypes. I. Neurochem. 56, 1997 2003.

Knook D.L. (1982) Verouderen, het venijn zit in de cel. Natuur en Techniek no.11, 831-849.

Koo E.H., Sisodia S.S., Archer D.R., Martin L.J., Weidemann A., Beyreither K., Fischer P., Masters C.L., and Price D.L. (1990) Precursor of amyloid protein in Alzheimer's disease undergoes fast anterograde axonal transport. Proc. Natl. Acad. Sci. LISA 87, 1561-1565.

Koreh K., and Monaco M.E. (1986) The relationship of hormone-sensitive and hormone-insensitive phosphatidylinositol to phosphatidylinositol 4,5-bisphosphate in the WRK-1 cell. J. Biol. Chem. 261, 88-91.

Kosik K.S., Duffy L.K., Dowling M.M., Abraham C., McCluskey A., and Selkoe D.J. (1984) Microtubuleassociated protein 2: monoclonal antibodies demonstrate the slective incorporation of certain epitopes into A.lzheimer neurofibrillary. Proc. Natl. Acad. Sci. USA 81, 7941-7945.

Kosik K.S., Joachim C.L., and Selkoe D.J. (1986) Microtubule-associated protein tau is a major antigenic component of paired helical filaments in Alzheimer disease. Proc. Nall. Acad. Sci. USA 83, 40444048 .

Kosik K.S., Orecchio L.D., Bakalis S., and Neve R.L. (1989) Developmentally regulated expression of specific tau sequences. Neuron 2, 1389-1397.

Krishnan S.S., Harrison J.E., Crapper D.R., and McLachlan D.R. (1987) Origin and resolution of the aluminium controversy concerning Alzheimer's neurofibrillary degeneration. Biol. Trace Elements Res. 13, 35-42.

Ksiezak-Reding H., Binder L.l., and Yen S.-H. (1990) /. Neurosci. Res. 25, 420-430.

Lapetina E.G., and Billah M.M. (1981) Phospholipase: role in cellular activation. The importance of the production of phosphatidic acid for the release of arachidonic acid in stimulated platelets. Agents Actions 11, 536-537.

Lee V.M.-Y., Otvos L., Schmidt M.L., and Trojanowski J.Q. (1988) Alzheimer disease tangles share immunological similarities with multiphosphorylation repeats in the two large neurofilament proteins. Proc. Nall. Acad. Sci. USA 85, 7384-7388.

Li Y.-S., Porter F.D. Hoffman R.M., and Deuel T.F. (1989) Separation and identification of two phosphatidylinositol 4-kinase activities in bovine uterus. Biochem! Biophys. Res. Comm. 160, 202209.

L.i P.P., Vecil G.G., Green M.A., and Warsh J.J. (1991) Inositol 1,4,5-trisphosphate receptor in developing and senescent rat cerebellum. Neurobiol. Aging 13, 89-92.

Ling L.E., Schulz J.T., and Cantley L.C. (1989) Characterization and purification of membraneassociated phosphatidylinositol-4-phosphate kinase from human red blood cells. /. Biol. Chem. 264, 5080-5088.

Linden J., and Delahunty T.M. (1989) Receptors that inhibit phosphoinositide breakdown. TIPS 10, 114120.

Lisanti M.P., Rodriguez-Boulan E., and Saltiel A.R. (1990) Emerging functional roles for the glycosylphosphatidylinositol membrane protein anchor. J. Membr. Biol. 117, 1-10.

Literski J.M., and Johnson G.V.W. (1992) Phosphorylation by cAMP-dependent protein kinase inhibits the degradation of tau by calpain. I. Biol. Chem. 267, 1563-1568.

Litosch I., Lin S.-H., and Fain J.N. (1983) Rapid changes in hepatocyte phosphoinositide induced by vasopressin. 1. Biol. Chem. 258, 13727-13732.

Litosch 1. (1987) Guanine nucleotide and NaF stimulation of phospholipase C activity in rat cerebralcortical rnembranes. 'Studies on substrate specificity.' Biochem. I. 244, 35-40.

Low M.G. (1987) Biochemistry of the glycosyl-phosphatidylinositol membrane protein anchors. Biochem. 1. 244, 1-13.

Low M.G. (1989) The glycosyl-phosphatidylinositol anchor of membrane proteins. Biochim. Biophys. 
Acta 988, 427-454.

Lukiw W.J., Krishnan B., Wong L., Kruck T.P.A., Bergeron C., and Crapper McLachlan D.R. (1991) Nuclear compartmentalization of aluminum in Alzheimer's disease (AD). Neurobiol. Aging 13, 115 . 121.

Lundberg G.A., and Jergil B. (1988) Generation of phosphatidylinositol 4,5-bisphosphate proceeds through an intracellular route in rat hepatocytes. FEBS Lett. 240, 171-176.

Lynch G., Larson J., and Baudry M. (1986) Proteases, neuronal stability and brain aging: An hypothesis. In: Treatment, development and strategies for Alzheimer's disease (Crook. T., Bartus R.T., Ferris S., and Gershon S., eds.), pp. 119-149.

Magnoni M.S., Govoni S., Battaini F., and Trabucchi M. (1991) The aging brain: protein phosphorylation as a target of changes in neuronal function. Life Sci. 48, 373-385.

Mann D.M.A., and Esiri M.M. (1988) The site of the earliest lesions of Alzheimer's disease. New Eng. I. Med. 318, 789-790.

Maragos W.F., Greenamyre J.T., Penney J.B., and Young A.B. (1987) Glutamate dysfínction in Alzheimer's disease: An hypothesis. TINS 10, 65-68.

Martin R.B. (1986) Citrate binding of AL3+ and Fe3+. I. Inorg. Biochem. 28, 181-187.

Masliah E., Cole G.M., Hansen L.A., Mallory M., Terry R.D., and Saitoh T. (1991) Protein kinase C alteration is an early biochemical marker in Alzheimer's disease. I. Neurosci, 11, 2759-2767.

Masliah E., Cole G.M., Shimohama S., Hansen L., DeTeresa R., Terry R.D., and Saitoh T. (1990) Differential involvement of protein kinase C isozymes in Alzheimer's disease. I. Neurosci. 10, 21132124.

Masters C.L., Simms G., Weinman N.A., Multhaup G., McDonald B.L., and Beyreuther K. (1985) Amyloid plaque core protein in Alzheimer disease and Down syndrome. Proc. Nati. Acad. Sci. USA 82, 4245-4249.

Mattson M.P., Rychlik B., and Engle M.G. (1991) Possible involvement of calcium and inositol phospholipid signalling pathways in neurofibrillary degeneration. In: Alzheimer's disease: Basic mechanisms, diagnosis and therapeutic strategies (Igbal K., McLachlan D.R.C., Winblad B., and Wisniewski H.M., eds.) pp. 191-198. J.Wiley \& Sons.

Matus A., and Green G.D.J. (1987) Age-related increase in cathepsin D like protease that degrades brain microtubule-associated proteins. Biochemistry 26, 8083-8086.

May W.S., Sahyoun N., Wolf M., and Cuatrecasas P. (1985) Role of intracellular calcium mobilization in the regulation of protein kinase C-mediated membrane processes. Nature 317, 549-551.

Mayer and Hanafusa (1990)

McDonald L.J., and Mamrack M.D. (1988) Aluminum affects phosphoinositide hydrolysis by phosphoinositidase C. Biochem. Biophys. Res. Comm. 155, 203-208.

McLaughlin M., Ross B.M., Milligan G., McCulloch J., and Knowler J.T. (1991) Robustness of G proteins in Alzheimer's disease: An immunoblot study. J. Neurochem. 57, 9-14.

Medawar P.B. (1952) An unsolved problem of biology. London:Lewis (see Hayflick, 1985).

Meites J., Goya R., and Takahashi S. (1987) Why the neuro-endocrine system is important in aging processes. Exp. Gerontol. 22, 1-15.

Meites J. (1988) Neuroendocrine basis of aging in the rat. Interdiscipl. Topics Geront. 24, 37-50.

Merida J., Diez E., and Gaulton G.N. (1991) IL-2 binding activates a tyrosine-phosphorylated phosphatidylinositol 3-kinase. J. Immunol. 147, 2202-2207.

Miyamoto A., Araiso T., Koyama T., and Oshika H. (1990) Membrane viscosity correlates with alpha1adrenergic signal transduction of the aged rat cerebral cortex. I. Neurochem. 55, 70-75.

Monaco M.E., and Woods D. (1983) Characterization of the hormone-sensitive phosphatidylinositol pool in WRK-1 cells. J. Biol. Chem. 258, 15125-15129.

Moolenaar W.H., Kruijer W., Tilly B.C., Verlaan I., Bierman A.J., and de Laat S.W. (1986) Growth factor-like action of phosphatidic acid. Nature 323, 171-173.

Morgan D.G., May P.C., and Finch C.E. (1988) In: Receptors and ligands in neurological disorders (Sen A.K., and Lee T., eds.), pp. 120-147. Cambridge University Press.

Morgan S.J., Smith A.D., and Parker P.J. (1990) Purification and characterization of bovine brain type I phosphatidylinositol kinase. Eur. J. Biochem. 191, 761-767. 
Moritz A., De Graan P.N.E., Ekhart P.F., Gispen W.H., and Wirtz K.W.A. (1990) Purification of a phosphatidylinositol 4-phosphate kinase from bovine brain membranes. I. Neurochem. 54, $351-354$.

Morris A.P., Gallacher D.V., Irvine R.F., and Peterson O.H. (1987) Synergism of inositol trisphosphate and tetrakisphosphate in activating Ca2+-dependent $\mathrm{K}+$ - channels. Nature 330, 653-655.

Moscona-Amir E. Henis Y.l., and Sokolovski M. (1989) Aging of rat heart myocytes disrupts muscarinic receptor coupling that leads to inhibition of CAMP accumulation and alters the pathway of muscarinic-stimulated phosphoinositide hydrolysis. Biochemistry 28, 7130-7137.

Mullaart E., Boerrigter E.T.I., Ravid R., Swaab D.F., and Vijg J. (1990) Increased levels of DNA breaks in cerebral cortex of Aizheimer's disease patients. Neurobiol. Aging 11, 169-173.

Muller E., Hegewald H., Jaroszewicz K., Cumme G.A., Hoppe H., and Frunder H. (1986) Turnover of phosphomonoester groups and compartmentation of polyphosphoinositides in human erythrocytes. Biochem. J. 235, 775-783.

Mulvihill P., and Perry G. (1989) Immunoaffinity demonstration that paired helical filaments of Alzheimer disease share epitopes with neurofilaments, MAP2. and tau. Brain Res. 184, 150-156.

Mundy W., Tandon P., Ali S., and Tilson H. (1991) Age-related changes in receptor-mediated phosphoinositide hydrolysis in various regions of rat brain. Life Sci. 49, 97-102.

Naeim F., and Walford R.L. (1985) Aging and cell membrane complexes: The lipid bilayer, integral proteins, and cytoskeleton. In: Handbook of the biology of aging (Finch C.E., and Sitheider E.L., eds.), pp. 272-289. Van Nostrand Reinhold, N.Y.

Nakamura Y., Takeda M., Niigawa H., Hariguchi S., and Nishimura T. (1992) Amyloid B-protein precursor deposition in rat hippocampus lesioned by ibotenic acid injection. Neurosci. Lett. 136, 95 98.

Nalepa I., Pintor A., Fortuna S., Vetulani J., and Michalek H. (1989) Increased responsiveness of the cerebral cortical phosphatidylinositol system to noradrenaline and carbachol in senescent rats. Neurosci. Lett. 107, 195-199.

Nishizuka $Y$. (1984) The role of protein kinase $C$ in cell surface signal transduction and tumour promotion. Nature 308, 693.698.

Nishizuka Y. (1986) Studies and perspectives of protein kinase C. Science 233, 305-312.

Nishizuka Y. (1988) The molecular heterogeneity of protein kinase $\mathrm{C}$ and its implications for cellular regulation. Nature $334,661-665$.

Nishizuka Y. (1989) Studies and prospectives of the protein kinase C family for cellular regulation. Cancer 63, 1892-1903.

Nitsch R.M., Blusztajn J.K., Piltas A.G., Slack B.E., Growdon J.H., and Wurtman R.J. (1992) Evidence for a membrane defect in Alzheimer disease brain. Proc. Nall. Acad. Sci. USA 89, 1671-1675.

Northwood I.C., and Davis R.I. (1989) Protein kinase C inhibition of the cpidermal growth factor receptor tyrosine protein kinase activity is independent of the oligomeric state of the receptor. J. Biel. Chem. 264l, 5746-5750.

Ohm T.G., Bohl J., and Lemmer B. (1991) Reduced basal and stimulated (isoprenaline, Gpp(NH)p, forskolin) adenylate cyclase activity in Alzheimer's disease correlated with histopathological changes. Brain Kes. 540, 229-236.

O'Neill C., Cowburn R.F., Wichager B., Alafuzoff I., Winblad B., and Fowler C.J. (1991) Conservation of 5-hydroxytryptamine-1A receptar-G protein interactions in the cerebral cortex of patients with Alzheimer's discase. Neurosci. Leth. 133, 15-19.

Oisu M., Hiles 1., Gout !., Fry M.J., Ruiz-Larrea F., Panayotou G., Thompson A., Dhand R., Hsuan J., Totty N., Smith A.D.: Morgan S.J. Courtneidge S.A., Parker P.J.: and Waterlield M.D. (1991) Characterization of two $85 \mathrm{kd}$ proteins that associate with receptor tyrosine kinases, middle-T / Pp60c-src complexes, and Pl 3-kinase. Cell 65, 91-104.

Otsuka N., Tomonaga M., and Ikeda K. (1991) Rapid appearance of B-amyloid precursor protein immunoreactivity in damaged axons and reactive glial cells in rat brain following needle stab injury. Brain Res. 568, 335-338.

Payrastre B., Van Bergen en Henegouwen P.M.P., Breton M., dẹn Hartigh J.C., Plantavid M., Verkleij A.)., and Boonstra J. (1991) Phosphoinosikide kinase, diacylglycerol kinase, and phosipholipase C activities associated to the cytoskeleton: Effect of epidermal growth factor. 1. Cell Biol. 115, 121- 
128.

Pearce B.D., and Potter L.T. (1991) Coupling of $\mathrm{m} 1$ Muscarinic receptors to G-protein in Alzheimer disease. Alz. Dis. Ass. Dis. 3, 163-172.

Peterson C., Ratan R.R., Shelanski M.L, and Goldman J.E. (1986) Cytosolic free calcium and cell spreading decrease in fibroblasts from aged and Alzheimer donors. Proc. Natl. Acad. Sci. USA 83, 7999-8001.

Pettegrew J.W. (1989). Molecular insights into Alzheimer's disease. In: Biological markers. of Alzheimer's disease (Boller F., Katzman R., Rascol A., Signoret I.L., and Christen Y., eds.) pp. 83104. Springer Verlag, Berlin.

Pettegrew J.W., and. Klunk W.E. (1990) Nuclear magnetic resonance study of phospholipid metabolites in Alzheimer's disease. In: Imaging, cerebral topography and Alzheimer's disease (Rapoport S.R., Petit H., Leys D., and Christen Y., eds.) pp. 159-165.

Pettegrew J.W., Panchalingham K., Withers G., McKeag D., and Strychor S. (1990) Changes in brain energy and phospholipid metabolism during development and aging in the Fisher 344 rat./. Neuropathol. Exp. Neurol. 49, 237-249.

Pietrzak E.R., Wilce P.A., and Shanley B.C. (1990) Effects of chronic ethanol treatment and aging on brain phosphoinositide turnover and adenylate cyclase activity. Neurochem. Int. 17, 593-598.

Pignataro O.P., and Ascoli M. (1990) Epidermal growth factor increases the labeling of phosphatidylinositol 3,4-bisphosphate in MA-10 Leydig tumor cells. I. Biol. Chem. 265, $1718-1723$.

Piomelli D., and Greengard P. (1990) Lipooxygenase metabolites of arachidonic acid in neuronal transmembrane signalling. TIPS 11, 367-373.

Porter F.D., Li Y.-S., and Deuel T.F. (1988) Purification and characterization of a phosphatidylinosilol 4-kinase from bovine uteri. J. Biol. Chem. 263, 8989-8995.

Price J.L., Davis P.B., Morris J.C., and White D.L. (1991) The distribution of tangles, plaques and related immunohistochemical markers in healthy aging and Alzheimer's disease. Neurobiol. Aging 12, 295-312.

Putney J.W. Jr., Weis S.J., Van De Walle C.M., and Haddas R.A. (1980) Is phosphatidic acid a calcium ionophore under neurohumoral control? Nature 284, 345-347.

Raff M.C. (1992) Social controls on cell survival and cell death. Nature 356, 397-400.

Rana R.S., Kowluree A., and MacDonald M.]. (1986) Arch. Biochem. Biophys. 245, 411-416.

Remillard B., Petrillo R., Maslinski W., Tsudo M., Strom T.B., Cantlcy L., and Varticovski L. (1991) Interleukin-2 receptor regulates activation of phosphatidylinositol 3-kinase. 1. Biol. Chem. 266, 14167-14170.

Renard D., Poggioli ]., Berthon B., and Claret M. (1987) How far does phospholipase C activity depend on the cell calcium concentration? Biochem. J. 243, 391-398.

Rhee S.G., Suh P.-G., Ryu S.-H., and Lee S.Y. (1989) Studies of inositol phospholipid-specific phospholipase C. Science 244, 546-550.

Rivnay B., Globerson A., and Shinitzky M. (1978) Perturbation of lymphocytic response to concanavalin A by exogenous cholesterol and lecithin. Eur. I. Immunol. 8, 185-189.

Rivnay B., Globerson A., and Shinitzky M. (1979) Viscosity of lymphocyte plasma membrane in aging mice and its possible relation to serum cholesterol. Mech. Aging Dev. 10, 71-79.

Rudermann N.B., Kapeller R., White M.F., and Cantley L.C. (1990) Activation of phosphatidylinositol 3-kinase by insulin. Proc. Nall. Acad. Sci. USA 87, 1411-1415.

Sacher G.A. (1982) Evolutionary theory in gerontology. Perspect. Biol. Med. 25, 339-353.

Sakane F., Yamada K., and Kanoh H. (1989) Different effects of sphingosine, R59022 and anionic amphiphiles on two diacylglycerol kinase isozymes purified from porcine thymus cytosol. FEBS Lett. 255,409-413.

Saltiel A.R., and Cuatrecasas P. (1986) Insulin stimulates the generation from hepatic plasma membranes of modulators derived from an inositol glycolipid. Proc. Natl. Acad. Sci. USA 83, 57935797.

Saltiel A.R., Fox J.A., Sherline P., and Cuatrecasas P. (1986) Insulin-stimulated hydrolysis of a novel glycolipid generates modulators of cAMP phosphodicsterase. Science 233, 967-972.

Saltiel A.R., Fox J.A., Sherline P., Sahyoun N., and Cuatrecasas P. (1987) Purification of 
phosphatidylinositol kinase from bovine brain myelin. Biochem. J. 241, 759-763.

Saltiel A.R., and Cuatrecasas P'. (1988) In search of a second messenger for insulin. Am. J. Physiol. 255, c1-c11.

Saltiel A.R. (1991) The role of glycosyl-phosphoinositides in hormone action. I. Bioenerg. Biomembr. 23, 29-41.

Scholz G., Barrit G.J., and Kwok F. (1991) Purification and chemical modification of a phosphatidylinositol kinase from sheep brain. Eur. J. Biochem. 201, 249-255.

Schuber F. (1989) Influence of polyamines on membrane functions. Biochem. J. 260, 1-10.

Sekar M.C., and Hokin L.E. (1986) The role of phosphoinositides in signal transduction. J. Membrane Biol. 89, 193-210.

Selkoe D.J. (1991) Amyloid protein and Alzheimer's disease. Scientific American 265, 40-47.

Serunian et al., 1989

Shapiro I.P., Masliah E., and Saitoh T. (1991) Altered protein tyrosine phosphoryaltion in Alzheimer's disease. J. Neurochem. 56, 1154-1162.

Sherman W.R., Leavitt A.L., Honchar M.P., Hallcher L.M., and Phillips B.E. (1981) Evidence that lithium alters phosphoinositide metabolism: Chronic administration elevates primarily D-myoinositol-1-phosphate in cerebral cortex of the rat. I. Neurochem. 36, 1947-1951.

Shibasaki F., Homma Y., and Takenawa T. (1991) Two types of phosphatidylinositol 3-kinase from bovine thymus. Monomer and heterodimer form. J. Biol. Chem. 266, 8108-8114.

Shimohama S., Homma Y., Suenaga T., Fujimoto S., Taniguchi T., Araki W., Yamaoka Y., Takenawa T., and Kimura J. (1991) Aberrant accumulation of phospholipase C-delta in Alzheimer brains. Am. I. Pathol. 139, 737-742.

Shimohama S., Fujimoto S., Taniguchi T., and Kimura J. (1992) Phosphatidylinositol-specific phospholipase $C$ activity in the postmortem human brain: no alteration in Alzheimer's disease. Brain Res. 579, 347-349.

Sihag R.K., Jeng A.Y., and Nixon R.A. (1988) Phosphorylation of neurofilament proteins by protein kinase C. FEBS Lett. 233, 181-185.

Sisodia, S.S., Koo E.H., Beyreuther K., Unterbeck A., and Price D.L. (1990) Evidence that B-amyloid protein in Alzheimer's disease is not derived by normal processing. Science 248, 492-495.

Skolnik E.Y., Margolis B., Mohammadi M., Lowenstein E., Fischer R., Drepps A., Ullrich A., and Schlessinger ]. (1991) Cloning of P13 kinase-associated p85 utilizing a novel method for expression / cloning of target proteins for receptor tyrosine kinases. Cell 65, 83-90.

Small D.H., Moir R.D., Fuller S.J., Michaelson S., Bush A.I., Li Q.-X., Milward E., Hilbich C., Weidemann A., Beyreuther K., and Masters C.L. (1992) A protease activity associated with acetylcholinesterase releases the membrane-bound form of the amyloid protein precursor of Alzheimer's disease. Biochemistry 30, 10795-10799.

Smith C.D., Carney I.M., Starke-Reed P.E., Oliver C.N., Stadtman E.R., Floyd R.A., and Markesbery W.R. (1991) Excess brain protein oxidation and enzyme dysfunction in normal aging and in Alzheimer disease. Proc. Natl. Acad. Sci. USA 88, 10540-10543.

Smith J.B., Smith L., and Higgins B.L (1985) Temperature and nucleotide dependence of calcium release by myo-ionsitol 1,4,5-trisphosphate in cultured vascular smooth muscle cells. I. Biol. Chem. 260, 14413-14416.

Stephens L., Hawkins P.T., and Downes C.P. (1989) Metabolic and structural evidence for the existence of a third species of polyphosphoinositide in cells: D-phosphatidyl-myo-inositol 3-phosphate. Biochem. J. 259, 267-276.

Stokes C.E., Gillon K.R.W., and Hawthorne J.N. (1983) Free and total lipid myo-inositol concentrations decrease with age in human brain. Biochim. Biophys. Acta 753, 136-138.

Stokes C.E., and Hawthome J.N. (1987) Reduced phosphoinositide concentrations in anterior temporal cortex of Alzheimer-diseased brains. I. Neurochem. 48, 1018-1021.

Storey D.J., Shears S.B., Kirk C.1., and Michell R.H. (1984) Stepwise enzymatic dephosphorylation of inositol 1,4,5-trisphosphate to inositol in liver. Nature 312, 374-376.

Streb H., Irvine R.F., Berridge M.J., and Schulz I. (1983). Release of Ca2+ from a non mitochondrial intracellular store in pancreatic acinar cells by inositol-1,4,5-trisphosphate. Nature 306, 67-69. 
Streb H., Bayerdorffer E., Haase H., Irvine R.F., and Schulz 1. (1984) Effect of inositol 1,4,5trisphosphate on isolated subcellular fractions of rat pancreas. J. Membr. Biol. 81, 241-253.

Strnad C.F., Parente J.E., and Wong K. (1986) Use of fluoride ion as a probe for the guanine nucleotidebinding protein involved in the phosphoinositide dependent neutrophil transduction pathway. FEBS Lett. 206, 20-24.

Strosznajder J., and Samochocki M. (1991) Ca2+-independent, Ca2+-dependent, and carbacholmediated arachidonic acid release from rat brain cortex membrane. J. Neurochem. 57, 1198-1206.

Stubbs E.B., Kelleher J.A., and Sun G.Y. (1988) Phosphtidylinositol kinase, phosphatidylinositol-4phosphate kinase and diacylglycerol kinase activities in rat brain subcellular fractions. Biochim. Biophys. Acta 958, 247-254.

Sugimoto Y., Whitman M., Cantley L.C., and Erikson R.L. (1984) Evidence that the Rous sarcoma virus. transforming gene product phosphorylates phosphatidylinositol and diacylglycerol. Proc. Natl. Acad. Sci. USA 81, 2117-2121.

Surichamorn W., Abdallah E.A., and EL-Fakahany E.E. (1989) Aging does not alter brain muscarinic receptor-mediated phosphoinositide hydrolysis and its inhibition by phorbol esters, tetrodotoxin and receptor desensitization. I. Pharmacol. Exp. Ther. 251, 543-549.

Suzuki T., Banno Y., and Nozawa Y. (1991) Partial purification and characterization of two forms of phosphatidylinositol 4-phosphate 5-kinase from human platelet membrane. Thrombosis Res. 64, 4556.

Svennerholm L., Bostrom K., Helander C.G., and Jungbjer B. (1991) Membrane lipids in the aging human brain. J. Neurochem. 56, 2051-2059.

Swaab D.F. (1991) Brain aging and Alzheimer's disease, "wear and tear" versus "use it or lose it". Neurobiol. Aging 12, 317-324.

Tacconi M.T., LLigona LL., Salmona M., Pitsikas N., and Algeri S. (1991) Aging and food restriction: Effect on lipids of cerebral cortex. Neurobiol. Aging 12, 55-59.

Tanaka S.-i., Tominaga I., Yasuda I., Kishimoto A., and Nishizuka Y. (1991) Protein kinase C in rat brain synaptosomes. Betall-subspecies as a major isoform associated with membrane-cytoskeleton elements. FEBS Lett. 294, 267-270.

Tandon P., Mundy W.R., Ali S.F., Nanry K., Rogers B.C., and Tilson H.A. (1991) Age-dependent changes in receptor-stimulated phosphoinositide turnover in the rat hippocampus. Pharmacol. Biochem. Behav. 38, 861-867.

Tanzi R.E., Gcorge-Hyslop P.H.St., and Gusella J.F. (1989) Molecular genetic approaches to Alzheimer's disease. TINS 12, 152-158.

Tanzi R.E., George-Hyslop P.St., and Gusella J.F. (1991) Molecular genetics of Alzheimer discase amyloid. 1. Biol. Chem. 266, 20579-20582

Tappel A.L., et al. (1973) J. Gerontol. 28, 415.

Taylor M.V., Metcalfe J.C., Hesketh T.R., Smith G.A., and Moore J.P. (1984) Mitogens increase phosphorylation of phosphoinositides in thymocytes. Nalure 312, 462-465.

Terry R.D., and Pena C. (1965) Experimental production of neurofibrillary degeneration.2. Electronmicroscopy phosphatase histochemistry and electron probe analysis. Neuropathol. Exp. Neurol. 24, 200-210.

Tilly B.C., van Paridon P.A., Verlaan I., Wirtz K.W.A., de Laat S.W., and Moolenaar W.H. (1987) Inositol phosphate metabolism in bradykinin-stimulated human A431 carcinoma cells: relationship to calcium signalling. Biochem. J. 244, 129-135.

Traynor-Kaplan A.E., Harris A.L., Thompson B.L., Taylor P., and Sklar L.A. (1988) An inositol tetrakisphosphate-containing phospholipid in activated neutrophils. Nalure 334, 353-356.

Vadnal R.E., and Parthasarathy R. (1989) The identification of a novel inositol lipid, phosphatidylinositol trisphosphate (PJP3), in rat cerebrum using in vivo techniques. Biochem. Biophys. Res. Comm. 163, 995-1001.

Vallejo M., Jackson T., Lightman S., and Hanley M.R. (1987) Occurrence and extracellular actions of inositol pentakis- and hexakisphosphate in mammalian brain. Nature 330, 656-658.

Van Dongen C.J., Hershkowitz M., Zwiers H., DeLaat S., and Gispen W.H. (1983) Lipid fluidity and phosphoinositide metabolism in brain membranes of aged rats: effects of ACTH(1-24). In: Aging of 
the brain (Gispen W.H., and Traber J., eds.), pp. 101-104. Elsevier, Amsterdam.

Van Dongen C.J., Zwiers H., and Gispen W.H. (1984) Purification and partial characterization of the phosphatidylinositol 4-phosphate kinase from rat brain. Biochem. I. 223, 197-203.

Van Rooijen L.A.A., Rossowska M., and Bazan N.G. (1985) Inhibition of phosphatidylinositol-4phosphate kinase by its product phosphatidylinositol-4,5-bisphosphate. Biochem. Biophys. Res. Comm. 126, 150-155.

Varticovski L., Druker B., Morrison D., Cantley L., and Roberts T. (1989) The colony stimulating factor1 receptor associates with and activates phosphatidylinositol 3-kinase. Nature 342, 699-702.

Varticovski L., Daley G.Q., Jackson P., Baltimore D., and Cantley L.C. (1991) Activation of phosphatidylinositol 3-kinase in cells expressing abl oncogene variants. Mol. Cell. Biol. 11, 11071113.

Viig J. (1990a) Levensverlenging: de apotheose van de moleculaire biomedische wetenschappen? Tijdschr. Gerontol. Geriatr. 21, 199-204.

Vijg ). (1990b) DNA seguence changes in aging: How frequent, how important? Aging 2, 105-123.

Vollicer L., and Crino P.B. (1990) involvement of free radicals in dementia of the Alzheimer type: A hypothesis. Neurobiol. Aging 11, 567-571.

Walker D.H., and Pike L.J. (1987) Phosphatidylinositol kinase is activated in membranes derived from cells treated with epidermal growth factor. Proc. Natl. Acad. Sci. USA 84, 7513-7517.

Walker D.H., Dougherty N., and Pike L.J. (1988) Purification and characterization of a phosphatidylinositol kinase from A431 cells. Biochemistry 27, 6504-6511.

Weingarten M.D., Lockwood A.H., Hwo S.-Y., and Kirschner M.W. (1975) A protein factor essential for microtubule assembly. Proc. Natl. Acad. Sci. USA 72, 1858-1862.

Wetzker R., Klinger R., Hsuan J., Fry M.J., Kauffmann-Zeh A., Muller E., Frunder H., and Waterfield M. (1991) Purification and characterization of phosphatidylinositol 4-kinase from human erythrocyte membranes. Eur. I. Biochem. 200, 179-185.

Whitman M., Kaplan D.R., Schaffhausen B., Cantley L., and Roberts T.M. (1985) Association of phosphatidylinositol kinase activity with polyoma middle-T competent for transformation. Nature 315, 239-242.

Whitman M., Kaplan D., Roberts T., and Cantley L. (1987) Evidence for two distinct phosphatidylinositol kinases in fibroblasts. Biochem. $1.247,165-174$.

Whitman M., Downes C.P., Keeler M., Keller T., and Cantley L. (1988) Type I phosphatidylinositol kinase makes a novel inositol phospholipid, phosphatidylinositol-3-phosphate. Nature 332, 644646.

Whitson J.S., Sekoe D.j., Cotman C.W. (1989) Amyloid B protein enhances the survival of hippocampal neurons in vitro. Science 243, 1488-1490.

Whitson J., Glabe C.G., Shintani E., Abcar A., and Cotman C.W. (1990) B-Amyloid protein promotes neuritic branching in hippocampal cultures. Neurosci. Lett. 110, 319-324.

Williams G.C. (1957) Pleiotropy, natural selection and the evolution of senescence. Evolution 11, 398411.

Wilson D.B., Neufeld E.J., and Majerus P.W. (1985) Phosphoinositide interconversion in thrombinstimulated human platelets. I. Biol. Chem. 260, 1046-1050.

Wolf B.A., Turk J., Sherman W.R., and McDaniel M.L. (1986) Intracellular Ca2+ mobilization by arachidonic acid in comparison with myo-inositol 1,4,5-trisphosphate in isolated pancreatic islets. 1. Biol. Chem. 261, 3501-3511.

Wood J.G., Mirra S.S., Pollock N.J.z and Binder L.1. (1986) Neurofibrillary tangles of Alzheimer discase share antigenic determinants with the axonal microtubule-associated protein tau. Proc. Natl. Acad. Sci. USA 83, 4040-4043.

Yada Y., Ozeki T., Kanoh H., and Nozawa Y. (1990) Purification and characterization of cytosolic diacylglycerol kinases of human platelets. I. Biol. Chem. 265, 19237-19243.

Yamada K., and Kanoh H. (1989) Occurrence of immunoreactive $80 \mathrm{kDa}$ and non-immunoreactive diacylglycerol kinases in different pig tissues. Biochem. 1. 255, 601-608.

Yamakawa A., and Takenawa T. (1988) Purification and characterization of membrane-bound phosphatidylinositol kinase from rat brain. ). Biol. Chem. 263, 17555-17560. 
Yamanishi J., Takai Y., Kaibuchi K., Sano K., Castagna M., and Nishizuka Y. (1983) Synergistic functions of phorbol ester and $\mathrm{Ca} 2+$ in serotonin release from human platelets. Biochem. Biophys. Res. Comm. 112, 778-786.

Yankner B.A., Duffy L.K., and Kirschner D.A. (1990) Neurotrophic and neurotoxic effects of amyloid beta protein: reversal by tachykinin neuropeptides. Science 250, 279-282.

Yates C.M., Simpson J., Russell D., and Gordon. (1980) Cholinergic enzymes in neurofibrillary degeneration produced by aluminium. Brain Res. 197, 269-274.

Young L.T., Kish S.J., Li P.P., and Warsh J.J. (1988) Decreased brain [3H]inositol 1,4,5-trisphosphate binding in Alzheimer's disease. Neurosci. Lett. 94, 198-202.

Zubenko G.S. (1986) Hippocampal membrane alteration in Alzheimer's disease. Brain Res. 385, 115121. 

CHAPTER 2

PHOSPHATIDIC ACID AND POLYPHOSPHOINOSITIDE FORMATION IN RAT BRAIN IN VITRO: EFFECTS OF POST-MORTEM DELAY AND PROCEDURAL MANIPULATIONS.

J. Bothmer, M. Markerink and J. Jolles 


\begin{abstract}
The effect of post mortem delay and procedural manipulations on phosphate incorporation into phosphatidylinositol phosphate (PIP), phosphatidylinostol bisphosphate $\left(\mathbb{P I P}_{2}\right)$ and phosphatidic acid (PA) in a lysed crude synaptosomal fraction from rat brain is studied in the present paper. $\mathrm{PIP}_{2}$ formation was already decreased in vitro after a post-mortem delay of $2 \mathrm{~min}$. Only $5 \%$ of activity was still present after 24 hours. PA formation increased 3-fold in this period whereas PIP formation did not change. A delay of 2 to 4 hours before the incubation resulted in a $25 \%$ increase in PIP formation whereas $\mathrm{PIP}_{2}$ and $\mathrm{PA}$ formation was, reduced in this period. Slow freezing of brain material after decapitation of animals had no effect on PIP and $\mathrm{PIP}_{2}$ formation in vitro, but increased the formation of PA. Rapid freezing resulted in a $30 \%$ increase in PIP formation and a $25 \%$ decrease in PA formation. Thawing had no eifect. Finally, age ( $8 \pm 1$ week) and body weight appeared to influence $\mathrm{PIP}_{2}$ and PA but not PIP formation, which is indicative of developmental changes in this period. The results suggest that it is of utmost importance to use a strict and standardized procedure in studies in which groups of subjects with different biological variables (e.g., pretreatment in vivo, age, post-mortern delay, diagnosis in case of human material) are compared with respect to inositol phospholipids measured in vitro.
\end{abstract}

\title{
Introduction
}

Nervous tissue is especially rich in phosphoinositides (Michell, 1975), which are involved in important neurochemical processes related to neurotransmission (Abdel-Latif, 1986; Berridge, 1987). An important feature of phosphoinositides is their rapid interconversion. The values reported for phosphoinositide phosphorus in nervous tissue vary greatly, which is probably caused by the rapid hydrolysis of phosphatidylinositol 4-phosphate (PIP) and phosphatidylinositol 4,5-bisphosphate $\left(\mathrm{PIP}_{2}\right.$ ) post-mortem (Hawthorne and Pickard, 1979). Hydrolysis of PIP and $\mathrm{PIP}_{2}$ by phospholipase $\mathrm{C}$ yields diacylglycerol (Aveldano and Bazan, 1975; Tang and Sun, 1985), which is rapidly phosphorylated to phosphatidic acid (PA) by diaglycerol kinase. This rapid hydrolysis places particular restrictions on the investigation of inositol phospholipids and PA in vitro and on studies which measure phospholipid levels and/or kinase activities with endogenous phospholipids as substrate in vitro in relation to biological manipulations in vivo. Earlier studies from our research group have shown that small variations in assay conditions can give rise to substantial changes in inositol phospholipids measured in an in vitro assay system. For instance, Jolles et al. (1981) used a synaptosomal fraction in which rat brain membranes were prelabeled in vivo and showed that half of the 32P from PIP and $\mathrm{PIP}_{2}$ was lost after two minutes of incubation at $37^{\circ} \mathrm{C}$. Furthermore, Bothmer et al. (1990) have shown that $\mathrm{PIP}_{2}$ formation in a 10 second incubation decreases substantially with preincubation periods longer than 10 seconds.

The issue of differences in the formation of inositol phospholipids and PA in relation to the time needed to prepare and use an enzyme fraction is of both 
fundamental and methodological importance. There is a great variance in the values reported for phosphoinositide phosphorus in nervous tissues in animals and in humans (Stokes et al., 1983; Stokes and Hawthorne, 1987) which may be because of differences in post-mortem interval. Jolles et al. (1992) fave recently shown that the brains of patients with Alzheimer's disease are characterized by a substantial decrease in PI kinase but not PIP kinase activity. The aging rodent, however, appears to be characterized by a general lowering in PA forming activity (Bothmer et al., 1992). These results show that it is essential to reduce variability between experimental subjects in studies in which the relation between biological variables (disease state, age, treatment in vivo etc.) and inositol phospholipids/PA formation in vitro is investigated. The present study was performed to establish whether the variance in the formation of PIP, $\mathrm{PIP}_{2}$ and PA in vitro is due to any of the following four methodological parameters: the post mortem-interval, the time between enzyme preparation and incubation, the developmental stage of the animal in terms of age and brain weight, and the freeze/thaw procedure used for storage of the brain material. It was also investigated whether $\mathrm{PIP}, \mathrm{PIP}_{2}$ and $\mathrm{PA}$ producing activities show a differential susceptibility to these parameters.

In the study presented here, a crude lysed synaptosomal fraction was used under hypo-osmotic conditions and (very) short incubation periods, which enables the simultaneous measurement -and thus comparison- of the three kinase activities (Bothmer et al., 1990; Jolles et al., 1981).

\section{Experimental procedures}

\section{Animals and brain dissection}

Male rats (about $160 \mathrm{~g}$ and 8 weeks old) of an inbred Brown Norway strain were used. After decapitation, the head was immediately immersed in liquid nitrogen for $8 \mathrm{sec}$. All subsequent operations were performed at $0-4^{\circ} \mathrm{C}$. The brain was taken out of the skull rapidly and the bulbi olfactory, the cerebellum and brainstem were removed.

\section{Subcellular fractionation}

Tissue from individual rats was homogenized in homogenization medium $(0.32$ M sucrose, $1 \mathrm{mM}$ EDTA, $10 \mathrm{mM}$ Tris- $\mathrm{HCl} \mathrm{pH} \mathrm{7.4;} \mathrm{Booth} \mathrm{and} \mathrm{Clark,1978)} \mathrm{in} \mathrm{a} \mathrm{total}$ volume ten times the brain tissue volume, by ten up and down strokes (16 s each) of a Potter Elvehjem teflon-glass homogenizer with a radial clearance of $0.125 \mathrm{~mm}$ and rotating at $700 \mathrm{rpm}$. The method of Gray and Whittaker (1962) was used for the subcellular fractionation of the homogenate. Briefly, the homogenate was centrifuged for $10 \mathrm{~min}$ at $1000 \mathrm{~g}$. After centrifugation of the supernatant at $10,000 \mathrm{~g}$ for $10 \mathrm{~min}$, the resulting crude mitochondrial/synaptosomal pellet $\left(\mathrm{P}_{2}\right)$ was subjected to osmotic lysis : the pellet was resuspended 
in 10 vol. distilled water and stirred for $20 \mathrm{~min}$ at $4^{\circ} \mathrm{C}$. This suspension was centrifuged for $20 \mathrm{~min}$ at $10,000 \mathrm{~g}$ to remove unlysed structures. The $10,000 \mathrm{~g}$ supernatant of the lysed $P_{2}$ fraction was taken as the enzyme fraction, and is referred to in the text as the lysed synaptosomal fraction. The influence of delay in the various stages of preparation of the lysed synaptosomal fraction was estimated by keeping the time needed for all steps constant except for the step to be examined. Changes per experiment are described in the legends of the figures. Protein was determined according to the method of Lowry et al. (1951).

\section{Phosphorylation assay}

Endogenous phosphorylating activity was assayed as described before (Jolles et al., 1981; Bothmer et al., 1990). The following conditions were used: $7.5 \mu \mathrm{M}$ ATP, 2-3 $\mu \mathrm{Ci}$ [y32P]-ATP (approx. $3000 \mathrm{Ci} / \mathrm{mmol}$, Amersham, U.K.), $50 \mathrm{mM} \mathrm{Na}$-Acetate, 10 $\mathrm{mM} \mathrm{Mg}$-Acetate, $\mathrm{pH} 6.5$, and $15 \mu \mathrm{l}$ enzyme fraction ( $10 \mu \mathrm{g}$ protein) in a final volume of $25 \mu \mathrm{l}$ at $30^{\circ} \mathrm{C}$. The lipid phosphorylation reaction was terminated after $10 \mathrm{~s}$ by the addition of $2 \mathrm{ml}$ ice-cold chloroform : methanol : $12 \mathrm{~N} \mathrm{HCl}$ (200:100:0.75, by volume; Shaikh and Palmer,1977).

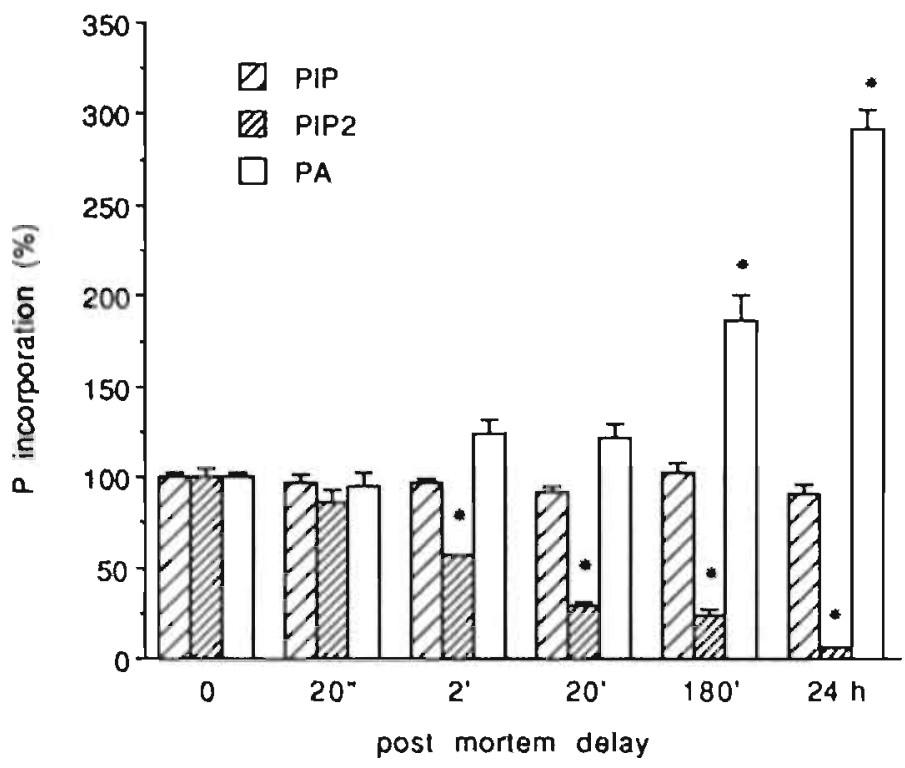

Fig.I: The effect of the post mortem delay, started by decapitation and ended by start of subcellular fractionation, on the incorporation of phosphate into PIP, PIP 2 and PA. Values shown are means ( $\mathrm{SEEM}$ ) of triplicate determinations. Data were analyzed with a T-test in which a deviation from the control value $(100 \%)$ was tested. ": $p<0.05$. 


\section{Lipid extraction, thin-layer chromatography and determination of radioactivity}

Lipid extraction and thin-layer chromatography were performed as described previously (Jolles et al.,1981). 32P was determined by liquid scintillation counting in a commercially available scintillation fluid (Ready safe liquid scintillation fluid, Beckman). Two hundred microlitres of water was added to the scraped silica portions followed by $3.8 \mathrm{ml}$ of scintillation fluid. The radioactivity was counted in a scintillation spectrometer (Beckman LS 1801) with an efficiency of $100 \%$.

\section{Results}

The influence of the post mortem interval on phospholipid phosphorylation activity in vitro was investigated in an experiment in which the time period between decapitation and brain dissection (followed by rapid homogenization at $0^{\circ} \mathrm{C}$ ) was varied from $0 \mathrm{~s}$ to $24 \mathrm{~h}$. A substantial reduction in $\mathrm{PIP}_{2}$ formation was already evident at a post-mortem interval of $2 \mathrm{~min}$, and the lysed crude synaptosomal fraction had lost $95 \%$ of its PIP kinase activity after a delay of 24 hours (Fig. 1). Interestingly, there was no change in PI kinase activity whereas PA formation increased threefold with increasing post-mortem interval.

The time the enzyme fraction was allowed to stand at $4^{\circ} \mathrm{C}$ before the start of the incubation had a marked effect on phosphorylation. As Figure 2 shows, increasing the time from 0 to 4 hours led to an increased formation of PIP and a decreased formation of $\mathrm{PIP}_{2}$ and $\mathrm{PA}$.

The third experiment investigated whether lipid phosphorylating activities are affected by the age of the animals. Rats were used of slightly different ages $(8 \pm 1$ weeks) and hence different body weights (weight range $120-200$ g.). The difference in age reflected the usual variation in age and weight of animals used in experiments. PI formation was not dependent upon age/weight, whereas both $\mathrm{PA}$ formation and $\mathrm{PIP}_{2}$ formation increased with increasing age and weight (Fig. 3) $\left(r^{2}=0.725(p<0.05)\right.$ and $r^{2}=0.435(p<0.05)$, respectively).

The fourth experiment investigated whether the way in which brain material is stored and regenerated by freezing and thawing has an influence on the lipid phosphorylating activities. Brain material obtained from different rats of the same age and weight was subjected to the various combinations of fast or slow freezing and fast or slow thawing. Freezing had a substantial influence on PIP formation (60\% increase compared to control) and PA formation (25\% decrease) whereas $\mathrm{PLP}_{2}$ formation was not affected (Fig. 4). Thawing had no effect on the formation of the lipids. With respect to storage of the lysed synaptosomal fraction, rapid freezing ( $5 \mathrm{~s}$ liquid nitrogen) and rapid thawing (contact with water at $0-4^{\circ} \mathrm{C}$ ) appeared to give the highest incorporation of phosphate (results not shown). Storage at $-80^{\circ} \mathrm{C}$ for periods up to three months did not decrease enzyme activity (results not shown). 


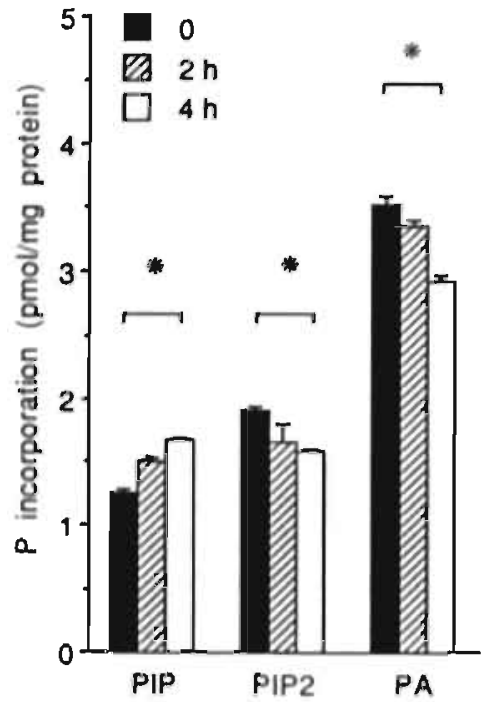

Fig. 2 : The effect of storage time of the lysed synaptosomal fraction (at $0-4^{\circ} \mathrm{C}$ ) on the incorporation of phosphate (pmol/mg protein) into PIP, PIP 2 and $\mathrm{PA}$. The storage times were 0 (subcellular fractionation followed directly by incubation), 2 and 4 hours. Each value is the mean of nine determinations $( \pm S E M)$. Data were analyzed with a repeated measures analysis of variance. ": $p<0.05$.

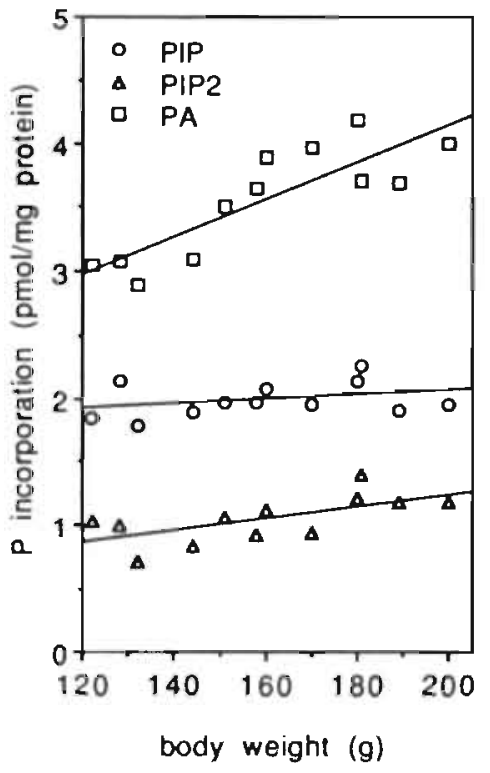

Fig. 3: The effect of body weight of $8( \pm 1)$ week-old-rats on the incorporation of phosphate into PIP, $\mathrm{PIP}_{2}$ and PA. Values shown are means of triplicate determinations. Data were analyzed with linear regression analysis.

\section{Discussion}

The present study shows that basal PIP, $\mathrm{PIP}_{2}$ and PA formation in the lysed synaptosomal fraction of rat brain is affected by delays at different stages of preparation of the lysed synaptosomal fraction. The differential centrifugation steps were not changed so the evaluated characteristics. (Whittaker, 1969) of the lysed synaptosomal fraction were not influenced.

A post-mortem delay from 2 minutes up to 24 hours caused a marked increase in PA formation and a decrease in $\mathrm{PIP}_{2}$ formation, whereas PIP formation remained unaffected (Fig. 2). $\mathrm{PIP}_{2}$ formation probably decreased as a result of the substantial decline, within a few minutes after death, in the content of $\mathrm{PP}_{2}$ and PIP, the substrate of PIP kinase, in rat brain (Dawson and Eichberg, 1965; Ikeda et 
al., 1986; Sun et al., 1990) and in gerbil brain (Abe et al., 1987). This decrease in inositol phospholipids after decapitation is immediately followed by an increase in the amount of diacylglycerol (Abe et al., 1987; Ikeda et al., 1986), which is the substrate for PA formation, and is the probable cause of the increased formation of PA measured in our assay system. The concentration of PI does not change after decapitation (Ikeda et al., 1986) or shows only a small decrease (Abe et al., 1987), which explains the unaltered PIP formation in our assay system after decapitation.
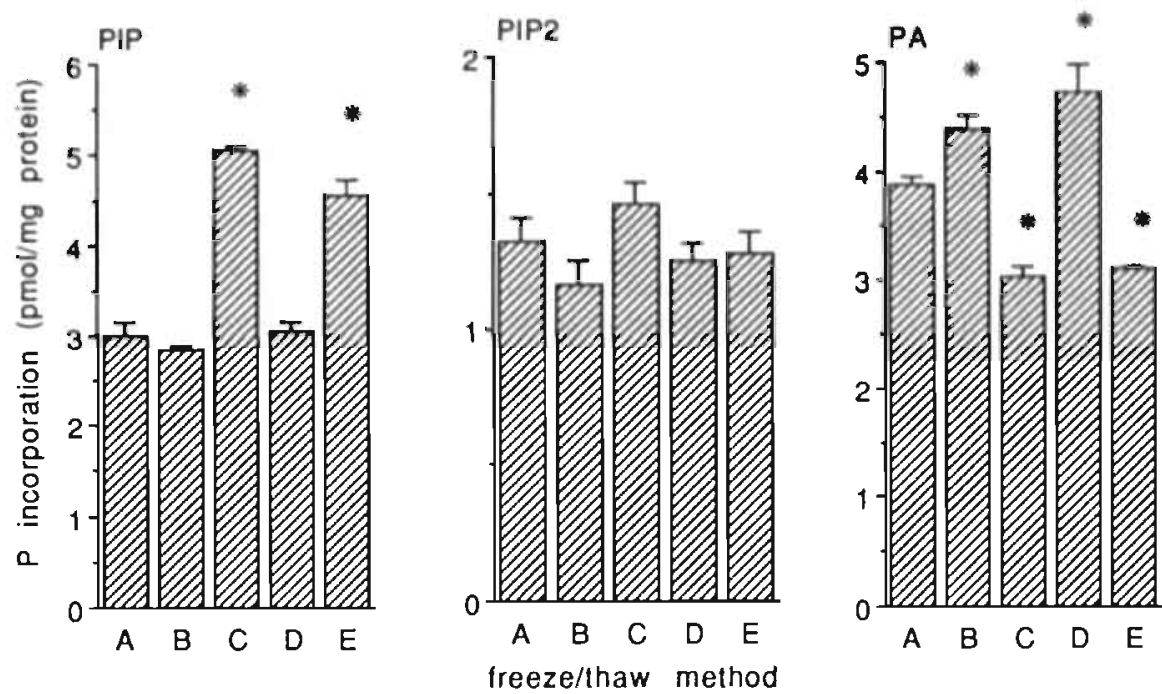

Fig. 4: The effect of different methods of freezing and thawing brain tissue on the incorporation of phosphate into PIP, $\mathrm{PIP}_{2}$ and PA. Values shown are means of triplicate determinations. A: control; B: slow freezing/rapid thawing; $C$ : rapid freezing/rapid thawing; D: slow freezing/slow thawing; E: rapid freezing/slow thawing. Rapid freezing, by immersion in liquid nitrogen, followed by storage at $-80^{\circ} \mathrm{C}$; slow freezing, placed in a polyethylene container at $-80^{\circ} \mathrm{C}$; rapid thawing, immersion in a water bath at $4^{\circ} \mathrm{C}$; slow thawing in a $4^{\circ} \mathrm{C}$ room. Data were analyzed by Duncan's multiple range Iest. ": different from control value, $\mathrm{p}<0.05$.

A delay after the subcellular fractionation / before the phosphate incorporation assay affected phosphate incorporation activities differently to the delay postmortem. A delay after subcellular fractionation resulted in a decrease in PIP $_{2}$ formation and PA formation but an increase in PIP formation. This differential effect was not the same as the one observed with increasing post-mortem delay. These differences are probably due to the difference in the concentration of 
calcium. Phospholipase $\mathrm{C}$ is $\mathrm{Ca} 2+$ dependent (see Abdel-Latif, 1986) and the phosphomonoesterases also require this ion (Jolles et al., 1981). Because the hypotonic lysed synaptosomal fraction contains less calcium than is present in the brain after decapitation, the enzymes responsible for inositol phospholipid degradation, such as phospholipase $\mathrm{C}$ and the phosphomonoesterases, will also have a different activity.

The range of the weight/age of the rats used correlated positively with the incorporation of phosphate into $\mathrm{PIP}_{2}$ and PA (Fig.1). This positive correlation probably reflects the development of inositol phospholipid metabolism in synaptosomal plasma membranes, or the development of a factor (e.g. myelination) which influences subcellular fractionation in such a way that it affects the incorporation of phosphate into $\mathrm{PIP}_{2}$ and $\mathrm{PA}$ in the lysed synaptosomal fraction. This is in accordance with the finding that both PI and PIP kinase activity increases 4-5 fold in chick brain during the period of active myelination (Shaikh and Palmer, 1977). Salway et al. (1968) observed a similar developmental pattern for PIP kinase activity in postnatal rat brain, but PI kinase activity reached a maximum immediately after birth, although clearly before the onset of the myelination in the rat. Interestingly, in our assay PI kinase activity did not change with weight / age.

We used a lysed synaptosomal fraction to assess the consequences of freezing and thawing procedures. Hardy et al. (1983) found that rapid freezing of brain tissue severely impaired the subsequent performance of synaptosomes. Our findings are consistent with this because slow freezing of brain tissue followed by storage at $-80^{\circ} \mathrm{C}$ results in a incorporation of phosphate into lipids comparable to that measured with fresh material (Fig.3), although incorporation into PA was slightly increased. Fast freezing increased PIP formation and decreased PA formation. The way of thawing the brain tissue before subcellular fractionation did not influence the incorporation of phosphate into PIP, PIP 2 and PA measured in vitro. However, Hardy et al. (1983) found a relatively good metabolic performance of synaptosomes prepared from tissue frozen slowly and thawed rapidly in contrast to slowly thawed material.

In conclusion, this study shows that basal formation of PIP, PIP 2 and PA in a lysed synaptosomal fraction is influenced differently by delays at different stages in the preparation of a lysed synaptosomal fraction. Thus the factor time must be controlled to reduce experimental error, especially in studies in which groups of subjects (animals, human brain material) are used, such as in aging research (Bothmer et al., 1992) and in studies on human brain (e.g. Jolles et al., 19912; Stokes et al., 1983). Furthermore, one should control for variations in age and weight within groups, because of the developmental effects found in the present and other studies. Further research should be devoted to the differential effects on PIP, PIP 2 and PA formation found in the present study. Care should be taken to use a strict and standardized procedure for the preparation of the enzyme fraction as variations in the method of preparation influence phospholipid phosphorylation measured in vitro. 


\section{References}

Abdel-Latif, A.A. (1986) Calcium-mobilizing receptors, polyphosphoinositides, and the generation of second messengers. Pharmacol. Rev. 38, 227-272.

Abe, K., Kogure, K., Yamamoto, H., Imazawa, M., and Miyamoto, K. (1987) Mechanism of arachidonic acid liberation during ischemia in gerbil cerebral cortex. I. Neurochem. 48, 503-509.

Aveldano, M.I., and Bazan, N.G. (1975) Rapid production of diacylglycerols enriched in arachidonate and stearate during early brain ischemia. I. Neurochem. 25, 919-920.

Berridge, M.J. (1987) Inositol trisphosphate and diacylglycerol: two interacting second messengers. Ann Rev. Biochem. 56, 159-193.

Booth, R.F.G., and Clark, J.B. (1978) A rapid method for the preparation of relatively pure metabolically competent synaptosomes from rat brain. Biochem. I. 176, 365-370.

Bothmer, J., Markerink, M., and Jolles, J. (1990) Phosphatidic acid and polyphosphoinositide formation in a broken cell preparation from rat brain: Effects of different incubation conditions. Neurochem. Int. 17, 27-33.

Bothmer, J., Markerink, M., and Jolles, J. (1992) Brain phosphatidic acid and polyphosphoinositide formation in a broken cell preparation: Regional distribution and the effects of age. Neurochem. Int. 21, 223-228.

Dawson, R.M.C., and Eichberg, J. (1965) Diphosphoinositide and triphosphoinositide in animal tissues. Extraction, estimation and changes post mortem. Biochem. I. 96, 634-643.

Gray, E.G., and Wittaker, V.P. (1962) The isolation of nerve endings from brain: an electron microscopic study of cell fragments derived by homogenization and centrifugation. I. Anatomy. 96, 79-87.

Hardy, J.A., Dodd, P.R., Oakley, A.E., Perry, R.H., Edwardson, J.A., and Kidd, A.M. (1983) Metabolically active synaptosomes can be prepared from frozen rat and human brain. $/$. Neurochem. 40, 608-615.

Hawthorne, J.N., and Pickard, M.R. (1979) Phospholipids in synaptic function. J. Neurochem. 32, 5.

Ikeda, M., Yoshida, S., Busto, R., Santiso, M., and Ginsberg, M.D. (1986) Polyphosphoinositides as a probable source of brain free fatty acids accumulated at the onset of ischemia. J. Neurochem. 47, 123-132.

Jolles, J., Schrama, L.H., and Gispen, W.H. (1981) Calcium-dependent turn over of brain phosphoinositides in vitro after prelabeling in vivo. Biochim. Buphys. Acta 666, 90.98.

Jolles, J., Bothmer, J., Markerink, M., and Ravid, R. (1992) Phosphatidylinositol kinase activity is reduced in Alzheimer's disease. J. Neurochem. 58, 2326-2329.

Lowry, O.H., Rosebrough, N.J., Farr, A.L., and Randall, R.J. (1951) Protein measurement with the folin phenol reagent. I. Biol. Chem. 193, 265-275.

Michell, R.H. (1975) Inositol phospholipids and cell surface receptor function. Biochem. Biophys. Acta 415, 81-147.

Salway, J.G., Harwood, J.L., Kai, M., White, G.L., and Hawthorne, J.N. (1968) Enzymes of phosphoinositide metabolism during rat brain development. J. Neurochem. 15, 221-226.

Shaikh, N.A., and Palmer, F.B.St.C. (1977) Phosphoinositide kinase in chick brain and sciatic nerve, a developmental study. J. Neurochem. 28, 395-402.

Stokes, C.E., Gillon, K.R.W., and Hawthorne, J.N. (1983) Free and total lipid myo-inositol concentrations decrease with age in human brain. Biuchim. Biophy:. Acta 753, 136-138.

Stokes, C.E., and Hawthorne, J.N. (1987) Reduced phosphoinositide concentrations in anterior temporal cortex of Alzheimer-discased brains. J. Neurochem. 48, 1018-1021.

Sun, G.Y., Yoa, F.-G., and Lin, T.-N. (1990) Degradation of poly-phosphoinositides in brain subcellular membranes in response to decapitation insult. Neurochem. Int. 17, 529-535.

Tang, W., and Sun, G.Y. (1985) Effects of ischemia on free fatty acids and diacylglycerols in developing rat brain. Int. J. dev. Neurosci. 3, 51-56.

Whittaker, V.P. (1969) The synaptosome, In: Handbook of neurochemistry (Laitha, A., ed.), vol.2, pp. 327-364. Plenum N.Y. 

CHAPTER 3

PHOSPHATIDIC ACID AND POLYPHOSPHOINOSITIDE FORMATION IN A BROKEN CELL PREPARATION FROM RAT BRAIN : EFFECTS OF DIFFERENT INCUBATION CONDITIONS.

J. Bothmer, M. Markerink and J. Jolles

Published in:

Neurochemistry International vol.17, 27-33 (1990). 


\begin{abstract}
The formation of phosphatidic acid (PA) and polyphosphoinositides in rat brains in vitro was studied under hypotonic conditions by incubating a lysed crude synaptosomal fraction with Igamma-32P]ATP for $10 \mathrm{sec}$. Only phosphatidic acid, phosphatidylinositol 4-phosphate (PIP) and phosphatidylinositol 4,5-biphosphate $\left(\mathrm{PIP}_{2}\right)$ were labelled. The formation of $\mathrm{PIP}_{2}$ decreased with increasing preincubation times. PIP and PA formation, however, were not affected. The rate of phosphorylation of PIP, PIP ${ }_{2}$ and PA was linear with incubation time for at least $10 \mathrm{sec}$, indicating that the ATP/enzyme ratio was sufficiently high. The maximal incorporation of phosphate into the three phospholipids was found at $30^{\circ} \mathrm{C}$. Ten millimolar $\mathrm{Mg}^{2+}$ and $\mathrm{pH} 6.5$ were the best compromise for measuring the incorporation of phosphate into PIP, $\mathrm{PIP}_{2}$ and PA simultaneously. A sodium acetate / magnesium acetate buffer system gave optimal kinase activities. The results obtained show that, with minor adjustments of the incubation conditions, it is possible to measure simultaneousiy the formation of PIP, $\mathrm{PIP}_{2}$ and $\mathrm{PA}$.
\end{abstract}

\title{
Introduction
}

The membrane phospholipids phosphatidylinositol (PI), phosphatidylinositol 4-phosphate (PIP), and phosphatidylinositol 4,5-bisphosphate (PIP $)$ are quantitatively minor components of cell membranes but they have an important physiological role (for reviews see Abdel-Latif, 1986; Berridge, 1987). They are rapidly interconverted by phosphorylation and dephosphorylation. Furthermore, their breakdown into diacylglycerol and inositol phosphates is followed by rapid phosphorylation of the diglyceride into phosphatidic acid (PA).

The majority of the biochernical studies on the inositol phospholipid system have been carried out with intact structures, such as synaptosomes derived from rat brain (e.g. Jolles et al., 1981b; Stubbs et al., 1988), whereby the incorporation of $3 \mathrm{H},{ }^{14} \mathrm{C}$ or $32 \mathrm{P}$ labelled substrates into inositol phospholipids was studied under isotonic conditions and relatively long incubation periods (minutes). A second method for the in vitro investigation of inositol phospholipids has not been used so often, but is "of potential relevance" according to Fisher et al. (1984). This method involves the incubation of isolated synaptic plasma membranes in the presence of cytosolic factors under hypotonic conditions. Gamma-labelled ATP is used as the phosphate donor in very short incubations (eg $10 \mathrm{~s})$. This is of importance because the enzymes involved in the interconversion of PI, PIP and $\mathrm{PIP}_{2}$ are among the fastest acting enzymes known (Hawthorne and Pickard,1979).

Previous studies with this method have shown phosphate incorporation into $\mathrm{PIP}_{2}$ and $\mathrm{PA}$ to be sensitive to adrenocorticotropin $\left(\mathrm{ACTH} \mathrm{H}_{1-24}\right)$, and phosphate incorporation into PIP, $\mathrm{PIP}_{2}$ and $\mathrm{PA}$ to be sensitive to $\mathrm{Ca}^{2+}$ and dependent on $\mathrm{Mg}^{2}$. (Jolles et al., 1981a). Besides $\mathrm{ACTH}_{\mathrm{i}-24}, \mathrm{c}-\mathrm{AMP}$ and endorphins have also been shown to affect phosphoinositide phosphorylation, albeit in a different way (Jolles et al., 1981b; Jolles et al., 1982).

Unfortunately, nothing is known about potentially important assay conditions such as incubation and preincubation times, temperature, concentration of $\mathrm{Mg}^{2+}$, 
ATP and tissue protein, $\mathrm{pH}$, and buffer systems. The present study was designed to provide more information about these variables so that future studies will be performed under optimal assay conditions.

\section{Experimental procedures}

\section{Animals and brain dissection}

Male rats (165 g) of an inbred Brown Norway strain were used. After decapitation, the head was immediatly immersed in liquid nitrogen for $8 \mathrm{~s}$. All subsequent operations were performed at $0-4^{\circ} \mathrm{C}$. The brain was taken out of the skull rapidly and the bulbi olfactori, the cerebellum and brainstem were removed.

\section{Subcellular fractionation}

Tissue from individual rats was homogenized in homogenization medium $(0.32$

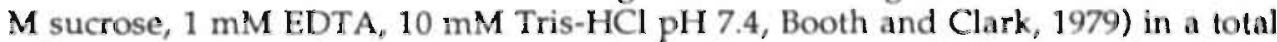
volume ten times the brain tissue volume, by ten up and down strokes (16 s each) of a Potter Elvehjem teflon-glass homogenizer with a radial clearance of $0.125 \mathrm{~mm}$ and rotating at $700 \mathrm{rpm}$. The method of Gray and Whittaker (1962) was used for the subcellular fractionation of the homogenate. Briefly, the homogenate was centrifuged for $10 \mathrm{~min}$ at $1000 \mathrm{~g}$. After centrifugation of the supernatant at $10,000 \mathrm{~g}$ for $10 \mathrm{~min}$, the resulting crude mitochondrial/synaptosomal pellet $\left(\mathrm{P}_{2}\right)$ was subjected to osmotic lysis : the pellet was resuspended in 10 vol. aqua bidest and stirred for $20 \mathrm{~min}$ at $4^{\circ} \mathrm{C}$. This suspension was centrifuged for $20 \mathrm{~min}$ at $10,000 \mathrm{~g}$ to remove unlysed structures. The $10,000 \mathrm{~g}$ supernatant of the lysed $P_{2}$ fraction was taken as the enzyme fraction. This fraction was frozen in $1 \mathrm{ml}$ aliquots in liquid nitrogen for $5 \mathrm{~s}$, and stored at $-80^{\circ} \mathrm{C}$. There was no decline in enzyme activity after at least one month of storage (results not shown).

\section{Phosphorylation assay}

Endogenous phosphorylating activity was assayed as described before. (Jolles et al., 1981a) Briefly, a routine incubation was performed under the following conditions : $7.5 \mu \mathrm{M}$ ATP, $2-3 \mu \mathrm{Ci}$ [gamma-32P]-ATP (approx. 3,000 Ci/mmol, Amersham, U.K.), $50 \mathrm{mM} \mathrm{Na}$-Acetate, $10 \mathrm{mM} \mathrm{Mg-Acetate,} \mathrm{pH} 6.5$, and $15 \mu \mathrm{l}$ enzyme fraction ( $10 \mu \mathrm{g}$ protein) in a final volume of $25 \mu \mathrm{l}$ at $30^{\circ} \mathrm{C}$. Unless otherwise specified, the membrane samples were thawed on ice ( 1 to 1.5 hours) and preincubated for $5 \mathrm{~min}$ and the incubation was started by the addition of ATP. The influence of the various assay conditions was estimated by keeping the conditions constant except for the condition to be tested. The changes in the assay per experiment are described in the legends of the figures. The lipid phosphorylation reaction was terminated by the addition of $2 \mathrm{ml}$ ice-cold 
chloroform : methanol : $12 \mathrm{~N} \mathrm{HCl}$ (200:100:0.75, by vol., Shaikh and Palmer, 1977). Protein determination was performed according to the method of Lowry et al. (1951).

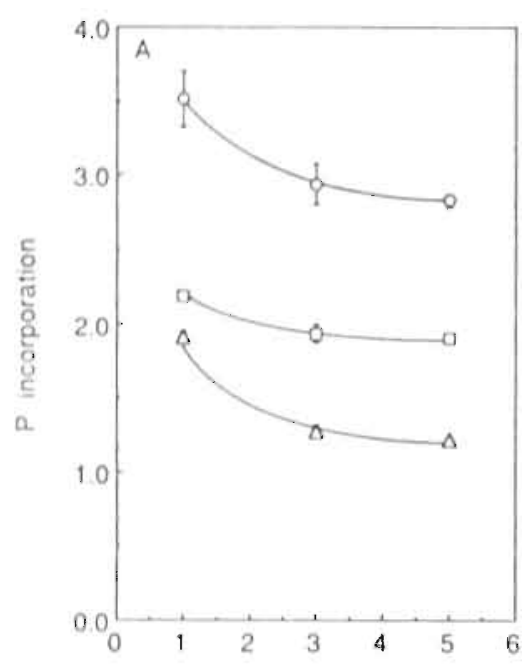

pre-incubation (min)

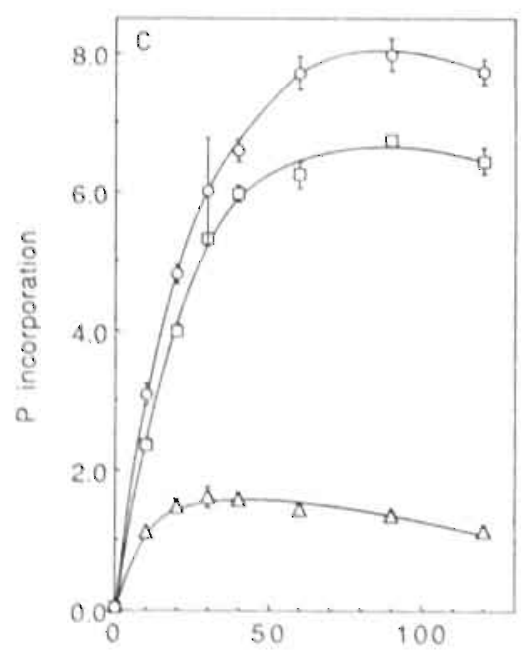

incubation time (sec)

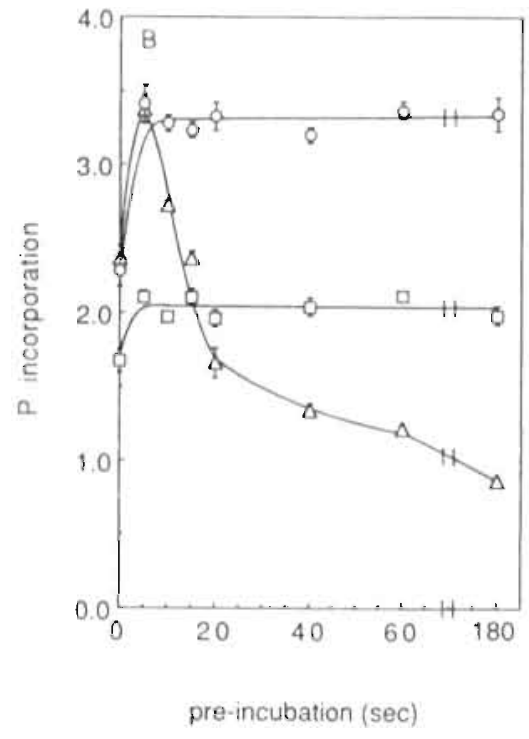

Fig. 1 : Effect of preincubation ( $A$ and $B$ ) and incubation times (C) on the incorporation of phosphate ( $\mathrm{pmol} / \mathrm{mg}$ protein) into phosphatidylinositol 4phosphate (PIP ; squares), phosphatidylinositol 4,5-bisphosphate $\left(\mathrm{PlP}_{2}\right.$; triangles) and phosphatidic acid (PA ; circles). The start of the preincubation in the first procedure (A) was the moment when the ice cold incubation tube, containing $15 \mu$ membranecytosol fraction, was put into the incubation bath $\left(30^{\circ} \mathrm{C}\right)$. The temperature of the content of the tube was $20^{\circ} \mathrm{C}$ after 15 s. $28.5^{\circ} \mathrm{C}$ after $1 \mathrm{~min}$ and $30^{\circ} \mathrm{C}$ after 1.5 $\min$. The start of preincubation in the second experiment $(B)$ was the moment when $15 \mu$ membrane-cylosol fraction was added 10 prewarmed $\left(30^{\circ} \mathrm{C}\right)$ incubation tubes. The membrane-cytosol fraction reached a temperature of $30^{\circ} \mathrm{C}$ within seconds. Each point is the mean of 6 ( $\mathrm{A}$ and B) or 3 (C) determinations ( \pm SEM). 
Lipid extraction, thin layer chromatography and determination of radioactivity

Lipid extraction and thin layer chromotography were performed as described previously (Jolles et al., 1981a). ${ }^{32} \mathrm{P}$ was determined by liquid scintillation counting in a commercially available scintillation fluid (Ready safe liquid scintillation fluid, Beckman). Two hundred microlitres of water was added to the scraped silica portions followed by $3.8 \mathrm{ml}$ of scintillation fluid. The radioactivity was counted in a scintillation spectrometer (Beckman LS 1801) with an efficiency of $100 \%$.

\section{Results}

\section{Effect of preincubation and incubation time}

Only radiolabelled PIP, $\mathrm{PIP}_{2}$ and PA were detected after incubation of the lysed crude synaptosomal fraction with [gamma-32P]ATP for $10 \mathrm{~s}$. The influence of the preincubation time on the incorporation of phosphate is shown in Fig. 1a. It appeared that $[32 \mathrm{P}]-\mathrm{PIP}_{2}$ formation decreased with increasing preincubation times. The difference between phosphate incorporation into PIP and PA with respect to different preincubation times was not significant. A second experiment was performed in order to gain more detailed information on shorter preincubation times. The procedure was adapted slightly in order to allow preincubation times in the range of seconds. Again, the preincubation time did not affect the incorporation of phosphate into PIP and PA whereas the incorporation into PIP 2 decreased with increasing preincubation times (Fig. 1b). It is probable that the values at $0 \mathrm{~s}$ are an artefact caused by the low temperature at that time. Phosphate incorporation into $\mathrm{PIP}_{2}$ reached its highest level with a $5 \mathrm{~s}$ preincubation and was reduced to $30 \%$ after 3 to $5 \mathrm{~min}$. Phosphate incorporation into the phospholipids did not change with preincubations of 3 to $5 \mathrm{~min}$ (results not shown).

The influence of the incubation time was investigated under standard incubation conditions with a 5 min preincubation. Fig. 1c shows that there was a linear incorporation of phosphate into PIP and PA over 20 to $30 \mathrm{~s}$, indicating that the amount of ATP was not limiting during the standard incubation $(10 \mathrm{sec})$. The: curve for phosphate incorporation into PIP $_{2}$ suggests that the reaction is also linear during the first ten seconds. A second experiment showed that there was a linear increase in phosphate incorporation into $\mathrm{PIP}_{2}$ from 5 to 15 seconds $(0.77$ $1.16-1.57 \mathrm{pmol} \mathrm{Pi} / \mathrm{mg}$ protein, respectivily). The degradation of ATP was linear for at least $20 \mathrm{~s}$ after which time it levelled off.

\section{Effect of incubation temperature}

The effect of the incubation temperature $\left(23^{\circ} \mathrm{C}, 30^{\circ} \mathrm{C}, 37^{\circ} \mathrm{C}\right.$ and $\left.44^{\circ} \mathrm{C}\right)$ was investigated under conditions of short $(5 \mathrm{~s})$ and long $(5 \mathrm{~min})$ preincubation times. The temperature optimum for PIP formation (Fig. 2a) under standard conditions 
(5 min preincubation) appeared to be $37^{\circ} \mathrm{C}$. The optimum for PA formation, however, was between $23^{\circ} \mathrm{C}$ and $30^{\circ} \mathrm{C}$ (Fig. 2c) whereas under standard conditions the optinum for $\mathrm{PIP}_{2}$ formation was lower than $23^{\circ} \mathrm{C}$ (Fig. 2b). The temperature effect appeared to be dependent on the preincubation time as the curves levelled off at a preincubation time of $5 \mathrm{~s}$. The temperature effects observed with a $5 \mathrm{~min}$ preincubation were thus probably caused during preincubation and not during incubation. With a $5 \mathrm{~s}$ preincubation, the overall incorporation of phosphate into PIP, $\mathrm{PIP}_{2}$ and PA was greater at $30^{\circ} \mathrm{C}$ than at $37^{\circ} \mathrm{C}$.
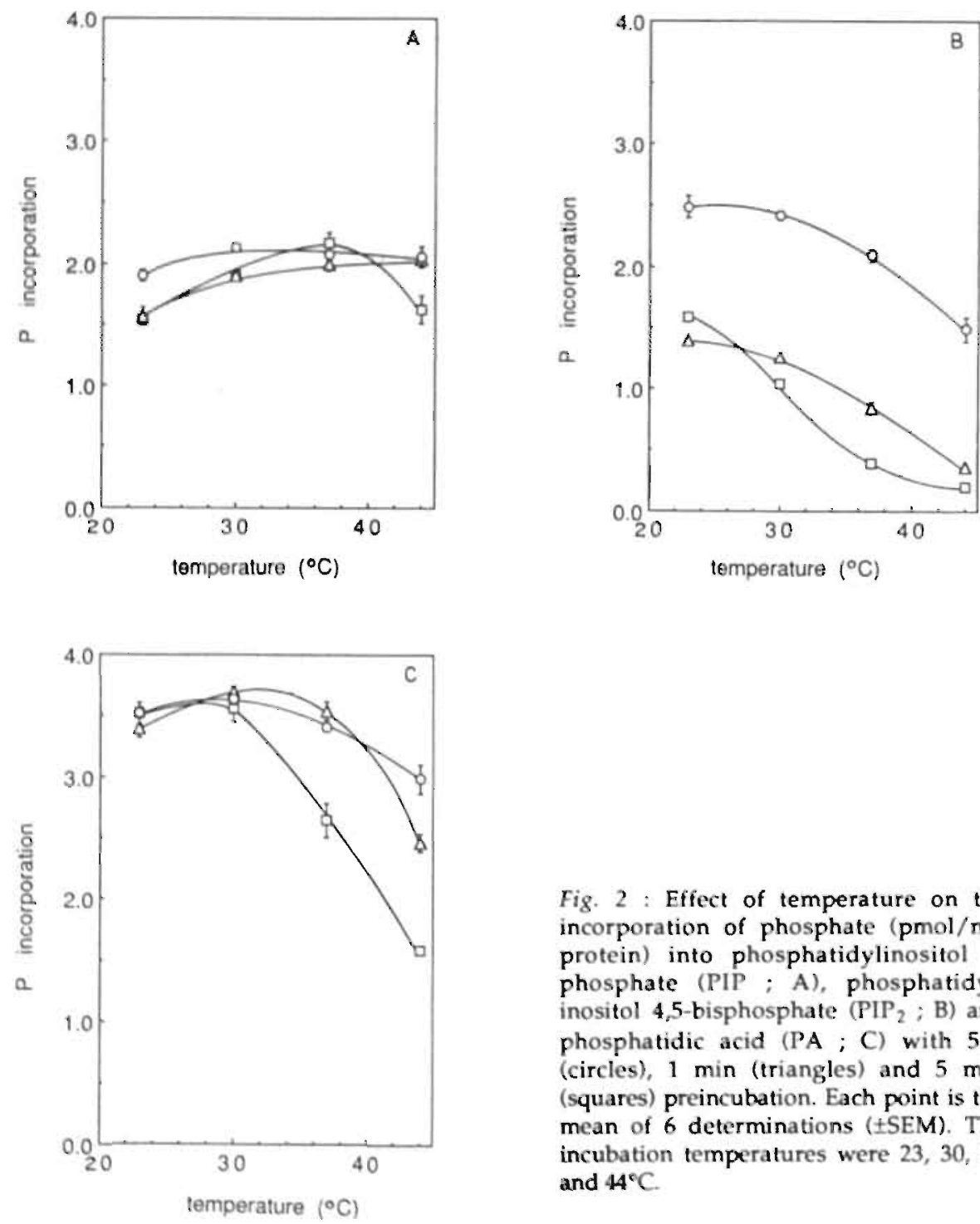

Fig. 2 : Effect of temperature on the incorporation of phosphate (pmol/mg protein) into phosphatidylinositol 4 phosphate (PIP' ; A), phosphatidylinositol 4,5 -bisphosphate: $\left(\mathrm{PIP}_{2} ; \mathrm{B}\right)$ and phosphatidic acid (PA ; C) with $5 \mathrm{~s}$ (circles), $1 \mathrm{~min}$ (triangles) and $5 \mathrm{~min}$ (squares) preincubation. Each point is the mean of 6 determinations ( \pm SEM). The incubation temperatures were $23,30,37$ and $44^{\circ} \mathrm{C}$. 


\section{Effect of magnesium ions, ATP and tissue concentration}

The incorporation of phosphate into PIP, $\mathrm{PIP}_{2}$ and PA appeared to be dependent on $\mathrm{Mg}^{2+}$ (Fig. 3a). The highest values for individual phosphate incorporation were measured for PIP at $60 \mathrm{mM} \mathrm{Mg}{ }^{2+}$ or higher and for $\mathrm{PIP}_{2}$ and $\mathrm{PA}$ at $1 \mathrm{mM} \mathrm{Mg} 2+$. Ten millimolar $\mathrm{Mg}^{2+}$ appeared to be a good compromise for measuring phosphate incorporation into $\mathrm{PIP}, \mathrm{PIP}_{2}$ and $\mathrm{PA}$ in the same assay.

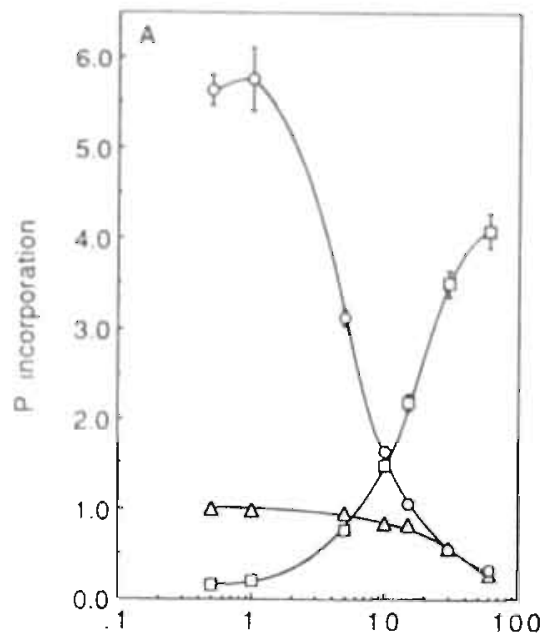

$\mathrm{Mg} 2+$ conc. ( $\mathrm{mM}$ )

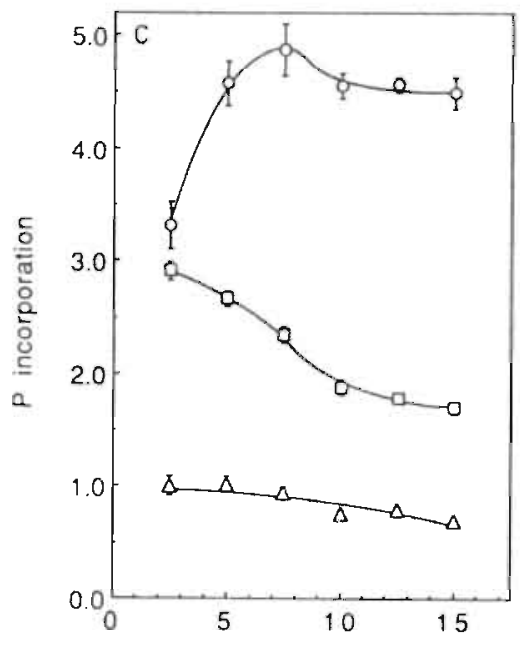

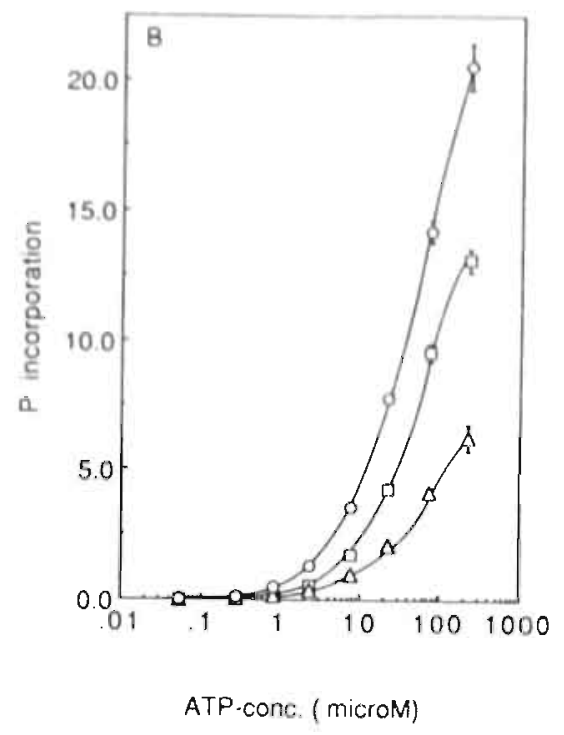

Fig. 3 : Effect of magnesium (A), ATP (B) and tissue ( $C ; \mu g /$ incubation) concentration on the incorporation of phosphate ( $\mathrm{pmol} / \mathrm{mg}$ protein) into phosphatidylinositol 4-phosphate (PIP ; squares), phosphatidylinositol 4,5bisphosphate $\left(\mathrm{PIP}_{2}\right.$; triangles) and phosphatidic acid (PA; circles). Each point is the mean of $3(A)$ or 6 (B and $C$ ) determinations ( \pm SEM). In (A) the buffer was $60 \mathrm{mM}$ Na-acetate ( $\mathrm{pH}$ 6.5) and $\mathrm{Mg}^{2+}$ was added as $\mathrm{MgCl}_{2}$ in the different concentrations. In (B) and (C) the $\mathrm{Mg}^{2+}$ concentration was $10 \mathrm{mM}$ and the specific aclivity of the Igamma-32PIATP-label was $3 \mu \mathrm{Ci}$.

protein 
The buffer system used in this experiment was $60 \mathrm{mM} \mathrm{Na}$-Acetate ( $\mathrm{pH}$ 6.5), and different concentrations of $\mathrm{Mg}^{2+}$ were added as a solution of $\mathrm{MgCl}_{2}$. With regard to the optimal ATP concentration, it appeared that the ATP concentration (7.5 $\mu \mathrm{M})$ used in our experiments did not yield the highest rates of phosphate incorporation into PIP, $\mathrm{PIP}_{2}$ and PA (Fig. 3b). ATP $(7.5 \mu \mathrm{M})$ degradation was linear for at least $20 \mathrm{sec}$ after which it levels of. Higher levels of ATP, up to at least 225 $\mu \mathrm{M}$, resulted in higher phosphate incorporation rates but the addition of cold ATP made the autoradiographic detection of the labelled products difficult because there was a lower ratio of labelled ATP to cold ATP. The influence of the amount of enzyme/membrane fraction used was investigated by varying the amount of protein in the incubation mixture (Fig. 3c). The ATP concentration in this experiment was $7.5 \mu \mathrm{M}$. It appeared that the specific incorporation of phosphate into PIP, $\mathrm{PIP}_{2}$ and PA was linear with the protein/tissue concentration over the range of 10 to $15 \mu \mathrm{g}$ per incubation. Higher protein/tissue concentrations cannot be obtained with this lysed crude synaptosomal fraction. At lower protein/tissue concentrations, PA formation decreased and PIP formation increased, although PIP ${ }_{2}$ formation was not influenced by alterations in the protein/tissue concentration.

\section{Effect of $\mathrm{pH}$ and the buffer system}

The effect of the $\mathrm{pH}$ on the incorporation of phosphate into PIP, PIP 2 and PA was tested over a $\mathrm{pH}$ range from 5.5 to 9.0 by using acetate, Tris-maleate and Tris$\mathrm{HCl}$ buffers. Fig. $4 \mathrm{a}, \mathrm{b}$ and $\mathrm{c}$ show that different buffer systems cannot be used indiscriminately in this assay. The acetate buffer used in this experiment resulted in the formation of more PIP (Fig. 4a) and PA (Fig. 4c) than both Tris buffers did. These Tris buffers were supplemented with $50 \mathrm{mM}$ Sodium ion and $10 \mathrm{mM}$ magnesium ion in order to make the three buffers comparable with regard to the possible effect of these ions. The increased ionic strength caused by the addition of $50 \mathrm{mM} \mathrm{NaCl}$ had no effect on the incorporation of phosphate into PIP and PIP ${ }_{2}$, but caused a $45 \%$ decrease in the incorporation of phosphate into PA (results not shown). A clear optimal $\mathrm{pH}$ for the formation of PIP and PA was not observed. The highest incorporation of phosphate was measured between $\mathrm{pH} 7.0$ to 8.5 for PIP and between $\mathrm{pH} 6.0$ and/or $\mathrm{pH} 7.5$ to 8.0 for PA. The optimal $\mathrm{pH}$ for $\mathrm{PIP}_{2}$ formation (Fig. $4 \mathrm{~b}$ ) in this assay system was 6.0. The values for $\mathrm{PIP}_{2}$ formation using the different buffer systems corresponded very well. Slightly more $\mathrm{PIP}_{2}$ was formed in the Tris-maleate buffer $(\mathrm{pH}$ 6.0) than in the sodium acetate buffer.

\section{Discussion}

Few investigators have validated the assays used to measure the kinase activities involved in PI metabolism. The present study examined the assay conditions for the phosphorylation of PI, PIP and DAG by kinases present in a lysed synaptosomal fraction. A short incubation time (10 sec) was used in the 
assay of these activities. It appears that the assay conditions used in earlier studies. (Jolles et al., 1981a and 1982) are not optimal for the activity of individual kinases, to incorporate phosphate into $\mathrm{PIP}, \mathrm{PIP}_{2}$ or $\mathrm{PA}$, but are a good compromise for measuring the kinase activities simultaneously.

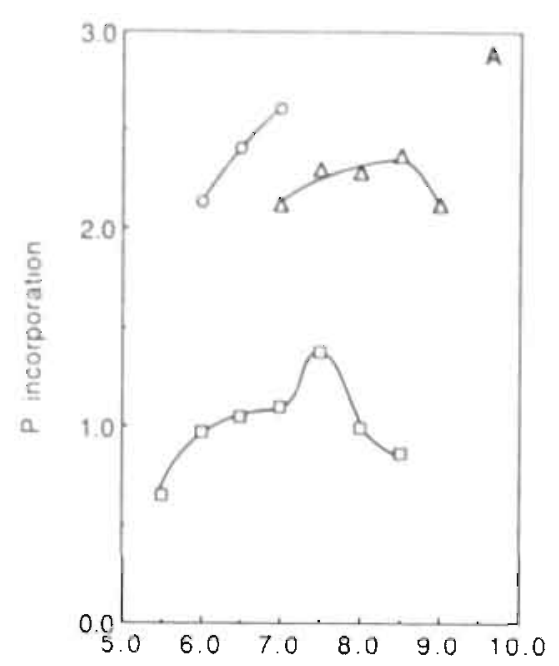

pH

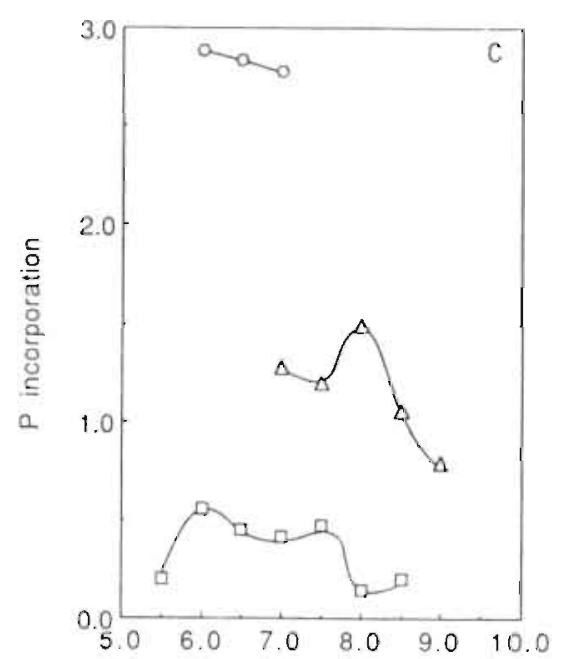

pH

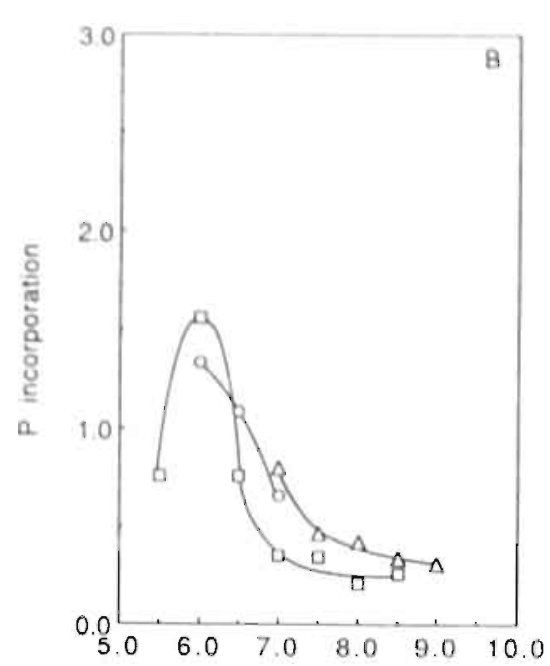

pH

Fig. 4 : Effect of $\mathrm{pH}$ and different buffer systems on the incorporation of phosphate (pmol/mg protein) into phosphatidylinositol 4-phosphate (PIP ; A), phosphatidylinusitol 4,5-bisphosphate $\left(\mathrm{PIP}_{2} ; \mathrm{B}\right)$ and phosphatidic acid (PA; C). The buffer systems used were Trismaleate (squar''s, $50 \mathrm{mM}$, $\mathrm{pH} 5.5,6.0,6.5$, $7.0,7.5,8.0,8.5)$, Tris- $\mathrm{HCl}$ (triangles, 50 $\mathrm{mM}, \mathrm{pH} 7.0,7.5,8.0,8.5,9.0$ ) and sodium acetate-magnesium acetate (circles, 50/10 $\mathrm{mM}, \mathrm{pH} 6.0,6.5,7.0$ ). All incubations contained $50 \mathrm{mM} \mathrm{Na}^{+}$and $10 \mathrm{mM} \mathrm{Mg}^{2+}$, the other conditions were standard. Each point is the mean of 9 dcterminations ( \pm SEM). 
The measurement of the three phosphate incorporation activities in one assay system is essential because these activities are present in the same membrane fraction and various agonists (eg $\mathrm{ACTH}_{1-24}$ or endorphins) have different, sometimes opposite, effects on individual phosphorylation activities (Jolles et al., $1981 \mathrm{a}, \mathrm{b})$. Unexpectedly, the duration of the preincubation markedly influenced the formation of $\mathrm{PIP}_{2}$. This and other findings from the present experiments are of interest:

Firstly, $\mathrm{PIP}_{2}$ forming activity appears to be inactivated during prolonged preincubations. At $30^{\circ} \mathrm{C}$ the incorporation of phosphate into $\mathrm{PIP}_{2}$ clearly decreased to a steady level during $5 \mathrm{~min}$ of preincubation whereas the other phosphorylating activities did not change (Fig. 1b). This effect on $\mathrm{PIP}_{2}$ formation was more pronounced at higher temperatures $\left(37^{\circ} \mathrm{C}\right.$ and $\left.44^{\circ} \mathrm{C}\right)$. At these temperatures, there was also a decrease in the incorporation of phosphate into PA (Fig. 2.b,c). These effects could be due to enzyme inactivation or substrate depletion or both. Smith and Wells (1983), who studied the incorporation of phosphate into PIP, $\mathrm{PIP}_{2}$ and PA in rat nuclear envelopes, suggested that $\mathrm{PIP}_{2}$ breakdown was probably not caused by phospholipase $A_{2}$ activity because lysophospholipids were not found. If the preincubation effect on $\mathrm{PIP}_{2}$ formation was caused by substrate breakdown, then this could only be the result of phosphomonoesterase and/or phosphodiesterase activity. However, if these enzymes were active there would be an immediate change in the activities of the other kinases at $30^{\circ} \mathrm{C}$, leading for instance to an increased PA formation. This is because phosphodiesterase activity is directly correlated with DAG-kinase activity via DAG production (Agranoff et al., 1983). The dereased incorporation of phosphate into $\mathrm{PIP}_{2}$ with increasing preincubation time is thus probably caused by inactivation of a specific enzyme. These findings concerning the effect of the preincubation time will be relevant for the design of future studies on the influence of agonists on $\mathrm{PIP}_{2}$ formation. The choice of the preincubation time depends on the problem to be studied. For instance, a $5 \mathrm{~min}$ preincubation is to be recommended if reactivation is to be studied. It is possible that the stimulatory effect of $\mathrm{ACTH}_{1-24}$ on $\mathrm{PIP}_{2}$ formation after a $5 \mathrm{~min}$ preincubation (Jolles et al., 1980,1981 a) is a reactivation phenomenon. Short preincubation times on the other hand are to be recommended when an inhibition of $\mathrm{PIP}_{2}$ formation is expected. Further studies will address this matter more specifically.

Secondly, when the amount of enzyme/membrane fraction per unit volume is low, diacylglycerol (DAG) kinase and PI kinase seem to compete for the available ATP (Fig. 3c). It also appears that the incorporation of phosphate into PIP $_{2}$ is independent of the incorporation of phosphate into PIP or PA. This may indicate that PIP kinase has a higher affinity for ATP than PI kinase and DAG kinase have. The ATP concentration in these experiments was $7.5 \mu \mathrm{M}$. A maximal incorporation of phosphate was attained with a concentration of ATP in excess of $225 \mu \mathrm{M}$. Similar findings have been made in studies on phosphoinositide kinases in rat brain homogenate (Kai et al., 1966) and chick brain homogenate (Shaikh and Palmer, 1977) in which millimolar concentrations of ATP yielded a maximal phosphate incorporation. Our findings suggest that it is not necessary to use 
higher ATP concentrations because phosphorylation is linear with time at an ATP concentration of $7.5 \mu \mathrm{M}$ and a short incubation time of $10 \mathrm{~s}$.

Thirdly, $10 \mathrm{mM} \mathrm{Mg} 2+$ appears to be the best compromise for measuring the three phosphorylation activities simultaneously at an ATP concentration of 7.5 $\mu \mathrm{M}$ (Fig. 3a), although it is not the optimal concentration for measuring individual phosphorylating activities. The relevance of the simultaneous measurement of these kinases has already been mentioned. The optimal concentrations of $\mathrm{Mg}^{2+}$ were dependent on the concentrations of the substrates in the assay system. Therefore, it is difficult to compare the $\mathrm{Mg}^{2}+$ optima found in other studies with the values obtained in this study.

Lastly, the choice of the buffer system appears to be very important when phosphorylation is measured in a system such as the lysed synaptosomal plasma membrane fraction. More phosphate was incorporated into phosphoinositides in an acetate buffer system than in a Tris-maleate buffer $(50 \mathrm{mM})$ of the same pH. Tris- $\mathrm{HCl}$ appeared to be a good buffer for measuring phosphate incorporation into PIP and PA. The difference between the Tris- $\mathrm{HCl}$ and acetate buffers with regard to PA formation was caused by the addition of $50 \mathrm{mM} \mathrm{NaCl}$ to the Tris$\mathrm{HCl}$ incubations. However, Tris- $\mathrm{HCl}$ buffer is not suited for simultaneous investigation of PIP, $\mathrm{PIP}_{2}$ and $\mathrm{PA}$ formation because its buffering capacity is very low at $\mathrm{pH}$ 6.0, the optimal $\mathrm{pH}$ value for $\mathrm{PIP}_{2}$ formation. Remarkably, only the incorporation of phosphate into PA was affected by the higher ionic strength caused by the addition of $50 \mathrm{mM} \mathrm{NaCl}$ to the Tris buffer incubations. The optimal $\mathrm{pH}$ for phosphate incorporation into $\mathrm{PIP}_{2}$ appeared to be $\mathrm{pH}$ 6.0. This contrasts with the optimum of $\mathrm{pH} 7.4$ (Shaikh and Palmer, 1977) in chicken brain and $\mathrm{pH}$ 8.0 (Smith and Wells, 1983) in rat liver nuclear envelopes. The pH optimum for PIP formation was found to be between $\mathrm{pH} 7.0$ and $\mathrm{pH} 8.5$. Jergil and Sundler (1983), who studied rat liver golgi, and Collins and Wells (1983), who studied rat liver lysosomal membranes, also found a broad $\mathrm{pH}$ optimum in the neutral range for PI-kinase. The pH curve for phosphate incorporation into PA did not show a clear pH optimum.

In conclusion, the assay conditions described in the present paper for the simultaneous measurement of PIP, PIP $_{2}$ and PA formation can be optimized for the determination of the individual enzyme activities. Compromises have to be made for the simultaneous assay in comparison with the optimal conditions for measuring the kinase activities individually. The results indicate that the method used, which is characterized by a short incubation time, hypotonic conditions and ATP as the phosphate donor, merits consideration in studies of inositol phospholipid metabolism. The method is well suited for the determination of the direct effects of pharmacological agents on the phosphorylation of individual phospholipids as has been shown in earlier studies with neuropeptides, neurotransmittors and cyclic nucleotides (Jolles et al., 1981a, 1981b, 1982). 


\section{References}

Abdel-Latif A.A. (1986) Calcium-mobilizing receptors, polyphosphoinositides, and the generation of second messengers. Pharmacol. Rev. 38, 227-272.

Agranoff B.W., Murthy P. and Seguin E.B. (1983) Thrombin-induced phosphodiesteratic cleavage of phosphatidylinositol biphosphate in human platelets. J. Biol. Chem. 258, 2076-2078.

Berridge M.J. (1987) Inositol triphosphate and diacylglycerol: Two interacting second messengers. Ann. Rev. Biochem. 56, 159-193.

Booth R.F.G. and Clark J.B. (1978) A rapid method for the preparation of relatively pure metabolically competent synaptosomes from rat brain. Biochem. J. 176, 365-370.

Collins C.A. and Wells W.W. (1983) Identification of phosphatidylinositol kinase in rat liver lysosomal membranes. I. Biol. Chem. 258, 2130-2134.

Fisher S.K., Van Rooien L.A.A. and Agranoff B.W. (1984) Renewed interest in the polyphosphoinositides. TIBS 9, 53-56.

Gray E.G. and Whittaker V.P. (1962) The isolation of nerve endings from brain: an electron microscopic study of cell fragments derived by homogenization and centrifugation. I. Anal. (Lond.) 96, 79-87.

Hawthorne J.N. and Pickard P. (1979) Phospholipids in synaptic function. J. Neurochem. 32, 5-14.

Jergil B. and Sundler R. (1983) Phosphorylation of phosphatidylinositol in rat liver golgi. J. Biol. Chem. 258, 7968-7973.

Jolles J., Van Dongen C.J., Ten Haaf J. and Gispen W.H. (1982) Polyphosphoinositide metabolism in rat brain: effects of neuropeptides, neurotransmitters and cyclic nucleotides. Peptides 3, 709-714.

Jolles J., Bär P.R. and Gispen W.H. (1981b) Modulation of brain polyphosphoinositide metabolism by ACTH and B-endorphins : structure-activity studies. Brain Res. 224, 315-326.

Jolles J., Zwiers H., Dekker A., Wirtz K.W.A. and Gispen W.H. (1981a) Corticotropin-(1-24)tetracosapeptide affects protein phosphorylation and polyphosphoinositide metabolism in rat brain. Biochem. 1. 194, 283-291.

Jolles J., Zwiers H., Van Dongen C.J., Schotman P., Wirtz K.W.A. and Gispen W.H. (1980) Modulation of brain polyphosphoinositide metabolism by ACTH-sensitive protein phosphorylation. Nature 286, 623-625.

Kai M., White G.L. and Hawthorne J.N. (1966) The phosphatidylinositol kinase of rat brain. Biochem. J. 101, 328-337.

Lowry O.H., Rosebrough N.J., Farr A.L. and Randall R.J. (1951) Protein measurement with the Folin phenol reagent. J. Biol. Chem. 193, 265-275.

Shaikh N.A. and Palmer F.B.St.C. (1977) Phosphoinositide kinases in chick brain and sciatic nerve, a developmental study. I. Neurochem. 28, 395-402.

Smith C.D. and Wells W.W. (1983) Phosphorylation of rat nuclear envelopes. J. Biol. Chem. 258, $9368-9373$.

Stubbs E.B., Jr., Kelleher J.A. and Sun C.Y. (1988) Phosphatidylinositol kinase, phosphatidylinositol-4-phosphate kinase and diacylglycerol kinase activities in rat brain subcellular fractions. Biochim. Biophys. Acta 958, 247-254. 


\title{
CHAPTER 4
}

\section{EVIDENCE FOR A NEW INOSITOL PHOSPHO- LIPID IN RAT BRAIN MITOCHONDRIA.}

\author{
J. Bothmer, M. Markerink and J. Jolles
}

Published in:

Biochemical and Biophysical Research Communications, in press. 


\begin{abstract}
Phosiphorylation of phosphatidylinositol (PI), phosphatidylinositol monophosphate (PIP) and diacylglycerol (DAG) was studied in rat brain cortex myelin, synaptosomal and mitochondrial fractions, with ATP as phosphate donor and endogenous phospholipids as substrate. All fractions had PI, PIP and DAG phosphorylating activity with their own characteristic subcellular distribution. However, in the mitochondrial fraction an unidentified lipid was phosphorylated, which had a slower Rf value than PIP 2 on TLC (Rf values of 0.167 and 0.222 , respectively). After hydrolysis of the polar head group of the lipid and separation on anion exchange columns, it appeared to be a phosphoinositide. The elution profile showed that it was not phosphatidylinositol trisphosphate $\left(\mathrm{PIP}_{3}\right)$, or a lysocompound. The available evidence suggests that the unknown inositol phospholipid in rat brain mitochondria is a phosphatidylinositol 4,5-bisphosphate isomer, although the possibility of it being a glycosyl-phosphoinositide cannot be excluded.
\end{abstract}

\title{
Introduction
}

Nervous tissue is especially rich in phosphoinositides, a class of phospholipids which are involved in important neurochemical processes related to neurotransmission (Abdel-Latif, 1986; Berridge, 1987). For instance, phosphatidylinositol 4-phosphate (PI(4)P) and phosphatidylinositol 4,5bisphosphate $\left(\mathrm{PI}(4,5) \mathrm{P}_{2}\right)$, which are synthesized by sequential phosphorylation of phosphatidylinositol (PI), are implicated in receptor-mediated signal transduction (Berridge, 1987). In this process, $\mathrm{PI}-4,5-\mathrm{P}_{2}$ is hydrolyzed by phospholipase $\mathrm{C}$ into the second messenger inositol trisphosphate and diacylglycerol (Akhtar and Abdel-Latif, 1980) followed by rapid phosphorylation of the diglyceride (DAG) into phosphatidic acid.

Phosphoinositide metabolism has become more complex with the discovery of D-3 phosphorylated inositides (Carpenter and Cantley, 1990). The inositides which are phosphorylated at the D-3 position of the inositol ring (PI(3), PI $(3,4) \mathrm{P}_{2}$ and phosphatidylinositol 3,4,5-trisphosphate $\left(\mathrm{PIP}_{3}\right)$ ) seem to be involved in cell proliferation (Martelli et al., 1991). In addition, it is suggested that these inositides are involved in the cytoskeletal rearrangment that occurs during the mitotic cell cycle and in post mitotic cells during exocytosis of protein tyrosine kinase and growth factor receptors (Auger and Cantley, 1991; Carpentex and Cantley, 1990; Cochet et al., 1991; Martelli et al., 1991; Varticovski et al., 1989). PIP 3 has been identified in several cell types (Carpenter and Cantley, 1990) and in rat brain (Vadnal and Parthasarathy, 1989).

Inositol phospholipids were thought to be primarily located in the plasma membrane (Abdel-Latif, 1986). Recent subcellular fractionation studies with rat brain, however, have shown that PI kinase. PIP kinase and DAG kinase activities are present in all subcellular fractions (Stubbs et al., 1988). The common feature in the subcellular distribution of these three lipid kinases appears to be their presence in both membrane and cytosol. 
The present paper is concerned with the phosphorylation of brain myelin, synaptosomal and mitochondrial fractions under hypotonic conditions with gamma-labeled ATP as phosphate donor and endogenous phospholipids as substrate. Our assay system has been shown to favor the phosphorylation of inositol phospholipids (Bothmer et al., 1990; Jolles et al., 1981). Our results suggest that a new phospholipid, probably an inositol phospholipid, is formed in rat brain mitochondria but not in synaptosomes.

\section{Experimental procedures}

\section{Animals and brain dissection}

Male rats (approx. $165 \mathrm{~g}$ ) of an inbred Brown-Norway strain were used. After decapitation the head was immediatly immersed in liquid nitrogen for 8 seconds. All subsequent operations were performed at $0-4^{\circ} \mathrm{C}$. The brain was taken out of the skull, and the cortex was dissected rapidly.

\section{Subcellular fractionation}

The tissue was homogenized in $0.32 \mathrm{M}$ sucrose, $1 \mathrm{mM}$ EDTA, $10 \mathrm{mM}$ Tris- $\mathrm{HCl}$, $\mathrm{pH} 7.4$, in a total volume 10 times the brain tissue volume by 10 up-and-down strokes of a Potter-Elvehjem Teflon-glass homogenizer (radial clearance 0.125 $\mathrm{mm}, 700 \mathrm{rpm}$ ). The homogenate was spun at $1000 \mathrm{~g}$ for 10 minutes. After centrifugation of the supernatant at $10,000 \mathrm{~g}$ for 10 minutes, the resulting crude mitochondrial-synaptosomal pellet was resuspended in homogenization buffer and then applied to a discontinous Ficoll-sucrose gradient as described by Booth and Clark (1978). The tubes were centrifuged at $100,000 \mathrm{~g}$ for 30 minutes. Myelin and synaptosomes banded at the first and second interphases, respectivily, with the free mitochondria being pelleted at the bottom. Membranes from each layer were carefully removed and contaminating synaptosomes appearing on the top of the mitochondrial pellet were eliminated by swirling the pellet with a small amount of $0.32 \mathrm{M}$ sucrose buffer. Myelin, synaptosomes and mitochondria were suspended in $0.9 \% \mathrm{NaCl} / 5 \mathrm{mM}$ Tris- $\mathrm{HCl}, \mathrm{pH} 7.4$, and spun down at $10,000 \mathrm{~g}$ for 10 minutes to remove the Ficoll. The pellets were subjected to osmotic lysis (the pellets were resuspended in $10 \mathrm{vol}$. aqua bidest) and stored at $-80^{\circ} \mathrm{C}$.

\section{Phosphorylation assay}

Endogenous phosphorylating activity was assayed as described earlier (Bothmer et al., 1990; Jolles et al., 1981). The lipid phosphorylation reaction was terminated by the addition of $2 \mathrm{ml}$ ice-cold chloroform: methanol: $12 \mathrm{~N} \mathrm{HCl}$ (200: 100: 0.75 , by vol., Shaikh and Palmer,1977). Protein determination was performed according to the method of Lowry et al. (1951). 

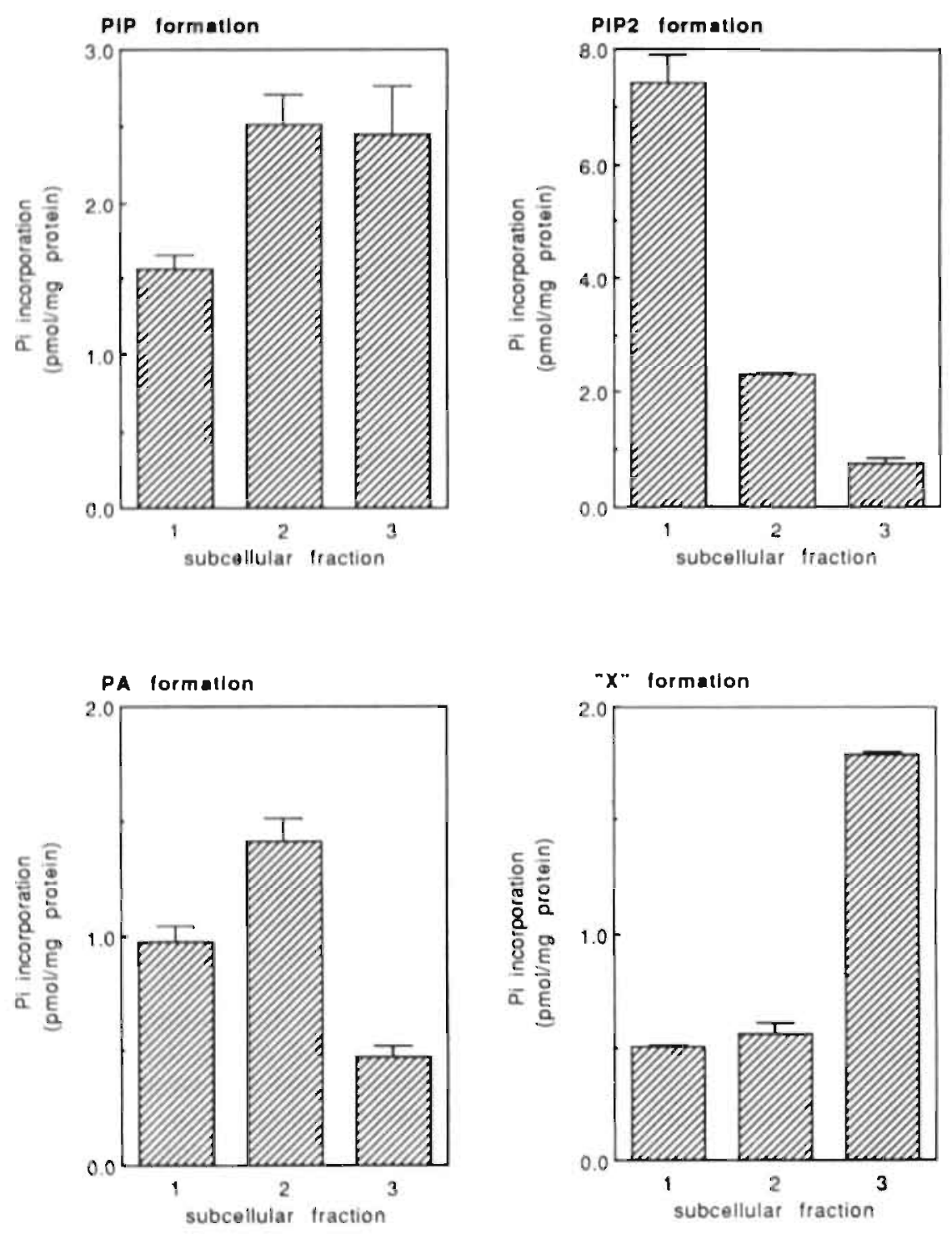

Fig.1: Distribution of phosphate incorporation (pmol phosphate/mg protein) in phosphatidylinositol monophosphate (PIP), phosphatidylinositol bisphosphate (PIP $)$. phosphatidic acid (PA) and the new phospholipid $(X)$ measured in the subcellular fractions: myelin (1), synaptosomes (2) and mitochondria (3) prepared by Ficoll discontinuous gradient centrifugation. 


\section{Lipid extraction, thin-layer chromatography and determination of radioactivity}

Lipid extraction and thin-layer chromatography were performed as described previously (Jolles et al., 1981). Two hundred microliters of water was added to the scraped silica proteins followed by $3.8 \mathrm{ml}$ scintillation fluid (Ready Safe, Beckman). Radioactivity was counted in a scintillation spectrometer (Beckman LS 1801) with an efficiency of $100 \%$.

\section{Alkaline hydrolysis of inositol phospholipids and separation of inositol phosphates}

The alkaline hydrolysis of PIP, $\mathrm{PIP}_{2}$ and band " $\mathrm{X}$ " was performed according to Vadnal and Parthasarathy (1989). The hydrolysates were buffered with $200 \mathrm{mM}$ Tricine, pH 8.0. Separation of inositol phosphates was performed according to Downes and Michell (1981) on Dowex AG1x8 anion exhange columns (formate form), with the exception of the last elution step when $1.5 \mathrm{M} \mathrm{HCOONH}_{4} / 0.1 \mathrm{M}$ HCOOH was used.

\section{Results}

The crude mitochondrial/synaptosomal pellet $\left(P_{2}\right)$ was further purified by Ficoll discontinuous gradient centrifugation resulting in myelin, synaptosomal and mitochondrial fractions. Fig. 1 shows that phosphate incorporation rates into PIP, PIP 2 and PA with endogenous lipid substrate had their own unique subcellular distribution, with the highest rate of PIP formation being in the synaptosomal and mitochondrial fractions, the highest rate of $\mathrm{PIP}_{2}$ formation being in the myelin fraction and the highest rate of PA formation being in the synaptosomal fraction.

Surprisingly, a fourth phospholipid was phosphorylated in our assay system which has a short incubation time and use endogenous lipids as substrate. This new phospholipid appeared to be enriched in rat brain mitochondria (Fig. 1). The phospholipid " $\mathrm{X}$ " had a Rf value on TLC of 0.167 ; PIP 2 , PIP and PA had Rf values of $0.222,0.300$, and 0.778 , respectively.

A time curve of phosphate incorporation, measured in the mitochondrial fraction, showed that phospholipid " $X$ " was formed within seconds and that formation reached a maximum at 60 seconds, whereafter dephosphorylation took place (Fig. 2).

To identify the new phospholipid, we subjected PIP, PIP 2 and " $X$ ", extracted and concentrated from the lipid spots on the TLC plate, to alkaline hydrolysis. The hydrolyzed polar head groups of the phospholipids were separated by anion exchange chromatography (Fig. 3). The PIP hydrolysate showed one peak eluting in the $0.2 \mathrm{M}$ and one in the $0.5 \mathrm{M}$ ammonium formate fractions, corresponding to IP, and $\mathrm{IP}_{2}$, respectively. The $\mathrm{PIP}_{2}$ hydrolysate and the "X" hydrolysate had peaks that eluted in the $0.2 \mathrm{M}, 0.5 \mathrm{M}$ and $0.8 \mathrm{M}$ ammonium formate fractions, 
corresponding to $\mathrm{IP}_{1}, \mathrm{IP}_{2}$ and normally $\mathrm{IP}_{3}$, respectively. The "X" hydrolysate peak eluting in the $0.8 \mathrm{M}$ fraction was much broader than the corresponding peak in the elution pattern of the $\mathrm{PIP}_{2}$ hydrolysate. No peak was found in the $1.5 \mathrm{M}$ ammonium formate fraction.

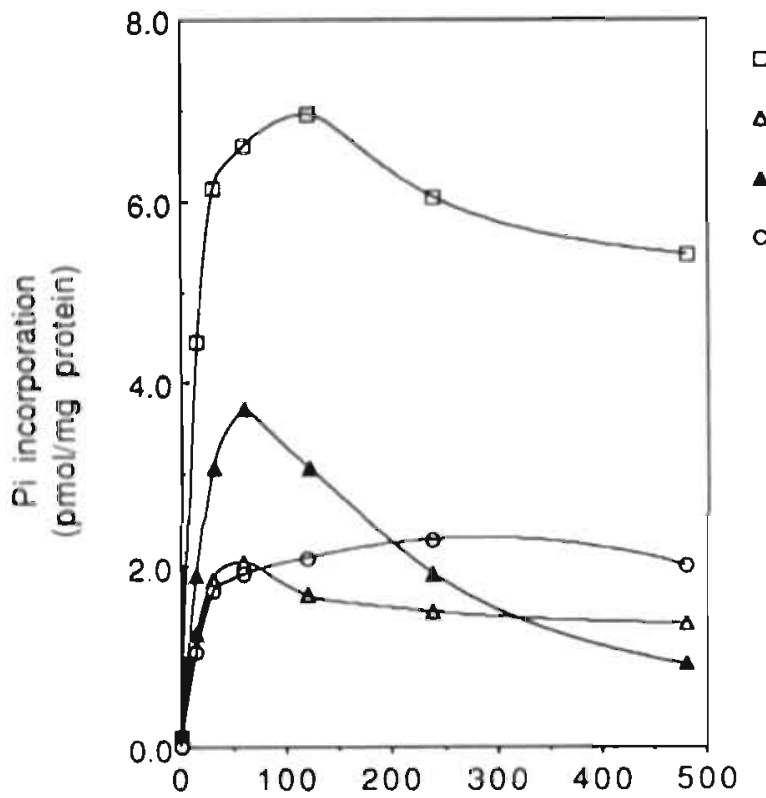

Fig.2 : Time of phosphate incorporation (pmol phosphate /mg protein) in phosphatidylinositol monophosphate (PIP), phosphatidylinositol bisphosphate $\left(\mathrm{PIP}_{2}\right)$, phosphatidic acid ( $P A)$ and the new phospholipid $(X)$ measured in

Incubation time (sec) rat brain mitochondria.

\section{Discussion}

The study presented reports the formation of a novel inositol phospholipid in vitro in a mitochondrial fraction of rat brain cortex after incubation with ATP under hypotonic conditions. Further subcellular differentiation of a crude mitochondrial-synaptosomal pellet by discontinuous Ficoll-sucrose gradient centrifugation resulted in myelin, synaptosomal and mitochondrial fractions. All fractions had PI, PIP and DAG phosphorylating activity as previously described by Stubbs et al. (1988), who also used endogenous lipid as substrate.

In the mitochondrial fraction, however, we found a fourth radiolabeled phospholipid which had a slower $R f$ value than $\mathrm{PIP}_{2}$ on TLC ( $R f$ values were 0.167 and 0.222 , respectively). Several investigators have described an inositol phospholipid that migrates slower than $\mathrm{PIP}_{2}$ does on TLC, and have identified this substance as phosphatidylinositol-trisphosphate $\left(\mathrm{PIP}_{3}\right)$ by revealing an 


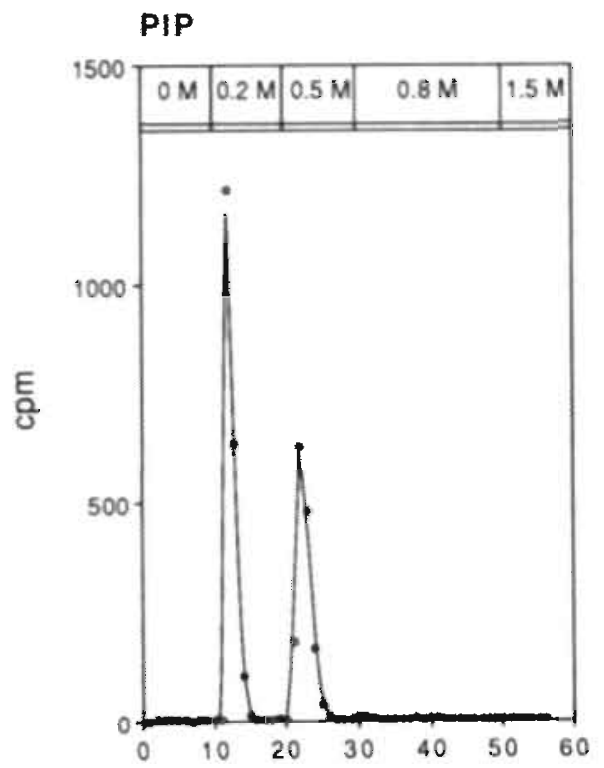

fraction number

\section{PIP 2}

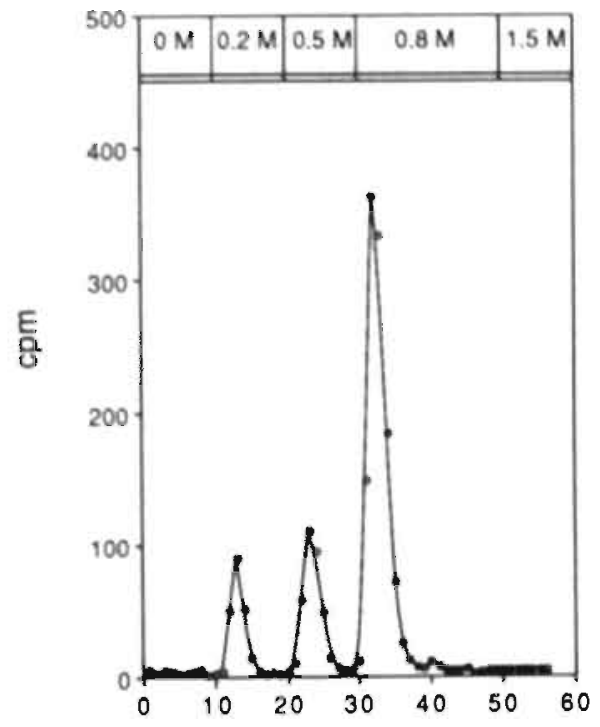

fraction number

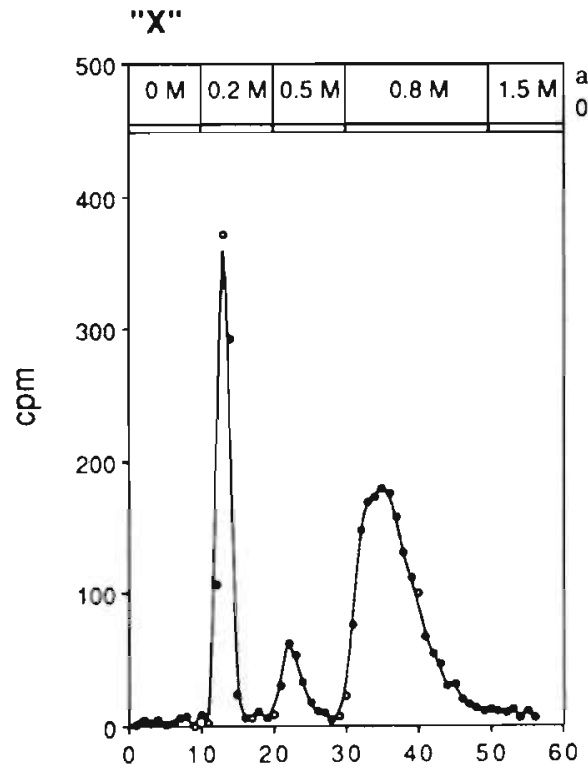

fraction number
Fig.3 : Elution profiles of alkaline hydrolysis products of phosphatidylinositol monophosphate (PIP), phosphatidylinositol bisphosphate $\left(P I P_{2}\right)$ and the new phospholipid $(X)$ on anion exchange columns. Inositol monophosphate is expected to elute in the $0.2 \mathrm{M}$ ammonium formate fractions, inositol bisphosphate in the $0.5 \mathrm{M}$ ammonium formate fractions, inositol trisphosphate in the $0.8 \mathrm{M}$ ammonium formate fractions and inositol tetrakisphosphate in the $1.5 \mathrm{M}$ ammonium formate fractions. 
inositol tetrakisphosphate after deacylation and deglyceration (Auger et al., 1989; Traynor-Kaplan et al., 1988; Vadnal and Parthasarathy, 1989). In order to identify the polar head group of the new phospholipid found in the mitochondria of rat brain cortex, we subjected this phospholipid to alkaline hydrolysis (Vadnal and Parthasarathy, 1989). Instead of an inositol tetrakisphosphate peak eluting in the $1.5 \mathrm{M}$ ammonium formate fraction on Dowex AG1 88 anion exchange columns, we found a peak at the position of inositol trisphosphate $\left(\mathrm{IP}_{3}\right)$. However, the pattern of this peak was clearly different from the inositol trisphosphate after $\mathrm{PIP}_{2}$ hydrolysis, as the peak showed partial retention on the column (tailing). This new phospholipid found in mitochondria is not $\mathrm{PIP}_{3}$ but possibly a $\mathrm{PIP}_{2}$-like substance. Gumber and Lowenstein (1986) reported non-enzymic phosphorylation of polyphosphoinositides catalyzed by bivalent metal ions resulting in pyrophosphates. Phosphatidylinositol 4-pyrophosphate had a slower Rf value than the PI $(4,5) \mathrm{P}_{2}$ standard. However, the new phospholipid described in the present study is probably not PI-pyrophosphate because the phosphorylation of mitochondrial lipids (mitochondria possibly contain higher concentrations of bivalent metal ions than synaptosomes, in analogy to the pyrophosphate hypothesis) would also reveal other pyrophosphates (Gumber and Lowenstein, 1986), which were not found in our experiments.

The new phospholipid is an inositol phospholipid, because $\mathrm{IP}_{1}$ and $\mathrm{IP}_{2}$ were also present in the mixture of products after hydrolysis of the new phospholipid. The unidentified phospholipid is not a lyso- $\mathrm{PIP}_{2}$ which also migrates slower than $\mathrm{PIP}_{2}$ (Traynor-Kaplan et al., 1988) because alkaline hydrolysis of a lyso-PIP 2 would produce a normal inositol trisphosphate. The polar head groups of $\mathrm{PI}(3,4) \mathrm{P}_{2}$ and $\mathrm{PI}(3,5) \mathrm{P}_{2}\left(\mathrm{I}(1,3,4) \mathrm{P}_{3}\right.$ and $\mathrm{I}(1,3,5) \mathrm{P}_{3}$, respectively) elute at somewhat lower salt concentrations than the polar head group of $\mathrm{PI}(4,5) \mathrm{P}_{2}\left(\mathrm{I}(1,4,5) \mathrm{P}_{2}\right)$ does (Auger et al., 1989), but on Dowex anion exchange columns these isomers cannot be separated. Another possibility could be a mitochondrion-specific glycosyl-phosphoinositide, phosphorylated in our assay system. Glycosyl-phosphoinositides are responsible for anchoring several proteins to the membrane (Low, 1989). Alkaline hydrolysis of a glycosyl-phosphoinositide could result in diacylglycerol and an inositolphosphate glycan which possibly coelutes with $\mathrm{IP}_{3}$ on Dowex anion exchange columns.

In conclusion, this study reports the in vitro formation of a new inositol phospholipid in purified rat brain mitochondria. The new inositol phospholipid was not identified as phosphatidylinositol trisphosphate. The new inositol phospholipid is probably a phosphatidylinositol 4,5 -bisphosphate isomer or a glycosyl-phosphoinositide.

\section{References}

Abdel-Latif A.A. (1986) Calcium-mobilizing receptors, polyphosphoinositides, and the generation of second messengers. Pharmacol. Rev. 38, 227-272.

Akhtar R.A., and Abdel-Latif A.A. (1980) Requirement for calcium ions in acetylcholine-stimulated 
phosphodiesteratic cleavage of phosphatidyl-myo-inositol 4,5-bisphosphate in rabbit iris smooth muscle. Biochem. J. 192, 783-791.

Auger K.R., and Cantley L.C. (1991) Novel polyphosphoinositides in cell growth and activation. Cancer Cells 3, 263-270.

Auger K.R., Serunian L.A., Soltoff S.P., Libby P., and Cantley L.C. (1989) PDGF-Dependent tyrosine phosphorylation stimulates production of novel polyphosphoinositides in intact cells. Cell 57, $167-175$.

Berridge M.J. (1987) Inositol triphosphate and diacylglycerol: two interacting second messengers. Ann. Reo. Biochem. 56, 159-193.

Booth R.F.G., and Clark J.B. (1978) A rapid method for the preparation of relatively pure metabolically competent synaptosomes. Biochem. /. 176, 365-370.

Bothmer J., Markerink M., and Jolles J. (1990) Phosphatidic acid and polyphosphoinositide formation in a broken cell preparation from rat brain: Effect of different incubation conditions. Neurochem. Int. 17, 27-33.

Carpenter C.L., and Cantley L.C. (1990) Phosphoinositide kinases. Biochemistry 29, 11147-11156.

Cochet C., Filhol O., Payrastre B., Hunter T., and Gill G.N. (1991) Interaction between the epidermal growth factor receptor and phosphoinositide kinases. I. Biol. Chem. 266, 637-644.

Downes C.P., and Michell R.H. (1981) The polyphosphoinositide phosphodiesterase of erythrocyte membranes. Biochem. J. 198, 133-140.

Gumber S.C, and Lowenstein J.M. (1986) Non-enzymic phosphorylation of polyphospho-inositides and phosphatidic acid is catalysed by bivalent metal ions. Biochem. J. 235, 617-619.

Jolles J., Zwiers., Dekker A., Wirtz K.W.A., and Gispen W.H. (1981) Corticotropin-(1-24)tetracosapeptide affects protein phosphorylation and polyphosphoinositide metabolism in rat brain. Biochem. J. 194, 283-291.

Low M.G. (1989) The glycosyl-phosphatidylinositol anchor of membrane proteins. Biochim. Biophys. Acta 988, 427-454.

Lowry O.H., Rosebrough N.J., Farr A.L., and Randall R.J. (1951) Protein measurement with the folin phenol reagent. J. Biol. Chem. 193, 265-275.

Martelli A.M., Gilmour R.S., Neri L.M., Manzoli L., Corps A.N., and Cocco L. (1991) Mitogenstimulated events in nuclei of Swiss 3T3 cells. Evidence for a direct link between changes of inositol lipids, protein kinase C requirement and the onset of DNA synthesis. FEBS Lell. 283, 243246.

Shaikh N.A., and Palmer F.B.St.C. (1977) Phosphoinositide kinases in chick brain and sciatic nerve, a developmental study. I. Neurochem. 28, 395-402.

Stubbs E.B., Kelleher J.A., and Sun G.Y. (1988) Phosphatidylinositol kinase, phosphatidylinositol4-phosphate kinase and diacylglycerol kinase activities in rat brain subcellular fractions. Biochim. Biophys. Acla 958, 247-254.

Traynor-Kaplan A.E., Harris A.L., Thompson B.L., Taylor P., and Sklar L.A. (1988) An inositol tetrakisphosphate-containing phospholipid in activated neutrophils. Nature 334, 353-356.

Vadnal R.E., and Parthasarathy R. (1989) The identification of a novel inositol lipid, phosphatidylinositol trisphosphate (P|P3), in rat cerebrum using in vivo techniques. Biochem. Biophys. Res. Comm. 163, 995-1001.

Varticovski L., Druker B., Murrison D., Cantley L., and Roberts T. (1989) The colony stimulating factor-1 receptor dssociates with and activates phusphatidylinositol 3-kinass. Nalure 342, 699702. 



\section{CHAPTER 5}

\section{BRAIN PHOSPHATIDIC ACID AND POLY. PHOSPHOINOSITIDE FORMATION IN A BROKEN CELL PREPARATION: REGIONAL DISTRIBUTION AND THE EFFECT OF AGE.}

J. Bothmer, M. Markerink and J. Jolles

Published in:

Neurochemistry International vol. 21, 223-228 (1992). 


\begin{abstract}
The effect of age on phosphate incorporation into phosphatidylinositol 4phosphate (PIP), phosphatidylinositol 4,5-bisphosphate $\left(\mathrm{PIP}_{2}\right)$ and phosphatidic acid (PA) was studied. Lysed crude synaptosomal fractions of different brain regions of 3-month-old and 32-month-old Brown Norway rats were used. The brain regions tested were the hippocampus, frontal cortex, occipital / parietal cortex, entorhinal / pyriformal cortex, striatum / septum, thalamus and hypothalamus. The individua! specific phosphorylating activities were unevenly distributed within the brain of Brown Norway rats. Strikingly, the distribution of phosphate incorporation into $\mathrm{PIP}_{2}$ was opposite from that of phosphate incorporation into PA. Phosphate incorporation into PA decreased $(-15 \%)$ with age in almost all brain regions tested, whereas phosphate incorporation into $\mathrm{PIP}_{2}$ decreased with age only in the frontal cortex $(-20 \%)$ and in the hypothalamus $(-8 \%)$. The effects of age may reflect a deterioration of phosphoinositide metabolism, with its function in signal transduction coupled to receptors via $\mathrm{G}$-proteins, in the brain regions involved. In addition, there was an age related decrease in protein content and total phospholipid phosphons content of lysed crude synaptosomal preparations of all brain regions. The high correlation between the changes in these parameters may be indicative of a decrease in the number or size of synaptosomes with age in the brain regions involved.
\end{abstract}

\title{
Introduction
}

Phosphatidylinositol and its phosphorylated congeners phosphatidylinositol 4monophosphate (PIP) and phosphatidylinositol 4,5-bisphosphate ( $\mathrm{PIP}_{2}$ ) play an important role in signal transduction. $\mathrm{PIP}_{2}$ is thought to be hydrolysed by phospholipase $C$ into the second messengers inositol trisphosphate and diacylglycerol (DAG) after receptor stimulation (Abdel-Latif, 1986; Berridge, 1987).

Recently, receptor-stimulated phosphoinositide hydrolysis was found to be increased in the hippocampus of old rats after muscarinic MI receptor stimulation (Tandon et al., 1991) and in the brain cortex of old rats after alpha-1 adrenoceptor and muscarinic M1 receptor stimulation (Nalepa et al., 1989). This increased responsivenes in senescence could be a compensatory mechanism for neuronal cell death and reduced levels of transmitters (Tandon et al., 1991). Protein phosphorylation, which is the final pathway in the action of transmitters and hormones at the neuronal level, is also affected in aging (Magnoni et al., 1991). Cyclic AMP-dependent protein kinase and protein kinase $C$ have been reported to be modified during aging in various cerebral areas. These changes may involve either enzyme activity or substrate availability (Magnoni et al., 1991).

However, hardly anything is known about possible changes in the conversions of brain phosphoinositides, other than receptor stimulated hydrolysis, with aging. This aspect of phosphoinositide metabolism is also essential for the conversion of extracellular signals into biological responses. The DAG-kinase activity in pig brain (Kanoh et al., 1983) appears to be regulated by its 
phospholipid microenvironment. PI-kinase and PIP-kinase in rat brain, which are partially attached to the plasma membrane (Stubbs et al., 1988), are probably also influenced by their phospholipid microenvironment. This phospholipid microenvironment changes during aging by way of an increased cholesterol / phospholipid ratio, which results in a more viscous membrane (Rouser et al., 1972). Changes in lipid fluidity can influence synaptic transmission processes, ligand-receptor binding properties, and the dynamics of membrane-bound enzymatic processes such as protein phosphorylation (Hershkowitz et al., 1982). A previous study on phosphoinositide metabolism and aging (Van Dongen et al,, 1983) showed a decrease in $\mathrm{PP}_{2}$ formation in synaptic plasma membranes of the hippocampus and whole brain with advancing age. Furthermore, the concentrations of free inositol and total phospholipid inositol decrease with age in humans (Stokes et al., 1983). These findings support the idea that the metabolism of phosphoinositides changes during aging. Such changes may affect the receptor-stimulated hydrolysis of polyphosphoinositides (Downes, 1982), and may also affect mitogenic signalling when phosphatidylinositol 3-kinase is involved (Carpenter and Cantley, 1991; Downes and MacPhee, 1990). A complicating factor in studies of the central nervous system is the heterogeneous structure of the brain. Little is known about the regional distribution of enzymes involved in phosphoinositide metabolism.

The present study was designed to provide more information on the effect of age on the incorporation of phosphate into PIP, $\mathrm{PIP}_{2}$ and PA in membrane-cytosol preparations. These were prepared from seven discrete brain regions of young adult (3-month-old) and old (32-month-old) Brown Norway rats. This preparation was used to measure age related changes in the relationship between enzyme activity and endogeneous substrate availability and not just enzyme activity or substrate concentrations. The three phosphorylation activities have been characterized previously (Bothmer et al., 1990a). Furthermore, studies with this method have shown phosphate incorporation into $\mathrm{PIP}_{2}$ and PA to be sensitive to adrenocorticotropin $\left(\mathrm{ACTH}_{1-24}\right)$, and phosphate incorporation into PIP, PIP 2 and PA to be sensitive to $\mathrm{Ca}^{2+}$ and dependent on $\mathrm{Mg}^{2+}$ (Jolles et al., 1981b). Besides $\mathrm{ACTH}_{1-24}, \mathrm{c}-\mathrm{AMP}$ and endorphins have also been shown to affect phosphoinositide phosphorylation, albeit in a different way (Jolles et al., 1981a; Jolles et al., 1982).

\section{Experimental procedures}

\section{Animals and brain dissection}

Male rats $(3$ months and 32 months old, 4 animals per group in each of 2 experiments) of an inbred Brown Norway strain were used. After decapitation, the head was immediatly immersed in liquid nitrogen for $8 \mathrm{sec}$ (Jolles et al., $1981 \mathrm{~b})$ to decrease brain temperature quickly. All subsequent operations were performed at $0-4^{\circ} \mathrm{C}$. Brains were taken out of the skull rapidly and dissected 
according to Gispen et al. (1972) with slight modifications. Briefly, the cerebellum was excised by cutting the brachium pontis. The medulla/pons was removed by a cut just rostral to the pons. The forebrain was cut transversally through the optic chiasm. The frontal part was dissected into the striatum, septum and frontal cortex. The tissue ventral to the septum, anterior commisure and rhinal fissure was removed. The cerebral cortex, hippocampus, entorhinal cortex and amyguala with overlying pyriformal cortex were removed from the caudal part and separated from each other. The entorhinal cortex and pyriformal cortex (with amygdala) were pooled. The remaining part was dissected in to the thalamus, hypothalamus, septum, striatum and midbrain, which was removed. Frontal and caudal parts of the septum and striatum were pooled.

\section{Subcellular fractionation}

Tissue from individual rats was homogenized in homogenization medium containing $0.32 \mathrm{M}$ sucrose, $1 \mathrm{mM}$ EDTA, $10 \mathrm{mM}$ Tris- $\mathrm{HCl}$ ( $\mathrm{pH} \mathrm{7.4)}$ as described before (Bothmer et al., 1990a). The method of Whittaker (1969) was used to prepare a crude mitochondrial-synaptosomal pellet $\left(\mathrm{I}_{2}\right)$ which was subjected to osmotic lysis: the pellet was resuspended in $10 \mathrm{vol}$ aqua bidest. This suspension was centrifuged for $20 \mathrm{~min}$ at $10,000 \times \mathrm{g}$ to remove unlysed structures. The supernatant was taken as the enzyme fraction referred to as the membranecytosol preparation which contains PI, PIP, and DAG kinase activity, but also endogeneous lipid substrates.

\section{Phosphorylation assay}

Endogeneous phosphorylating activity was assayed as described before (Bothmer et al., 1990a; Jolles et al., 1981b). Briefly, a routine incubation was performed under the folowing conditions: $7.5 \mu \mathrm{M}$ ATP, 2-3 $\mu \mathrm{Ci}$ [gamma-32P]ATP (approx. $3000 \mathrm{Ci} / \mathrm{mmol}$, Amersham, U.K.), $50 \mathrm{mM} \mathrm{Na-acetate,} 10 \mathrm{mM} \mathrm{Mg-acetate,} \mathrm{pH} \mathrm{6.5,}$ and $15 \mu \mathrm{l}$ enzyme fraction $\left(10 \mu \mathrm{g}\right.$ protein) in a final vol of $25 \mu \mathrm{l}$ at $30^{\circ} \mathrm{C}$. After 10 sec the lipid phosphorylation reaction was terminated by the addition of $2 \mathrm{ml}$ icecold chloroform : methanol : $12 \mathrm{~N} \mathrm{HCl}$ (200: $100: 075$, by vol.). Lipid extraction, thin layer chromatography and determination of radioactivity were performed as described previously (Bothmer et al., 1990a; Jolles et al., 1981b). Protein content was determined according to the method of Lowry et al. (1951).

\section{Total phospholipid phosphorus determination}

Phospholipids were extracted according to the method of Folch et al. (1956). Briefly, $2 \mathrm{ml}$ chloroform : methanol $(2: 1(\mathrm{v} / \mathrm{v}))$ and $310 \mu \mathrm{l}$ water were added to $90 \mu \mathrm{l}$ membrane-cytosol preparation. The lower phase of the resulting biphasic system was removed and stored. The upper phase was washed again with chloroform : methanol (2:1 $(\mathrm{v} / \mathrm{v}))$. Both lower phases were pooled and dried under a stream of nitrogen at $30^{\circ} \mathrm{C}$. Perchloric acid ( 350 ill) was added to the dried 
lower phase to digest the phospholipids (Duck-Chong, 1978). The tubes were covered with glass marbles to minimize evaporation during 90 min heating at $180^{\circ} \mathrm{C}$. After brief cooling, total phospholipid phosphorus was determined according to Fiske and Subbarow (1925).

\section{Results}

The regional distribution of basal specific phosphate incorporation into PIP, $\mathrm{PIP}_{2}$ and $\mathrm{PA}$ within the rat brain was uneven (Fig. 1). Strikingly, the distribution of the three individual phosphorylating activities was different. Phosphate incorporation into PIP was highest, in terms of specific activity, in the thalamus, hypothalamus and striatum / septum. The regions with the lowest rates of phosphate incorporation into $\mathrm{PIP}_{2}$ (hippocampus, entorhinal / pyriformal cortex, thalamus and hypothalamus) appeared to be the regions with the highest rates of phosphate incorporation into PA. The correlation between the distribution of these two activities was -0.56 (Pearson correlation coefficient), which is statistically significant $(\mathrm{p}<0.001)$.

With age, phosphate incorporation into PA tended to decrease in all brain regions tested (Fig. 1). The decrease in PA formation in the hippocampus $(-17 \%)$, frontal cortex $(-11 \%)$, striatum / septum $(-15 \%)$, thalamus $(-14 \%)$ and hypothalamus $(-15 \%)$ reached statistical significance $(p<0.05$, Students t-test). A decrease in phosphate incorporation into $\mathrm{PIP}_{2}$ with age was found in the frontal cortex $(-20 \%, \mathrm{p}<0.05)$ and hypothalamus $(-8 \%, \mathrm{p}<0.05)$. Phosphate incorporation into PIP was not affected by age in any of the seven brain regions tested.

Table 1 shows the effect of age on the protein content and the phospholipid phosphorus content of the membrane cytosol preparations of different brain regions. Protein content per mg tissue (wet weight) tended to decrease with age in all brain regions tested. The differences in protein content of the membranecytosol preparations of the entorhinal / pyriformal cortex, occipital / parietal cortex, thalamus and hypothalamus reached statistical significance.

The effect of age on phospholipid content of the membrane-cytosol preparation was determined by measuring total phospholipid phosphorus in these fractions. The total phospholipid phosphorus content (per mg tissue used to make the membrane-cytosol preparations) also showed an overall tendency to decrease with age. The differences in total phospholipid phosphorus of the membrane-cytosol preparation of the entorhinal / pyriformal cortex, striatum / septum and hypothalamus reached statistical significance. The protein content and the phospholipid phosphorus content of the membrane-cytosol preparation of the hippocampus, frontal cortex, entorhinal / pyriformal cortex, and hypothalamus were highly correlated. There was no correlation between the protein content and phospholipid phosphorus content of the membrane-cytosol preparation of the occipital / parietal cortex, striatum / septum and thalamus. 


\section{CHAPTER 5}
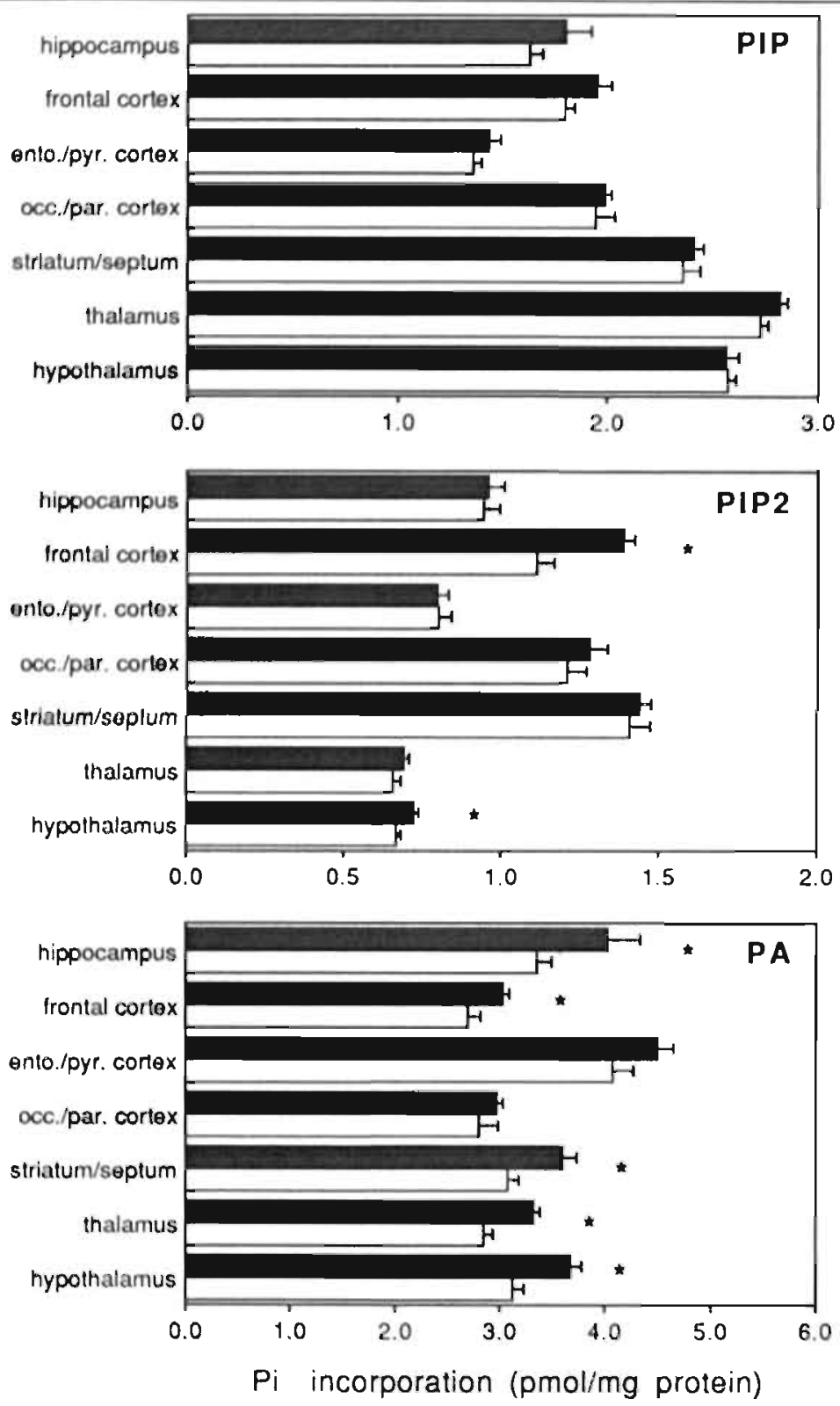

Fis 1: Effect of age on the incorporation of phosphate (pmol/mg protein) into phosphatidylinositol 4-phosphate (PIP), phosphatidylinositol 4,5-bisphosphate $\left(\mathrm{PIP}_{2}\right.$ ) and phosphatidic acid (PA) in membrane cytosol preparations of seven brain regions. Threemonth-old (black bars) Brown Norway rats were compared with 32 -month-old (white bars) rats. Values shown are means $( \pm$ SEM) from eight rats per group. Statistical analysis was performed according to Students t test (two tailed). " : p<0.05 
Table 1: Protein content and total phospholipid phosphorus content of the membrane cytosol preparations of different brain regions from Brown Norway rats of different ages. Values shown are means ( \pm SEM) from four rats per group. Statistical analysis of the age differences was performed according to Students t test (two tailed).

\begin{tabular}{|c|c|c|c|c|c|c|c|}
\hline \multirow[t]{2}{*}{ Brain region } & \multicolumn{3}{|c|}{$\begin{array}{l}\text { Total protein } \\
(\mu \mathrm{g} / \mathrm{mg} \text { wet weight } \pm \text { SEM) }\end{array}$} & \multicolumn{3}{|c|}{$\begin{array}{l}\text { Total phospholipid phosphorus } \\
\text { (ng/mg wet weight } \pm S E M \text { ) }\end{array}$} & \multirow{2}{*}{$\begin{array}{l}\text { Correlation } \\
\text { (r) } 1\end{array}$} \\
\hline & 3 month & 32 month & diff. $(\%)$ & 3 month & 32 month & diff. $(\%)$ & \\
\hline Hippocampus & $1.13 \pm 0.05$ & $1.06 \pm 0.03$ & -6 & $8.47 \pm 0.42$ & $8.10 \pm 0.26$ & -4 & $0.860^{*}$ \\
\hline Frontal cortex & $1.30 \pm 0.05$ & $1.23 \pm 0.07$ & -6 & $9.96 \pm 0.38$ & $9.19 \pm 0.66$ & -8 & $0.941 *$ \\
\hline Entorhinal/pyriformal cortex & $1.67 \pm 0.04$ & $1.45 \pm 0.06$ & -13 & $11.23 \pm 0.54$ & $9.31 \pm 0.44$ & $-17 \cdot$ & $0.894 *$ \\
\hline Occipital/parietal cortex & $1.24 \pm 0.04$ & $1.08 \pm 0.03$ & $-13^{*}$ & $9.86 \pm 0.71$ & $8.90 \pm 0.55$ & -10 & 0.575 \\
\hline Striatum/septum & $1.00 \pm 0.06$ & $0.85 \pm 0.05$ & -15 & $9.88 \pm 0.50$ & $8.04 \pm 0.10$ & $-19 \cdot$ & 0.659 \\
\hline Thalamus & $1.06 \pm 0.01$ & $0.94 \pm 0.02$ & $-11 * *$ & $10.73 \pm 0.26$ & $9.60 \pm 0.34$ & -12 & 0.748 \\
\hline Hypothalamus & $0.97 \pm 0.03$ & $0.85 \pm 0.04$ & $-12 *$ & $10.82 \pm 0.40$ & $9.28 \pm 0.27$ & $-14^{*}$ & $0.920 * *$ \\
\hline
\end{tabular}

$\because \mathrm{p}<0.05$

* : $p<0.005$

1 : Pearson correlation ( $r$ ) between protein and phospholipid phosphorus content. 


\section{Discussion}

This study describes the effect of age on phosphate incorporation into phosphatidylinositol 4-phosphate (PIP), phosphatidylinositol 4,5-bisphosphate $\left(\mathrm{PIP}_{2}\right)$ and phosphatidic acid (PA). A membrane-cytosol preparation of different brain regions from 3-month-old and 32-month-old Brown Norway rats was used as a source of enzyme and of endogeneous phospholipid substrate.

Basal phosphate incorporation in to PIP, $\mathrm{PIP}_{2}$ and PA, was unevenly distributed in the rat brain, and the distribution appeared to be different for each phosphorylation product. The opposite distribution within the brain of $\mathrm{PIP}_{2}$ and PA formation could reflect a regional distribution of basal phospholipase C (PLC) activity because PIP $_{2}$-specific PLC activity and DAG kinase activity are directly correlated (Agranoff et al., 1983). Thus, brain regions with high DAG kinase activities would be expected to have high basal PLC activities. However, studies on the regional distribution of agonist stimulated PLC activities (Fisher and Bartus, 1985; Gonzales and Crews, 1985) do not confirm this notion.

With respect to the effects of age on the basal rates of phosphate incorporation into PIP, $\mathrm{PIP}_{2}$ and PA, our results show that phosphate incorporation into PA was decreased in the membrane-cytosol preparation of the hippocampus, frontal cortex, striatum / septum, thalamus and hypothalamus of aged rats. Phosphate incorporation into $\mathrm{PIP}_{2}$ was decreased in the membrane-cytosol preparation of the frontal cortex and hypothalamus of aged rats, and phosphate incorporation into PIP was not affected. In a previous study on the rates of phosphate incorporation into endogeneous $\mathrm{PIP}, \mathrm{PIP}_{2}$ and $\mathrm{PA}$ in a crude synaptosomal fraction ( $\mathrm{P}_{2}$-fraction) of whole rat brain cortex of young ( 7 months) and old (27 months) Wistar rats, we also found a decrease in PA formation with age (Bothmer et al., 1990b). Strosznajder and Samochocki (1991) showed a decreased $\mathrm{Ca}^{2+-i n d e p e n d e n t ~ a r a c h i d o n i c ~ a c i d ~(A A) ~ r e l e a s e ~ i n ~ s y n a p t o n e u r o s o m e s ~ f r o m ~}$ brain cortex of 27-month-old rats compared with 4-month-old rats. This lower $\Lambda \mathrm{A}$ release was due to a modified substrate utilization which seems to be connected with lower phosphorylation of DAG to PA and higher degradation of DAG. This conclusion of Strosznajder and Samochocki (1991) is in agreement with our findings presented here.

Previous studies on phosphoinositide metabolism (Van Dongen et al., 1983) in synaptic plasma membranes, revealed a decrease in PIP ${ }_{2}$ formation in the hippocampus and whole brain of the rat with age, but no age-related changes in PIP and PA formation. In the study presented here, we did find changes in PA formation but (almost) not in $\mathrm{PIP}_{2}$ formation. These differences are probably caused by the fact that Van Dongen et al. used a synaptic plasma membrane preparation without cytosolic factors. Such a fraction contains little or no DAGkinase activity because this enzyme is predominantly located in the cytosol (Lundberg and Jergil, 1988; Stubbs et al., 1988). PIP-kinase is not as tightly associated with the membrane as PI-kinase is, as it can be solubilized with low salt concentrations, whereas PI-kinase solubilization requires detergents (Saltiel et al., 1987). With age, PIP-kinase may be translocated from the particulate pool to 
the soluble pool. This could be caused by the increased viscosity of the membrane in aged subjects (Rouser et al., 1972). PI-kinase, which is more tightly attached to the membrane, may not be affected by this change in the microenvironment. In. our study, we did not differentiate between synaptosome membrane and synaptosome cytoplasm, so a possible change in the distribution pattern between these two pools could not be observed.

We also found that the protein content of membrane-cytosol preparations from various brain regions decreased with age. The decrease in protein content appeared to be a result of a lower number or size of nerve endings because the agerelated changes in total protein content correlated highly with the age-related changes in total phospholipid content in the membrane cytosol preparation of hippocampus, frontal cortex, entorhinal / pyriformal cortex and hypothalamus. Calderini et al. (1983) also found a parallel decrease in protein and phospholipid content in synaptic plasma membrane (whole brain) of aged rats, a result which is consistent with our data. Decreased numbers of synapses have been shown in the dentate gyrus of human brain (Bertoni-Freddari et al., 1990) with age and Alzheimer's disease, and in frontal cortex biopsies from subjects with Alzheimer's disease (DeKoski and Scheff, 1990). Both studies also showed a primarily compensatory mechanism of increased synapse size with decreasing synapse number. The functional implications of these morphological processes were shown in the studies of DeKosky and Scheff (1990) and of Geinisman et al.(1986). Lower mental status scores appear to be associated with greater loss of synapses (DeKoski and Scheff, 1990) and old, spatial memory-impaired rats have a decreased number of perforated axospinous synapses as compared to old, memory-intact rats (Geinisman et al., 1986). Both old groups of rats had a diminished number of non-perforated axospinous synapses as compared to young rats.

In conclusion, it can be said that basal specific incorporation of phosphate into PIP, PIP 2 and PA, measured in a lysed synaptosomal fraction, also called a membrane-cytosol preparation, is unevenly distributed within the rat brain. Therefore, future studies on basal phosphate incorporation into PIP, PIP 2 and PA, but probably also other biochemical studies, should take these regional differences into account. Furthermore, age seems to decrease endogenous PA formation in whole brain and $\mathrm{PIP}_{2}$ formation in the frontal cortex and hypothalamus. The effects of age may reflect a deterioration of phosphoinositide metabolism in the brain regions involved. Therefore, the function of polyphosphoinositide metabolism in, for example, signal transduction coupled to receptors via $G$-proteins could be affected by aging. This study also supports data of some morphological studies showing a decline in the number of syraptic nerve endings in brain with age.

\section{References}

Abdel-Latif, A.A. (1986) Calcium-mobilizing receptors, poly-phosphoinositides, and the 
generation of second messengers. Pharmacol. Rev. 38, 227-272.

Agranoff, B.W., Murthy, P., and Seguin, E.B. (1983) Thrombin-induced phosphodiesteratic cleavage of phosphatidylinositol bisphosphate in human platelets. J. Biol. Chern. 258, 2076-2078.

Berridge, M.J. (1987) Inositol trisphosphate and diacylglycerol: two interacting second messengers. Ann. Rev. Biochem. 56, 159-193.

Bertoni-Freddari, C., Fattoretti, P., Casoli, T., Meier-Ruge, W., and Ulrich, J. (1990) Morphological adaptive response of the synaptic junctional zones in the human dentate gyrus during aging and Alzheimer's disease. Brain Res. 517, 69-75.

Bothmer, J., Markerink, M., and Jolles, J. (1990a) Phosphatidic acid and polyphosphoinositide formation in a broken cell preparation from rat brain: effects of different incubation conditions. Neurochem. Int. 17, 27-33.

Bothmer, J., Markerink, M., Jolles, J. (1990b) Age related changes in the interconversion of inositol phospholipids in the rat brain cortex. In: From Gene to Man (Van Bezooijen, C.F.A., Ravid, R., Verhofstad, A.A.J., Eds) pp. 186-189. J.H. Pasmans publishers, The Hague, The Netherlands.

Calderini, G., Bonetti, A.C., Battistella, A., Crews, F.T., and Toffano, G. (1983) Biochemical changes of rat brain membranes with aging. Neurochem. Res, 8, 483-492.

Carpenter, C.L. and Cantley, L.C. (1991) Phosphoinositide kinases. Biochemistry 29, 11147-11156.

DeKosky, S.T., and Scheff, S.W. (1990) Synapse loss in frontal cortex biopsies in Alzheimer's disease : Correlation with cognitive severity. Ann. Neurol. 27, 457-464.

Downes, C.P. (1982) Receptor stimulated inositol phospholipid metabolism in the central nervous system. Cell Calcium 3, 413-428.

Downes, C.P., and MacPhee, C.H. (1990) myo-Inositol metabolites as cellular signals. Eur. J. Biochem. 1931, 1-18.

Duck-Chong, C.G. (1978) A rapid sensitive method for determining phospholpid phosphorus involving digestion with magnesium nitrate. Lipids 14, 492-497.

Fisher, S.K., and Barlus, R.T. (1985) Regional differences in the coupling of muscarinic receptors to inositol phospholipid hydrolysis in guinea pig brain. J. Neurochem. 45, 1085-1095.

Fiske, C.H., and Subbarow, Y. (1925) The colorimetric determination of phosphorus. J. Biol. Chem. 66, 375-400.

Folch, J., Lees, M., and Stanley, G.H.S. (1957) A simple method for the isolation and purification of total lipids from animal tissues. /. Biol. Chem. 226, 497-509.

Gispen, W.H., Schotman, P., and de Kloet, E.R. (1972) Brain RNA and hypophysectomy; a topographical study. Neuroendocrinology 9, 285-296.

Geinisman, Y., Tolledo-Morrell de, L., and Morrell, F. (1986) Aged rats need a preserved cumplement of perforated axospinous synapses per hippocampal neuron to maintain good spatial memory. Brain Res. 398, 266-275.

Gonzales, R.A., and Crews, F.T. (1985) Cholinergic- and adrenergic-stimulated inositide hydrolysis in brain : interaction, regional distribution, and coupling mechanism. J. Neurochem. 45, 1076-1084

Hershkowitz, M., Heron, D., Samuel, D., and Shinitzky, M. (1982) The modulation of protein phosphorylation and receptor binding in synaptic membranes by changes in lipid fluidity : Implications for ageing. Prog. Brain Res. 56, 419-434.

Jolles, J., Bär, P.R., and Gispen, W.H. (1981a) Modulation of brain polyphosphoinositide metabolism by $\mathrm{ACTH}$ and B-endorphin: structure activity studies. Brain Res. 224, 315-326.

Jolles, J., Zwiers, H., Dekker, A., Wirtz, K.W.A., and Gispen, W.H. (1981b) Corticotropin-(1-24)tetracosapeptide affects protein phosphorylation and polyphosphoinositide metabolism in rat brain. Biochem. 1. 194, 283-291.

Jolles, J., Dongen, C.J. van, Haaf, J.H. ten, and Gispen, W.H. (1982) Polyphosphoinositide metabolism in rat brain: effects of neuropeptides, neurotransmittors and cyclic nucleotides. Peptides 3, 709-714.

Kanoh, H., Kondoh, H., and Ono, T. (1983) Diacylglycerol kinase from pig brain: Purification and phospholipid dependencies. J. Biol. Chem. 258, 1767-1774.

Lowry, O.H., Rosebrough, N.J., Farr, A.L., and Randall, R.J. (1951) Protein measurement with the folin phenol reagent. J. Biol. Cham. 193, 265-275. 
Lundberg, G.A., and Jergil, B. (1988) Generation of phosphatidylinositol 4,5-bisphosphate proceeds through an intracellular route in rat hepatocytes. FEBS Lett. 240, 171-176.

Magnoni, M.S., Govoni, S., Battaini, F., and Trabucchi, M. (1991) The aging brain: Protein phosphorylation as a target of changes in neuronal function. Life Sci. 48, 373-385.

Nalepa, I., Pintor, A., Fortuna, S., Vetulani, J., and Michalek, H. (1989) Increased responsiveness of the cerebral cortical phosphatidylinositol system to noradrenaline and carbachol in senescent rats. Neurosc. Lett. 107, 195-199.

Rouser, G., Kitchensky, G., Yamamoto, A., Baxter, C.F. (1972) Lipids in the nervous system of different species as a function of age : Brain, spinal cord peripheral nerves, purified whole cell preparations and subcellular particulates: Regulatory mechanisms and membrane structure. Adv. Lipid Res. 10, 261-360.

Saltiel, A.R., Fox, J.A., Sherline, P., Sahyoun, N., and Cuatrecasas, P. (1987) Purification of phosphatidylinositol kinase from bovine brain myelin. Biochem. 1. 241, 759-763.

Stokes, C.E., Gillon, K.R.W., and Hawthorne, J.N. (1983) Free and total lipid myo-inositol concentrations decrease with age in human brain. Biochim. Biophys. Acta 753, 136-138.

Strosznajder, J., and Samochocki, M. (1991) Aging modified arachidonic acid release from the prelabelled lipid of brain cortex synaptoneurosomes. J. Neurochen. 57 (suppl.), S25.

Stubbs, E.B., Kelleher, J.A., and Sun, G.Y. (1988) Phosphatidylinositol kinase, phosphatidylinositol-4-phosphate kinase and diacylglycerol kinase activities in rat brain subcellular fractions. Biochim. Biophys. Acta 958, 247-254.

Tandon, P., Mundy, W.R., Ali, S.F., Nanry, K., Rogers, B.C., and Tilson, H.A. (1991) Age-dependent changes in receptor-stimulated phosphoinositide turnover in the rat hippocampus. Pharmacol. Biochem. Behav. 38, 861-867.

Van Dongen, C.J., Hershkowitz, M., Zwiers, H., De Laat, S., and Gispen, W.H. (1983) Lipid fluidity and phosphoinositide metabolism in brain membranes of aged rats : Effects of ACTH(1-24). In: Aging of the brain (Gispen, W.H., and Traber, J., eds.) pp.101-104. Elsevier Science Publishers, Amsterdam, The Netherlands.

Whittaker, V.P. (1969) The synaptosome. In Handbook of Neurochemistry (Laitha A., ed.) vol 2, 327-364. Plenum N.Y. 



\section{CHAPTER 6}

\section{THE EFFECT OF AGE ON PHOSPHOINOSITIDE KINASE, PHOSPHOINOSITIDE PHOSPHATE KINASE AND DIACYLGLYCEROL KINASE IN RAT BRAIN CORTEX.}

J. Bothmer, M. Mommers, M. Markerink and J. Jolles 


\begin{abstract}
The effect of age on PI kinase, PIP kinase and DAG kinase activities in the cerebral cortex was studied in 8-month-old, 14-month-old and 26-month-old Brown Norway rats. Three protein preparations were used: a cytosolic preparation (A), a saltsolubilized preparation (loosely membrane-bound proteins, B) and a Triton X-100solubilized preparation (integral or tightly membrane-bound proteins, C). PI kinase activity was predominantly located in the tight membrane-bound fraction, DAG kinase activity in the cytosolic and loosely membrane-bound fraction, and PIP kinase activity was present in all three protein preparations. The effects of age were limited to a small increase in PI kinase activity in fraction $\mathrm{C}$ in 14 -month-old and 26 -month-old rats compared to 8-month-old rats, and a $10 \%$ decrease in PIP kinase activity in fraction A in 14-month-old and 26-month-old rats compared to 8-month-old rats. DAG kinase activity showed no age-related changes. In conclusion, one should take care in comparing rat aging with human aging as PI kinase activity shows an age-related decline in human brain cortex. Furthermore, previously reported decreases in PA formation rates in rat brain are probably not due to changes in DAG kinase itself but to changes in DAG availability.
\end{abstract}

\title{
Introduction
}

Normal aging is associated with numerous functional and morphological alterations of the central nervous system (CNS) in animals as well as humans. Phosphoinositides, which are present in relatively high concentrations in the CNS, play an important role in receptor-mediated signal transduction, resulting in the release of the second messengers inositol trisphosphate $\left(\mathrm{IP}_{3}\right)$ and diacylglycerol (DAG) (Berridge, 1984). In the CNS, various receptors are coupled, via G-proteins, to this phosphoinositide hydrolyzing signal transduction system (Fisher et al., 1992) in which $\mathrm{IP}_{3}$ releases calcium from intracellular stores (Streb et al., 1983). This results in the activation of $\mathrm{Ca}^{2+} / \mathrm{Calmodulin-dependent} \mathrm{protein}$ kinase (Berridge, 1984), whereas DAG activates protein kinase C directly (Nishizuka, 1984). These protein kinases regulate many other enzymes, ionchannels etc. by phosphorylation ultimately resulting in a biological response (Magnoni et al., 1991). As mentioned by Li et al. (1991), a disruption of the phosphoinositide second messenger system with aging could be related to the impairment of neurological responsiveness and behavioral deficits observed with aging.

The membrane-associated processes involved in receptor-stimulated inositol phosphate release (Burnett et al., 1990; Mundy et al., 1991; Nalepa et al., 1989; Pietrzak et al., 1990; Surichamorn et al., 1989; Tandon et al., 1991) but also the effectiveness of the inositol phosphate response, such as $\mathbb{P}_{3}$ receptor density and affinity (Li et al., 1991), the maintanance of calcium homeostasis (Barritt, 1987; Martinez-Serrano et al., 1992) and protein kinase activity (Magnoni et al., 1991; Battaini et al, 1990), have been studied as a function of age. However, the production of the $\mathrm{IP}_{3}$ precursor phosphatidylinositol bisphosphate $\left(\mathrm{PIP}_{2}\right)$ by 
phosphatidylinositol (PI) kinase and phosphatidylinositol phosphate (PIP) kinase, and the phosphorylation of DAG into phosphatidic acid (PA) have not received this attention in aging research. The relevance of a study of the phosphoinositide phosphorylation system is strengthened by the notion that changes in the activity of these enzymes could also explain changes in the receptor-stimulated inositol phosphate response. Interestingly, the function of PI kinase has received an additional dimension with the discovery of novel phosphoinositides which are phosphorylated at the D-3 position of the inositol ring. These substances are implicated in growth, mitogenic signalling and cytoskeletal turn-over processes (Carpenter and Cantley, 1990). PI, PIP and DAG kinases are partially membranebound (Stubbs et al., 1988), and can therefore be influenced by the changes in membrane fluidity associated with aging (Hershkowitz et al., 1982). In addition, enzymes or other functional proteins can lose their functionality as a result of covalent modifications such as mixed function oxidation, deamidation, ubiquitin conjugation and glycation as a particular consequence of the aging process (Smith et al., 1991).

A previous study, in which a lysed $P_{2}$ fraction was used with endogenous phospholipids as substrate, revealed that phosphatidic acid (PA) formation decreased with age in almost all brain regions tested. In contrast, $\mathrm{PIP}_{2}$ formation was only decreased in the frontal cortex and the hypothalamus, and PIP formation was not affected at all (Bothmer et al., 1992). Furthermore, Stokes et al. (1983) reported a decrease in total lipid myo-inositol with age in human brain cortex, and Jolles et al. (submitted) showed an age-related decrease in PI kinase activity in human brain cortex. Finally, Jolles et al. (1992) found a 50\% reduction in PI kinase activity in patients suffering from pathological brain aging, i.e., Alzheimer's disease.

In the present study, the effect of age on PI kinase, PIP kinase and DAG kinase activities was investigated in the rat brain cortex. Brain cortical structures of 8month-old, 14-month-old and 26-month-old Brown Norway rats were fractionated into a cytosolic protein preparation, a salt-solubilized protein preparation and a Triton X-100-solubilized preparation.

\section{Experimental procedures}

\section{Animals and brain dissection}

Eight-month-old, 14-month-old and 26-month-old male rats of an inbred Brown Norway strain were used. After decapitation, the head was immediately immersed in liquid nitrogen for $8 \mathrm{~s}$. All subsequent operations were performed at $0-4 \mathrm{C}$. The brain was rapidly taken out of the skull and dissected according to Gispen et al. (1972) with slight modifications. Briefly, the cerebellum was excised by cutting the brachium pontis. The medulla/pons was removed by a cut just rostral to the pons. The forebrain was cut transversally through the optic chiasm. 
The frontal part was dissected into the frontal cortex and a remaining part, which was removed. The cerebral cortex, hippocampus, entorhinal cortex and amygdala with overlying pyriformal cortex were removed from the caudal part and separated from each other. The frontal cortex, cerebral cortex, entorhinal cortex and pyriformal cortex were pooled, and the remaining parts were discarded.

\section{Subcellular fractionation}

Cellular proteins were fractionated according to Yamakawa and Takenawa (1988). Briefly, tissue was homogenized $(1: 10$, wet weight/volume) in homogenization buffer (20 mM Tris-HCl, $1 \mathrm{mM}$ EGTA, $1 \mathrm{mM}$ DTT, pH 7.4) by 12 up-and-down strokes of a Potter-Elvehjem Teflon glass homogenizer (radial clearance of 0.125 $\mathrm{mm}, 700 \mathrm{rpm}$ ), followed by homogenization in a glass-glass homogenizer with 3 up-and-down strokes (clearance $0.125 \mathrm{~mm}$ ). The homogenate was centrifuged $\left(100,000 \times \mathrm{g}, 4^{\circ} \mathrm{C}, 45 \mathrm{~min}\right)$, and the resulting membrane-free supernatant was taken as the "cytosolic protein preparation" (fraction A). The pellet was homogenized as described above in homogenization buffer containing $1 \mathrm{M} \mathrm{NaCl}$, and the homogenate was stirred for $60 \mathrm{~min}$ at $4^{\circ} \mathrm{C}$. After centrifugation $\left(100,000 \times g, 4{ }^{\circ} \mathrm{C}, 45\right.$ $\min$ ), the supernatant was taken as the "salt-solubilized protein preparation" (fraction B). The pellet was homogenized as described above in homogenization buffer containing $1 \%$ Triton $X-100(w / v)$, followed by sonication on ice for $3 \times 10 \mathrm{~s}$ at maximal power, with $1 \mathrm{~min}$ pauses. breaks. The homogenate was stirred for 60 min at $4^{\circ} \mathrm{C}$ and centrifuged $\left(100,000 \times g, 4^{\circ} \mathrm{C}, 45 \mathrm{~min}\right)$. The supernatant was taken as the "Triton-solubilized protein preparation" (fraction $\mathrm{C}$ ). The pellet or residual fraction was discarded.

\section{PI kinase, PIP kinase and DAG kinase assay}

The phospholipid kinase activities were assayed as described earlier (Jolles et al., 1992). Briefly, the incubation volume (normally $25 \mu \mathrm{l}$ ) of the PIP kinase assay was doubled to reduce interassay variability. Before the start of the kinase assay, the "salt" and "Triton" preparations were dialysed (1:100) against $20 \mathrm{mM}$ Tris- $\mathrm{HCl}, 1$ mM EGTA, $1 \mathrm{mM}$ DTT, pH 7.4. Protein solutions were preincubated for $20 \mathrm{~min}$. Lipid precursors (20 $\mu \mathrm{M}$ PI, $20 \mu \mathrm{M}$ PI-4-P or $100 \mu \mathrm{M}$ 1-stearoyl-2-arachidonoyl-snglycerol (Sigma), solubilized in $0.1 \%$ Triton $x-100,20 \mathrm{mM}$ Tris- $\mathrm{HCl}, 1 \mathrm{mM}$ EGTA, $1 \mathrm{mM}$ DTT, pH 7.4, were added $15 \mathrm{~s}$ prior to phosphorylation, which was started by the addition of $\mathrm{ATP}$ and lasted $1 \mathrm{~min}$. Incubations were performed under the following conditions: $7.5 \mu \mathrm{M}$ ATP, 2-3 $\mu \mathrm{Ci}$ [gamma-32P] ATP (approx. 3000 Ci/mmol, Amersham U.K.) $20 \mathrm{mM}$ Tris-HCl, $10 \mathrm{mM} \mathrm{MgCl}$, $1 \mathrm{mM}$ EGTA, $1 \mathrm{mM}$ DTT and $0.02 \%$ Triton $X-100, \mathrm{pH} 7.4$. The reaction was terminated, and the extraction and further analysis of the $32 \mathrm{P}$ incorporated into PIP, PIP 2 and PA were performed as described elsewere (Bothmer et al., 1990a; Jolles et al., 1981). Protein determination was performed according to the method of Lowry et al. (1951). 
PI Kinase activity
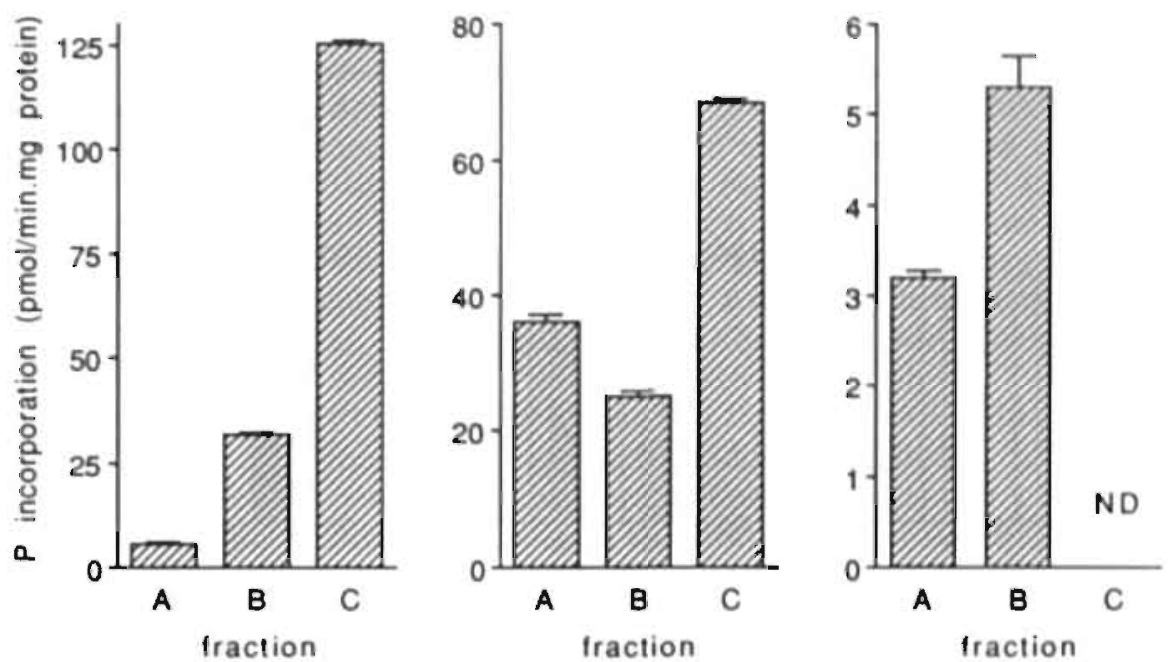

Fig.1 : Distribution of phosphatidylinositol (PI) kinase, phosphatidylinositol phosphate (PIP) kinase and diacylglycerol (DAG) kinase activities in a cytosolic protein preparation (fraction A), a salt-solubilized protein preparation (fraction B), and a triton X-100) solubilized protein preparation (fraction $C$ ) of 8 -month-old rat brain cortex. ND: not detected. Values shown are means ( $($ SEM).

\section{Results}

In the present study, the effect of age on PI kinase, PIP kinase and DAG kinase activities was measured in three rat brain cortex protein preparations: a cytosolic protein preparation (fraction A), a salt-solubilized protein preparation (fraction B) and a triton $\mathrm{X}-100$-solubilized protein preparation (fraction $\mathrm{C}$ ). The saltsolubilized preparation contains proteins which are under physiological conditions loosely attached to the membrane although with a cytoplasmic location, in contrast to the triton-solubilized preparation, which contains proteins which are, under physiological conditions integral or tightly-bound membrane proteins.

Fig.1 shows that PI kinase activity seemed to be located primarily in fraction $C$. The fractions with proteins of a cytoplasmic location (fraction A and B) contained only small amounts of PI kinase activity. PIP kinase activity was located in all three protein fractions, although primarily in fraction $C$. In contrast, DAG kinase activity was not detected in fraction $C$, but could only be detected in the fractions with proteins of a cytoplasmic location (fraction $A$ and $B$ ). 


\section{PI kinase activity}

PIP kinase actlvity

DAG kinase activity
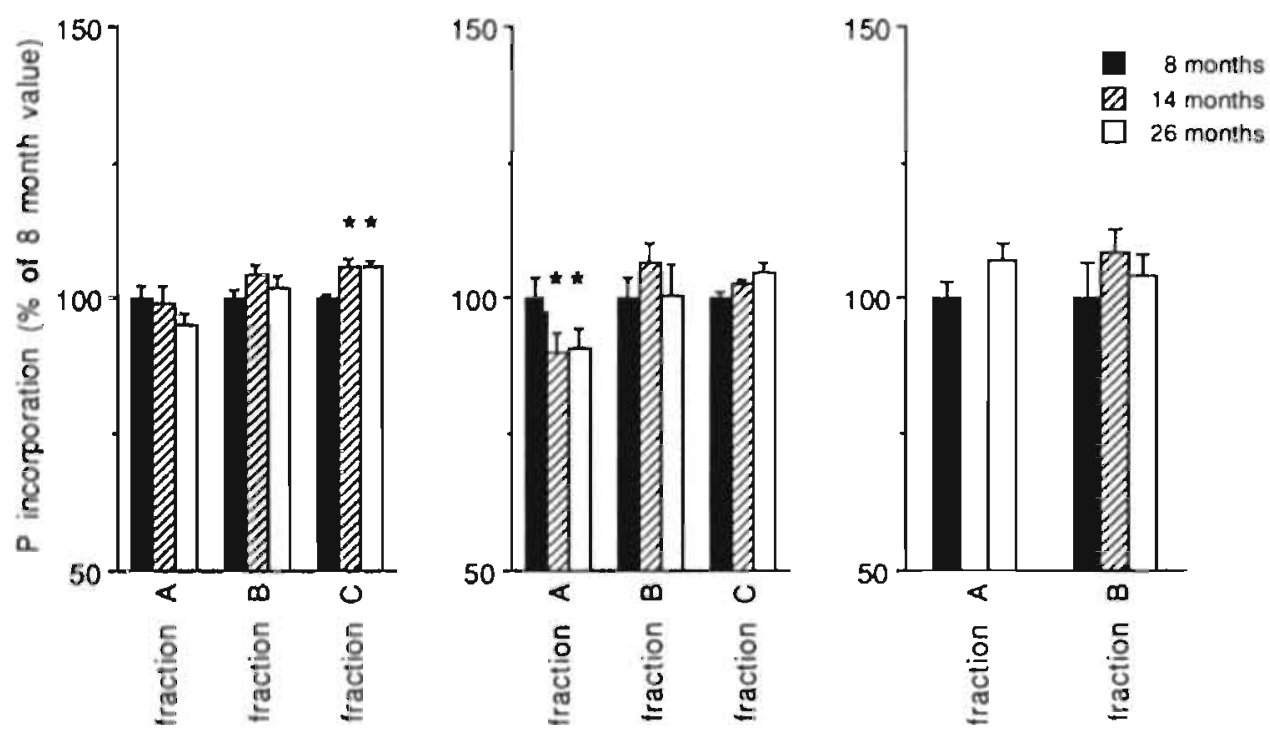

Fig.2 : Effect of age on phosphatidylinositol (PI) kinase, phosphatidylinositol phosphate (PII) kinase and diacylglycerol (DAG) kinase activities in a cytosolic preparation (fraction A), a salt-solubilized protein preparation (fraction B), and a Triton $X-100$-solubilized protein preparation (fraction C) of rat brain cortex. Eight-month-old, 14-month-old and 26-monthold Brown Norway rats were used. Values shown are means ( $I$ SEM) as a \% of values of 8 month-old rats. Statistical analysis was done with Duncan's Multiple Range Test. * : p<0.05.

Fig.2 shows the effect of age on PI kinase, PIP kinase and DAG kinase activities in the different protein fractions of rat brain cortex, measured with exogenous lipids as substrates. PI kinase activity showed no age-related changes with the exception of fraction $C$, which showed a statistically significant $(p<0.05)$ but small increase in PI kinase activity with age. PIP kinase activity was decreased by $10 \%$ in fraction $A$ in 14- and 26-month old rats, but was not affected in fractions $B$ and $C$. DAG kinase activity showed no age-related changes in any of the fractions tested. The protein content of these fractions also showed no age-related changes (data not shown)

\section{Discussion}

In this study, three protein preparations were used to differentiate between cytosolic (fraction A) and membrane-bound (fraction B and C) proteins of rat 
brain cortex. As shown in Fig. 1, DAG kinase was predominantly located in the cytosolic compartment (fraction A) or just loosely bound to the membrane (fraction B), which is consistent with previous findings (Lundberg and Jergil, 1988; Stubbs et al., 1988). PI kinase was located in fraction C and to a small extent in fraction B, which is consistent with the findings of Saltiel et al. (1987), who reported that PI kinase is tightly associated with the membrane because its solubilization requires detergent. PIP kinase of bovine brain is located for $40 \%$ in the cytosolic compartment and for $60 \%$ in the membrane-bound compartment (Moritz et al., 1990). Saltiel et al. (1987) also reported that PIP kinase can be solubilized with low salt concentrations. These findings are in contrast with the findings presented in this study in which the highest PIP kinase activity was found in the Triton-solubilized fraction (C). In a study with human brain cortex material (Bothmer et al., submitted), we did find high PIP kinase activity in fractions A and B, and very low PIP kinase activity in fraction C.

In a previous study, PI kinase, PIP kinase and DAG kinase activities in rat brain were measured as a function of age with endogenous lipids, present in the membrane-cytosol preparation, as substrate (Bothmer et al., in press). In that study, we could not differentiate between an effect of age on substrate availability and an effect of age on enzyme activity. In the present study, we used exogenous phospholipids (PI, PIP and DAG) as substrate for measuring PI kinase, PIP kinase and DAG kinase, respectively, in different protein fractions of the rat cerebral cortex.

DAG kinase activity did not show age-related changes when 8-month-old rats were compared with 26-month-old rats, in contrast to PA formation measured with endogenous lipids as substrate, which decreased $(-15 \%)$ with age in almost all brain regions tested (Bothmer et al., 1992). This decrease in PA formation with age was also found in a crude synaptosomal fraction $\left(\mathrm{P}_{2}\right.$-fraction) of whole rat brain cortex of old (27 months) compared to young ( 7 months) Wistar rats (Bothmer et al., 1990b) in experiments in which endogenous lipids were also used as substrate. The present findings combined with the findings of Bothmer et al. (1990b, 1992) show that the decrease in PA formation with age found in previous studies is not caused by changes in DAG kinase itself, but by changes in the availability of DAG. This is in agreement with the conclusion of Strosnajuer and Samochocki (1991), who found a decreased $\mathrm{Ca}^{2+-i n d e p e n d e n t ~ a r a c h i d o n i c ~ a c i d ~}$ (AA) release in synaptoneurosomes from rat brain cortex of 27-month-old rats compared with 5-month-old rats. These authors concluded that their findings were due to a decreased availability of DAG.

The decrease in PIP kinase activity with age in rat brain cortex seems to be restricted to the cytosolic compartment. $\mathrm{PIP}_{2}$ formation in a membrane-cytosol preparation of rat brain frontal cortex was also found to decrease $(-20 \%$, Bothmer et al., 1992) with age, which supports our present findings. Van Dongen et al. (1983) also found a decrease in PIP ${ }_{2}$ formation with age, although they used a synaptic plasma membrane preparation of whole brain. It is possiblethat no decrease in PIP kinase activity was found in fraction C (tightly membrane-bound proteins) because there was no differentiation between synaptic membranes and 
other membranes in this study.

With respect to PI kinase activity, we found only a small increase with age in fraction $C$, and no differences in fraction $A$ and $B$ (the cytosolic and loosely membrane-bound protein preparations, respectively). In previous studies (Bothmer et al., 1990b, in press), PI kinase activity or PIP formation rates were not changed in old rats compared to young rats. In crude cytosolic preparations of human cerebral cortex, however, PI kinase activity decreased with advancing age (Jolles et al., submitted). In addition, Stokes et al. (1983) reported a decrease in total lipid myo-inositol with age in human brain cortex. The lack (or almost lack) of age-related changes in PI kinase activity in rat brain, in contrast to the agerelated decline in PI kinase activity in human brain, might be due to species differences or to the fact that old people are more likely to have been exposed to biological live events (BLE) than young people (Houx et al., 1991), and than rats. These rats are kept under standarized conditions and are well-cared for. BLE are factors other than severily impairing conditions like dementia that are known to damage optimal brain functioning. Examples of BLE are mild, closed-head injuries, repeated anesthesia and intoxication (Houx et al., 1991).

In conclusion, PI kinase, PIP kinase and DAG kinase activities show no, or only minor, age-related changes in the rat cerebral cortex. The changes in PA formation with advancing age (Bothmer et al., 1990b, 1992) found when using endogenous phospholipids as substrate are probably caused by age-related changes in the availability of DAG, the substrate for PA formation. The lack of an agerelated change in PI kinase activity in rat brain cortex is in contrast to the agerelated decline in PI kinase activity in human brain cortex (Jolles et al., submitted) and shows that care should be taken when using rats, which are kept under standarized conditions and which are exposed to environmental factors that are known to damage optimal brain functioning, as a model for human aging.

\section{References}

Barritt G.J. (1987) Intracellular fres calcium and inositol polyphosphate action as potential targets in the ageing process. Neurobiol. Aging 8, 357.359.

Battaini F., Del Vesco R., Govoni S., and Trabucchi M. (1990) Regulation of phorbol ester binding and protein kinase $C$ activity in aged rat brain. Neurobiol Aging 11, 563-566.

Berridge M.J. (1984) Inositol trisphosphate and diacylglycerol as second messengers. Biochem. J. 220, $345-360$.

Bothmer J., Markerink M.s and Jolles J. (1990a) Phosphatidic acid and polyphosphoinositide formation in a broken cell preparation from rat brain: Effects of different incubation conditions. Neurochem. In!. 17, 27-33.

Bothmer J., Markerink M., and jolles ]. (1990b) Age related changes in the interconversion of inositol phospholipids in the rat brain cortex. In : From gene to man (Van Bezooijen C.F.A., Ravid R. Verhofstad A.A.1., eds.), pp. 186.189. J.H. Pasmans Publishers, The Hague, The Netherlands.

Bothmer J., Markerink M., and Jolles J. (1992) Brain phosphatidic acid and polyphosphoinositide formation in a broken cell preparation: regional distribution and the effect of age. Neurochem. In!. 21, 223-228. 
Burnett D.M., Bowyer J.F., Masserano J.M., and Zahniser N.R. (1990) Effect of aging on alpha-1 adrenergic stimulation of phosphoinositide hydrolysis in various regions of rat brain. $I$. Pharmacol. Exp. Ther. 255, 1265-1270.

Carpenter C.L., and Cantley L.C. (1990), Phosphoinositide kinases. Biochemistry 29, 11147-11156.

Fisher S.K., Heacock A.M., and Agranoff B.W. (1992) Inositol lipids and signal transduction in the nervous tissue: Un update. I. Neurochem. 58, 18-38.

Gispen W.H., Schotman P., and de Kloet. E.R. (1972) Brain RNA and hypophysectomy; a topographical study. Neuroendocrinol. 9, 285-296.

Hershkowitz M., Heron D., Samuel D., and Shinitzky M. (1982) The modulation of protein phosphorylation and receptor binding in synaptic membranes by changes in lipid fluidity: implications for ageing. Prog. Brain Res. 56, 419-434.

Houx P.J., Vreeling F.W., and Jolles J. (1991) Age-associated cognitive decline is related to biological live events. In : Alzheimer's disease: Basic mechanisms, diagnosis and therapeutic strategies. (Iqbal K., McLachlan D.R.C., Winblad B., and Wisniewski H.M., eds.) pp.353-358. J.Wiley \& Sons, Chichester, England.

Jolles J., Zwiers H., Dekker A., Wirtz K.W.A., and Gispen W.H. (1981) Corticotropin-(1-24)tetracosapeptide affects protein phosphorylation and polyphosphoinositide metabolism in rai brain. Biochem. I. 194, 283-291.

Jolles J., Bothmer J., Markerink M., and Ravid R. (1992) Phosphatidylinositol kinase activity is reduced in Alzheimer's disease. J. Neurochem. 58, 2326-2329.

Li P., Vecil G.G., Green M.A., and Warsh J.J. (1991) Inositol 1,4,5-trisphophate receptor in developing and senescent rat cerebellum. Neurobiol. Aging 13, 89-92.

Lowry O.H., Rosebrough N.\}., Farr A.L., and Randall R.). (1951) Protein measuremen ( with the folin phenol reagent. f. Biol. Chem. 193, 265-275.

Lundberg G.A., and Jergil B. (1988) Generation of phosphatidylinositol 4,5-bisphosphate proceeds through an intracellular route in rat hepatocytes. FEBS Lett. 240, 171-176.

Magnoni M.S., Govoni S., Battaini F., and Trabucchi M. (1991) The aging brain: Protein phosphorylation as a target of changes in neuronal function. Life Sci. 48, 373-385.

Martinez-Serrano A., Blanco P., and Satrustegui J. (1992) Calcium binding to the cytosol and calcium extrusion mechanisms in intact synaptosomes and their alterations with aging. J. Biol. Chem. $267,4672-4679$.

Moritz A., DeGraan P.N.E., Ekhart P.F., Gispen W.H., and Wirtz K.W.A. (1990) Purification of a phosphatidylinositol 4-phosphate kinase from bovine brain membranes. I. Neurochem. 54, 351354.

Mundy W., Tandon P., Ali S., and Tilson H. (1991) Agc-related changes in receptor-mediated phosphoinositide hydrolysis in various regions of rat brain. Life Sci. 49, 97-102.

Nalepa 1., Pintor A., Fortuna S., Vetulani J., and Michalek H. (1989) Increased responsiveness of the cerebral cortical phosphatidylinositol system to noradrenaline and carbachol in senescent rats. Neurosci. Lett. 107, 195-199.

Nishizuka Y. (1984) The role of protein kinase $C$ in cell surface signal transduction and tumor promotion. Nalure 308, 693-698.

Pietrzak E.R., Wilce P.A., and Shanley B.C. (1990) Effects of chronic ethanol treatment and aging on brain phosphoinositide turnover and adenylate cyclase activity. Neurochem. Int. 17, 593-598.

Saltiel A.R., Fox J.A., Sherline P., Sahyoun N., and Cuatrecasas P. (1987) Purification of phosphatidylinositol kinase from bovine brain myelin. Biochem. I. 241, 759-763.

Smith C.D., Carney J.M., Starke-Reed P.E., Oliver C.N., Stadtman E.R., Floyd R.A., and Markesbery W.R. (1991) Excess brain protein oxidation and enzyme dysfunction in normal aging and in Alzheimer disease. Proc. Nall. Acad. Sci. USA 88, 10540-10543.

Stokes C.E., Gillon K.R.W., and Hawthorne J.N. (1983) Free and total lipid myo-inositol concentrations decrease with age in human brain. Biochim. Biophys. Acta 753, 136-138.

Streb H., Irvine R.F., Berridge M.J., and Schulz I. (1983) Release of $\mathrm{Ca}^{2+}$ from a non-mitochondrial intracellular store in pancreatic acinar cells by inositol-1,4,5-trisphosphate. Nalure 306, 67-69.

Strosnajder J., and Samochocki M. (1991) Aging modified arachidonic acid release from the 
prelabelled lipid of brain cortex synaptoneurosomes. I. Neurochem. 57 (Suppl), S25.

Stubbs E.B., Kelleher J.A., and Sun G.Y. (1988) Phosphatidylinositol kinase, phosphatidylinositol4-phosphate kinase and diacylglycerol kinase activities in rat brain subcellular fractions. Biochim. Biophys. Acta 958, 247-254.

Surichamorn W., Abdallah E.A.M., and El-Fakahany E.E. (1989) Aging does not alter brain muscarinic receptor-mediated phosphoinositide hydrolysis and its inhibition by phorbol esters, tetrodotoxin and receptor desensitization. J. Pharmacol. Exp. Ther. 251, 543-549.

Tandon P., Mundy W.R., Ali S.F., Nanry K., Rogers B.C., and Tilson H.A. (1991) Age-dependent changes in receptor-stimulated phosphoinositide turnover in the rat hippocampus. Pharmacol. Biocherm. Behav. 38, 861-867.

Van Dongen C.J., Hershkowitz M., Zwiers H., De Laat S., and Gispen W.H. (1983) Lipid fluidity and phosphoinositide metabolism in brain membranes of aged rats: Effects of ACTH(1-24). In : Aging of the brain (Gispen W.H., and Traber J., eds.), pp. 101-104. Elsevier Amsterdam, The Netherlands.

Yamakawa A., and Takenawa T. (1988) Purification and characterization of membrane-bound phosphatidylinositol kinase from rat brain. J. Biol. Chem. 263, 17555-17560. 


\section{CHAPTER 7}

\section{PHOSPHATIDYLINOSITOL KINASE IS REDUCED IN ALZHEIMER'S DISEASE.}

J. Jolles, J. Bothmer, M. Markerink and R. Ravid

Published in:

Journal of Neurochemistry vol.58, 2326-2329 (1992). 


\begin{abstract}
Phosphatidylinositol kinase (PI kinase) and phosphatidylinositol phosphate kinase (PIP kinase) were measured in post-mortem samples of brain tissue from patients with Alzheimer's disease and non-demented control subjects. A membrane-free cytosolic fraction from four neocortical locations, with exogenous inositol lipids as substrate, was used. Tissue from patients with Alzheimer's disease was characterized by reduced PIP formation; the reduction was $50 \%$ in prefrontal cortex, temporal cortex and parietal cortex, and $40 \%$ in precentral gyrus. In contrast, no alterations were found in phosphatidylinositol bisphosphate $\left(\mathrm{PIP}_{2}\right)$ formation in these four neocortical locations. The specific changes in PI kinase but not PIP kinase activity suggest that the findings may have functional relevance to the involvement of brain membrane processes in Alzheimer's disease.
\end{abstract}

\title{
Introduction
}

Alzheimer's disease (AD) is a neurodegenerative disease and the most common cause of adult onset dementia. The etiology and pathogenesis are presently not known. Interest in brain membrane phospholipids was aroused several years ago in relation to the hypothesis of a cholinergic dysfunction in AD (e.g. Bartus et al., 1982) and the notion that these neurons utilize choline for the formation of the membrane-phospholipid phosphatidylcholine (Wurtman et al., 1990). Alterations in phosphatidylcholine and its metabolites, and in other phospholipids in AD brains have now been described (e.g., Blusztajn et al., 1990; Miatto et al., 1986; Pettegrew et al., 1989). Changes in other phospholipids, notably phosphatidylinositol (PI) and its breakdown product myo-inositol have also been investigated in $\mathrm{AD}$ and in normal aging (Stokes et al., 1983; Stokes and Hawthorne, 1987). Such findings may have functional significance because the interconversion of PI into phosphatidylinositol phosphate (PIP) and phosphatidylinositol bisphosphate $\left(\mathrm{PIP}_{2}\right)$, and the breakdown of the latter substance into diacylglycerol and inositolphosphate, are key processes in neuronal function (see for review, Abdel-Latif, 1986; Berridge, 1987; Downes and MacPhee, 1990).

The present study was undertaken to investigate whether inositol phospholipid phosphorylating activity is different in brains from patients with $\mathrm{AD}$ as compared with brains from non-demented control subjects. Considering the rapid breakdown of inositol phospholipids after death (Lin et al., 1990) and after low-energy periods in vitro (Jolles et al., 1981b), we chose to measure enzyme activity rather than analyze phospholipid contents. Brain samples were obtained by rapid autopsy (within 4 to 6 hours after death). AD and control subjects were matched for age in order to reduce possibly confounding factors such as interaction between age and disease, and duration of disease. Four neocortical locations were compared in order to detect possible regional variations like those observed in old animals (Bothmer et al., 1990a). PI kinase and PIP kinase were studied in a membrane-free supernatant of AD and control brain, with exogenous PI and PIP as lipid substrates. 


\section{Experimental procedures}

\section{Subjects}

Brain samples from 5 patients with $\mathrm{AD}(3 \mathrm{M}, 2 \mathrm{~F}$; mean age $65.2 \mathrm{yrs})$ and 5 control subjects ( $3 \mathrm{M}, 2 \mathrm{~F}$; mean age $69 \mathrm{yrs}$ ) were used in this study (see Table 1 ). Patients and controls were individually matched for age and post-mortem interval. Brain tissue was obtained from the Netherlands Brain Bank. The mean post-mortem interval was $5 \mathrm{~h}$ for $\mathrm{AD}$ subjects and $5 \mathrm{~h} 15 \mathrm{~min}$ for the controls. The patients with AD were clinically diagnosed as "probable Alzheimer's disease" (McKhann et al., 1984, APA 1987) and this was verified by post-mortem neuropathological examination. Control subjects had no history of dementia, or any other neurological or psychiatric disorder.

Table 1: Autopsy data of subjects used in the study.

\begin{tabular}{|c|c|c|c|c|c|c|}
\hline $\begin{array}{l}\text { Subjects. } \\
\text { experiment } \\
\text { number }\end{array}$ & $\begin{array}{l}\text { Age } \\
\text { (years) }\end{array}$ & Sex & $\begin{array}{l}\text { Brain } \\
\text { weight } \\
\text { (g) }\end{array}$ & $\begin{array}{l}\text { PM } \\
\text { delay } \\
\text { (min) }\end{array}$ & $\mathrm{PH}$ & Cause of Death \\
\hline \multicolumn{7}{|l|}{ Controls } \\
\hline $\mathrm{Cl}$ & 60 & $\mathrm{~m}$ & 1350 & 360 & 6.45 & $\begin{array}{l}\text { Septic shock following, } \\
\text { aorta valve inplantation }\end{array}$ \\
\hline $\mathrm{C} 2$ & 65 & m & 1310 & 315 & 6.18 & Heart failure \\
\hline C3 & 66 & $\mathrm{f}$ & 1100 & 375 & 6.24 & Metastases of breast cancer \\
\hline $\mathrm{C} 4$ & 71 & $f$ & 1240 & 305 & 6.28 & $\begin{array}{l}\text { Sepsis and cardiogenic } \\
\text { shock }\end{array}$ \\
\hline C5 & 73 & $\mathrm{~m}$ & 1340 & 255 & 6.89 & $\begin{array}{l}\text { Cerebral infarct without } \\
\text { evident cause }\end{array}$ \\
\hline C6 & 73 & $\mathrm{~m}$ & 1410 & 320 & 6.93 & $\begin{array}{l}\text { Postoperative heart } \\
\text { failure }\end{array}$ \\
\hline \multicolumn{7}{|r|}{ ole } \\
\hline Al & 59 & $f$ & 780 & 305 & 6.59 & Cardiac arrest \\
\hline A2 & 64 & m & 1210 & 330 & 6.21 & $\begin{array}{l}\text { Collum-fracture; died } \\
\text { after operation }\end{array}$ \\
\hline A3 & 68 & f & 895 & 345 & 6.52 & Bronchopneumonia \\
\hline A4 & 70 & m & 1075 & 270 & 6.38 & Cachexia \\
\hline A5 & 65 & $\mathrm{~m}$ & 1360 & 240 & $\cdot$ & $\begin{array}{l}\text { Cachexia/lungemboli/ } \\
\text { dehydration }\end{array}$ \\
\hline A6 & 72 & m & 1040 & 285 & 6.89 & Pneumonia and cachexia \\
\hline
\end{tabular}

Crude enzyme fractions from the frontal superior gyrus and the parietal lobe were prepared from subjects $\mathrm{C} 1-\mathrm{C} 5$ and $\mathrm{A} 1-\mathrm{A} 5$, crude enzyme fractions from the precentral gyrus were prepared from subjects $\mathrm{C} 1-\mathrm{C} 4$ and $\mathrm{C} 6$ and $\mathrm{A} 1-\mathrm{A} 5$, and crude enzyme fractions from the medial temporal gyrus were prepared from patients $\mathrm{C} 1-\mathrm{C} 5$ and $\mathrm{A} 2-\mathrm{A} 6$. 


\section{Brain dissection}

Brain specimens for analysis of inositol phospholipid kinase activity were obtained from four neocortical locations in the right hemisphere: 1) the frontal superior gyrus; 2) the precentral gyrus; 3) the medial temporal gyrus, and 4) the parietal lobe. The leptomeninges were removed and samples were excised. These samples were sealed in plastic, rapidly frozen by immersion in liquid nitrogen, and stored at $-80^{\circ} \mathrm{C}$ until use.

\section{Preparation of crude enzyme fraction}

Pieces of approximately $0.5 \mathrm{~g}$ were excised from the tissue samples, and thawed in a water bath at $0^{\circ} \mathrm{C}(20 \mathrm{~min})$. The tissue was homogenized in a medium consisting of $0.32 \mathrm{M}$ sucrose, $1 \mathrm{mM}$ EGTA, $50 \mathrm{mM}$ Tris. $\mathrm{HCl}, \mathrm{pH} 7.4$ in a total volume 10 times the brain tissue volume, by 12 up and down strokes of a PotterElvehjem Teflon-glass homogenizer (radial clearance: $0.125 \mathrm{~mm}, 700 \mathrm{rpm}$ ), followed by homogenization by hand in a glass-glassi homogenizer with 3 up and down strokes. The homogenate was centrifuged for $60 \mathrm{~min}$ at $100,000 \times \mathrm{g}$, and the resulting membrane-free supernatant was used as the crude enzymie fraction. This fraction was stored at $-80^{\circ} \mathrm{C}$.

\section{Pl kinase and PIP kinase assay}

Inositol phospholipid kinase activity was measured as described before (Moritz et al., 1990; Van Dongen et al., 1986), with some modifications. The incubation volume (normally $25 \mu \mathrm{l}$ ) was doubled for the PIP kinase assay in order to reduce interassay variability. Supernatant fractions of 15 or $30 \mu \mathrm{l}(10$ and $20 \mu \mathrm{g}$ protein, respectively), were preincubated for 2 minutes. Lipid precursors $(20 \mu \mathrm{M}$ PI or 20 $\mu \mathrm{M}$ PIP (Sigma), solubilized in $0.1 \%$ Triton X-100/50 mm Tris-HCl / $1 \mathrm{mM}$ EGTA, pH 7.4) were added $15 \mathrm{sec}$ before the phosphorylation reaction was started by the addition of ATP. The reaction lasted $1 \mathrm{~min}$. Incubations were performed under the following conditions: $7.5 \mu \mathrm{M}$ ATP, 2-3 $\mu \mathrm{Ci}$ [gamma-32P] ATP (approximately $3000 \mathrm{Ci} / \mathrm{mmol}$, Amersham UK) $50 \mathrm{mM}$ Tris- $\mathrm{HCl} \mathrm{pH} 7.4,10 \mathrm{mM} \mathrm{MgCl}$, $1 \mathrm{mM}$ EGTA and $0.02 \%$ Triton $X-100$. The reaction was terminated, and the extraction and further analysis of the $32 \mathrm{P}$ incorporated into PIP and $\mathrm{PIP}_{2}$ were performed, as described elsewhere (Bothmer et al., 1990b; Jolles et al., 1981a). Protein was determined according to the method of Lowry et al. (1951).

\section{Results}

The results of the PI kinase assay in brain samples from patients with $A D$ and controls are shown in Fig. 1A. A significant difference between AD and control patients was found in the four neocortical locations tested (MANOVA; $p<0.01$ ). The AD group was characterized by a reduction in $32 \mathrm{P}$-PIP formation by $50 \%$ (prefrontal cortex, temporal cortex and parietal cortex) or $40 \%$ (precentral cortex). 

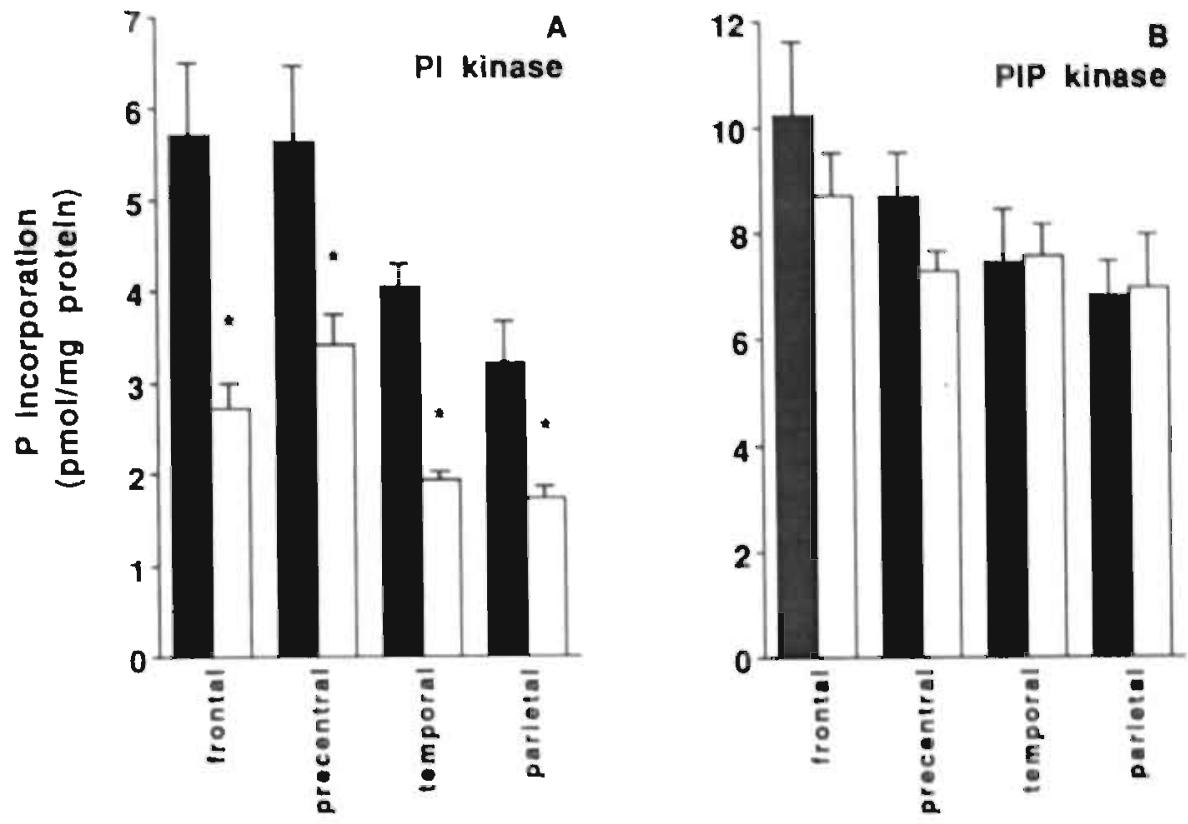

Fig. 1: PI kinase (A) and PIP kinase (B) activities in crude cytoplasmic fractions from four neocortical regions of $\mathrm{AD}$ brains and age-matched controls, expressed as pmol Pi incorporated into phosphatidylinositol monophosphate per $\mathrm{mg}$ protein. Data were analyzed by MANOVA. * $p<0.01$.

In the control samples, there was a regional variation in PIP formation: $32 \mathrm{P}-\mathrm{PIP}$ formation was significantly lower in the temporal and parietal cortex than in the prefrontal and precentral cortex ( $p<0.01$; Siegel and Catellan, 1988). There were no such differences in the AD samples. The results of the PIP kinase assay with tissue from patients with $\mathrm{AD}$ and controls are shown in Fig. 1B. There were no differences between $\mathrm{AD}$ and control subjects in any of the four structures.

\section{Discussion}

The present study shows that a crude cytosolic PI kinase fraction obtained from neocortical structures taken from brains of patients with AD has about $50 \%$ less activity than similar fractions obtained from control brains. This effect appears to be quite specific as there was no decrease in PIP kinase activity. The difference between the two patients groups can not be ascribed to factors such as age and postmortem delay because the groups had been matched for these factors. The postmortem interval ( $4-6 \mathrm{~h}$ ) was very short, which is an advantage considering the rapid breakdown of the various compounds after death. The large standard deviations in the studies of Stokes and Hawthorne (1987), in which they measured the absolute concentrations of free myo-inositol and inositol 
phospholipid-bound inositol in brains from patients with $A D$ and control subjects, are probably caused by the post-mortem interval (7-83 hrs.), as they suggested. In this study we measured enzyme activities and thus circumvented the problem that the levels of PIP and PIP 2 -and to a lesser extent PI- are dependent upon the post-mortem interval. A rapid post-mortem breakdown of the polyphosphoinositides in rat brain has been described in previous studies (Dawson and Eichberg, 1965; Jolles et al., 1981b): Jolles and coworkers showed that $50 \%$ of the labile form of PIP and $\mathrm{PIP}_{2}$ was no longer detectable within $2 \mathrm{~min}$. Likewise, Lin et al. (1990) provided evidence for a very rapid hydrolysis of rat brain $\mathrm{PIP}_{2}$ within minutes after decapitation.

Both the present results and the findings of Stokes and Hawthorne (1987) suggest that the inositol phospholipid system may be involved in the pathogenesis of AD. It is of importance in this respect that other investigators have also found evidence for an involvement of membrane phospholipids and their metabolites in AD. Several research groups, using ${ }^{31} \mathrm{P}$ NMR spectroscopy, have found elevations in the phosphomonoesters (e.g., phosphocholine) early in the course of the disease, followed by an elevation of phosphodiesters (e.g., glycerol-3 phosphorylcholine; Barany et al., 1985; Blusztajn et al., 1990; Brown et al., 1989; Miatto et al., 1986). In addition, $A D$ brain appears to be characterized by a decrease in phosphatidylcholine, phosphatidylethanolamine, phosphatidylserine and cholesterol (Pettegrew et al., 1986). Apart from phospholipids, phosphorylated proteins are implicated in $A D$ as well. For example, the phosphorylation of protein tyrosine (Shapiro et al., 1991) and of microtubuleassociated proteins (Hanger et al., 1991) has received much attention over the last years. It remains to be established whether there is any relation between these changes and the findings reported in the present paper.

The change in PI kinase activity is of potential relevance because of the large effect found: a reduction of $50 \%$ in enzyme activity is substantial in view of the fact that neocortical tissue can be expected to contain cell types which do not degenerate in AD. Thus if the reduced PI kinase activity is confined to (a) particular cell type(s), the effect may be still greater. Furthermore, inositol phospholipids play a key role in impulse initiation and propagation, and thus with intrinsic neuronal and brain functions (see for reviews Abdel-Latif, 1986; Berridge, 1987). A large decrease in PIP formation can therefore be expected to have a widespread influence on membrane function, because the pathway which leads to $\mathrm{PIP}_{2}$ formation is blocked. This may result in a blockade of $\mathrm{PIP}_{2}$ hydrolysis, and thus inhibit the formation of the second messengers inositol trisphosphate $\left(\mathrm{IP}_{3}\right)$ and diacylglycerol. It is relevant in this respect that reduced $\mathbb{I P}_{3}$ binding sites have been found in the parietal cortex and hippocampus of patients with AD (Young et al., 1988).

With respect to the biochemical mechanisms underlying the reduced incorporation of ${ }^{32} \mathrm{P}$ into $\mathrm{PIP}$, it is possible that the AD brain samples are characterized by a reduced quantity of PI kinase, by changes in enzyme kinetics, or by the presence or absence of cofactors. Questions as to the type of PI kinase involved are also relevant in view of the fact that two different types of PI kinase are known, 
namely the kinase which phosphorylates PI at the 4 position of the inositol ring (the so-called "PI 4-kinase") and the one which phosphorylates the 3 position ("PI 3-kinase"). This difference is of importance because the two kinases are implicated in different functions in the cell (Downes and MacPhee, 1990). Involvement of the PI 3-kinase would be of great relevance because this kinase is suggested to be involved in cell growth and in the maintenance of the cytoskeleton. (Carpenter and Cantley, 1990). The fact that the present findings were obtained with a membrane-free supernatant suggests that the kinase responsible for these findings might be the PI 3-kinase. Research is in progress to investigate whether the present findings are due to changes in the activity of PI 3kinase or PI 4-kinase.

The finding that the differences between AD brains and control brains were quite similar for the four structures tested is indicative of a global degeneration of the neocortex. Indeed, the patients were in the terminal stage of the disease (i.e., stage 7 on the Global Deterioration Scale, Reisberg et al., 1983) when most neocortical tissue is known to be involved. Research is planned to compare the tertiary association zones investigated in the present study with the primary sensory cortex and limbic zones and with the cerebellum. A comparison with the latter structure is judged to be especially relevant because this region is not pathologically affected in AD. In addition, other neurological disease groups (Parkinson's disease and multi-infarct dementia) are investigated in order to ascertain the specificity of the observed changes in PI kinase activity. In conclusion, specific alterations in inositol phospholipid phosphorylation have been found in the present study. The findings may be important because of the key role played by inositol phospholipids in neuronal functioning.

\section{References}

Abdel-Latif, A.A. (1986) Calcium-mobilizing receptors, polyphosphoinositides, and the generation of second messengers. Pharmacol. Rev, 38, 227-272.

American Psychiatric Association: Diagnn:tic and Statistical Manual of Mental Disorders, third ed., revised. Washington, DC, American Psychiatric Asseciation, 1987.

Barany, M., Chang, Y., Arus, A., Rustan, T., and Frey, W.H. (1985) Increased glyceral-3 phosphorylcholine in post mortem Alzheimer brain. Lancet $I, 517$.

Bartus, R.T., Dean, R.L., III, Beer, B., and L.ippa, A.S. (1982) The cholinergic hypothesis of geriatric memory dysfunction. Science 217, 40R-417.

Berridge, M.J. (1987) Inositol triphosphate and diacylglycerol: Two interacting second messengers. Ann. Ret. Biochem. 56, 159-193.

Blusztajn, J.K., Lopez-Gonzales-Coviella, L., Logue, M., Growdon, J.H., and Wurtman, R.J. (1990) Levels of phospholipid catabolic intermediates, glycerolphosphocholine and glycerolphosphoethanolamine, are elevated in brains of Alzheimer's disease but not of Down's syndrome patients. Brain Res. 536, 240-244.

Bothmer, J., Markerink, M., and Jolles, J. (1990a) Age related changes in the interconversion of inositol phospholipids in the rat brain cortex. In From Gene to Man (Van Bezooijen, C.F.A., Ravid, R., and Verhufstad, A.A.J., eds), pp. 186-189. J.H. Pasmans publishers, The Hague, The Netherlands.

Bothmer, J., Markerink, M., and Jolles, J. (1990b) Phosphatidic acid and polyphosphoinositide 
formation in a broken celi preparation from rat brain: effects of different incubation conditions. Neurochem. Int. 17, 27-33.

Brown, G.G., Levine, S.R., Gorell, J.M., Pettegrew, J.W., Gdowski, B.J., Buerri, J.A., Helpern, J.A., and Welch, K.M.A. (1989) In vivo 31PNMR profilles of Alzheimer's Disease and multiple subcortical infarct dementia. J. Neurol. 39, 1423-1427.

Carpenter, C.L., and Cantley, L.C. (1990) Phosphoinositide kinases. Biochemistry 29, 11147-11156.

Dawson, F.M.C., and Eichberg, J. (1965) Diphosphoinositide and triphosphoinositide in animal tissue: Extraction, estimation and changes post-mortem. Biochem. J. 96, 634-643.

Dongen, C.J., van, Kok, J.W., Schrama, L.H., Oestreicher, A.B., and Gispen, W.H. (1986) Immunochemical characterization of phosphatidylinositol 4-phosphate kinase from brain. Biochen. J. 233, 859-864.

Downes, C.P., and MacPhee, C.H. (1990) Myo-Inositol metabolites as cellular signals. Eur. J. Biochem. 193, 1-18.

Hanger, D.P., Brion, J.-P., Gallo, J.-M., Caims, N.J., Luthert, P.J., and Anderton, B.H. (1991) Tau in Alzheimer's Disease and Down's syndrome is insoluble and abnormally phosphorylated. Biochem. J. 275, 99-104.

Jolles, J., Zwiers, H., Dekker, A., Wirtz, K.W.A., and Gispen, W.H. (1981a) ACTH1-24 affects protein phosphorylation and polyphosphoinositide metabolism in the rat brain. Bivhern. /. 194, 283.291 .

Jolles, J., Schrama, 1..H., and Gispen, W.H. (1981b) Calcium-dependent turnover of brain polyphosphoinositides in vitro after prelabelling in vivo. Biochem. Biophys. Acta 666, 90-98.

Lin, T.N., Sun, G.Y., Premkumar, N., MacQuarry, R.A., and Carter, S.R. (199N) Decapicitationinduced changes in inositol phosphates in rat brain. Biochern. Biophys. Res. Com. 16\%, 1294-1301.

Lowry, O.H., Rosebrough, N.J., Farr, A.L., and Randall, R.J. (1951) Protein measurennent with the Folin Phenol reagent. ]. Biol. Chem. 193, 265-275.

McKhann, G., Drachman, D., Folstein, M., Katzman, R., Price, D. and Stadlan, E.M. (1984) Clinical Diagnosis of Alzheimer's Disease: Report of the NINCDS-ADRDA Work Group under auspices of Department of Health and Human Services Task Force on Alzheimer's Disease. Neurology 34, 939-945

Miatto, O., Gonzalez, R.G., Bounanno, F., and Growden, J.H. (1986) In vitro 31PNMR spectroscopy detects altered phospholipid metabolism in Alzheimer's disease. Can. I. Neurosci. 13, 535-539.

Moritz, A., De Graan, P.N.E., Ekhart, P.F., Gispen, W.H., and Wirtz, K.W.A. (1990) Purification of a phosphatidylinositol 4-phosphate kinase from bovine brain membranes. J. Neurochem. 54, 351354.

Pettegrew, J.W., Moossy, J., Panchalingham, K., Martinez, J., Strychor, S., McKcag, G., Brantoover, G., and Boller, F. (1989) Correlation of phospholipids and senile plaques in Alzheimer's disease. Neurology 39 (suppl. 1), 396.

Shapiro, I.P., Masliah, E, and Saitoh, T. (1991) Altered protein tyrosine phosphorylation in Alzheimer's Disease. I. Neurochem. 56, 1154-1162.

Reisberg, B., Ferris, S.H., DeLeon, M.], and Crook, T. (1983) Clinical presentation, diagnosis and symptomatology of age-associated cognitive decline and Alzheimer's Disease. In Alzheimer's disense (Reisberg, B., ed.), pp 173-183. The Free Press, New York.

Siegel, S., and Castellan, N.J. (1988) Nonparametric statistics for the behaoioral sciences. McGraw Hill, New York.

Stokes, C.E., and Hawthorne, J.N. (1987) Reduced phosphoinositide concentrations in anterior temporal cortex of Alzheimer-diseased brains. I. Neurochem. 48, 1018-1021.

Wurtman, R.J. Blusztajn. J.K., Ulus, I.H., Lopez Gonzalez-Conviella, I., Buyukuysal, L.R., Growdon. I.H. and Slack, B.E. (1990). Choline metabolism in cholinergic neurons: implications for the pathogenesis of neurodegenerative diseases, in Advances in Neurology, Vor. 57. Alzheimer's Disease (Wurtman, R.J., Corkin, S.H., Growdon, J.H., and Ritter-Walker, E., eds), pp. 117-125. Raven Press, New York.

Young, L.T., Kish, S.H, Li, P.P., and Warsh, J.J. (1988) Decreased brain $\left[{ }^{3} \mathrm{H}\right]$ inositol-1,4,5triphosphate binding in Alzheimer's disease. Neurosci. Lett. 94, 198-202 
CHAPTER 8

\section{REDUCED PI KINASE ACTIVITY IN ALZHEIMER'S DISEASE: EFFECTS OF AGE AND ONSET.}

J. Jolles, J. Bothmer, M. Markerink and R. Ravid

Published in:

Dementia, in press. 


\begin{abstract}
Phosphatidylinositol kinase (PI kinase) and phosphatidylinositol phosphate kinase (P'IP kinase) were assayed in a membrane-free cytosolic fraction prepared from the medial temporal cortex of patients with Alzheimer's disease (AD) and nondemented controls, with exogenous lipids as substrate. ${ }^{32} \mathrm{P}$-PIP formation appeared to be reduced by $21 \%$ in patients with Alzheimer's disease who diecl before 80 years, compared to matched controls. In addition, there was an age-related decrease in PI kinase activity in the control group. In the $A D$ patients group there was no age-related decrease, because Pl kinase activity was increased in old AD patients (older than 80 when they diedl) with a short duration of the disease. No differences were found in the closely related enzyme PIP kinase. The results are indicative for heterogeneity in AD.
\end{abstract}

\title{
Introduction
}

Alzheimer's disease (AD) is a neurodegenerative disease and the most common cause of dementia. The etiology and pathogenesis are presently not known. Interest in brain membrane phospholipids in AD was aroused several years ago when it was found that cholinergic neurons especially are vulnerable to the degenerative process of Alzheimer's disease (e.g. Bartus et al., 1982). Thesi. neurons utilize choline both for the synthesis of acetylcholine and for the formation of the membrane-phospholipid phosphatidylcholine (PC). Alterations in PC and its metabolites, and in other phospholipids in $A D$ brain have now been described (Blusztajn et al., 1990; Miatto et al., 1986; Pettegrew et al., 1989).

Recently, cytosolic fractions obtained from neocortical structures taken from brains of AD patients were found to have approximately $50 \%$ less activity in phosphatidylinositol (PI) kinase activity than similar fractions obtained from control brains. No such differences were found in the activity of the closely related enzyme phosphatidylinositol phosphate (PIP) kinase (Jolles et al., 1992). Stokes and Hawthorne (1987) had earlier reported that AD brain is characterized by a decreased content of phosphatidylinositol (PI). Phospholipids which have the sugar moiety inositol as their polar head group are particularly important for membrane functioning. Nervous tissue is especially rich in inositol phospholipids, which are involved in neurochemical processes related to neurotransmission (for review see Abdel-Latif, 1986; Berridge, 1987). Specifically, this class of compounds is implicated in agonist-receptor coupling, $\mathrm{Ca}^{2+}$ gating and $\mathrm{Ca}^{2}++$ mobilization from internal stores, and the formation of the intracellular second messengers diacylglycerol and inositoltrisphosphate (Downes and MacPhee, 1990).

The present study elaborates on the findings of an earlier study (Jolles et al., 1992). The focus is not on phosphoinositide levels but on the formation of phosphatidylinositol 4-phosphate (PIP) and phosphatidylinositol 4,5-bisphosphate $\left(\mathrm{PIP}_{2}\right)$. Phosphoinositides are very labile and are rapidly broken down after death (Jolles et al., 1981b; Lin et al., 1990), which makes it difficult to study these 
substances in brain material obtained hours after death. It was therefore decided to investigate the activity of the enzymes involved in the interconversion of the inositol phospholipids and not the concentration of the inositol phospholipids. PI kinase and PIP kinase were studied in a membrane-free supernatant of medial temporal cortex prepared from $\mathrm{AD}$ and control brains, with exogenous PI and PIP as lipid substrate. Care was taken to use brain material from rapid autopsies (between 4 and 6 hours after death). In the first experiment, we investigated the possible importance of the factor age: groups of AD patients and controls younger and older than 80 years at death were compared. This age was chosen in view of the finding of Rossor et al. (1984) that there are differences in the neurotransmitter systems of $\mathrm{AD}$ patients who were younger than 79 years when they died compared to patients who were older when they died. In a second experiment, we investigated the age of disease onset in patients older than 80 years, in view of increasing clinical evidence that the clinical course of $\mathrm{AD}$ is heterogeneous. Very old patients who develop the great symptoms at great age (e.g., above 75 years) are often characterized by depression and psychosocial changes. In this study we set the age of onset of first symptoms arbitrarily at 75 years and compared old $\mathrm{AD}$ patients with an onset before or after 75 years.

\section{Experimental procedures}

\section{Subjects}

Brain samples from patients with $A D$ and non-demented controls were obtained from the Netherlands Brain Bank in Amsterdam. For the first experiment, $18 \mathrm{AD}$ brains and 17 controls were used. Subgroups were composed of "aged" subjects, aged 80 or younger, and "very old" subjects, older than 80 years. Care was taken to include only patients in whom AD started when they were 75 or younger. The duration of illness did not differ between aged and very old $A D$ subjects (see Table 1 for description). In all cases the interval between death and autopsy did not exceed 5 1/4 hrs: the mean post-mortem delay was 240 and 230 minutes for the aged and very old $A D$ groups and 320 and 310 for the controls, respectively. The difference in post-mortem delay was not significant. In the second experiment, $15 \mathrm{AD}$ patients aged 81-90 years were divided into two subgroups which differed with respect to age of onset (75 years and younger, or over 75) and compared with 6 control subjects aged 82-90 years. There was a statistically significant difference in the mean duration of illness between the two AD groups (14.3 \pm 3.2 versus $8.3 \pm 1.1$; see Table 2 for description). The patients with $A D$ were clinically diagnosed as "probable Alzheimer Disease" (McKahn et al., 1984; APA, 1987), and this was verified by post-mortem neuropathologic examination. Control subjects had no history of dementia or any other neurological or psychiatric disorder. 


\section{Brain dissection}

Brain specimens for analysis of inositol phospholipid kinase activity were taken from the medial temporal gyrus in the right hemisphere. The leptomeninges were removed and samples were excised measuring approximately $1 \mathrm{~cm}^{3}$. These samples were sealed in plastic and rapidly frozen by immersion in liquid nitrogen. The frozen samples were stored at $-80^{\circ} \mathrm{C}$ until use.

\section{Preparation of crude enzyme fraction}

Pieces of approximately $0.5 \mathrm{~g}$ were excised from the tissue samples and thawed in a water bath at $0^{\circ} \mathrm{C}(20 \mathrm{~min})$. The tissue was homogenized in medium consisting of $0.32 \mathrm{M}$ sucrose, $1 \mathrm{mM}$ EGTA, $50 \mathrm{mM}$ Tris. $\mathrm{HCl}$, ( $\mathrm{pH} \mathrm{7.4)} \mathrm{in} \mathrm{a} \mathrm{total} \mathrm{volume} 10$ times the brain tissue volume, by 12 up-and-down strokes ( $16 \mathrm{~s}$ each) of a PotterElvehjem Teflon-glass homogenizer (radial clearance, $0.125 \mathrm{~mm} ; 700 \mathrm{rpm}$ ), followed by homogenization by hand in a glass-glass homogenizer with 3 up-anddown strokes (clearance of cylindrical section: $0.125 \mathrm{~mm}$ ) in order to destroy synaptosomes and thus increase the yield of intrasynaptosomal enzymes. The homogenate was centrifuged for $60 \mathrm{~min}$ at $100,000 \times \mathrm{gg}$, and the resulting membrane-free supernatant was used as the crude enzyme fraction. This fraction was frozen in $0.2 \mathrm{ml}$ aliquots in liquid nitrogen for $5 \mathrm{~s}$ and stored at $-80^{\circ} \mathrm{C}$. There was no decline in enzyme activity after 1 month of storage.

\section{PI kinase and PIP kinase assay}

Inositol phospholipid kinase activity was measured, with some modifications, as described by Van Dongen et al. (1984) and Moritz et al. (1990). The incubation volume (normally $25 \mu \mathrm{l}$ ) was doubled in the case of the PIP kinase assay in order to reduce interassay variability. Supernatant fractions of 15 or $30 \mu \mathrm{l}$ (10 and $20 \mu \mathrm{g}$ of protein, respectively) were preincubated for $2 \mathrm{~min}$. Lipid precursors $(20 \mu \mathrm{M}$ PI or $20 \mu \mathrm{M}$ PIP; Sigma) were solubilized in $0.1 \%$ Triton X-100, $50 \mu \mathrm{M}$ Tris-HCl, and $1 \mathrm{mM}$ EGTA ( $\mathrm{pH} 7.4$ ) and added to the incubation mixture $15 \mathrm{~s}$ before the phosphorylation reaction was started by addition of ATP. The reaction lasted $1 \mathrm{~min}$. Incubations were performed under the following conditions: $7.5 \mu \mathrm{M} \mathrm{ATP}, 2-3 \mu \mathrm{Ci}$ [gamma-32P] ATP (approximately $3000 \mathrm{Ci} / \mathrm{mmol}$, Amersham UK), $50 \mathrm{mM}$ Tris$\mathrm{HCl} \mathrm{pH} 7.4,10 \mathrm{mM} \mathrm{MgCl}, 1 \mathrm{mM}$ EGTA, and $0.02 \%$ Triton X-100. The reaction was terminated and the extraction and further analysis of the 32P incorporated into PIP and PIP ${ }_{2}$ were performed as described elsewhere (Bothmer et al., 1990; Jolles et al., 1981a). Protein content was determined according to the method of Lowry et al. (1951).

\section{Results}

In the first experiment, a comparison was made between aged AD patients (who were younger than 80 when they died) and very old AD patients (who were 
older than 80 when they died), in whom the onset of disease occurred before 75 years, and age-matched controls.

Table 1: Patient characteristics of study 1: EFFECT OF AGE.

\begin{tabular}{|c|c|c|c|c|}
\hline & \multicolumn{2}{|c|}{ AL.ZHEIMER } & \multicolumn{2}{|c|}{ CONTROL } \\
\hline & Aged & Very old & Aged & Very old \\
\hline N & 10 & 8 & 11 & 6 \\
\hline Age mean (years) & $70.4 \pm 2.4$ & $83.2 \pm 0.8$ & $68.1 \pm 2.2$ & $86.0 \pm 1.4$ \\
\hline Age range (years) & $55-79$ & $81-88$ & $51-76$ & $82 \cdot 90$ \\
\hline Male/female & $7 \mathrm{M} / 3 \mathrm{~F}$ & $0 \mathrm{M} / 8 \mathrm{~F}$ & $8 \mathrm{M} / 3 \mathrm{~F}$ & $3 \mathrm{M} / 3 \mathrm{~F}$ \\
\hline Duration of illness (years) & $10.4 \pm 1.9$ & $14.4 \pm 3.2$ & - & - \\
\hline Brain weight $(\mathrm{g})$ & $1101 \pm 38$ & $1010+25$ & $1314 \pm 34$ & $1188+48$ \\
\hline Post mortem delay (min) & $233 \pm 16$ & $231 \pm 7$ & $384 \pm 93$ & $348 \pm 43$ \\
\hline $\mathrm{pH}$ of the brain & $6.6 \pm 0.2$ & $6.6 \pm 0.11$ & $6.5 \pm 0.1$ & $6.6 \pm 0.2$ \\
\hline Choline acetyltransferase (ChAT) & $0.48 \pm 0.16$ & $0.46 \pm 0.21$ & $5.77 \pm 0.77$ & $3.68 \pm 0.47$ \\
\hline
\end{tabular}

The $\mathrm{pH}$ of the brain, as a measure of post-mortem delay, did not differ between any of the groups. However, the groups were different with respect to the factor brain weight (see Table 1). The brains of AD patients weighed less than those of controls ( $<<0,001$; Student-Newman-Keuls test). In addition, there was an effect of the factor 'age': the brains of AD patients and control subjects older than 80 weighed less than the brains of subjects younger than 80 ( $p<0,01)$. Remarkably, the mean brain weight of very old controls $(118 \mathrm{~g})$ was not different from that of aged AD patients (1102 g). Choline acetyltransferase (ChAT) activity was reduced by $90 \%$ in both aged and very old AD brains. Interestingly, the older controls were characterized by a significant decrease in ChAT activity compared to the younger controls.

Data on PI kinase activity were analyzed with a two-way ANOVA with factors group and age. A group effect was found and an interaction age $x$ group. Thus, as shown in Fig. 1, there was a reduction in PI kinase activity in aged AD patients compared to aged controls $(p<0.05)$. This group effect was absent in very old controls because of the reduction in PI kinase activity in very old controls compared to aged controls. A regression analysis of PI kinase activity versus age (Fig. 2) indicated that PI kinase activity decreased with age $(P<0.05)$. Furthermore, in agreement with findings presented elsewhere (Jolles et al., 1992), AD patients and controls had similar PIP kinase activity (results not shown). In addition, age did not affect PIP kinase activity in either AD patients or controls. 


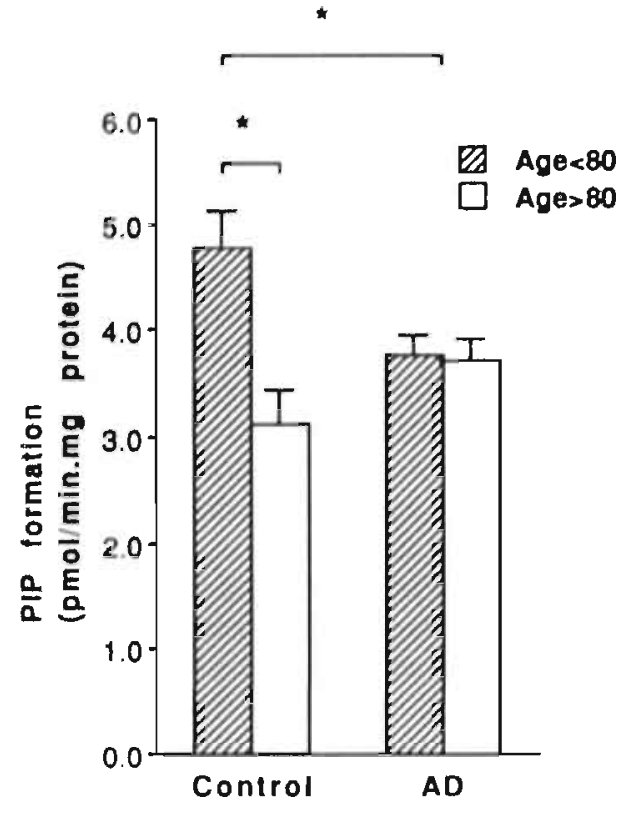

Fig. 1 : Pl kinase activity in cytosolic fractions from brain cortex of controls and $A D$ patients with onset 575 years. Data were analyzed with a two-way ANOVA with factors group and age. " p $<0.05$.

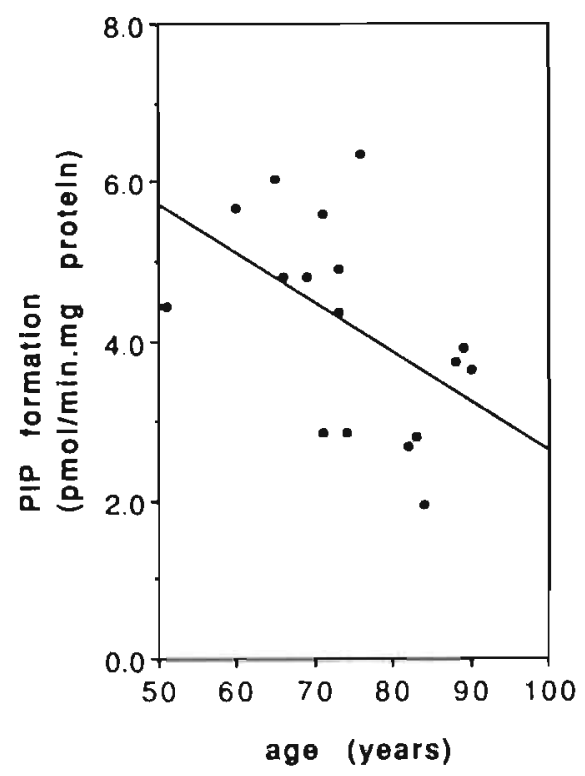

Fig. 2 : Effeets of age on PI kinase activity in cytosolic fractions of control brain cortex. Data were analyzed with regression analysis.

The second experiment was devised to analyze the possible influence of the factor 'onset'. Very old $\mathrm{AD}$ patients and controls older than 80 were compared (see Table 2). As Table 3 shows, PI kinase activity in AD patients in whom the onset of first symptoms occurred before and after 75 years were significantly different. Very old $A D$ patients in whom $A D$ started when they were older than 75 had increased PI kinase activity compared to AD patients with an earlier onset and controls. Remarkably, the PI kinase activity in this group was even higher than in the younger controls measured in experiment 1 ( $20 \%$ increase, $p<0.01)$. The incorporation of $32 \mathrm{P}$ into $\mathrm{PIP}_{2}$ was similar in patients in whom the onset of AD occurred after 75 years and in patients with an earlier onset (results not shown). 
Table 2: Patient characteristics of study 2: EFFECT OF ONSET

ALZHEIMER

$\overline{\text { ONSET } \leq 75 \quad \text { ONSET }>76}$

\section{CONTROL}

\begin{tabular}{llll}
$\mathrm{N}$ & 8 & 7 & 6 \\
Age mean (years) & $83.3 \pm 0.8$ & $88.3 \pm 0.7$ & $86.0 \pm 1.4$ \\
Age range (years) & $81-88$ & $85-90$ & 82.90 \\
Male/female & $0 \mathrm{M} / 8 \mathrm{~F}$ & $0 \mathrm{M} / 7 \mathrm{~F}$ & $3 \mathrm{M} / 3 \mathrm{~F}$ \\
Duration of illness (years) & $14.4 \pm 3.2$ & $8.3 \pm 1.1$ & - \\
Brain weight (g) & $1010 \pm 26$ & $961 \pm 27$ & $1188 \pm 48$ \\
Post mortem delay (min) & $231 \pm 7$ & $221 \pm 16$ & $347 \pm 43$ \\
pH of the brain & $6.6 \pm 0.1$ & $6.4 \pm 0.1$ & $6.6 \pm 0.2$ \\
Choline acetyltransferase & $0.46 \pm 0.21$ & $1.01 \pm 0.32$ & $3.68 \pm 0.47$ \\
\hline
\end{tabular}

\section{Discussion}

Recently, cytosolic PI kinase fractions obtained from neocortical structures taken from brains of patients with $\mathrm{AD}$ were found to have approximately $50 \%$ less activity than similar fractions obtained from control brains. No such differences were detected in PIP kinase activity (Jolles et al., 1992). The fractions were prepared from patients with early onset $A D$ who died at a relatively early age (below 72 years). The present series of investigations confirms this finding for a larger group of subjects, some of whom lived to be 80 . Interestingly, very old controls (older than 80 , with a mean age of 85 years) had a reduced li kinase

Table 3 : PI kinase activity in old patients: EFFECT OF ONSET

$\begin{array}{ll}\text { group } & \text { PI kinase activity } \\ & \text { (pmol/min.mg protein) }\end{array}$

$\begin{array}{lll}\text { Onset } 575 \text { years } & 8 & 3.719 \pm 0.200 \\ \text { Onset }>76 \text { years } & 7 & 5.523 \pm 0.484 \\ \text { Control } & 6 & 3.125 \pm 0.314\end{array}$


activity compared to younger controls (younger than 80 , with a mean age of 67.3 years), and evidence for an age gradient in PI kinase activity was found. The decreased activity in old controls could explain the lack of difference between old controls and very old $\mathrm{AD}$ patients (older than 80 ) with onset before 75 years in the present series of investigations. The factor 'onset' - which is defined as 'age of first symptoms'- was found to be important in the second experiment in which old AD subjects with a relatively long duration of disease (mean duration 14.4 years, onset before 75) were compared with $\mathrm{AD}$ patients with a short duration of disease (mean duration 8.3 years; onset after 75 ). The results clearly show that the latter group is characterized by high PI kinase activity.

The present findings are important for both methodological and theoretical considerations. Age-related decreases in myo-inositol and inositol bound to phosphatidylinositol have been found in normal subjects aged 20-70 (Stokes et al., 1983). An age-related decrease in PI kinase activity, found in the present study, has relevance for $A D$ research, as the lack of brain material from well-defined $A D$ patients forces the researcher to use groups which are composed of AD patients of widely different ages (e.g., 60 through 90 years; Stokes and Hawthorne, 1987). The present data suggest that care should be taken in the selection of patient groups. The use of control and patient groups that are more homogeneous with respect to age is to be recommended in view of the age-related decline in enzyme activity.

Old AD subjects with an onset before and after 75 years had different PI kinase activity, which could be important in view of the fact that the late onset group showed an increased formation of 32P-PIP compared to the early onset group, whereas the late onset group was older and thus -in view of the findings of the first study - would be expected to have a decreased formation of PIP. In addition, old AD patients with a short disease duration (onset after 75 years) had a much higher PI kinase activity than subjects with a longer disease duration. In conclusion, the present data suggest that the pathogenesis of $A D$ in old $A D$ patients with a short duration of disease might be different, as far as PI kinase is concerned, from that of old patients with a longer duration of disease. This is of relevance in view of the ongoing discussion on the possible heterogeneity of AD.

Until now, the question whether or not early and late onset AD differ has not been settled. An increasing number of studies favor such a distinction in order to account for clinical heterogeneity and different syndromes which are observed in early and late onset Alzheimer dementia (Chui et al., 1985; Filley et al., 1986; Mayeux et al., 1985). Likewise, there is increasing evidence that early and late onset $A D$ also differ with respect to neurobiological parameters (Bondareff et al., 1987; 1988). Even age at death appears to be a relevant variable in the differentiation of $A D$ patients in view of the findings reported by Rossor et al. (1984). These authors found clearcut differences in neurotransmitter systems in $A D$ patients younger than 79 years versus $A D$ patients dying at an older age. The present findings corroborate these observations for another enzyme system. In addition to age at death, age at onset of first symptoms also appeared to be relevant, which suggests that it might be necessary to reevaluate existing data in 
order to find whether our findings on the effect of onset are paralleled by similar early/late discrepancies found in other neurobiological or neurochemical parameters.

Both the present results and those presented by Stokes and coworkers (Stokes et al., 1983; Stokes and Hawthorne, 1987) suggest that the inositol phospholipid system may be involved in the pathogenesis of AD. Stokes and Hawthorne (1987) measured absolute levels of myo-inositol and lipid-bound inositol and found a significant decrease in PI in the temporal cortex from AD brain. In addition, an age gradient for myo-inositol and lipid-bound inositol was found, although there was a large individual variation. Several other investigators have reported the involvement of membrane phospholipids and their metabolites in Alzheimer's disease, for instance, by 31P NMR spectroscopic examination of AD brains. Elevated levels of phosphomonoesters such as phosphocholine early in the course of the disease have been reported, followed by elevation of phosphodiesters such as glycerol-3 phosphocholine (Barany et al., 1985; Blusztajn et al., 1990; Brown et al., 1989; Miatto et al., 1986; Pettegrew et al., 1989). In addition, AD brain appears to be characterized by a decrease in phosphatidylcholine, phosphatidylethanolamine, phosphatidylserine and cholesterol (Peltegrew et al., 1989). It remains to be established whether there is a relation between these changes and the findings reported in the present paper.

The changes in PI kinase activity seem to be relevant because of the large effect found, especially in young AD patients (Jolles et al., 1992) and because of the key role played by inositol phospholipids in impulse initiation and propagation, the most intrinsic neuronal and brain functions (Abdel-Latif, 1986; Berridge, 1987). A large decrease in PIP formation can therefore be expected to have a widespread influence on membrane function. $\mathrm{PIP}_{2}$ hydrolysis could be blocked, and formation of the second messengers inositol phosphate and diacylglycerol inhibited. This in turn can be expected to give rise to a number of tertiary changes in intracellular mechanisms and lead to neuronal deactivation and possibly degeneration.

With respect to the biochemical mechanisms involved in the reduced incorporation of 32P into PIP with age and in AD patients, changes in the absolute amount of enzymes or changes in enzyme kinetics are possible. Alternatively, the presence or absence of particular ions or other cofactors could also be causal to the decreased incorporation. Follow-up research into the various possibilities is presently being undertaken. In addition, uncertainty exists about the nature of the PI kinase involved. It is known that this enzyme exists in two forms, namely the kinase which phosphorylates PI at the 4 position of the inositol ring, and the one which phosphorylates at the 3 position. This difference is of importance because the two kinases appear to have different functions in the cell. The PI 4kinase is involved in the pathways leading to hormone stimulated phospholipase $C$ action, whereas the PI 3-kinase is suggested to have a function in mitogenesis, cell differentiation, and in the control of cytoskeletal rearrangements (Carpenter and Cantley, 1990; Downes and MacPhee, 1990). Various isoenzymes of PI 4-kinase exist, which are located either in the membrane as an 
integral membrane protein (e.g. Porter et al., 1988), or in the cytoplasm, or both (Carpenter and Cantley, 1990).

In conclusion, the alterations in inositol phospholipid phosphorylation found in the present study may be relevant for AD research because of the key role played by inositol phospholipids in neural functioning. In addition, the results indicating an age related effect in $\mathrm{AD}$ patients suggest that PI kinase activity can be used to divide AD patients into subgroups characterized by the age of onset of the disease. More attention should be given to the factors age and onset in future $\mathrm{AD}$ research.

\section{References}

Abdel-Latif A.A. (1986) Calcium mobilizing receptors, polyphosphoinositides, and the generation of second messengers. Pharmacol. Rev. 38, 227-272.

American Psychiatric Association: Diagnostic and Statistical Manual of Mental Disorders, third ed., revised. Washington, DC, American Psychiatric Association, 1987.

Barany M., Chang A., Arns A., Ruston T., and Frey W.N. (1985) Increased glycerol-3 phosphorylcholine in post mortem Alzheimer brain. Lancet 1, 517.

Bartus R.T., Dean R.L., III, Beer B., and L.ippa A.S. (1982) The cholinergic hypothesis of geriatric memory dysfunction. Science $217,408-417$.

Berridge M.J. (1987) Inositol triphosphate and diacylglycerol: two interacting second messengers. $A$. Rev. Biochem. 56, 159-193.

Blusztajn J.K., Lopez-Gonzales-Coviella L., Logue M., Growdon J.H., and Wurtman R.J. (1990) Levels of phospholipid catabolic intermediates, glycerolphosphocholine and glycerolphosphoethanolamine, are elevated in brains of Alzheimer's disease but not of Down's syndrome patients. Brain Res. 536, 240-244.

Bondareff W., Mountjoy C.Q., Roth M., Rossor M.N., Iversen L.L., and Reynolds G.P. (1987) Age and histopathologic heterogeneity in Alzheimer's disease. Arch. Gen. Psychial. 44, 412-417.

Bondareff W., Mountjoy C.Q., Roth M., Rossor M.N., Iversen L.L., and Reynolds G.P. (1987) Pathologic heterogeneity of Alzheimer's disease: In Reply. Arch. Gen. Psychiat. 45, 962-963.

Bothmer J., Markerink M., and Jolles J. (1990) Phosphatidic acid and polyphosphoinositide formation in a broken cell preparation from rat brain: effects of different incubation conditions. Neurochem. Int. 17, 27-33.

Brown G.G., Levine S.R., Gorell J.M., Pettegrew J.W., Gdowski B.J., Bueri J.A., Helpern J.A., and Welch K.M.A. (1989) In vivo 31 PNMR profiles of Alzheimer's disease and multiple subcortical infarct dementia. I. Neurol. 39, 1423-1427.

Carpenter C.L., and Cantley L.C. (1990) Phosphoinosite kinases. Biochemistry 29, 11147-11156.

Chui H.C., Teng E.L., Henderson V.W., and Moy A.C. (1985) Clinical Subtypes of dementia of the Alzheiner type. Neurology 35, 1544-1550.

Downes C.P., and MacPhee C.H. (1990) Myo-Inositol metabolites as cellular signals. Eur. I. Biochem. 193, 1.18.

Filley C.M., Kelly J., and Heaton R.K. (1986) Neuropsychologic features of early and late onset Alzheimer's disease. Arch. Neurol. 43, 574-576.

Jolles J., Zwiers H., Dekker A., Wirtz K.W.A., and Gispen W.H. (1981a) ACTHI-24 affects protein 
phosphorylation and polyphosphoinositide metabolism in the rat brain. Biochem. 1. 194, 283-291.

Jolles J., Schrama L.H., and Gispen W.H. (1981b) Calcium-dependent turnover of brain polyphosphoinositides in vitro after prelabelling in vivo. Biochem. Biophys. Acta 666, 90-98.

Jolles J., Bothmer J., Markerink M., and Ravid R. (1992) Phosphatidylinositol kinase is decreased in Alzheimer's disease. J.Neurochem. 58, 2326-2329.

Lin T.N., Sun G.Y., Premkumar N., MacQuarry R.A., and Carter S.R. (1990) Decapitation-induced changes in inositol phosphates in rat brain. Biochem. Biophys. Res. Comm. 167, 1294-1301.

Lowry O.H., Rosebrough N.J., Farr A.L., and Randall R.J. (1951) Protein measurement with the Folin Phenol reagent. J. Biol. Chem. 193, 265-275.

Mayeux R., Stern Y., and Spanton S. (1985) Heterogeneity in dementia of the Alzheimer type: evidence of subgroups. Neurology 35, 453-461.

McKahn G., Drachman D., Folstein M., Katzman P., Price D., and Stadlan E.M. (1984) Clinical diagnosis of Aizheimer's disease: report of the NINCDS-ADRDA work group. Neurology 34, 939. 944.

Miatto O., Gonzalez R.G., Bounanno F., and Growden 1.H. (1986) In vitro 31PNMR spectroscopy detects altered phospholipid metabolism in Alzheimer's disease. Can. J. Neurosci. 13, 535-539.

Moritz A., De Graan P.N.E., Ekhart P.F., Gispen W.H., and Wirtz K.W.A. (1990) Purification of phosphatidylinositol 4-phosphate-kinase from bovine brain membranes. I. Neurochem. 54, 351354.

Pettegrew J.W., Moossy J., Panchalingham K., Martinez J., Strychor S., McKeag G., Brantoover G., and Boller F. (1989) Correlation of phospholipids and senile plaques in Alzheimer's disease. Neurology 39 (suppl. 1), 396.

Porter F.D., Li Y.-S., and Deuel T.F. (1988) Purification and characterization of a phosphatidylinositol 4-kinase from bovine uteri. J. Biol.Chem. 263, 8989-8995.

Rossor M.N., Iversen L.L., Reynolds G.P., Mountjoy C.Q., and Roth M. (1984) Neurochemical characteristics of carly and late onset types of Alzheimer's disease. Br. Med. J. 288, 961-964.

Stokes C.E., and Hawthorne J.N. (1987) Reduced phosphoinositide concentrations in anterior temporal cortex of Alzheimer-diseased brains. I. Neurochem. 48, 1018-1021.

Stokes C.E., Gillon K.R.W., and Hawthorne I.N. (1983) Free and total lipid myo-inositol concentration decrease with age in human brain. Biochim. Biophys. Acta 753, 136-138.

Van Dongen C.J., Kok J.W., Schrama L.H., Oestreichelr A.B., and Gispen W.H. (1986) Immunochemical characterization of phosphatidylinositol 4-phosphate-kinase irom ralt brain. Biochern. J. 233, 197-203. 



\section{CHAPTER 9}

EVIDENCE FOR A SELECTIVE DECREASE IN TYPE 1 PHOSPHATIDYLINOSITOL KINASE ACTIVITY IN BRAINS OF PATIENTS WITH ALZHEIMER'S DISEASE.

J. Bothmer, M. Markerink and J. Jolles 


\begin{abstract}
We have previously: shown that phosphatidylinositol (RI) kinase activity is $40-$ $50 \%$ lower in cytosolic fractions of neocortical regions. from brains of patients with Alzheimer's disease (AD) than in similar fractions prepared from control brains. To investigate whether changes in the amount of inhibiting or stimulating compounds are. involved, we performed chelation and combination experiments with cytosolic preparations of temporal cortex from $A D$ brains and control brains. Chelation of ions didl not increase PI kinase activity. Combination of $\mathrm{AD}$ and control cy tosolic fractions did not result in stimulation or inhibition of PI kinase activity. These resultsi suggest that no inhibiting or stinnulating comprounds are involved in the mechanism underlying the lower PI kinase activity in AD brains. The PI kinase activity in the cytosolic fraction and in the loosely membrane-bound protein preparation of the temporal cortex of $A . D$ brains was predominantly affected $(70 \%$ lewer PI kinase activity compared to control brain samples). $P$ kinase in these fractions was inhibited $(.75 \%)$ by $1 \%$ Triton $X$ 100 , whereas the PI kinase in the tightly membrane-bound protein preparation was, stimulated ( $(80 \%)$ by $1 \%$ Triton X-100. PI kinase activity in the loosely membranebound protein preparation was almost unaffected by adenosine in contrast to PI kinase activity in the tightly membrane-bound protein preparation, which wasi strongly inhibited by adenosine. These results indicate that the PI kinase that is specifically affected in $A D$ is the PI 3-kinase, or type 1 Pl kinase, because 1.) the cytosolic localization; 2.) the inhibition by the non-ionic detergent Triton $\mathrm{X}-100$; and 3.) the insensitivity to adenosine inhibition are characteristic features of type 1 PI kinase. The specificity of the elfect on PI kinase is strengthened by the observation that PIP kinase was not affected in any of the subcellular fractions of the temporal cortex of $A D$ brains. The relevance of our findings namely that type 1 PI kinase scems to be specifically affected in AD brains is that this type of PI kinase is thought to be involved in the regulation of eytoskeletal tumover processes. In this context, changes in the type 1 PI kinase activity could be related to the cellular pathology of AD because neurofibrillary tangles, which are a prominent feature of AD, are partially composed of wrongly phosphorylated cytoskeletal components.
\end{abstract}

\title{
Introduction
}

Alzheimer's disease (AD) is a neurodegenerative disease characterized by the occurrence of protein deposits in brain neurons, the neurofibrillary tangles, as well as in the extracellular space, the neuritic plaques (Holtzman and Mobley, 1991). Although these features are always found in AD they are not unique to $A D$. $A D$ is also characterized by changes in the metabolism of phospholipids. The metabolism of phosphatidylcholine is altered in AD brain (Miatto et al., 1986; Pettegrew, 1989), as is the amount of the $\mathrm{M}_{2}$ cholinergic muscarinic receptor (Bird et al., 1985) coupled to phosphoinositide specific phospholipase C (Berridge and Irvine, 1984). The concentration of phosphoinositides, a class of phospholipids enriched in neuronal membranes, is lower in AD brains than in brains from agematched controls (Stokes and Hawthorne, 1987). Furthermore, aluminum, which probably plays a role in AD (MacDonald and Martin, 1987), influences the interconversion of phosphoinositides in a very specific way (MacDonald and Mamrack, 1988). Jolles et al. (1991, 1992) have shown that cytosolic fractions 
prepared from neocortical areasi of AD brains have about $50 \%$ less PI kinase activity than similar fractions from control brains. PIP kinase activity was the same in AD and control brains. The importance of these findings is suggested by the fact that phosphoinositides are involved in impulse initiation and propagation, calcium mobilization, agonist-receptor interactions, and the formation of the intracellular second messengers, diacylglycerol and inositol trisphosphate (Abdel-Latif, 1986; Berridge, 1987; Downes and MacPhee, 1990). Furthermore, PI kinase seems to be involved in cell proliferation (Martelli et al.; 1991), and in the cytoskeletal rearrangement that occurs during the mitotic cell cycle and in post-mitotic cells during exocytosis (Downes and MacPhee, 1990). Interestingly, a prominent feature of AD brains is the abnormal accumulation of neurofibrillary tangles which are partially composed of multi-phosphorylated microtubule-associated proteins (Hanger et al., 1991; Kosik, 1991). Under physiological conditions these proteins stabilize the cytoskeleton (Kosik, 1991).

Different types of PI kinases have been discovered and are probably responsible for the different functions in which PI kinases seem to be involved (Carpenter and Cantley, 1990). There are two PI kinases, type 1 or PI 3-kinase and type 2 or P1 4-kinase (Whitman et al., 1987), which differ from each other in the phosphorylation position of the inositol ring of their products. Thus, PI 3-kinase phosphorylates at position D-3 and PI 4-kinase at position D-4 of the inositol ring (Whitman et al., 1988). The PI 4-kinases can be further divided into type 2 and type 3 PI kinase, which differ from each other in size (55 and 230 kDa, respectively) and in some kinetic properties (Endemann et al., 1987). Type 1 PI kinase, or PI 3-kinase, is not implicated in the pathway producing the second messenger precursor $\mathrm{PI}(4,5) \mathrm{P}_{2}$, unlike type 2 PI kinase which is (Downes and MacPhee, 1990). Type 1 PI kinase, which is located in the cytosolic compartment, is implicated in growth, mitogenic signalling, and cytoskeletal turnover, and appears to be associated with protein tyrosine kinases and growth factor receptors (Carpenter and Cantley, 1990; Cochet et al., 1991; Martelli et al., 1991; Varticovski et al., 1989). Type 1 PI kinase associates with receptors and is activated by stimulation of these receptors by agonists (e.g., insulin-receptors, platelet-derivedgrowth-factor receptor; Auger and Cantley, 1991).

PI and PIP kinase activities have been studied in a cytosolic fraction from AD brains (Jolles et al., 1991, 1992). However, nothing is known about PI and PIP kinase activities in the membranes of $A D$ brains. In fact, the identity of the PI kinase measured earlier (Jolles et al., 1991, 1992) is not clear, and we do not know what biochemical mechanisms underlie the reduced incorporation of 32Pi into PIP. The present study was therefore, designed to provide more information about the identity of the type of PI kinase affected in AD, and on the biochemical mechanism underlying the lower level of PI kinase activity in AD brains, as. PIP kinase is not affected. We therefore prepared four subcellular fractions from $A D$ and control brains in order to measure both cytosolic and membrane-bound PI kinases. We also investigated whether changes in the amount of inhibiting (e.g., metal) or stimulating (e.g., cofactor) compounds are involved in the low PI kinase activity of AD brains. 


\section{Experimental procedures}

\section{Subjects}

Brain samples from five AD patients (three males and two females; mean age 65.2 years) and five controls (three males and two females; mean age 69 years) were used in this study. The brains were individually matched for age and postmortem interval with brain tissue obtained from the Netherlands Brain Bank. The mean postmortem interval was $5 \mathrm{~h}$ for the AD patients and $5 \mathrm{~h} 15 \mathrm{~min}$ for the controls. The $\mathrm{AD}$ patients had been clinically diagnosed as "probable Alzheimer's Disease" and this was verified by postmortem neuropathological examination. Controls were age-matched individuals without a history of dementia, or any other neurological or psychiatric disorder.

\section{Brain dissection}

Brain specimens for analysis of inositol phospholipid kinase activity were obtained from the medial temporal gyrus. The leptomeninges were removed and samples were excised. These samples were sealed in plastic, rap̧idly frozen by immersion in liquid nitrogen, and stored at $-80^{\circ} \mathrm{C}$ until use.

Preparation of crude enzyme fraction

Pieces of approximately $0.5 \mathrm{~g}$ were excised from the tissue samples and rapidly thawed in a water bath at $0^{\circ} \mathrm{C}(20 \mathrm{~min})$. The tissue was homogenized in a

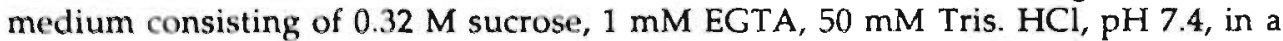
total volume 10 times the brain tissue volume, by 12 up-and-clown strokes of a Potter-Elvehjem Teflon-glass homogenizer (radial clearance: $0.125 \mathrm{~mm}, 700 \mathrm{rpm}$ ), followed by homogenization by hand in a glass-glass homogenizer with 3 up-anddown strokes (radial clearance: $0.125 \mathrm{~mm}$ ). The homogenate was centrifuged for $60 \mathrm{~min}$ at $100,000 \times \mathrm{g}$ and the resulting membrane-free supernatant was used as the crude enzyme fraction. This fraction was stored at $-80^{\circ} \mathrm{C}$. There was no decline in enzyme activity after 1 month of storage.

\section{Solubilization of membrane-bound PI and PIP kinase}

Solubilization of PI and PIP kinases, loosely attached to the membrane or membrane bound, was performed according to Yamakawa and Takenawa (1988). Briefly, tissue was homogenized $(1: 10$, wet $w / v)$ in homogenization buffer (20 $\mathrm{mM}$ Tris-HCl, $1 \mathrm{mM}$ EGTA, $1 \mathrm{mM}$ DTT, pH 7.4) by 12 up-and-down strokes of a Potter-Elvehjem Tefion glass homogenizer (radial clearance of $0.125 \mathrm{~mm}, 700$ rpm), followed by homogenization in a glass-glass homogenizer with 3 up-anddown strokes (clearance $0.125 \mathrm{~mm})$. The homogenate was centrifuged $(100,000 \times \mathrm{xg}$, 
$4^{\circ} \mathrm{C}, 60 \mathrm{~min}$ ), and the resulting membrane-free supernatant was taken as the "cytosolic fraction". The pellet was homogenized as described above in homogenization buffer containing $1 \mathrm{M} \mathrm{NaCl}$, and the homogenate was stirred for $60 \mathrm{~min}$ at $4^{\circ} \mathrm{C}$. After centrifugation $\left(100,000 \times \mathrm{xg}, 4^{\circ} \mathrm{C}, 60 \mathrm{~min}\right)$, the supernatant was taken as the "salt fraction". The pellet was homogenized as described above in homogenization buffer containing $1 \%$ Triton $X-100(w / v)$, followed by sonication on ice for $3 \times 10 \mathrm{~s}$ at maximal power. The homogenate was stirred for $60 \mathrm{~min}$ at $4^{\circ} \mathrm{C}$ and centrifuged $\left(100,000 \times \mathrm{xg}^{\circ} 4^{\circ} \mathrm{C}, 60 \mathrm{~min}\right)$. The supernatant was taken as the "Triton fraction", and the pellet, after homogenization in homogenization buffer as described above, as the "residual fraction".

\section{PI kinase and PIP kinase assay}

Inositol phospholipid kinase activity was measured as described earlier (van Dongen et al., 1986), with some modifications. The incubation volume (normally $25 \mu \mathrm{l}$ ) of the PIP kinase assay was doubled to reduce interassay variability. Before

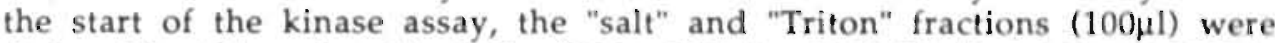
dialyzed for $2 \mathrm{~h}$ against $10 \mathrm{ml} 20 \mathrm{mM}$ Tris- $\mathrm{HCl} / 1 \mathrm{mM}$ EGTA/1 mM DTT (pH 7.4). Protein solutions of 15 or $30 \mu l(10,20 \mu g$ protein, respectively) were preincubated for $2 \mathrm{~min}$. Lipid precursors ( $20 \mu \mathrm{M}$ PI or $20 \mu \mathrm{M}$ PIP' (Sigma), solubilized in $0.1 \%$ Triton X-100/20 mm Tris-HCl / $1 \mathrm{mM} \mathrm{EGTA/1} \mathrm{mM} \mathrm{DTT} \mathrm{(pH} \mathrm{7.4),} \mathrm{were} \mathrm{added} 15 \mathrm{~s}$ prior to phosphorylation, which was started by the addition of ATP, and lasted 1 min. Incubations were performed under the following conditions: $7.5 \mu \mathrm{M}$ ATP, 2$3 \mu \mathrm{Ci}$ (gamma-32P) ATP (approximately $3000 \mathrm{Ci} / \mathrm{mmol}$, Amersham UK) $20 \mathrm{mM}$ Tris- $\mathrm{HCl} \mathrm{pH} \mathrm{7.4,} 10 \mathrm{mM} \mathrm{MgCl}$, $1 \mathrm{mM}$ EGTA, $1 \mathrm{mM} \mathrm{DTT}$, and $0.02 \%$ Triton X-100. The reaction was terminated, and the extraction and further analysis of the $32 \mathrm{P}$ incorporated into PIP and $\mathrm{PIP}_{2}$ were performed as described elsewhere (Bothmer et al., 1990; Jolles et al., 1981). Protein determination was performed according to the method of Lowry et al. (1951).

\section{Results}

As shown previously (Jolles et al., 1991, 1992), PI kinase activity in cytosolic fractions of $\mathrm{AD}$ brains was lower than that of age-matched controls. In the first series of experiments we investigated whether the lower PI kinase activity in cytosolic fractions of $\mathrm{AD}$ brains is due to the presence of metal ions as modulating cofactors. Cytosolic fractions of $\mathrm{AD}$ and control tissue were treated with chelating agents. Chelation of the cytosolic fraction with EDTA and EGTA (both $5 \mathrm{mM}$ ) under standard conditions appeared to have had a small stimulating effect on PI kinase activity in both $\mathrm{AD}$ and control preparations (Fig. 1). However, this effect was accounted for by a small loss of protein, probably without loss of PI kinase, during dialysis after the chelation. Total PI kinase activity did not increase after chelation (results not shown). 


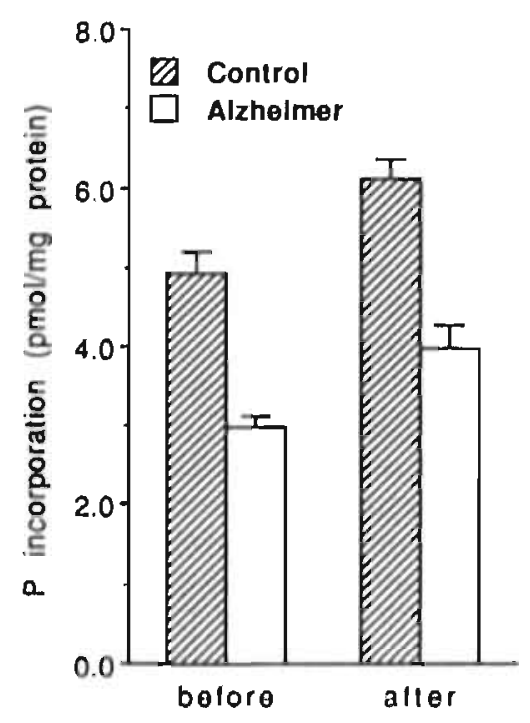

Fig. 1 : Eifect of chelation (5 $\mathrm{mM}$ EDTA and $5 \mathrm{mM}$ EGTA) on PI kinase activity (pmol/mg protein) in crude cytosolic preparations of $A D$ and control brains. Values shown are means $( \pm$ SEM) of triplicate determinations from one of two experiments that gave similar results.

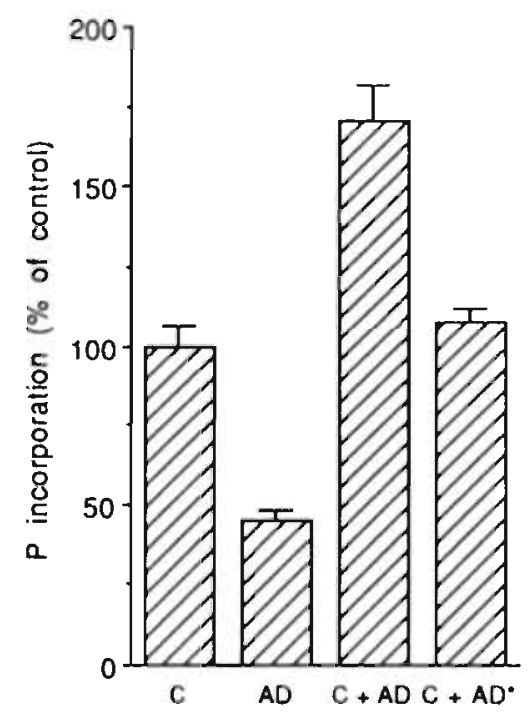

Fig. 2 : Effect of combination of crude cytosolic preparations of $A D$ and control brains on PI kinase activity (\% of control brain value). $C$ : cytosolic preparation from control brains, $A D$ : cytosolic preparation from $A D$ brains, $C+A D$ : combined cytosolic: preparation of control and $A D$ cytosolic fractions, $C+A D^{*}$ : combined cytosolic preparation of control and denaturated (10 min. $100^{\circ} \mathrm{C}$ ) AD cytosolic fractions. Values shown are means ( \pm SEM) of triplicate determinations from one of two experiments that gave similar results.

In order to investigate whether other (non-metal) cofactors are involved in the lower PI kinase activity in cytosolic fractions from AD brains, we assayed PI kinase activity in combined $A D$ and control fractions. PI kinase activity was neither stimulated nor inhibited (Fig. 2): PI kinase activity in the combined preparation $(C+A D)$ was equal to the sum of activities of the individual preparations (C and $A D)$. Denaturation $\left(10 \mathrm{~min}\right.$ at $100^{\circ} \mathrm{C}$ ) of the cytosolic fraction from $A D$ brains also had no effect on PI kinase activity in the combined preparation $\left(\mathrm{C}+\mathrm{AD}^{*}\right)$ compared with control (C).

The following experiments were designed to provide more information about the membrane-bound PI and PIP kinases. Solubilization experiments (Fig. 3) 

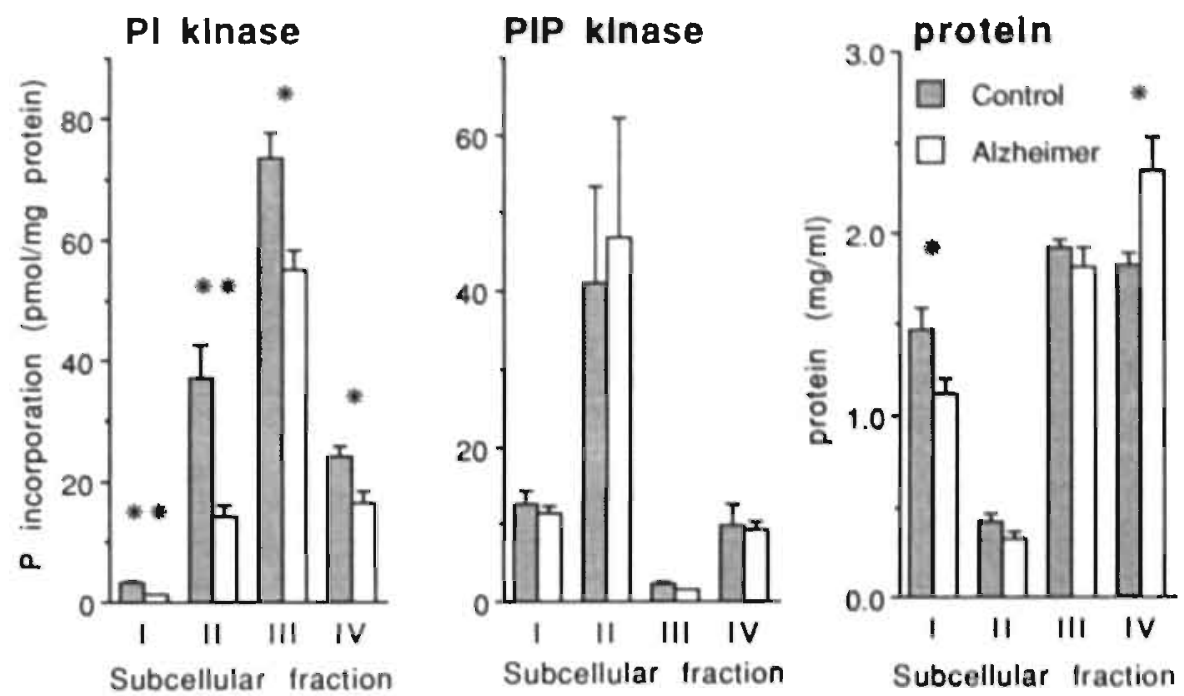

Fig. 3 : PI kinase activity (pmol/mg protein), PIP kinase activity (pmo!/mg protein) and protein content $(\mathrm{mg} / \mathrm{ml})$ of four subcellular fractions from $A D$ and control brains. 1 : cytosolic protein preparation, II : $1 \mathrm{M} \mathrm{NaCl}$-solubilized protein preparation, III : 1\% Triton X-100solubilized protein preparation, IV : residual protein preparation. Values shown are means $( \pm S E M)$ of five control subjects and five AD subjects. Statistical analysis was periormed according to Student's t-test (two-tailed). " : p<0.05, * : $p<0.005$.

showed that PI kinase activity (Fig. 3a) was located in the membrane-bound (=Triton) fraction as well as in the soluble fraction (cytosolic and salt fraction). Total PI kinase activity was located for $10 \%$ in the soluble fraction and for $90 \%$ in the insoluble fraction (Triton and residual fraction). PIP kinase activity (Fig. 3b) was located primarily in the soluble fraction (cytosolic and salt fraction). Total PIP kinase activity was located for $60 \%$ in the soluble fraction and for $40 \%$ in the insoluble fraction. PI kinase activity in $\mathrm{AD}$ brains was decreased in the cytosolic fraction as well as in the other fractions tested ("salt", "Triton", and "residual") (Fig. 3a). However, the cytosolic and salt fractions showed a $70 \%$ decrease in PI kianse activity and the Triton and residual fraction only a $25 \%$ decrease in PI kinase activity. PIP kinase activity in AD brains was not different from that of control brains in any of the fractions tested (Fig. 3b). The cytosolic fraction of AD brains contained less protein and the residual fraction more protein than similar fractions prepared from control brains (Fig. 3c).

The two types of PI kinases (type 1 and 2, or PI 3-kinase and PI 4-kinase) described by Whitman et al. (1987) have a different subcellular distribution and are affected differently by the non-ionic detergent Triton X-100 and the potentially inhibiting component adenosine. In order to investigate which type of PI kinase 


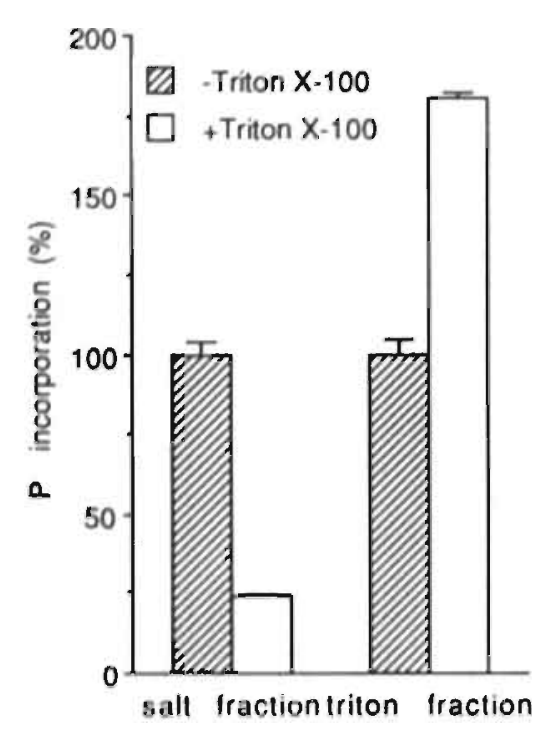

Fig. 4 : Effect of $1 \%$ Triton $X-100$ on PI kinase activity (expressed as \% of control) in the $1 \mathrm{M}$ NaCl-solubilized protein preparation (salt fraction) and the $1 \%$ Triton $X=100-$ solubilized protein preparation (Triton fraction) of control brains. Triton $X-100$, present in the Tritonsolubilized protein preparation, was first removed with detergent-removing gel. Values shown are means ( \pm SEM) of triplicate determinations from one of two experiments that gave similar results.

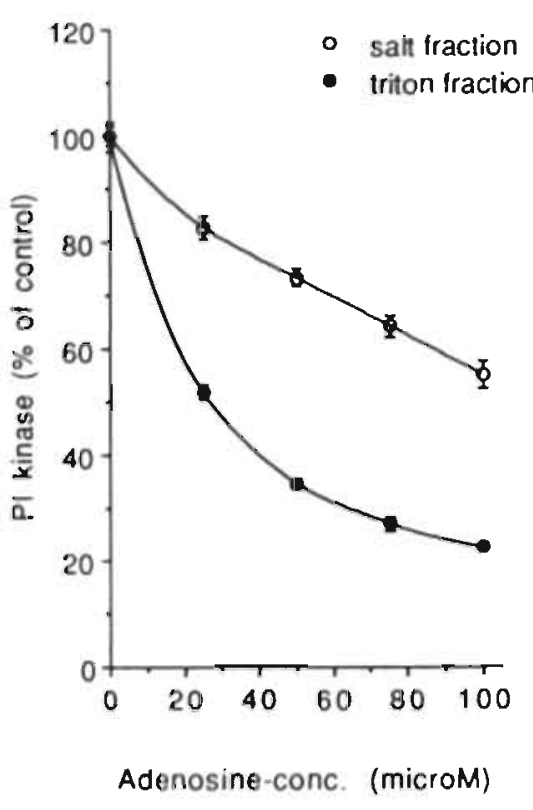

Fig. 5 : Effect of adenosine on PI kinase activity (expressed as \% of control) in the 1 $\mathrm{M} \mathrm{NaCl}-$ solubilized protein preparation (salt fraction) and the $1 \%$ Triton $\times-100-$ solubilized protein preparation (Triton fraction) of control brains. Values shown are means ( $\triangle S E M$ ) of triplicate determinations from one of two experiments that gave similar results.

was the most abundant in the different solubilized fractions, we measured the effect of $1 \%$ Triton X-100 on PI kinase activity in the salt fraction and in the Triton fraction of control brains. Triton $X-100$, present in the Triton-solubilized fraction, was first removed with a detergent-removing gel (Extracti-Gel D, Pierce). PI kinase activity was inhibited in the salt fraction $(-75 \%)$ and stimulated in the Triton fraction $(+80 \%)$ after addition of $1 \%(w / v)$ Triton X-100 (Fig. 4). Furthermore, adenosine appeared to inhibit PI kinase activity in the Triton fraction whereas PI kinase activity in the salt fraction was rather insensitive to adenosine (Fig. 5).

\section{Discussion}

In this paper we investigated the biochemical mechanism underlying the 
lower levels of PI kinase activity in cytosolic fractions from AD brains than in agematched control brains. We explored what type of PI kinase is affected in AD, and whether inhibiting or stimulating compounds are involved in the lower PI kinase activity found in $\mathrm{AD}$ brains.

Jolles et al. (1991, 1992) have shown a 50\% decrease in PI kinase activity in cytosolic fractions of four neocortical regions from $\mathrm{AD}$ brains compared with control brains. Our results suggest that this difference is not caused by increased levels of inhibitory (e.g., metal ion) or decreased levels of stimulatory (e.g., cofactor) compounds. Potentially inhibitory metal ions were chelated (Fig. 1) in the first experiment, but PI kinase activity was not changed in $A D$ and control preparations. An inhibitory compound in the cytosolic fractions of $\mathrm{AD}$ brains would have been expected to decrease PI kinase activity in a combined preparation to below the level of the sum of both cytosolic fractions (control and A.D) assayed individually. No difference was observed (Fig. 2). If levels of a stimulatory compound were decreased in AD brains and normal in control brain, we would have expected an increase in PI kinase activity in combined preparations compared with the sum of individual activities. We observed no such increase. Our results suggest that the AD brain samples are characterized by changes in PI kinase itself or by changes in the amount of PI kinase, and probably not by changes in the level of other compounds that influence PI kinase activity.

Different types of PI kinases have been discovered recently, which differ from each other in molecular weight, enzyme kinetic properties, probable physiologic function, and subcellular localization (Carpenter and Cantley, 1990). In order to make a crude separation between these types of PI kinases, we prepared four subcellular fractions: the "cytosolic" fraction, the "salt" fraction (proteins loosely attached to the membrane), the "Triton" fraction (membrane-bound proteins), and the "residual" fraction. The decrease in PI kinase activity (Fig. 3a) was markedly greater in the cytosolic and salt fractions than in the Triton and residual fractions of $A D$ brains.

These differences between the four fractions in control brains and the differences between control and $A D$ brains are relevant in view of the findings of Whitman et al. (1987). These authors found two distinct PI kinases in fibroblasts. Type 1 PI kinase appeared to be a PI 3-kinase and type 2 PI kinase a PI 4-kinase (Whitman et al., 1988). The latter is located primarily in the membranes of bovine brain myelin (Sâltiel et al., 1987), human platelets (Kanoh et al., 1990), and human cell cultures (Walker et al., 1988), whereas type 1 PI kinase is located primarily in the cytosol (Carpenter et al., 1990; Shibasaki et al., 1991). However, a significant amount of type 1 PI kinase appears to be associated with the membrane in growth factor-stimulated and/or oncogene-transformed fibroblasts (Auger and Cantley, 1991; Cohen et al., 1990a,b). Thus the PI kinase activity in the cytosolic and salt fractions, which was affected to a greater extent than in the Triton and residual fractions in $A D$ preparations, is probably predominantly due to a type 1 or PI 3-kinase, whereas the PI kinase activity in the Triton and residual fractions is probably due to a PI 4-kinase, with some PI 3-kinase also being present. The observation that the PI kinase activity in the salt fraction was 
inhibited by $1 \%$ Triton $X-100$ and the PI kinase activity in the Triton fraction was stimulated by this detergent (Fig. 4) also points in this direction because Whitman et al. (1988) showed that type 1 PI kinase is inhibited by Triton X-100 in contrast to type 2 and 3 PI kinase, which are stimulated by Triton X-100. Furthermore, adenosine, which is a potent inhibitor of type 2 PI 4-kinase at concentrations where type 1 PI 3-kinase remains unaffected (Carpenter and Cantley, 1990), inhibited the PI kinase activity in the Triton fraction whereas the PI kinase activity of the salt fraction was rather insensitive to adenosine inhibition. Thus, the soluble fractions (cytosolic and salt), which were affected the most in AD brains, are probably enriched in one specific type of PI kinase, namely type 1 or PI 3-kinase.

This finding is important in view of the different physiologic functions of the different PI kinases. Type 2 and probably aiso type 3 PI kinase are involved in the pathways leading to hormone-stimulated phospholipase $C$ activity, which results in the release of the second messengers inositol trisphosphate and diacylglycerol (Carpenter and Cantley, 1990). Type 1 PI kinase, however, is suggested to function in mitogenesis and cytoskeletal rearrangments as this enzyme associates with tyrosine kinases and growth factor receptors (Auger and Cantley, 1991; Carpenter and Cantley, 1990; Martelli et al., 1991; Varticovski et al., 1989). A lack of association with tyrosine kinases and growth factor receptors of type 1 PI kinase correlates with a lack of actin reorganization and the mitogenic signal (Auger and Cantley, 1991). Thus the relationship between type 1 PI kinase and the turnover of the cytoskeleton could have implications for the cellular pathology of AD because this disorder is characterized by the occurrence of neurofibrillary tangles (Holtzman and Mobley, 1991). These tangles are protein deposits inside the neurons, and are partially composed of abnormally phosphorylated microtubuleassociated proteins (Hanger et al., 1991; Kosik, 1991). Under physiologic conditions microtubule-associated proteins stabilize the cytoskeleton (Kosik, 1991).

The specificity of the effect on PI kinase is suggested by the lack of a difference between PIP kinase activity in control and AD preparations (Fig. 3b). Jolles et al. (1991, 1992) also found no differences in PIP kinase activity in cytosolic fractions from $\mathrm{AD}$ and control brains. The fact that PIP kinase, which like type 2 PI kinase is implicated in the pathways leading to hormone-stimulated phosphoinositide specific PLC activity, is not affected in $A D$ brains suggests that this physiologic function of PI kinase is not affected in AD brains. The highest PIP kinase activity was measured in the cytosolic and salt fractions (Fig. 3b). Previous studies have revealed a cytosolic PIP kinase and a loosely membrane-bound PIP kinase in human erythrocytes (Bazenet et al., 1990; Ling et al., 1989) and bovine brain (Moritz et al., 1990).

Protein deposits in the brain are a prominent characteristic of AD. Our results are of interest in this respect because there appeared to be a shift of protein from the cytosolic fraction to the residual fraction (Fig. 3c) in AD brains compared with control brains. This shift probably represents a shift of protein from the soluble fraction to the insoluble fraction in AD brains, which would be consistent with 
the cellular pathology of $\mathrm{AD}$.

In conclusion, we have shown that the lower PI kinase activity in cytosolic fractions from $A D$ brains is not caused by increased levels of an inhibitory compound or decreased levels of a stimulatory compound in the cytosol of $\mathrm{AD}$ brains. Furthermore, our results suggest that just one type of PI kinase is affected in AD brains, namely type 1. PI kinase. Interestingly, type 1 PI kinase seems to be involved in the turnover of the cytoskeleton, which is closely related to the cellular pathology of AD. PIP kinase, which is implicated in hormone-stimulated phosphoinositide specific phospholipase $\mathrm{C}$ activity and results in the release of the second messengers inositol trisphosphate and diacylglycerol, is not affected in $A D$ brains. The present data provide new avenues for investigating the biochemical mechanism underlying the well-known cellular pathology of Alzheimer's disease.

\section{References}

Abdel-Latif A.A. (1986) Calcium-mobilizing receptors, polyphosphoinositides, and the generation of second messengers. Pharmacol. Rev. 38, 227-272.

Auger K.R., and Cantley L.C. (1991) Novel polyphosphoinositides in cell growth and activation. Cancer Cells 3, 263-270.

Bazenet C.E., Kuano A.R., Brockman J.L., and Anderson R.A. (1990) The human erythrocyte contains two forms of phosphatidylinositol-4-phospliate 5-kinases which are differently active toward membranes. J. Biol. Chem. 265, 18012-18022.

Berridge M.J. (1987) Inositol triphosphate and diacylglyceroll: two interacting second messengers. Ann. Rev. Biochem. 56, 159-193.

Berridge M.J., and Irvine R.F. (1984) Inositol triphosphate, a novel second messenger in cellular signal transduction. Nature 312, 315-321.

Bird et al. (1985) Alzheimer's disease: choline acetyltransferase activity in brain tissue from clinical and pathological subgroups. Ann. Neurol. 14, 284-293.

Bothmer J., Markerink M., and Jolles J. (1990) Phosphatidic acid and polyphosphoinositide formation in a broken cell preparation from rat brain: Effect of different incubation conditions. Neurochem. Int. 17, 27-33.

Carpenter C.L., and Cantley L.C. (1990) Phosphoinositide kinases. Biochemisiry 29, 11147-11156.

Carpenter C.L., Duckworth B.C., Auger K.R., Cohen B., Schaffhausen B.S., and Cantiey L.C. (1990) Purification and characterization of phosphoinositide 3-kinase from rat liver. I. Biol. Chem. 265, 19704-19711.

Cochet C., Filhol O., Payrastre B., Hunter T., and Gill G.N. (1991) Interaction between the epidermal growth factor receptor and phosphoinositide kinases. J. Biol. Chem. 266, 637-644.

Cohen B., Yoakim M., Piwnica-Worms H., Roberts T.M., and Schafthasen B.S. (1990a) Tyrosine. phosphorylation is a signal for the trafficking of pp85, an $85-\mathrm{kDa}$ phosphorylated polypeptide associated with phosphatidylinositol kinase activity. Proc. Nall. Acad. Sci. USA 87, 4458-4462.

Cohen B., Liu Y., Druker B., Roberts T.M., and Schaffhausen B.S. (1990b) Characterization of pp85, a target of oncogenes and growth factor receptors. Mol. Cell. Biol. 10, 2909-2915.

Dongen C.J. van, Kok J.W., Schrama L.H., Oestreicher A.B., and Gispen W.H. (1986) Immunochemical characterization of phosphatidylinositol 4-phosphate kinase from rat brain. Biochem. I. 233, 859-864.

Downes C.P., and MacPhee C.H. (1990) myo-lnositol metabolites as cellular signals. Eur. J. Biochem. 193, 1-18.

Endernann G., Dunn S.N., and Cantley L.C. (1987) Bovine brain contains two types of phosphatidylinositol kinase. Biochemis!ry 26, 6845-6852. 
Hanger D.P., Brion J.-P., Gallo J.-M., Cairns N.\}., Luthert P.J., and Anderton B.H. (1991) Tau in Alzheimer's disease and Down's syndrome is insoluble and abnormally phosphorylated. Biochem. J. 275, 99=104.

Holtzman D.M., and Mobley W.C. (1991) Molecular studies in Alzheimer's disease. TIBS 16, 140144.

Jolles J., Bothmer J., and Markerink M. (1991) Decreased formation of phosphatidylinositolphosphate (PIP) but not phosphatidylinositolbisphosphate $\left(\mathrm{PIP}_{2}\right)$ in Alzheimer's diseased brain versus control brain. 1. Neurochew. 57 (suppl.), 65C.

Jolles J., Bothmer J., and Markerink M. (1992) Phosphatidylinositol kinase is reduced in Alzheimer's disease. I. Neurochem. 58, 2326-2329.

Jolles J., Zwiers., Dekker A., Wirtz K.W.A., and Gispen W.H. (1981) Corticotropin-(1-24)tetracosapeptide affects protein phosphorylation and polyphosphoinositide metabolism in rat brain. Biochem. J. 194, 283-291.

Kanoh H., Banno Y., Hirata M., and Nozawa Y. (1990) Partial purification and characterization of phosphatidylinositol kinases from human platelets. Biochim. Biophys. Acta 1046, 120-126.

Kosik K.S. (1991) Alzheimer's plaques and tangles: advances on both fronts. TINS 14, 218-219.

Ling L.E., Schulz J.T., and Cantley L.C. (1989) Characterization and purification of membraneassociated phosphatidylinositol-4-phosphate kinase from human red blood cells. J. Biol. Chem. 264, 5080-5088.

Lowry O.H., Rosebrough N.J., Farr A.L., and Randall R.J. (1951) Protein measurements with the folin phenol reagent. J. Biol. Chem. 193, 265-275.

MacDonald T.L., and Martin R.B. (1987) Aluminum ions in biological systems. TIBS 13, 15-19.

MacDonald L.l., and Mamrack M.D. (1988) Aluminum affects phosphoinositide hydrolysis by phosphoinositidase C. Biochem. Biophys. Res. Comm. 155, 203-208.

Martelli A.M., Gilmour R.S., Neri L.M., Manzoli L., Corps A.N., and Cocco L. (1991) Mitogenstimulated events in nuclei of Swiss $3 \mathrm{~T} 3$ cells. Evidence for a direct link between changes of inositol lipids, protein kinase C requirement and the onset of DNA synthesis. FEBS Lett. 283, 243246.

Miatto O., Gonzales R.G., Buonanno F, Growdon J. (1986) In vitro 31P NMR spectroscopy detects altered phospholipid metabolism in Alzheimer's disease. Can. J. Neurol. Sci. 13, 535-539.

Moritz A., DeGraan P.N.E., Ekhart P.F., Gispen W.H., and Wirtz K.W.A. (1990) Purification of a phosphatidylinositol-4-phosphate kinase from bovine brain membranes. J. Neurochem. 54, 351.

Pettegrew J.W., Moossy J., Panchalingham K., Martinez J., Strychor S., McKeag G., Brantoover G., and Boller F. (1989) Correlation of phospholipids and senile plaques in Alzheimer's Disease. Newroloxy 39 (suppl. 1), 396.

Saltiel A.R., Fox J.A., Sherline P., Sahyoun N., and Cuatrecasas P. (1987) Purification of phosphatidylinositol kinase from bovine brain myelin. Biochem. J. 241, 759-763.

Shibasaki F., Homma $Y$., and Takenawa T. (1991) Two types of phosphatidylinositol 3-kinase from bovine thymus. I. Biol. Chem. 266, 8108-8114.

Stokes C.E., and Hawthome I.N. (1987) Reduced phosphoinositide concentrations in anterior temporal cortex of Alzheimer-diseased brains. J. Neurochem. 48, 1018-1021.

Varticovski L., Druker B., Morrison D., Cantley L., and Roberts T. (1989) The colony stimulating factor-1 receptor associates with and activates phosphatidylinositol 3-kinase. Nature 342, 699702 .

Walker D.H., Dougherty N., and Pike L.J. (1988) Purification and characterization of a phosphatidylinositol kinase from A431 cells. Biochemistry 27, 6504-6511.

Whitman M. Downes C.P., Keeler M., Keller T., and Cantley L. (1988) Type 1 phosphatidylinositol kinase makes a novel inositol phospholipid, phosphatidylinositol-3-phosphate. Nature 332, $644-646$.

Whitman M., Kaplan D., Roberts T., and Cantley L. (1987) Evidence for two distinct phosphatidylinositol kinases in fibroblasts. Biochem. 1. 247, 165-174.

Yamakawa A., and Takenawa T. (1988) Purification and characterization of membrane-bound phosphatidylinositol kinase from rat brain. I. Biol. Chem. 263, 17555-17560. 
CHAPTER 10

\section{PLATELET PHOSPHOINOSITIDE KINASE ACTIVITY IS NOT ALTERED IN ALZHEIMER'S DISEASE.}

J. Bothmer, M. Markerink, R. Coppens and J. Jolles

Published in:

Molecular and Chemical Neuropathology, accepted for publication. 


\begin{abstract}
We previously reported a specific decline in phosphatidylinositol (PI) kinase activity in the neocoriex of patients with Alzheimer's disease (AD) as compared to controls, whereas phosphatidylinositol phosphate (PIP) kinase activity appeared not to be affected (Jolles et al. (1992) J.Neurochem. 58, 2326-2329). In search for a possible systemic effect of Alzheimer's disease, in the present study we investigated phosphoinositide kinase activity in platelets from patients with $\mathrm{AD}$ and from control subjects. The study was based upon the notion that disease-specific abnormalities in the brain could be reflected in blood platelets. PI kinase activity was studied in platelet homogenates and in a salt-solubilized protein fraction of platelets, because of the difference in subcellular localization of the different types of PI kinases. In addition, NADH cytochrome-C reductase was measured in platelet homogenates as a marker for the endoplasmic reticulum, to detect a possible proliferation of the endoplasmic reticulum. AD patients and normal elderly controls showed no difference in PI kinase activity in either enzyme fraction. Furthermore, NADH cytochrome-C reductase activity and the protein / phospholipid ratio per $10^{6}$ platelets were the same for AD patients and controls. This was taken as an indication that platelets in AD patients do not show proliferation of intracellular membranes.
\end{abstract}

\title{
Introduction
}

Alzheimer's disease is a neurodegenerative disorder characterized by large numbers of neurofibrillary tangles and neuritic plaques in the central nervous system (CNS) (Selkoe, 1991). The neuritic plaques are composed of amyloid or B/A4 protein, which is produced by abnormal proteolytic cleavage of a cellsurface protein, the amyloid precursor protein (APP; Selkoe, 1991). Studies on the expression of APP have shown that it is not restricted to the brain, but that it is almost ubiquitously present (Bush et al., 1991). The potentially amyloidogenic APP is, for example, present in human platelets (Bush et al., 1990) which also show an abnormal membrane fluidity in AD (Zubenko et al., 1987a,b), probably caused by the proliferation of internal membranes (Hajimohammadreza et al., 1990; Piletz et al., 1991; Zubenko et al., 1987a). Furthermore, abnormalities of the function and morphology of platelets in Parkinson's disease, Huntington's disease and depression indicate that disease-specific abnormalities in the brain could be reflected in human platelets (Bush et al., 1991).

The metabolism of phosphoinositides, a class of phospholipids enriched in neuronal membranes, is also affected in the CNS of AD patients. The concentration of phosphoinositides is lower in AD brains than in brains from controls (Stokes and Hawthorne, 1987). Furthermore, Jolles et al. (1992) reported a substantial decline in PI kinase activity in AD brains whereas PIP kinase activity was not affected. If the $50 \%$ lower PI kinase activity found in AD brains were also reflected in AD platelets, platelets could be used as a diagnostic tool. With respect to the type of PI kinase involved in the decrease in PI kinase activity in AD brain, there is some evidence that type 1 PI kinase or PI 3-kinase is specifically affected (Bothmer et al., submitted). This is also a reason why platelets were chosen in 
this study and not erythrocytes, because platelets contain a complete phosphoinositide metabolizing system with both PI 4-kinase (Kanoh et al.,1990) and PI 3-kinase (Cunningham et al., 1990; Huang et. al., 1991), in contrast to human erythrocytes in which PI 3-kinase has not been identified (Wetzker et al., 1991). These authors purified PI 4-kinase to near homogenity from human erythrocytes, but found no evidence for any PI 3-kinase activity. The AD patients in the present study had an "age of first symptoms" below 75 years, which is important because AD patients with an "age of first symptoms" above 75 years did not differ from age-matched controls with respect to brain cytosolic PI kinase activity (Jolles et al., in press). Because disease-specific abnormalities in the brain can be reflected in platelets, and because platelets have a complete phosphoinositide metabolism with both PI 4-kinase and PI 3-kinase we compared PI kinase activity in platelets from AD patients with that of platelets from agematched controls. We also measured NADH cytochrome-C reductase as a marker for the endoplasmic reticulum (Sun et al., 1988).

\section{Experimental procedures}

\section{Patient selection}

The subjects were five patients (three males and two females) with Alzheimer's disease and five normal elderly controls (three males and two females). Prior to entry in this study, all subjects underwent thorough medical, neurological and psychiatric examinations. The psychogeriatric scales for determination of the severity of dementia were Global Deterioration Scale, Blessed Dementia Scale, Mini Mental State Exam, Haschinski ischemic score and Hamilton depression scale (Verhey et al., 1992). All patients met ADRDA-NINCDS criteria for "probable Alzheimer's Disease" (McKhann et al,, 1984). AD patients (mean age 69.2 years) and controls (mean age 70.6 years) were individually matched for age and sex. The mean age of first symptoms in the AD patient group was 63.6 years with a maximum of 72 years.

\section{Preparation of platelet homogenates and cytosolic fractions}

Blood was drawn into a tube containing $2 \mathrm{ml} \mathrm{ACD}(80 \mathrm{mM}$ tri-Na-citrate, $52 \mathrm{mM}$ citric acid and $183 \mathrm{mM}$ glucose, $\mathrm{pH} 4.5$ ) and centrifuged at $250 \mathrm{xg}$ for $15 \mathrm{~min}$ (room temperature). The resulting platelet-rich plasma (4 m]) was added to 200 $\mu \mathrm{l} \mathrm{ACD}$ and centrifuged at $850 \times \mathrm{xg}$ for $15 \mathrm{~min}$ (room temperature). The platelet pellet thus obtained was resuspended in $1 \mathrm{ml}$ Hepes buffer (10 mM, pH 6.6) containing 5 $\mathrm{mg} / \mathrm{ml}$ bovine serum albumin (BSA). The volume was adjusted to $14 \mathrm{ml}$ with the same buffer, $1 \mathrm{ml} A C D$ was added and the suspension was centrifuged for 15 $\mathrm{min}$ at $850 \mathrm{xg}$. The supernatant was discarded and the pellet was resuspended in 1 $\mathrm{ml}$ Hepes buffer ( $10 \mathrm{mM}, \mathrm{pH}$ 6.6) without BSA. After centrifugation at $850 \times \mathrm{g}$ for $15 \mathrm{~min}$, the pellet was resuspended in $1 \mathrm{ml}$ ice-cold Tris-buffer $(20 \mathrm{mM}, 1 \mathrm{mM}$ 
EGTA, $1 \mathrm{mM}$ DTT, pH 7.4) and put on ice. The platelet suspension was homogenized by 10 up-and-down strokes in a. Teflon-glass homogenizer rotating at $700 \mathrm{rpm}$. The homogenate was sonicated on ice at maximum power for $3 \times 10$ sec with $1 \mathrm{~min}$ pauses. The resulting homogenate was stored at $-80^{\circ} \mathrm{C}$. Crude cytosolic and salt-solubilized protein fractions were prepared by the addition of an equal volume of Tris-buffer (as described above) containing $2 \mathrm{M} \mathrm{NaCl}$ to the homogenate. After thorough mixing, the sample was allowed to stand for 1 hour at $4^{\circ} \mathrm{C}$, and was then spun down at $15,000 \times \mathrm{g}$ for $15 \mathrm{~min}$ at $4^{\circ} \mathrm{C}$. The resulting supernatant was dialysed (1:100) on micro-dialysis filters (Millipore, pore size 5 $\mu \mathrm{m})$ against Tris-buffer for 2 hours at $4^{\circ} \mathrm{C}$.

\section{Enzyme assays}

Phosphatidylinositol (PI) kinase activity was measured as described before (Jolles et al., 1992). Homogenate and cytosolic fractions $(15 \mu \mathrm{l}$ corresponding to $10 \mu \mathrm{g}$ protein) were preincubated for $2 \mathrm{~min}$. Lipid precursors (20 $\mu \mathrm{M}$ PI, Sigma), solubilized in $0.1 \%$ Triton $X-100$ in $50 \mathrm{mM}$ Tris- $\mathrm{HCl} / 1 \mathrm{mM}$ EGTA / pH 7.4, were added $15 \mathrm{sec}$ before the phosphorylation reaction was started by the addition of ATP. Incubations were performed under the following conditions: $7.5 \mu \mathrm{M}$ ATP, 2 $3 \mu \mathrm{Ci}$ [gamma-32P]ATP (approx. $3000 \mathrm{Ci} / \mathrm{mmol}$, Amersham, U.K.), $50 \mathrm{mM}$ Tris$\mathrm{HCl} \mathrm{pH} 7.4,10 \mathrm{mM} \mathrm{MgCl}_{2}, 1 \mathrm{mM}$ EGTA and $0.02 \%$ Triton $X-100$. The reaction was terminated after $1 \mathrm{~min}$, and the extraction and further analysis of the $32 \mathrm{P}$ incorporated into PIP were performed as described elsewhere (Jolles et al., 1981; Bothmer et al., 1990). NADH cytochrome-C reductase, a marker enzyme for the endoplasmic reticulum, i.e., the microsome fraction, was assayed according to the method of Sun et al. (1988). Briefly, the assay mixture contained $0.1 \mathrm{mM}$ NADH, $36 \mu \mathrm{M}$ cytochrome-C, $0.3 \mathrm{mM} \mathrm{KCN}$ and $50 \mathrm{mM}$ phosphate buffer ( $\mathrm{pH} 7.6$ ) with 0.1 $\mathrm{mM}$ EDTA. After addition of the homogenate, the reaction was monitored spectrofotometrically at $A_{550}$ for $30 \mathrm{~min}$. Protein was determined according to the method of Lowry et al. (1951) and total lipid phosphorus was determined as described belore (Bothmer et al., 1992).

\section{Results}

Platelets from AD patients and normal elderly controls incorporated phosphate into PIP (Fig. 1A) in both the homogenate as well as in the cytosolic / salt-solubilized enzyme fraction. The cytosolic / salt-solubilized protein fraction had a higher specific PI kinase activity than the platelet homogenate, but there was no difference in PI kinase activity between AD patients and controls.

A second experiment was performed in order to determine whether there was proliferation of internal membranes in platelets of AD patients. NADH cytochrome-C reductase, which is a specific marker for the endoplasmic reticulum, and the protein / total phospholipid ratio, which is expected to be 

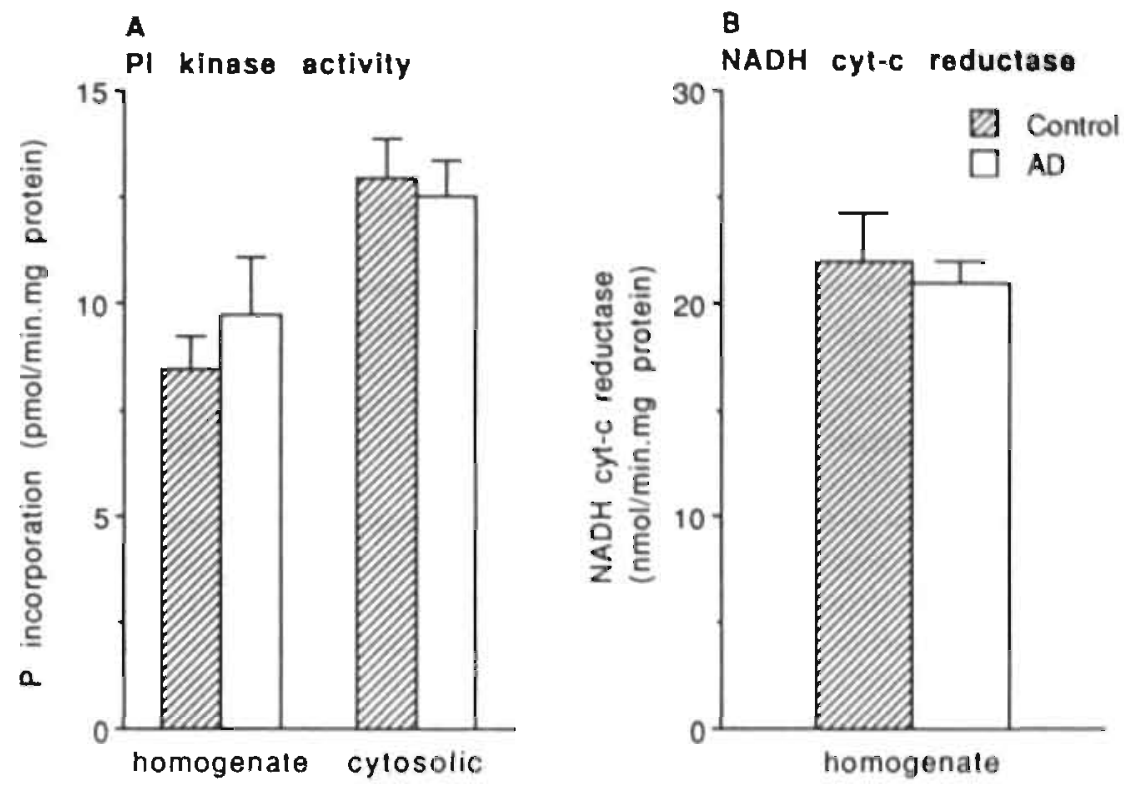

Fig. 1: PI kinase (Fig. 1A) activity (pmol/min.mg protein) and NADH cytochrome C reductase (Fig. 1B) activity (nmol/min.mg protein) in homogenates and cytosolic/saltsolubilized fractions of platelets from patients with probable Alzheimer's disease (AD) $(n=5)$ and age-matched controls $(n=5)$. Values shown are means ( + SEM).

decreased in the case of proliferating internal membranes, were measured. Fig. $1 \mathrm{~B}$ shows that NADH cytochrome-C reductase activity was not increased in homogenates of platelets from $\mathrm{AD}$ patients as compared to controls.

Proliferation of internal membranes (increasing content of phospholipids) without expansion of the cytoplasm (slight or no increase in protein) would result in a decrease in the protein / total phospholipid ratio per $10^{6}$ platelets. However, the protein / phospholipid ratio per 106 platelets, the protein content per $10^{6}$ platelets and the total phospholipid phosphorus content per $10^{6}$ platelets were not altered in homogenates of platelets from AD patients as compared to controls (Table 1).

\section{Discussion}

We previously reported a specific decline in PI kinase activity in the neocortex of $\mathrm{AD}$ patients as compared to controls, whereas PIP kinase appeared not to be affected (Jolles et al., 1992). The identity of the type of PI kinase affected in AD is not yet clear, but we have experimental evidence that PI 3-kinase is involved 
Table 1 : Protein content, total phospholipid phosphorus content and the ratio protein content vs tota! phospholipid phosphorus content in the homogenate of platelets from both controls and probable Alzheimer (AD) patients. Values shown are means ( \pm SEM). Data were analysed with paired student T-test (two tailed).

\begin{tabular}{llll}
\hline subjects & $\begin{array}{l}\text { protein } \\
\left(\mathrm{mg} / 10^{6} \text { platelets }\right)\end{array}$ & $\begin{array}{l}\text { phospholipid phospho- } \\
\text { rus }(\mu \mathrm{g} / 106 \text { platelets })\end{array}$ & $\begin{array}{l}\text { protein/phosphorus } \\
\text { (per 106 platelets) }\end{array}$ \\
\hline $\begin{array}{l}\text { Controls } \\
(\mathrm{n}=5)\end{array}$ & $0.778( \pm 0.053)$ & $0.323( \pm 0.020)$ & $2.416( \pm 0.114)$ \\
$\begin{array}{l}\mathrm{AD} \\
(\mathrm{n}=5)\end{array}$ & $0.768( \pm 0.065)$ & $0.311( \pm 0.02: 1)$ & $2.461( \pm 0.044)$ \\
\hline
\end{tabular}

paired stu- $\quad \mathrm{p}=0.87 \quad \mathrm{p}=0.43 \quad \mathrm{p}=0.76$

dent T-test

(two tailed)

(Bothmer et al., submitted). Because disease-specific abnormalities in the brain, such as those occuring in diseases like Parkinson's disease, Huntington's disease, and depression, can be reflected in platelets, this study focussed on the PI kinase activity in platelets from AD patients and controls.

The results presented in this study show that PI kinase activity in platelet homogenates from AD patients was not different from PI kinase activity in platelet homogenates from controls. PI kinase activity was also measured in a cytosolic / salt-solubilized fraction of platelets because in this fraction, prepared from $\mathrm{AD}$ brain, PI kinase activity was affected to a greater extent than in the tritonsolubilized fraction and the residual fraction (Bothmer et al., submitted). However, PI kinase activity in this fraction of platelets also revealed no differences between $\mathrm{AD}$ patients and controls. The number of controls and $\mathrm{AD}$ patients in the study ( $n=5$ for each) may seem small, this number of experimental subjects was sufficient to detect the clear difference in PI kinase activity in the brains of AD patients and controls (Jolles et al., 1992). Moreover, the patient group was very homogenous as to age, age of first symptoms, and other patient characteristics.

The membranes of platelets from AD patients appear to have an elevated platelet membrane fluidity (PMF), which correlates with the severity of dementia in patients with $\mathrm{AD}$, as assesed with the Mini-Mental Status Exam (Zubenko et al., $1987 \mathrm{C}$ ). The plasma membrane of platelets do not show an elevated PMF, but the intracellular membranes do (Piletz et al., 1991). That intracellular membranes are affected in platelets from AD patients had been shown earlier by Zubenko et al. (1987a), and was confirmed by Hajimohammadreza et al. (1990), who found proliferation of a system of trabeculated cisternae bounded by the smooth 
endoplasmic reticulum (SER) in platelets from AD patients as compared to controls after electron microscopic analysis. For the determination of such a. proliferation of intracellular membranes in platelets, we measured NADH cytochrome-C reductase, which is a marker enzyme for the smooth endoplasmic reticulum (Sun et al., 1988), and the protein / phospholipid ratio in platelet homogenates, which is expected to be decreased when there is proliferation of intracellular membranes without an increase in the cytoplasm. These markers for the possible increase in the amount of intracellular membranes did not differ in homogenates of platelets from AD patients and controls. However the literature provides contradictory evidence as to whether an increase or decrease in NADH cytochrome-C reductase activity can be expected as a result of proliferating intracellular platelet membranes in AD patients. Zubenko (1989) reported an increased activity of $\mathrm{NADH}$ cytochrome-C reductase in platelets from AD patients. In contrast, Hajimohammadreza et al. (1990) found a decreased activity of antimycin A-sensitive NADH cytochrome-C reductase in platelets from AD patients as compared to controls. This decrease in the activity of the smooth endoplasmic reticulum marker enzyme is explained as an abnormal proliferation off the smooth endoplasmic reticulum without normal levels of enzyme markers. In both studies, however, there were more control subjects and AD patient groups than in the present study, which is possibly to small for these measurements although the variation between subjects was reasonable.

Despite the indications that, firstly, specific abnormalities of some diseases in the brain can be reflected in platelets, and secondly, PI kinase activity is substantially decreased in AD brains, the present study revealed no differences in PI kinase activity in platelets from $\mathrm{AD}$ patients as compared to controls. Although evidence for a proliferation of intracellular membranes in platelets from AD patients has been described in the literature, no evidence for such proliferation was found in this study.

\section{References}

Bothmer J., Markerink M., and Jolles J. (1990) Phosphatidic acid and polyphosphoinositide formation in a broken cell preparation from rat brain: effects of different incubation conditions. Neurochem. Int. 17, 27-33.

Bothmer J., Markerink M., and Jolles J. (1992) Brain phosphatidic acid and polyphosphoinositide formation in a broken cell preparation: Regional distribution and the effect of age. Neurochem. Int. 21, 223-228.

Bush A.l., Beyreuther K., and Masters C. (1991) Circulating forms of amyloid precursor protein of Alzheimer's disease. In: Alzheimer's disease: Basic mechanisms, diagnosis and therapeutic strategies. (Iqbal K. et al., eds.) pp. 547-556. J. Wiley \& Sons Ltd., U.K.

Bush A.I., Martins R.N., Rumble B., Moir R., Fuller S., Milward E., Currie J., Ames D., Weidemann A., Fischer P., Multhaup G., Beyreuther K., Masters C.L. (1990) f. Biol. Chem. 265, 15977-15983.

Cunningham T.W., Lips D.L., Bansal V.S., Caldwell K.K., Mitchell C.A., and Majerus P.W. (1990) Pathway for the formation of D-3 phosphate containing inositol phospholipids in intact human platelets. I. Biol. Chem. 265, 21676-21683.

Hajimohammadreza I., Brammer M.J., Eagger S., Burns A., and Levy R. (1990) Platelet and 
erythrocyte membrane changes in Alzheimer's disease. Biochim. Biophys. Acta 1025, 2086-214.

Huang R.-s., Sorisky A., Church W.R., Simons E.R., and Rittenhouse S.E. (1991) "Thrombin" Receptor-directed ligand accounts for activation by thrombin of platelet phospholipase $C$ and accumulation of 3-phosphorylated phosphoinositides. J. Biol. Chem. 266, 18435-18438.

Jolles J., Zwiers H., Dekker A., Wirtz K.W.A., and Gispen W.H. (1981) ACTH1-24 affects protein phosphorylation and polyphosphoinositide metabolism in the rat brain. Biochem. J. 194, 283291.

Jolles J., Bothmer J., Markerink M., and Ravid R. (1992) Phosphatidylinositol kinase activity is reduced in Alzheimer's disease. J. Neurochem. 58, 2326-2329.

Jolles J., Bothmer J., Markerink M., and Ravid R. Reduced PI kinase activity in Alzheimer's disease: Effects of age and onset. Dementia, in press.

Kanoh H., Banno Y., Hirata M., and Nozawa Y. (1990) Partial purification and characterization of phosphatidylinositol kinases from human platelets. Biochim. Biophys. Acta 1046, 120-126.

Lowry O.H., Rosebrough N.J., Farr A.L., and Randall R.J. (1951) Protein measurement with the Folin phenol reagent. J. Biol. Chem. 193, 265-275.

McKharn G., Drachman D., Folstein M., Katzman R., Price D., and Stadlan E.M. (1984) Clinical diagnosis of Alzheimer's disease: a report of the NINCDS-ADRDA work-group under the auspices of the Department of Health and Human Services Task Force on Alzheimer's Disease. Newrology 34, 939-944.

Piletz J.E., Sarasua M., Whitehouse P., and Chotani M. (1991) Intracellular membranes are more fluid in platelets of Alzheimer's disease patients. Neurobiol. Aging 12, 401-406.

Selkoe D.J. (1991) Amyloid protein and Alzheimer's disease. Scientific American 265 (4), 40-47.

Stokes C.E., and Hawthome J.N. (1987) Reduced phosphoinositide concentrations in anterior temporal cortex of Alzheimer-diseased brains. /. Neurochem. 48, 1018-1021.

Sun G.Y., Huang H.-M., Kelleher J.A., Stubbs jr. E.B., and Sun A.Y. (1988) Marker enzymes, phospholipids and acyl group composition of a somal plasma membrane fraction isolated from rat cerebral cortex: A comparison with microsomes and synaptic plasma membranes. Neurochem. Int. 12, 69-77.

Verhey F., Jolles J., Ponds R., Rozendaal N., Plugge L., de Vet H., Vreeling F., and van der Lugt P. (in press) Diagnosing dementia: a comparison between a monodisciplinary and a multidisciplinary approach. J. Neuropsychiatry. Clin. Neurosci.

Wetzker R., Klinger R., Hsuan J., Fry M.J., Kaufmann-Zeh A., Müller E., Frunder H., and Waterfield M. (1991) Purification and characterization of phosphatidylinositol 4-kinase from human erythrocyte membranes. Eur. J. Biochem. 200, 179-185.

Zubenko G.S., Malinakova 1., Chojnacki B. (1987a) Proliferation of internal membranes in platelets Irom patients with Alzheimer's disease. J. Neuropathol. Exp. Neurol. 46, 407-418.

Zubenko G.S., Cohen B.M., Boller F., Malinakova 1., Keefe N., Chojnacki B. (1987b) Platelet membrane abnormality in Alzheimer's disease. Ann. Neurol. 22, 237-244.

Zubenko C.S., Cohen B.M., Reynolds C.F., Boller F., Malinakova I., Keefe N. (1987c) Platelet membrane fluidity in Alzheimer's disease and major depression. Am. J. Psychiatry 144, 860-868.

Zubenko G.S. (1989) Endoplasmic reticulum abnormality in Alzheimer's discase: Selective alteration in platelet NADH-cytochrome $C$ reductase activity. 1. Geriatr. Psychiatry Neurol. 2, 3-10. 
CHAPTER 11

SUMMARY AND CONCLUDING REMARKS.

J. Bothmer 


\section{SUMMARY AND CONCLUDING REMARKS.}

The aim of this thesis was to provide more information about the neurochemical changes that occur in the brain with age and Alzheimer's disease (AD). Inositol phospholipids and diacylglycerol phosphorylation were chosen as neurochemical parameters because of their involvement in various important cell functions, such as receptor-mediated signal transduction and calcium release, but also mitogenic signalling and the regulation of protein kinases. Several investigators have described age-related changes in phosphoinositide metabolism and their possible involvement in the age-related decline in cell function. Phosphoinositide metabolism also seems to be involved in AD, as AD-related changes at different levels of the phosphoinositide cascade have been reported. However, phosphatidylinositol (PI) kinase, phosphatidylinositol phosphate (PIP) kinase and diacylglycerol (DAG) kinase have not been studied with respect to aging and $\mathrm{AD}$ up to now, even there is enough evidence that these enzymes could be affected.

\section{- Experiments with rat brain material}

PI, PIP and DAG kinase activities were studied in cytosolic, salt-solubilized and Triton-solubilized protein fractions of rat brain cortex as a function of age. This crude purification was used to differentiate between the different enzymes and enzyme subtypes, each of which have their own subcellular localization. There appeared to be no, or only minor, age-related changes in the formation of PIP, PIP2 and PA after addition of exogenous substrate (chapter 6).

However, when endogenous lipids were used as substrate, $\mathrm{PLP}_{2}$ formation was decreased in the frontal cortex. PA formation was also decreased in almost all brain regions tested (chapter 5). The enzyme/endogenous substrate fraction used for this study was a membrane-cytosol preparation containing plasma membranes and cytosol obtained from a fraction enriched in synaptosomes. The kinases in this fraction are probably still associated with the membrane, as they are in vivo, and in direct contact with their substrates PI, PIP and DAG. Therefore, the age-related changes in PIP kinase activity and DAG kinase activity found in this fraction of rat brain, in contrast to the lack of changes in an assay system with solubilized proteins and exogenous lipid substrate, could be due to changes in the properties of the membrane. As elaborated in chapter 1, agerelated changes in the physical properties of membranes can result in changes in the activity of enzymes attached to this membrane (Naeim and Walford, 1985); however, we did not measure the correlation between enzyme activity and membrane fluidity.

A decrease in endogenous substrate availability could also have caused the decrease in PIP $_{2}$ and PA formation. It is possible that basal PLC activity is decreased as a result of the age-related changes in membrane properties. This would result in a decreased hydrolysis of $\mathrm{PIP}_{2}$ and a decreased supply of DAG. 
This in turn would result in a decreased formation of PA in our phosphorylation assay. In addition, decreased $\mathrm{PIP}_{2}$ hydrolysis would result in an increased level of $\mathrm{PIP}_{2}$, which can inhibit PIP kinase activity by product feedback inhibition (Van Rooijen et al., 1985).

In conclusion, PI, PIP and DAG kinase activities are not affected by age in the rat brain. The age-related changes measured in the membrane cytosol preparation with endogenous lipids as substrates could be a reflection of the age-related changes in the physical properties of the membrane. Thus, the age-related changes in phospholipid phosphorylation rates reported in this thesis cannot explain the age-related changes in receptor-mediated inositol phospholipid hydrolysis reported by other investigators, as suggested in chapter 1 . These data are therefore consistent with the membrane hypothesis of aging (Naeim and Walford, 1985). The main concept of this hypothesis is that the membrane shows an ageassociated increase in microviscosity, which correlates with an increase in the cholesterol/phospholipid ratio. A less fluid membrane would result in a decline in the functioning of membrane-bound enzymes, receptors and ion channels, and, ultimately, in a decline in cell function.

in these aging studies, groups of Brown-Norway rats of different age were used. Young Brown-Norway rats showed no, or only minor, differences compared with Sprague-Dawley and Wistar rats with respect to PI, PIP and DAG kinase activities in a membrane-cytosol preparation (results not shown). Because of the high interexperimental and inter-individual variation in phosphorylation (with the membrane-cytosol preparation as enzyme/lipid substrate fraction), several variables in the preparation of the enzyme/lipid substrate fraction and the phosphorylation assay were tested. After the influence of each variable on the ultimately measured kinase activities had been evaluated, a value was chosen which was kept constant in following studies. These studies on the experimental variables revealed some interesting data.

First, the effect of time variation within experiments appeared to be very important for the different kinases, which were affected in different ways Chapter 2 shows that the effect of time variation is dependent on the phase of the subcellular iractionation procedure. After decapitation, which is regarded as a form of global cerebral ischaemic insult, PLC activity is activated in both brain tissue as well as brain homogenate, probably as a result of higher intra-celiular calcium concentrations under such conditions (Sun et al., 1990). The high levels of DAG formed under these conditions explain the increased PA formation and the decieased PIP ${ }_{2}$ formation (chapter 2) as PIP (substrate for PIP 2 formation) is also hydrolysed with increasing post-mortem delay (Dawson and Eichberg, 1965). A delay after the subcellular fractionation or before the phosphorylation assay is characterized by low calcium concentrations. The rates of $\mathrm{PIP}_{2}$ and PA formation appeared to be decreased and the rate of PIP formation increased. This is probably due to phosphomonoesterase activity increasing the level of PI (Jolles et al., 1981).

Chapter 3 shows that the amount of $\mathrm{PIP}_{2}$ ultimately formed in the phosphorylation assay decreases markedly with prolonged preincubation times. PA and PIP formation were not affected by changes in preincubation time. This 
could be an effect of increased phosphomonoesterase activity; however, if this were so, PIP formation would be expected to be increased. Another mechanism for this phenomenon could be a regulation by protein phosphorylation, as Jolles et al. (1980) reported a relationship between phosphoinositide phosphorylation and protein phosphorylation. A comparable protein fraction also showed an analogous decrease in the phosphorylation of some membrane proteins (Dunkley and Robinson, 1981).

Second, chapter 5 shows that there are regional differences in PI, PIP and DAG kinase activities in the rat brain. These differences probably reflect a regional distribution of PLC activity. This is because the rates of $\mathrm{PIP}_{2}$ and PA formation, measured in seven rat brain regions, showed an inverse correlation. A high basal PLC activity would result in high levels of DAG and, consequently, in an increased formation of PA in the phosphorylation assay used. In addition, a high basal PLC activity would result in decreased levels of PIP and PIP 2 and, consequently, in lower rates of $\mathrm{PIP}_{2}$ formation in the phosphorylation assay. However, no studies on regional differences in basal PLC activity in rat brain have been reported up to now.

Third, a study of the subcellular distribution of endogenous lipid phosphorylation activities (chapter 4) revealed an unidentified phosphorylated inositol phospholipid, specifically located in the mitochondrial fraction. The unknown inositol phospholipid was not phosphatidylinositol trisphosphate or lyso-phosphatidylinositol 4,5-bisphosphate, as judged from the elution profiles on Dowex anion-exchange columns. It could be a phosphatidylinositol bisphosphate isomer, a glycosyl-phosphoinositide or a phosphatidylinositol pyrophosphate. The formation of phosphatidylinositol pyrophosphates can be catalysed non-enzymically by bivalent metal ions (Gumber and Lowenstein, 1986). Because mitochondria contain high levels of $\mathrm{Ca}^{2+}$ a substance such as PI 4 pyrophosphate could be formed. PI-4-pyrophosphate has a $\mathrm{Rf}$ value on TLC similar to that of the unknown inositol phospholipid. HPLC analysis of the chemically hydrolysed inositol phosphate head-group or even NMR analysis is needed to identify this unknown inositol phospholipid.

\section{- Experiments with human brain material}

Pl kinase activity in cytosolic preparations of normal human brain cortex appeared to decrease with age, whereas PIP kinase activity showed no age-related change (chapter 8 ). These enzyme activities were analysed with exogenous lipids as substrate. These findings are in contrast to the findings in rat brain cortex, where no age-related differences were found (chapter 6). This discrepancy between rats and humans can be ascribed to various factors. First, species differences may provide an explanation. Although the rat is regarded as a valid model for age-related changes in physiological parameters in man, various processes are known to be different in aging rats than in aging humans. It can be questioned whether the aging rat can be regarded as a valid model for pathological brain aging in humans (AD). Second, environmental influences 
may affect the aging organism. The fact that old people are more likely to have been exposed to biological life events than young people and than rats, which are kept under standarized conditions and are well-cared for, may also underlie the difference in inositol phospholipid metabolism in aging rats and humans. Biological life events are factors other than severily impairing conditions like dementia that damage optimal brain fuctioning (Houx et al., 1991). Aged rats of an inbred strain kept under standarized conditions without almost any damaging influence of the environment are, therefore, possibly not an adequate model for human aging. However, mimicking human biological life events in rats as a model for human aging would probably meet with ethical problems. The use of animals that have been used in other studies, in which for example the animals were anaesthezised, should be taken into consideration.

In cytosolic preparations of brain cortex of AD patients, PI kinase activity appeared to be decreased as compared with that of age-matched control subjects. PIP kinase activity was not altered (chapter 7). No age-related decline in PI kinase activity and PIP kinase activity could be detected in the AD patient group (chapter 8). However, AD patients with an "age of first syptoms" above 75 years had a higher PI kinase activity (comparable to control values) than AD patients with an "age of first symptoms" below 75 years. These results suggest that Pl kinase activity can be used to differentiate AD patients into subgroups, characterized by a difference in the age of onset of AD. This interesting finding could be interpreted as an indication for heterogenity in Alzheimer's disease, in line with the results of an earlier study (Rossor et al., 1984) in which enzyme activities were found to differ in old and young $A D$ patients. The present results suggest that more research should be performed into the biochemical differentiation of $\mathrm{AD}$ subtypes.

The decline in PI kinase activity in AD is probably not caused by the presence of an inhibitory compound in $\mathrm{AD}$ cytosol, for instance metal ions, or by the loss of a soluble activating compound in $\mathrm{AD}$ cytosol, for instance cofactors, because chelation experiments and experiments in which AD cytosol and control cytosol were combined did not reveal inhibition or stimulation of PI kinase activity (chapter 9). PI kinase can be divided into at least three subtypes (Carpenter and Cantley, 1990), each with a different subcellular localization, adenosine sensitivity, detergent sensitivity, and supposed function. The greatest decline in PI kinase activity was found in the cytosolic fractions. The PI kinase activity in these fractions was inhibited by Triton $X-100$ and was relatively insensitive to adenosine, in contrast to the PI kinase activity in integral membrane protein fractions, which was stimulated by Triton X-100 and inhibited by adenosine. The PI kinase in the cytosolic fraction has the characteristics of type 1 PI kinase, or PI 3kinase, suggesting that this PI 3-kinase could be specifically affected in AD. Identification of the products of the PI kinases in AD and control brains will reveal the ultimate proof of identity. These experiments will be done in future studies.

If type 1 PI kinase, or PI 3-kinase, is specifically affected in AD, then protein tyrosine kinase activity could be involved. Several receptors which induce 
cytoskeletal rearrangements in the cell after stimulation contain intrinsic protein tyrosine kinase activity (listed in chapter 1). Activation of these receptors results in stimulation of protein tyrosine activity, resulting in the coupling and activation of PI 3-kinase and cytoskeletal rearrangements. This possible involvement of PI 3-kinase and protein tyrosine kinase in the regulation of cytoskeletal rearrangements, together with the decline in PI kinase activity (chapter 7) and tyrosine kinase activity (Shapiro et al., 1991) in AD patients, suggests that these enzymes may be involved in the cellular pathology of AD. This is because neurofibrillary tangles, which are a prominent feature of $A D$, are composed predominantly of wrongly metabolized cytoskeletal components.

There is growing evidence that AD may be a systemic disease and not just a disease with central effects. For this reason, PI kinase activity was measured in blood platelets from AD patients and age-matched controls. Platelets were chosen because disease-specific abnormalities in the brain, such as those occurring in diseases like Parkinson's disease, Huntington's disease, and depression, are also detected in platelets (Bush et al., 1991). Furthermore, platelets contain a complete phosphoinositide-metabolizing system, including type 1 or PI 3-kinase, and are easy to obtain. However, we did not find any difference between the PI kinase activities of platelets obtained from $A D$ patients and control subjects. More research into the PI kinase activities present in peripheral tissues and cells should be performed to be able to conclude whether the changes in the brain cortex are reflected systemically.

In conclusion, the results in this thesis provide new information about the neurochemical basis of brain aging and AD. Three enzymes of phosphoinositide metabolism, phosphatidylinositol kinase, phosphatidylinositol phosphate kinase and diacylglycerol kinase, appeared to be affected in aging and/or AD. The microenvironment of these enzymes appeared to be important for their activity. Therefore, the operationalization used in this thesis with a differentiation in measuring kinase activities as a function of age with and without their microenvironment was essential. In addition, the decrease in type 1 PI kinase activity in $A D$, in view of the proposed relation between this kinase activity and cytoskeletal turnover processes, could be relevant to the cellular pathology of AD.

\section{References.}

Bush A.l., Beyreuther K., and Masters C.L. (1991) Circulating forms of amyloid precursor protein of Alzheimer's disease. In: Alzheimer's disease: Basic mechanisms, diagnosis and therapeutic strategies (Igbal K., McLachlan D.R.C., Winblad B., and Wisniewski H.M., eds.), pp. 353-358. J.Wiley \& Sons, Chichester, England.

Carpenter C.L., and Cantley L.C. (1990) Phosphoinositide kinases. Biochemistry 29, 11147-11156.

Dawson R.M.C., and Eichberg J. (1965) Diphosphoinositide and triphosphoinositide in animal tissue. Extraction, estimation and changes post mortem. Biochem. J. 96. 634-643.

Dunkley P.R., and Robinson P.J. (1981) Calcium stimulated protein kinases from rat cerebral cortex are inactivated by preincubation. Biochem. Biophys. Res. Comm. 102, 1196-1202.

Gumber S.C., and Lowenstein J.M. (1986) Non-enzyrnic phosphorylation of poly-phosphoinositides and phosphatidic acid is catalysed by bivalent metal ions. Biochem. J. 235, 617-619.

Houx P.J., Vreeling F.W., and Jolles J. (1991) Age-associated cognitive decline is related to biological 
live events. In: Alzheimer's disease: Basic mechanisms, diagnosis and therapeutic strategies (1gbal K., McLachlan D.R.C., Winblad B., and Wisniewski H.M., eds.), pp. 353-358. J.Wiley \& Sons, Chichester, England.

Jolles J., Zwiers H., Van Dongen C.J., Schotman P., Wirtz K.W.A., and Gispen W.H. (1980) Modulation of brain poly-phosphoinositide melabolism by ACTH-sensitive protein phosphorylation. Nature 286, 623-625.

Jolles J., Schrama L.H., and Gispen W.H. (1981) Calcium dependent hurnover of brain polyphosphoinositides in vitro after prelabeling in vivo. Biochim. Biophys. Acta 666, 90-98.

Naeim F., and Walford R.L. (1985) Aging and cell membrane complexes: The lipid bilayer, integral proteins, and cytoskeleton. In: Handbook of the biology of aging (Finch C.E., and Schneider E.L., eds.), pp. 272-289. Van Nostrand Reinhold, N.Y.

Rossor M.N., Iverson L.L., Reynolds G.P., Mountjoy C.Q., and Roth M. (1984) Neurochemical characteristics of early and late onset types of Alzheimer's disease. Clin. Res. 288, 961-964l.

Shapiro I.P., Masliah E., and Saitoh T. (1991) Altered protein tyrosine phosphorylation in Alzheimer's disease. J. Neurochenn. 56, 1154-1162.

Sun C.Y., Yoa F.-G., and Lin T.-N. (1990) Degradation of poly-phosphoinositides in brain subcellular membranes in response to decapitation insult. Neurochem. Int. 17, 529-535.

Van Rooijen L.A.A., Rossowska M., and Bazan N.G. (1985) Inhibition of phosphatidylinositol 4phosphate kinase by its product phosphatidylinositol 4,5-bisphosphate. Biochem. Biophys. Res. Comm. 16, 150-155. 



\section{SAMENVATTING EN CONCLUSIES}

De doelstelling van het onderzoek beschreven in dit proefschrift, was meer informatie te verkrijgen over neurochemische veranderingen die plaatsvinden in de hersenen tijdens veroudering en de ziekte van Alzheimer (AD). De fosforyleringen van inositol fosfolipiden en diacy!glycerol werden gekozen als neurochemische parameters omdat deze betrokken zijn bij verschillende belangrijke celfuncties zoals receptor gemedieerde signaal transductie en het vrijmaken van calcium, maar tevens bij mitogene signaal overdracht en de regulatie van eiwit kinases. Leeftijdsafhankelijke veranderingen in het inositol fosfolipiden metabolisme en de mogelijke betrokkenheid van deze veranderingen bij de leeftijdsgerelateerde afname in het functioneren van de cel zijn door meerdere onderzoekers beschreven. Het inositol fosfolipiden metabolisme lijkt ook betrokken te zijn bij de ziekte van Alzheimer, omdat op verschillende nivo's van de fosfoinositiden cascade veranderingen zijn waargenomen, die aan de ziekte van Alzheimer zijn gerelateerd. De enzymen fosfatidylinositol (PI) kinase, fosfatidylinositol fosfaat (PIP) kinase en diacylglycerol (DAG) kinase zijn echter nog niet onderzocht in relatie tot veroudering en $A D$, hoewel er voldoende aanwijzingen zijn dat deze enzymen veranderd zouden kunnen zijn.

\section{- Experimenten met hersen materiaal van de rat}

PI, PIP en DAG kinase activiteiten werden gemeten in relatie tot de leeftijd, in cytosolaire, zout-gesolubiliseerde en Triton-gesolubiliseerde eiwit fracties van de hersen cortex van de rat. Deze ruwe zuivering werd toegepast om onderscheid te maken tussen de verschillende enzymen en hun sub-types welke allemaal hun eigen subcellulaire localisatie hebben. In dit experiment waarbij exogeen substraat werd toegevoegd, werden geen, of maar zeer kleine, aan de leeftijd gerelateerde veranderingen gevonden in de mate van PIP, PIP ${ }_{2}$ en PA vorming (Hoofdstuk 6).

Als endogeen aanwezige lipiden als substraat werden gebruikt, nam in de frontale cortex de vorming van $\mathrm{PIP}_{2}$ af met de leeftijd. De vorming van fosfatide zuur (PA) uit DAG nam in dit geval in bijna alle bestudeerde hersen regio's af met de leeftijd (Hoofdstuk 5). De voor deze studie gebruikte enzym/endogeen substraat fractie bestond uit een membraan-cytosol preparaat verkregen uit een fractie verrijkt aan synaptosomen. De kinases in deze fractie zijn waarschijnlijk nog gebonden aan de membraan en staan in direct contact met hun substraten PI, PIP en DAG, vergelijkbaar met de in vivo situatie. De aan de leeftijd gerelateerde verschillen in PIP kinase en DAG kinase activiteit in deze fractie, in tegenstelling tot de assay met gesolubiliseerde eiwitten en exogeen substraat waarin geen verschillen werden gevonden, worden dus mogelijk veroorzaakt door veranderingen in de eigenschappen van de membraan. Veranderingen in de fysische eigenschappen van de membraan als functie van de leeftijd kunnen, 
zoals beschreven in hoofdstuk 1 , de activiteit van membraan-gebonden enzymen beïnvloeden (Naeim en Walford, 1985). Wij hebben echter geen correlatie bepaald tussen enzym activiteiten en, bijvoorbeeld, membraan vloeibaarheid.

De afname in $\mathrm{PIP}_{2}$ en $\mathrm{PA}$ vorming met de leeftijd kan ook veroorzaakt worden door een afname in de hoeveelheid endogeen substraat. De niet gestimuleerde PLC activiteit kan afgenomen zijn ten gevolge van leeftijds afhankelijke veranderingen in de eigenschappen van de membraan. Dit zou dan resulteren in een verlaagde hydrolyse van $\mathrm{PIP}_{2}$ en een verlaagd aanbod van DAG. In de in dit proefschrift beschreven fosforylerings assay leidt een verlaagd aanbod van $D A G$ tot een verlaagde vorming van $P A$. Een verlaagde $\mathrm{PIP}_{2}$ hydrolyse leidt tot een toename in de hoeveelheid $\mathrm{PIP}_{2}$, met als mogelijk resultaat de remming van PIP kinase door produkt inhibitie (Van Rooijen et al., 1985).

De conclusie uit het voorgaande is dat de PI, PIP en DAG kinase activiteiten in ratte hersenen niet veranderen als functie van de leeftijd. De leeftijds gerelateerde veranderingen gemeten in het membraan-cytosol preparaat met endogene fosfolipiden als substraat zijn waarschijnlijk een afspiegeling van de leeftijds gerelateerde veranderingen in de fysische eigenschappen van de membraan. Deze leeftijds gerelateerde veranderingen in fosfolipiden fosforylerings ratio's kunnen de door andere onderzoekers beschreven leeftijds gerelateerde veranderingen in receptor gemedieerde inositol fosfolipiden hydrolyse dus niet verklaren, zoals gesuggereerd werd in Hoofdstuk 1. Deze gegevens stroken met de membraan hypothese voor veroudering (Naeim en Walford, 1985). Het hoofdpunt van deze hypothese is de leeftijds gerelateerde toename in de micro-viscositeit van de membraan, welke correleert met een toename in de cholesterol/fosfolipiden ratio. Een lagere membraan vloeibaarheid zou resulteren in een afname in het functioneren van membraan gebonden enzymen, receptoren en ion kanalen, en uiteindelijk in een afname in het functioneren van de cel.

In de beschreven verouderings studies zijn Brown-Norway ratten van verschillende leeftijden gebruikt. Jonge Brown-Norway ratten vertonen geen, of nauwelijks, verschillen met Sprague-Dawley en Wistar ratten met betrekking tot PI, PIP en DAG kinase activiteiten in een membraan cytosol preparaat van de hersenen (resultaten niet getoond). Omdat de inter-experimentele en interindividuele variatie in fosforylerings nivo (met membraan/cytosol preparaat als enzym/substraat fractie) te hoog bevonden werd, werden verschillende variabelen binnen de bereiding van de enzym/lipide substraat fractie en binnen de fosforylerings assay getest. Na meting van het effect van een variabele op de uiteindelijke kinase activiteit, werd een constante waarde gekozen voor de volgende studies. Het bestuderen van de experimentele variabelen leverde enkele interessante gegevens op.

Ten eerste blijken veranderingen in experimenteer tijd zeer belangrijk voor de verschillende kinases, die elk op een verschillende wijze hierdoor beinvloed werden. Hoofdstuk 2 laat zien dat het effect van tijd afhankelijk is van het stadium binnen de subcellulaire fractionering. Na decapitatie, wat gezien wordt als een vorm van volledige cerebrale ischemie, neemt de PLC activiteit toe in 
zowel hersenweefsel als hersenhomogenaat. Dit wordt waarschijnlijk veroorzaakt door de hoge intra-cellulaire calcium concentraties onder deze condities (Sun et al., 1990). Zowel $\mathrm{PIP}_{2}$ als P'IP worden gehydrolyseerd waarbij DAG gevormd wordt (Dawson and Eichberg, 1965). De post mortem hydrolyse van het substraat voor $\mathrm{PIP}_{2}$ vorming (PIP) verklaard de afname in $\mathrm{PIP}_{2}$ vorming, en de post mortem toename in DAG concentratie verklaard de toename in $\mathrm{PA}$ vorming in de hier gebruikte assay (Hoofdstuk 2). Een verlenging van de experimenteer tijd na de subceliulaire fractionering, of voor de fosforylerings assay wordit gekarakteriseerd door lage calcium concentraties. De $\mathrm{PIP}_{2}$ en PA vorming zijn hierdoor toegenomen en de PIP vorming is hierdoor afgenomen. Dit wordt waarschijnlijk veroorzaakt door fosfomonoesterase activiteit waardoor de hoeveelheid PI toeneennt.

Hoofdstuk 3 laat zien dat de uiteindelijk in de fosforylerings assay gevormde hoeveelheid $\mathrm{PIP}_{2}$ sterk afneemt bij langere preïncubatie tijden. De vorming van PA en PIP worden niet beïnvloed door veranderingen in de preincubatie tijd. Als dit een gevolg van fosfomonoesterase activiteit zou zijn, dan mocht verwacht worden dat de PIP vorming ook zou zijn toegenomen, wat dus niet het geval is. Een andere mogelijke verklaring voor dit verschijnsel is de regulatie van $\mathrm{PIP}_{2}$ vorming door eiwit fosforylatie. Jolles et al. (1980) laten namelijk een relatie zien tussen fosfoinositide fosforylatie en eiwit fosforylatie, en Dunkley en Robinson (1981) laten een afname in de fosforylatie van enkele membraan eiwitten zien t.g.v. langere preïncubatie tijden in een vergelijkbare subcellulaire fractie, analoog aan de afname in $\mathrm{PIP}_{2}$ fosforylatie zoals hier beschreven.

Ten tweede laat hoofdstuk 5 zien dat er regionale verschillen in PI, PIP en DAG kinase activiteit bestaan in de hersenen van de rat. Deze verschillen zijn waarschijnlijk een afspiegeling van een regionale verdeling van PLC activiteit. De mate van $\mathrm{PIP}_{2}$ en PA vorming, gemeten in zeven hersen gebieden van de rat, laten een negatieve correlatie zien. Een hoge basale PLC activiteit resulteert in een hoge DAG concentratie en, als gevolg hiervan, in een verhoogde PA vorming in de fosforylerings assay. Daarnaast resulteert een hoge basale PLC activiteit in verlaagde PIP en PIP concentraties en, als gevolg hiervan, in een verlaagde vorming van $\mathrm{PIP}_{2}$ in de fosforylerings assay. Tot nu toe zijn er echter nog geen gegevens bekend $m$.b.t. de regionale verdeling van basale PLC activiteit in de hersenen van de rat.

Ten derde leverde een onderzoek naar de subcellulaire distributie van de fosforylerings activiteiten van endogene lipiden een nog niet geidentificeerd inositol lipide op, specifiek gelocaliseerd in de mitochondriele fractie. Na beoordeling van de elutie profielen verkregen na scheiding van de polaire kopgroep van het "nieuwe" inositol lipide op Dowex anionen wisselaar, bleek het onbekende inositol lipide in ieder geval geen fosfatidylinositol trisfosfaat of een lyso-fosfatidylinositol 4,5-bisfosfaat te zijn. Andere kandidaten zijn een fosfatidylinositol bisfosfaat isonneer, een glycosyl-fosfoinositide of een fosfatidylinositol pyrofosfaat. De vorming van fosfatidylinositol pyrofosfaten kan non-enzymatisch gekatalyseerd worden door twee-waardige metaalionen (Gumber and Lowenstein, 1986). Omdat mitochondriën relatief veel $\mathrm{Ca}^{2+}$ 
bevatten zou een stof als fosfatidylinositol 4-pyrofosfaat mogelijk gevormd kunnen worden. Fosfatidylinositol 4-pyrofosfaat heeft een Rf waarde op TLC die vergelijk.baar is met de Rf waarde van het onbekende inositol lipide. Verdere identificatie van dit onbekende inositol lipide vereist HPLC analyse van de chemisch gehydrolyseerde kopgroep of zelfs NMR analyse.

\section{- Experimenten met hersen materiaal van de mens.}

PI kinase activiteit in cytosolaire fracties van de hersencortex van de mens neemt af met de leeftijd, in tegenstelling tot PIP kinase activiteit welke niet verandert (Hoofdstuk 8). Deze enzym activiteiten werden gemeten met exogene lipiden als substraat. De bevinding staat in contrast met de bevindingen gedaan in de hersencortex van de rat, waar geen leeftijds gerelateerde verschillen gevonden werden (Hoofdstuk 6). Deze discrepantie kan toegeschreven worden aan verschillende factoren. Ten eerste kurınen species verschillen een verklaring zijn. Ondanks het feit dat de rat wordt gezien als een valide model voor leeftijds gerelateerde veranderingen in fysiologische parameters in de mens, is het bekend dat meerdere processen in de verouderende rat verschillen t.o.v. de verouderende mens. Het blijft de vraag of de verouderende rat gezien kan worden als een valide model voor pathologische hersenveroudering bij de mens (AD). Ten tweede kunnen omgevings factoren het verouderende organisme beinvloeden. Het feit dat oude mensen meer waarschijnlijk zijn blootgesteld aan zogenaamde 'biological life events' t.o.v. jonge mensen en t.o.v. ratten, welke onder constante condities worden gehouden en tevens goed verzorgd worden, kan ook een oorzaak zijn van het verschil in fosfoinositide metabolisme tussen verouderende ratten en mensen. 'Biological life events' zijn factoren die het optimaal functioneren van het brein aantasten, uitgezonderd de factoren die het functioneren van het brein in zeer sterke mate aantasten, zoals dementie (Houx. et al., 1991). Oude ratten uit een inteelt stam, gehouden onder gestandaardiseerde condities met nauwelijks schadelijke invloeden uit hun omgeving zijn mogelijk dus geen adequaat model voor de verouderende mens. Echter, het nabootsen van 'biological life events' in de rat als model voor veroudering bij de mens zal hoogst wăarschijnlijk stuiten op ethische bezwaren. Het gebruik van dieren die reeds gebruikt zijn in andere studies, waarin zij bijvoorbeeld een anaesthesie hebben ondergaan, zou daarom overwogen moeten worden.

PI kinase activiteit in cytosolaire fracties van de hersencortex van $A D$ patienten is afgenomen vergeleken met die van op leeftijd gematchte controle personen. PIP kinase activiteit is niet veranderd (Hoofdstuk 7 ). In de AD patienten groep werd geen leeftijds gerelateerde afname gevonden van PI kinase en PIP kinase activiteit (Hoofdstuk 8). AD patienten met een leeftijd waarop de eerste symptomen van de ziekte werden waargenomen boven de 75 jaar hebben echter een hogere PI kinase activiteit (vergelijkbaar met controle waarden) dan AD patienten met een leeftijd van eerste symptomen beneden de 75 jaar. Deze resultaten suggereren dat Pi kinase activiteit gebruikt kan worden om binnen de 
AD patienten populatie subgroepen te onderscheiden die verschillen in de leeftijd waarop de ziekte toegeslagen heeft. Deze interessante bevinding kan geïterpreteerd worden als een indicatie voor heterogeniteit binnen de ziekte van Alzheimer, vergelijkbaar met de resultaten van een eerdere studie (Rossor et al., 1984) waarin enzym activiteiten verschillend waren in oude t.o.v. jonge AD patienten. Deze resultaten geven aan dat meer onderzoek gedaan moet worden naar de biochemische differentiatie van $\mathrm{AD}$ subtypen.

De daling van PI kinase activiteit in AD wordt waarschijnlijk niet veroorzaakt door de aanwezigheid van een inhiberende component in AD cytosol, bijvoorbeeld een metaal ion, of door het verlies van een oplosbare activerende component in AD cytosol, bijvoorbeeld een cofactor. Chelatie experimenten en experimenten watarin $\mathrm{AD}$ cytosol en controle cytosol gecombineerd werden, gaven namelijk geen inhibitie of stimulatie te zien (Hoofdstuk 9). Van het enzym PI kinase kunnen drie subtypen onderscheiden worden (Carpenter and Cantley, 1990), elk met een andere subcellulaire localisatie, adenosine gevoeligheid, gevoeligheid voor detergentia, en veronderstelde functie. De sterkste afname in PI kinase activiteit werd aangetroffen in de cylosolaire fracties. De PI kinase activiteit in deze fracties werd geremd door Triton X-100 en was relatief ongevoelig voor adenosine, in tegenstelling tot de Pl kinase activiteit in de integrale membraaneiwit fractie die gestimuleerd werd door Triton X-100 en geremd werd door adenosine. Het PI kinase in de cytosolaire fractie heeft de eigenschappen van het type1 PI kinase, oftewel het PI 3-kinase, waardoor dit Pl 3kinase specifiek lijkt aangedaan in AD. Het uiteindelijke bewijs hiervoor dient te komen uit de identificatie van de produkten van de PI kinases welke actief zijn in de hersenen van AD patienten en controles. Deze experimenten zullen deel uitmaken van vervolg studies.

Als type 1 PI kinase, of PI 3-kinase, specifiek is aangedaan in AD, dan kan eiwit tyrosine kinase activiteit hierbij betrokken zijn. Verschillende receptoren, die na stimulatie cytoskelet veranderingen in de cel induceren, bevatten een intrinsieke eiwit tyrosine kinase activiteit (opgesomd in Hoofdstuk 1). Stimulatie van deze receptoren resulteert in stimulatie van deze tyrosine kinase activiteit, gevolgd door de koppeling en activatie van PI 3-kinase en cytoskelet veranderingen. Deze mogelijke betrokkenheid van PI 3-kinase en tyrosine kinase activiteit bij de regulatie van cytoskelet veranderingen, samen met de daling van PI kinase activiteit (Hoofdstuk 7) en tyrosine kinase activiteit (Shapiro et al., 1991) in AD, duidt op een mogelijke betrokkenheid van deze enzymen bij de cellulaire pathologie van AD. 'Neurofibrillary tangles', welke één van de hoofd kenmerken zijn van $A D$, zijn namelijk hoofdzakelijk opgebouwd uit verkeerd gemetaboliseerde cytoskelet componenten.

Een toenemende hoeveelheid onderzoeks resultaten laat zien dat AD een ziekte van het gehele lichaam zou kunnen zijn, en niet een ziekte met alleen centrale effecten. Dit is de reden waarom PI kinase activiteit werd gemeten in bloed plaatjes van AD patienten en op leeftijd gematchte controles. Voor deze studie werden bloed plaatjes gekozen omdat ziekte-specifieke abnormaliteiten in de hersenen, welke bijvoorbeeld optreden bij aandoeningen als de ziekte van 
Parkinson, de ziekte van Huntington en depressie, ook worden aangetroffen in bloed plaatjes (Bush et al., 1991). Daarnaast bevatten bloed plaatjes een compleet fosfoinositide metaboliserend systeem, inclusief type 1 of PI 3-kinase, en zijn ze gemakkelijk te verkrijgen. De PI kinase activiteit in bloedplaatjes afkomstig van AD patienten en controle personen bleken echter niet van elkaar te verschillen. Om te concluderen dat veranderingen in PI kinase activiteit in de hersen cortex niet perifeer te zien zijn, moet echter meer onderzoek gedaan worden in meerdere perifere weefsels en/of cellen.

Concluderend kan gesteld worden dat de resultaten van dit onderzoek nieuwe informatie leveren over de neurochemische basis van hersenveroudering en AD. Drie enzymen, betrokken bij het fosfoinositide metabolisme, fosfatidylinositol kinase, fosfatidylinositol fosfaat kinase en diacylglycerol kinase, blijken te zijn aangedaan in hersenveroudering en/of AD. De micro-omgeving van deze enzymen blijkt heel belangrijk te zijn voor hun activiteit. De in dit proefschrift gebruikte operationalisatie, namelijk het onderscheiden van kinase activiteits metingen als functie van de leeftijd met en zonder de aanwezigheid van hun micro-omgeving, was om deze reden essentieel. Verder kan de afname in type 1 PI kinase activiteit in AD, met het oog op de veronderstelde relatie tussen dit kinase en cytoskelet turn-over processen, zeer relevant zijn voor de cellulaire pathologie van $\mathrm{AD}$.

\section{Referenties}

Bush A.l., Beyreuther K., and Masters C.L. (1991) Circulating forms of amyloid precursor protein of Alzheimer's disease. In: Alzheimer's disease: Basic mechanisms, diagnosis and therapeutic stralegies (Igbal K., McLachlan D.R.C., Winblad B., and Wisniewski H.M., eds.), pp. 353-358. J.Wiley \& Sons, Chichester, England.

Carpenter C.L., and Cantley L.C. (1990) Phosphoinositide kinases. Biochemistry 29, 11147-11156

Dawson R.M.C., and Eichberg J. (1965) Diphosphoinositide and triphosphoinositide in animal tissue. Extraction, estimation and changes post mortem. Biochem. /. 96, 634-643.

Dunkley P.R., and Robinson P.J. (1981) Calcium stimulated protein kinases from rat cerebral cortex are inactivated by preincubation. Biochem. Biophys. Res. Comm. 102, 1196-1202.

Cumber S.C., and Lowenstein I.M. (1986) Non-enzymic phosphorylation of poly-phosphoinositides and phosphatidic acid is catalysed by bivalent metal ions. Biochem. J. 235, 617-619.

Houx P.J." Vreeling F.W., and Jolles ]. (1991) Age-associated cognitive decline is related to biological live events. In: Alzheimer's disease: Basic mechanisms, diagnosis and therapeutic strategies (Igbal K., McLachlan D.R.C., Winblad B., and Wisniewski H.M., eds.), pp. 353-358. J.Wiley \& Sons, Chichester, England.

Jolles J., Zwiers H., Van Dongen C.J., Schotman P., Wirtz K.W.A., and Gispen W.H. (1980) Modulation of brain poly-phosphoinositide metabolism by ACTH-sensitive protein phosphorylation. Nature 286, 623-625.

Jolles J., Schrama L.H., and Gispen W.H. (1981) Calcium dependent turnover of brain polyphosphoinositides in vitro after prelabeling in vivo. Biochim. Biophys. Acta 666, 90-98.

Naeim F., and Walford R.L. (1985) Aging and cell mernbrane complexes: The lipid bilayer, integral proteins, and cytoskeleton. In: Hamdbook of the biology of aging (Finch C.E., and Schneider E.L., eds.), pp. 272-289, Van Nostrand Reinhold, N.Y. 
Rossor M.N., Iverson L.L., Reynolds G.P., Mountjoy C.Q., and Roth M. (1984) Neurochemical characteristics of early and late onset types of Alzheimer's disease. Clin. Res. 288, 961-964.

Shapiro I.P., Masliah E., and Saitoh T. (1991) Altered protein tyrosine phosphorylation in Alzheimer's disease. I. Neurochem. 56, 1154-1162.

Sun G.Y., Yoa F.-G., and Lin T.-N. (1990) Degradation of poly-phosphoinositides in brain subcellular membranes in response to decapitation insult. Neurochem. Int. 17, 529-535.

Van Rooijen L.A.A., Rossowska M., and Bazan N.G. (1985) Inhibition of phosphatidylinositol 4phosphate kinase by its product phosphatidylinositol 4,5-bisphosphate. Biochem. Biophys. Res. Comm. 16, 150-155. 



\section{LIST OF PUBLICATIONS}

Papers:

Bothmer J., M. Markerink and J. Jolles (1990) Phosphatidic acid and polyphosphoinositide formation in a broken cell preparation from rat brain: Effects of different incubation conditions. Neurochem. Int. 17, 27-33.

Bothmer J., M. Markerink and J. Jolles (1990) Age related changes in the interconversion of inositol phospholipids in the rat brain cortex. In: From Gene to Man (Van Bezooijen C.F.A., Ravid R., Verhofstad A.A.J., eds.) pp. 186189. J.H. Pasmans Publishers, The Hague, The Netherlands.

Bothmer J., M. Markerink and J. Jolles (1992) Brain phosphatidic acid and polyphosphoinositide formation in a broken cell preparation: Regional distribution and the effect of age. Neurochem. Int. 21, 223-228.

Bothmer J., M. Markerink and J. Jolles. Evidence for a new inositol phospholipid in rat brain mitochondria. Biochem. Biophys. Res. Comm., in press.

Bothmer J., J. Jolles, M. Markerink and R. Ravid. Inositol phospholipid kinases in Alzheimer's disease. In: Alzheimer's disease: Advances in clinical and basic research. J. Wiley \& Sons, Ltd., in press.

Bothmer J., M. Markerink, R. Coppens and J. Jolles. Platelet phosphoinositide kinase activity is not altered in Alzheimer's disease. Mol. Chem. Neuropathol., accepted for publication.

Jolles J., J. Bothmer, M. Markerink and R. Ravid (1992) Phosphatidylinositol kinase is reduced in Alzheimer's disease. J. Neurochem. 58, 2326-2329.

Jolles J., J. Bothmer, M. Markerink and R. Ravid. Reduced PI kinase activity in Alzheimer's disease: Effects of age and onset. Dementia, in press.

Submitted for publication:

Bothmer J., M. Markerink and J. Jolles. Phosphatidic acid and polyphosphoinositide formation in rat brain in vitro: Effects of post-mortem delay and procedural manipulations. Neurochem. Res.

Bothmer J., M. Mommers, M. Markerink and J. Jolles. The effect of age on phosphoinositide kinase, phosphoinositide phosphate kinase and diacylglycerol kinase in rat brain cortex. Mol. Chem. Newropathol. 
Bothmer J., M. Markerink and J. Jolles. Evidence for a selective decrease in type 1 phosphatidylinositol kinase activity in brains of patients with Alzheimer's disease. I. Neurochem.

Blokland A., J. Bothmer, W. Honig and J. Jolles. A new paradigm for assessing behavioural and biochemical effects of acute central metabolic inhibition: Effects of acetyl-L-carnitine. Eur. J. Pharmacol.

\section{Abstracts:}

Bothmer J., J. Jolles and M. Markerink (1991) Inositol phospholipid formation in purified synaptosiomes and mitochondria: Evidence for a novel polyphosphoinositide. J. Neurochem. 57 (suppl.), 44.

Jolles J., J. Bothmer and M. Markerink (1991) Decreased formation of phosphatidylinositol phosphate (PIP) but not phosphatidylinositol bisphosphate $\left(\mathrm{PIP}_{2}\right)$ in Alzheimer's disease brain versus control brain. J. Neurochem. 57 (suppl.), 65.

Bothmer J., M. Markerink and J. Jolles (1992) PI kinases in cytosolic and membrane-bound fractions are differentially affected in Alzheimer's disease. Neurobiol. Aging 13 (suppl.), 60.

Jolles J., J. Bothmer and M. Markerink (1992) Alzheimer brain is characterized by decreased formation of phosphatidylinositol phosphate (PIP) but not phosphatidylinositol bisphosphate (PIP 2 ). Neurobiol. Aging 13 (suppl.), 62.

Bothmer J., M. Markerink and J. Jolles (1992) Phosphatidylinositol (PI) kinase but not phosphatidylinositol phosphate (PIP) kinase is affected in Alzheimer's disease. Proceedings of the 33rd Dutch Federation meeting, pp. 51, April 1992, Rotterdam, The Netherlands.

Bothmer J., M. Markerink and J. Jolles. Decreased ChAT-activity as a result of in vivo i.c.v. streptozotocin treatment correlates with increased PI kinase activity in rat brain hippocampus. Arch. Int. Pharmacod. Ther., in press.

Markerink M., J. Bothmer, M. Mommers and J. Jolles. PI kinase activity shows agerelated changes in control subjects and divides Alzheimer patients into subgroups. Arch. Int. Pharmacod. Ther., in press. 


\section{Curriculum Vitae}

John G.M. Bothmer werd geboren op 26 augustus 1964 te Geleen. In 1982 behaalde hij het einddiploma Atheneum-B aan de Albert Schweitzer Scholengemeenschap te Geleen. In september van dat jaar startte hij de studie Biologie aan de Katholieke Universiteit Nijmegen waar het propadeutisch examen werd behaald in 1983. Zijn doctoraalfase was opgebouwd uit de bijvakken Toxicologie (Prof. Dr. P. Henderson) en Bio-Organische Chemie (Prof. Dr. E. Meyer, DSM) en het hoofdvak Microbiologie (Prof. Dr. Ir. G.D. Vogels), en werd in 1988 afgesloten met het afleggen van het doctoraal examen. Vanaf juli 1988 tot september 1992 was hij werkzaam als assistent-in-opleiding binnen de afdeling Neuropsychologie en Psychobiologie (Prof. Dr. J. Jolles) van de Rijksuniversiteit Limburg, alwaar het hier beschreven promotie onderzoek werd verricht. Sinds september 1992 wordt het onderzoek binnen deze afdeling voortgezet en is hij op tijdelijke basis aangesteld als toegevoegd onderzoeker. 



\section{Dankwoord}

Ofschoon op de omslag van dit boekje slechts éen auteur wordt vermeld, moge het duidelijk zijn dat meerdere personen aan de totstandkoming ervan hebben bijgedragen. Voordat ik enkele personen bij naam noem wil ik eerst iedereen bedanken die op enigerlei wijze hierbij betrokken is geweest.

Als eerste noem ik hier Marjanne Markerink. Behalve dat zij verantwoordelijk was voor een groot deel van het praktische werk, zorgde Marjanne ook altijd voor een plezierige, opgewekte sfeer. Haar bijzondere gave om bepaalde stofjes, nodig voor ons onderzoek, uit het niets (of misschien toch van andere afdelingen) te voorschijn te toveren is verbazingwekkend. Wiel Honig bedank ik voor zijn assistentie bij het omgaan met en het decapiteren van de ratten welke gebruikt zijn in de in dit boekje beschreven experimenten. In het laatste jaar van mijn promotie onderzoek werd ik ook nog bijgestaan door Monique Mommers, waardoor de laatste loodjes minder zwaar wogen. Mijn promotor Jelle Jolles dank ik voor zijn belangstelling en begeleiding gedurende alle fasen van mijn promotie onderzoek. Verder dank ik alle collega's voor de prettige sfeer, en dan met name tijdens de altijd te korte koffie pauzes in de 'muurkast' op de lokatie BMC.

Tot slot wil ik hier mijn ouders en Francine in mijn dank betrekken. Francine, bedankt voor je voortdurende interesse en geduld, maar zeker ook voor je enorme steun tijdens een voor mij moeilijke situatie. Mam en Pap, bedankt voor jullie jarenlange inzet om deze voetbalgek toch aan het studeren te krijgen. Met mijn vader kan ik het resultaat hiervan helaas niet delen aangezien hij enkele dagen na aanvang van mijn promotie onderzoek overleden is. 


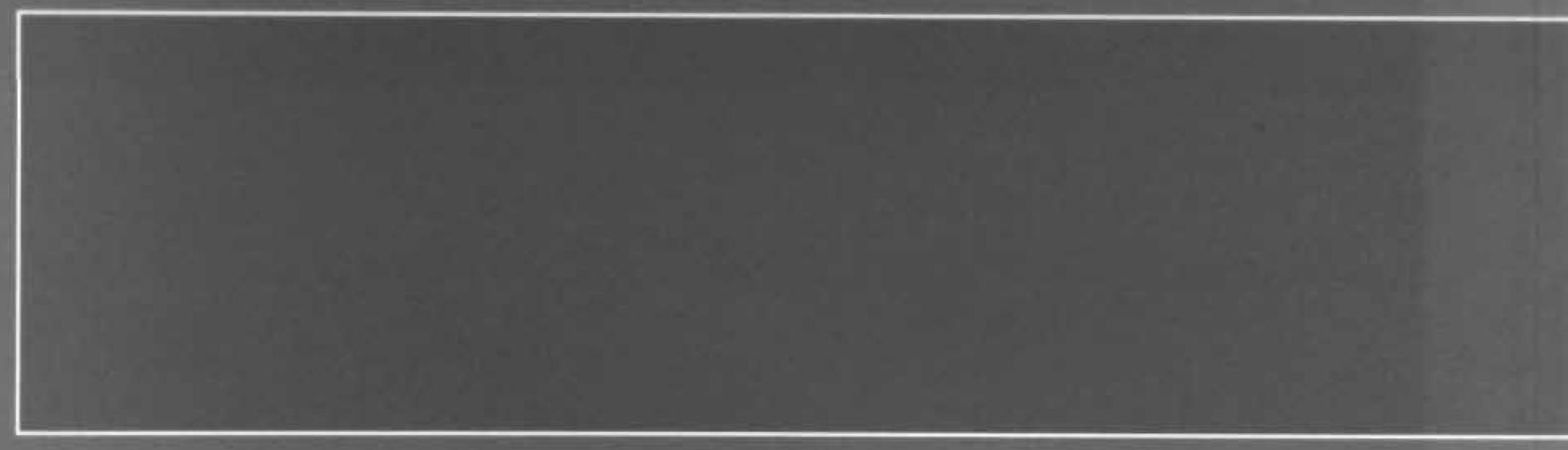

DATAWYSE I Universitaire Pers Maastricht ISBN 9052780463

NUGI 743 